\title{
RIVERTON DOME GAS EXPLORATION AND STIMULATION TECHNOLOGY DEMONSTRATION, WIND RIVER BASIN, WYOMING
}

Final Technical Progress Report, Revised

Reporting Period Start Date: October 1, 1997

Reporting Period End Date: March 5, 1999

Dr. Ronald C. Surdam

Project Manager \& Principal Investigator

August 1999

\section{D.O.E. Contract No. DE-FC26-97FT34181}

Department of Energy Contracting Of œr: Ms. Mary Beth Pearse

Institute for Energy Research

Dr. Ronald Steel, Interim Director

University of Wyoming

Laramie, Wyoming 82071 


\section{Disclaimer}

This report was prepared as an account of work sponsored by an agency of the United States Government. Neither the United States Government, nor any agency thereof, nor any of their employees, makes any warranty, express or implied, or as-sumes any legal liability or responsibility for the accuracy, completeness, or usefulness of any information, apparatus, product, or process disclosed, or represents that its use would not infringe on privately owned rights. Reference herein to any specific commercial product, process, or service by trade name, trademark, manufacturer, or otherwise does not necessarily constitute or imply its endorsement, recommendation, or favoring by the United States Government or any agency thereof. The views and opinions of the authors expressed herein do not necessarily state or reflect those of the United States Government of any agency thereof. 


\title{
Title: Riverton Dome Gas Exploration and Stimulation Technology Demonstration, Wind River Basin, Wyoming
}

\author{
D.O.E. Contract No. DE-FC26-97FT34181
}

Contractor Name and Address:

Institute for Energy Research

University of Wyoming, P.O. Box 4068

Laramie, Wyoming 82071

Date of Report: $\quad$ March 5, 1999

Award Date:

October 1, 1997

Completion Date:

March 31, 1999

Government Award, Current Fiscal Year:

$\$ 1,197,989.00$

Project Manager \&

Principal Investigator:

Ronald C. Surdam

Reporting Period:

Final Report

Executive Summary: The new exploration technology for basin center gas accumulations developed by R.C. Surdam and Associates at the Institute for Energy Research, University of Wyoming, was applied to the Riverton Dome 3-D and Emigrant seismic areas. Application of the technology in the Riverton Dome area resulted in the development of important new exploration leads in the Frontier, Muddy, and Nugget formations. The new leads are adjacent to a major north-south trending fault, which is downdip from the crest of the major structure in the area. In the Emigrant 3-D seismic survey area, there are three preliminary drilling targets. All three of these sites are focused on the Muddy Formation, although the stratigraphic section above and below the Muddy has promise.

In a blind test, the drilling results from six new Muddy test wells were accurately predicted. The range of initial production values (IP) for the six test wells was < one mmcf/day to four mmcf/day. The three wells with the highest IP values (i.e., three to four mmcf/ day) were drilled into an intense velocity anomaly (i.e., anomalously slow velocities). The well drilled at the edge of the velocity anomaly had an IP value of one mmcf/day, and the two wells drilled outside of the velocity anomaly have IP values of <one mmcf/day and are presently shut in. Based on these test results, it is concluded that the new IER exploration strategy for detecting and deline- 
ating commercial, anomalously pressured gas accumulations is valid in the southwestern portions of the Wind River Basin, and can be utilized to signi cant ly reduce expl $\alpha$ at ion $\mathrm{n}$ sk and to ircrease po tability of so-called basin center gas accumulations.

Most importantly, this study strongly suggests that a prime exploration prospect exists in the Riverton Dome 3-D seismic survey area. At this location, the new IER conceptual model and exploration technology can be tested in three targeted formations (i.e., the Frontier, Muddy, and Nugget) in a single well. At the prospect, in each of the formations there is an intense velocity anomaly that is 1800 to $1900 \mathrm{~ms}$ slower than would be predicted by the regional velocity-depth gradient. A velocity anomaly of this magnitude can only be explained by the presence of signi cant gis accumu lations. A so t thi s p os pect site, the rel aity anomaly overlaps an ESP (e.g., events similarity prediction) discontinuity in the Muddy Formation. The ESP discontinuity in the Muddy Formation is interpreted as a valley- 11 deposit. Gre studi es in the Riverton Dome area suggest that the best reservoir characteristics in the Muddy Formation are found in the wi d dannel deposits viv thi $n$ valley- 11 depositional set tings. Theref ore, it is suggested that for the Muddy Formation, the nominated drilling site characterized by an intense velocity anomaly (e.g., gas-saturated) that overlaps an ESP discontinuity interpreted as a valley- 11 deposit (e g, opt im m porosity and permeability) is an excellent Muddy Formation prospect. Thus, it is concluded that a well drilled at CDP 124896 in the Riverton Dome 3-D seismic survey is not only an ideal test of the IER exploration technology, but also the highest priority drill site for so-called basin center gas accumulations within the survey area.

In the Emigrant study, the potential drilling sites are prioritized as follows:

1. CDP 098437. This is an outstanding Muddy target at $2200 \mathrm{msec}$; the section at 1400 to $1700 \mathrm{msec}$ TWTT also has signi cant gas pot ent id (see Appendix II and Figures 38 and 39).

2. CDP 037106. This site is primarily a Muddy target, for the stratigraphic section above is not as attractive as in target 1 above. However, the section below, down to the Nugget Formation, shows promise (see Appendix II and Figures 43 and 44).

3. CDP 017887. This site is primarily a Muddy target, although the section below the Muddy down to $1700 \mathrm{msec}$ has promise. This is the most shallow Muddy target and it occurs close to the crest of the structure (see Appendix II and Figures 41 and 44).

The results of this study suggest that the above three prioritized drilling targets have the highest potential for success in the search for anomalously pressured gas accumulations in the Emigrant area. All three of these nominated targets are characterized by the following features: (1) significant, anomalously slow velocities; (2) an associated ESP discontinuity, and (3) a chimney-shaped anomalous velocity con gur ation. 


\section{Summary of Technical Progress}

\section{INTRODUCTION}

A primary objective of the Institute for Energy Research (IER)-Santa Fe Snyder Corporation DOE Riverton Dome project is to test the validity of a new conceptual model and resultant exploration paradigm for so-called "basin center" gas accumulations (Surdam, 1997; see Figure 1). This paradigm and derivative exploration strategy suggest that the two most important elements crucial to the development of prospects in the deep, gas-saturated portions of Rocky Mountain Laramide Basins (RMLB) are (1) the determination and, if possible, three-dimensional evaluation of the pressure boundary between normal and anomalous pressure regimes (i.e., this boundary is typically expressed as a signi cant inversi on in both sonic and seismic velocity-depth pro les), and (2) the detection and delineation of porosity/permeability "sweet spots" (i.e., areas of enhanced storage capacity and deliverability) in potential reservoir targets below this boundary (Figure 1). There are other critical aspects in searching for basin center gas accumulations, but completion of

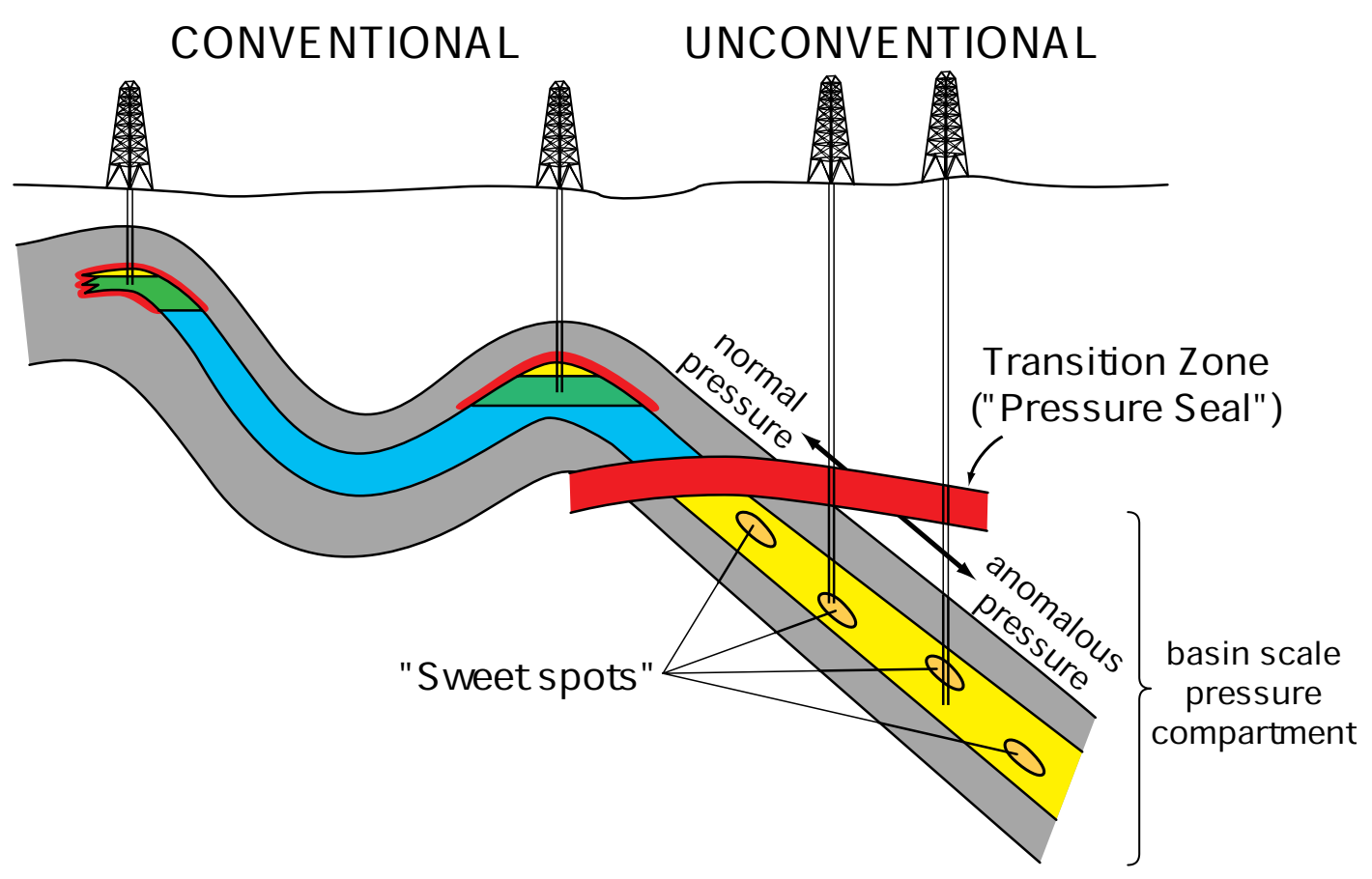

IER

Figure 1. Conceptual model for basin-center, anomalously pressured gas accumulations. Key elements are (1) the regional pressure seal expressed as a sonic or seismic velocity inversion (i.e., regional boundary that separates normally pressured rocks above from anomalously pressured rocks below), and (2) production sweet spots below the regional pressure seal (i.e., domains characterized by enhanced porosity and permeability). Blue is uid that is dom rant ly vat $\Theta$ (si rgl e phase); yel low is uid cont aining a signi cat f regas phase (multiphase) and red are capillary seals. 
these two tasks is essential to the successful exploration for the unconventional gas resources present in anomalously pressured rock/ $\mathrm{i} d$ systens in the Boky $M$ unt ai $n$ Laramide Basins.

The southern Wind River Basin, in particular the Riverton Dome and Emigrant areas, is a neat location for testing this exploration paradigm (Figure 2). Preliminary work within the Wind River Basin has demonstrated that there is a regionally prominent pressure surface boundary that can be detected by inversions in sonic velocitydepth gradients in individual well log pro les (Figure 3) and that can be seen as a velocity inversion on seismic lines (Figure 4). Also, the Wind River Basin in general - and the Riverton Dome area speci cal ly-i s characterized by a signi cant numb er of anomalously pressured gas accumulations (Figure 5). Most importantly, Santa Fe Snyder Corporation has provided the study with sonic logs, two 3-D seismic studies $\left(40 \mathrm{mi}^{2}\right.$ and $30 \mathrm{mi}$ ) and a variety of other necessary geological and geophysical information.

\section{DATA SET AND METHODOLOGY}

The most important portions of the available data set are the 3-D Riverton Dome and Emigrant seismic studies, for they allow not

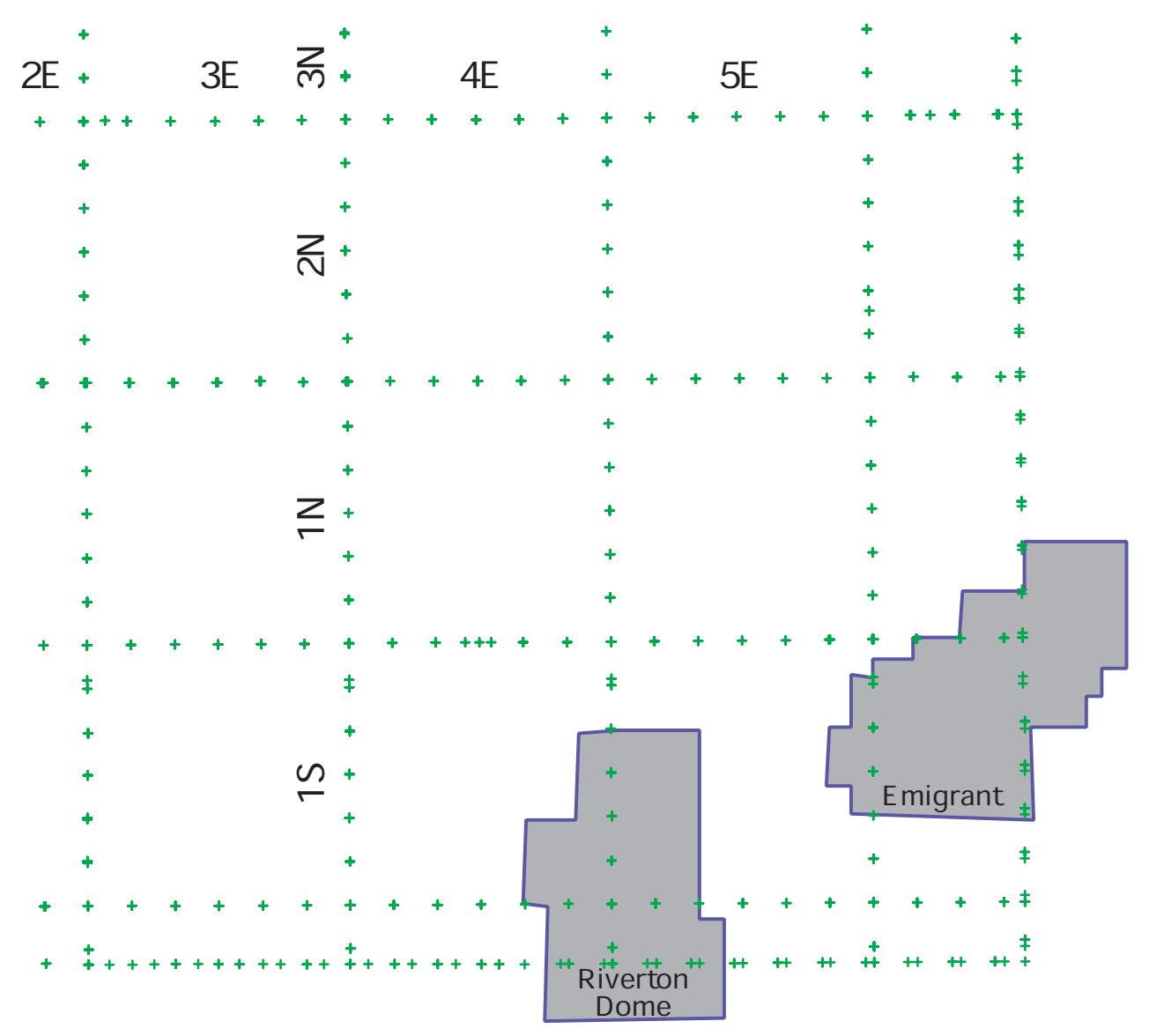

Figure 2. Index map for Riverton Dome and Emigrant 3-D seismic survey areas. 

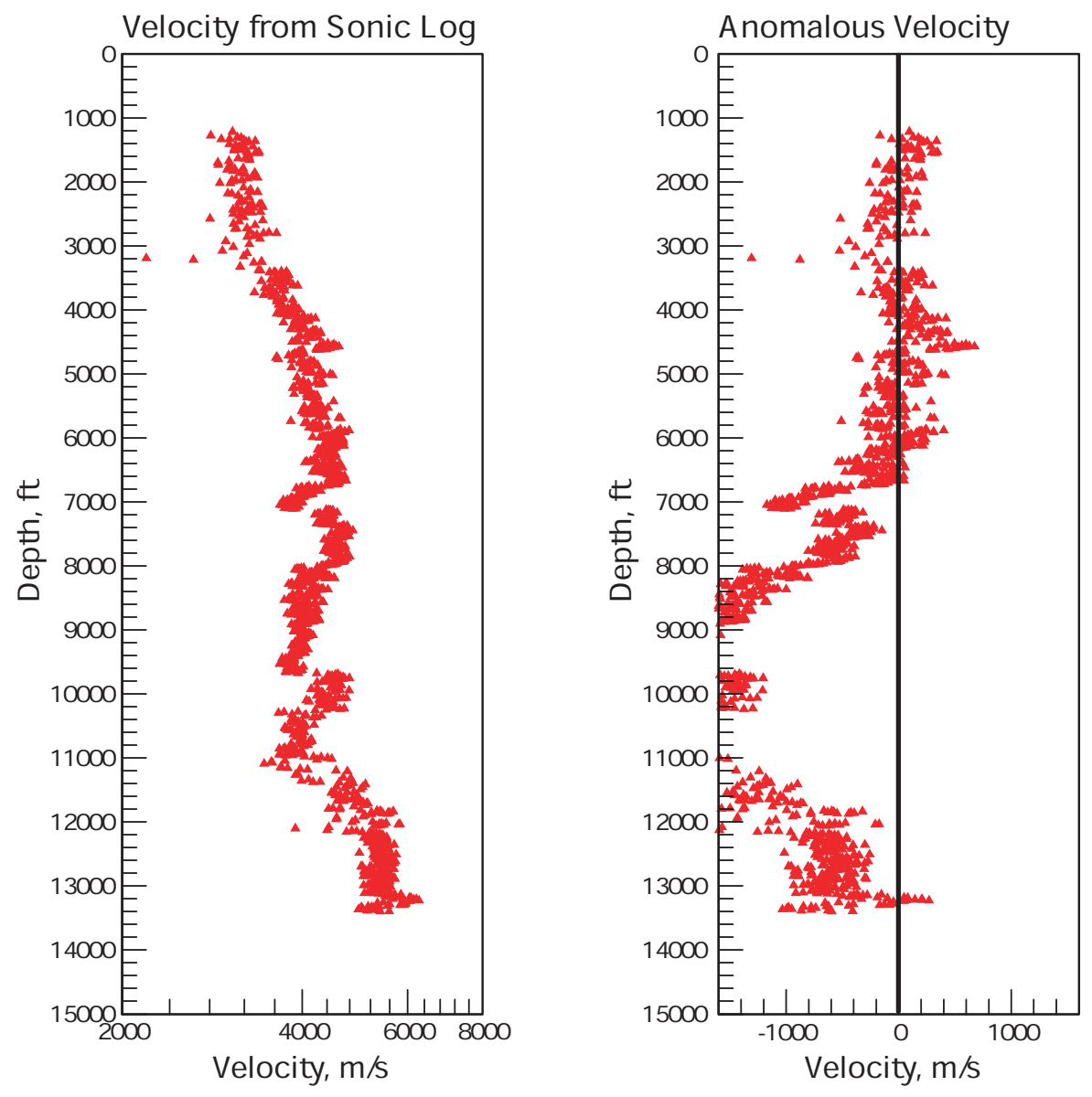

IER

Figure 3. Sonic velocity log, and anomalous sonic velocity-depth pro le af te remo val of nor ma I regi mal velocity-depth gradient. This example is from within the Riverton Dome 3-D seismic survey area.

only a three-dimensional velocity evaluation, but they also facilitate the application of new and/or modified existing technologies developed at IER to detect, visualize, and delineate basin center gas accumulations.

In this study, Echo Geophysical-processed seismic data were used as the basis for the velocity analysis. The processing stream included true amplitude recovery, surface consistent deconvolution, time variant spectral whitening, statics, and applied residual statics. The data were summed in $500550 \mathrm{ft}$ bins with maximum offsets of $15,000 \mathrm{ft}$ and then input to the ProMAX velocity analysis program.
In more detail, the Riverton Dome 3-D survey consists of 382 inlines and 577 cross lines. The inlines typically are separated by 100 feet and the cross lines are separated by 110 feet. For the purposes of this study, the velocity analysis was done on every tenth inline (i.e., $1000 \mathrm{ft}$ intervals) and at every ninth cross line (i.e., $990 \mathrm{ft}$ ). The vertical sampling for the velocity study was done at $100 \mathrm{~ms}$ intervals. In contrast, commercial processing for velocity constructions typically utilize a grid of every 25th end line (i.e., every $2500 \mathrm{ft}$ ) and a sample point at every 50 th cross line (5500 ft). Thus, the sampling grid utilized in this study (i.e., 60 points per inline) was considerably clo- 


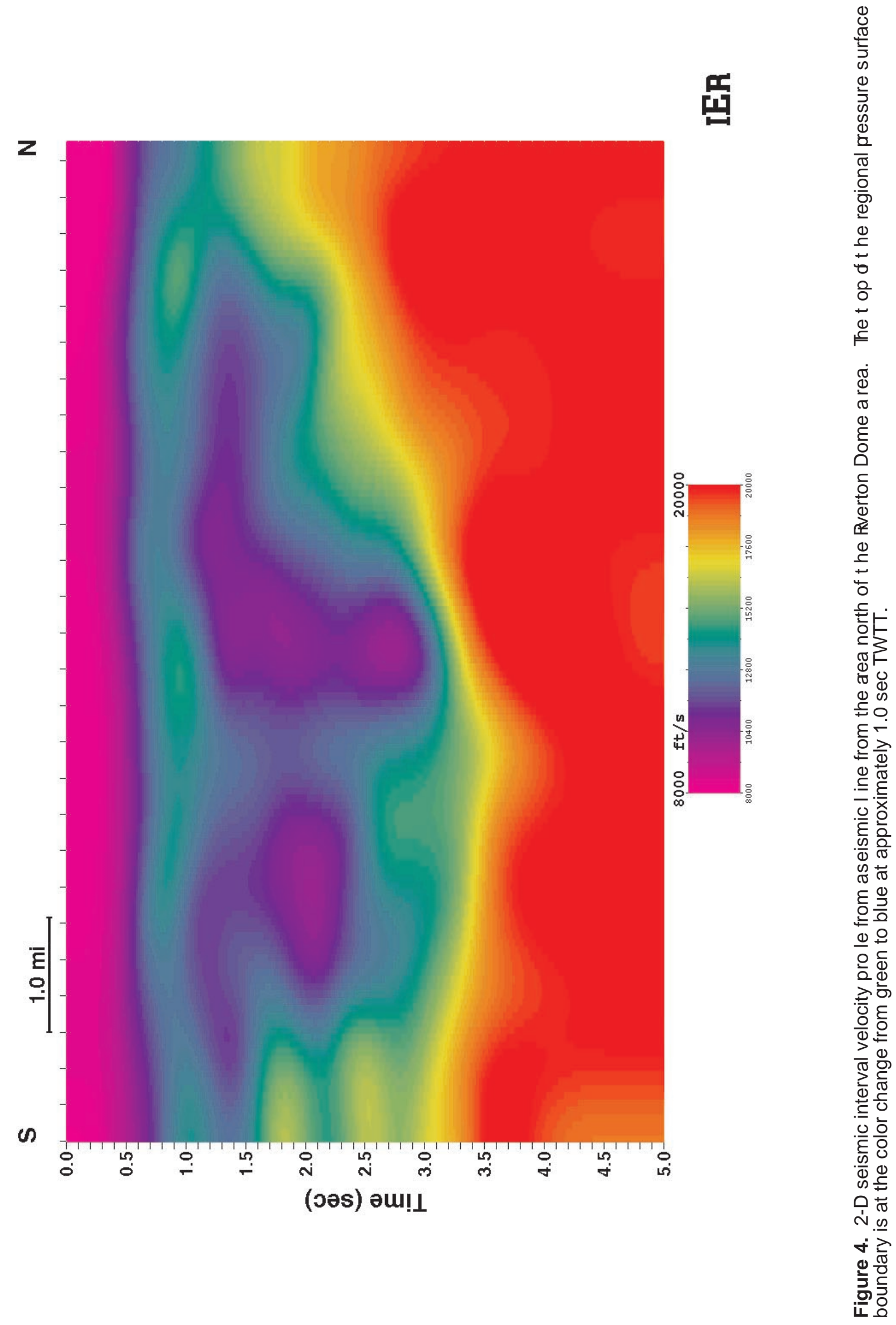




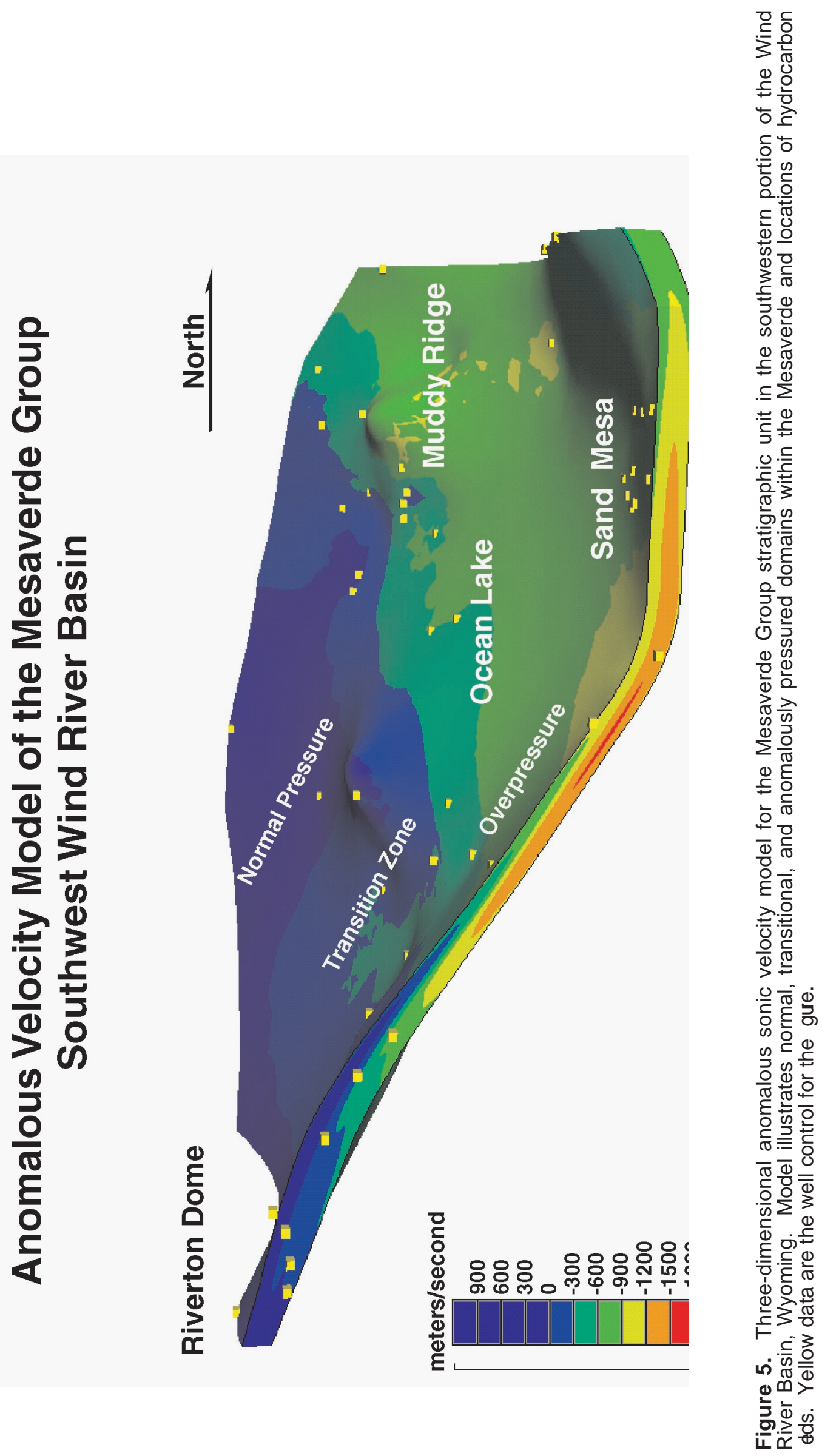


ser than that used in typical commercial processing (i.e., 10 to 11 samples per inline).

The Emigrant 3-D survey consists of 330 inlines and 322 cross lines. The inlines typically are separated by 100 feet and the cross lines are separated by 110 feet. Like the Riverton Dome study, the Emigrant velocity analysis was done on every tenth inline (i.e., $1000 \mathrm{ft}$ intervals) and at every ninth cross line (i.e., $990 \mathrm{ft}$ intervals). The vertical sampling for the velocity study was done at $100 \mathrm{~ms}$ intervals. In the Emigrant study, originally the velocity analysis consisted of 1150 CDP's, but at the edges of the survey, CDP's with less than 15 fold were rejected, leaving 705 velocity pro les avai labl e to the $30 \mathrm{mi}^{2}$ study.

In the study of the Riverton Dome and Emigrant areas, the following two tasks were accomplished: (1) the evaluation and construction of the velocity fields in the Riverton Dome and Emigrant areas according to the sampling strategy outlined above, and (2) isolation of anomalously slow velocity domains. Task 2 was accomplished by subtracting the normal regional velocitydepth gradient from the observed velocitydepth pro le at 1620 samp le poi it s (i.e, CDP's; see Figure 6A) in the Riverton Dome 3 -D survey, and 705 sample points in the Emigrant 3-D survey (see Figure 6B). A typical normal velocity-depth gradient for each of the study areas was determined by modelling the compaction trend- sonic velocity-depth pro le rel at ions hi ps from nearby well logs from within and/or from nearby well logs in the study area (Figure $3)$. In summary, the anomalous velocity pro les (F gur es 7A - 7 ) and the vol ume $s$ (Figures $8 \mathrm{~A}$ and $8 \mathrm{~B}$ ) are the result of re-

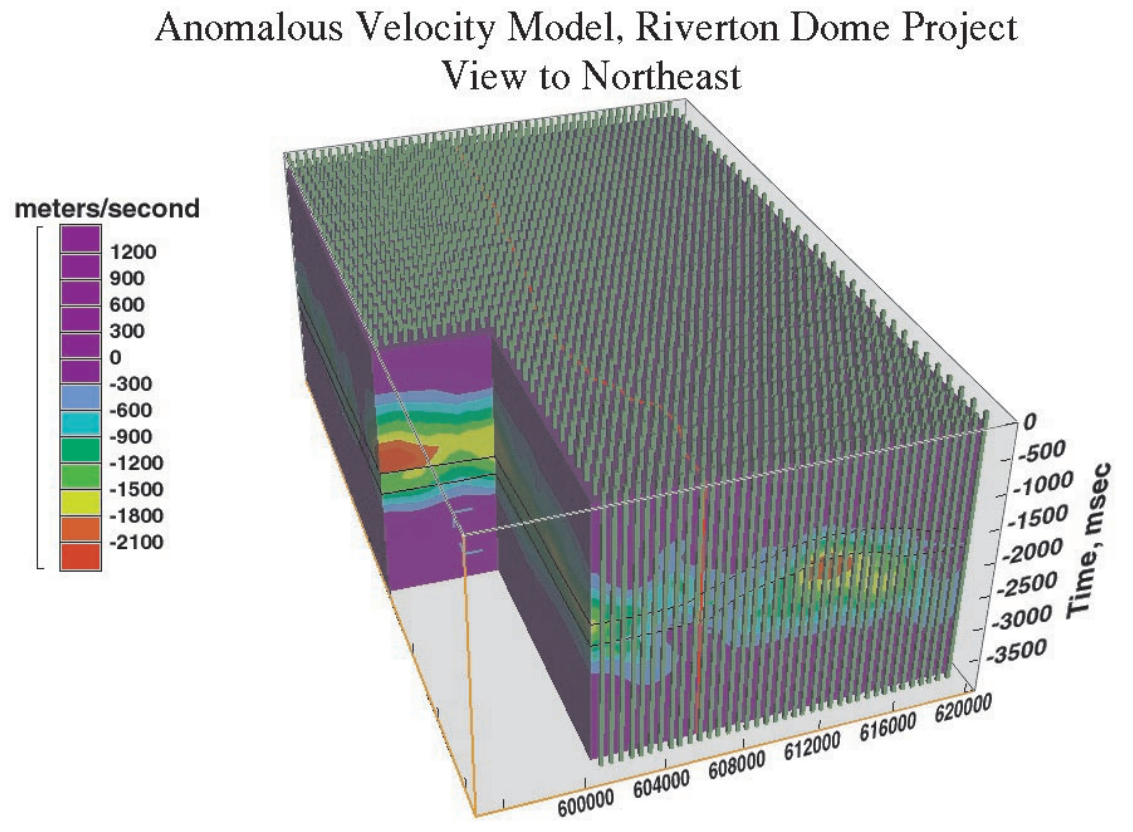

IER

Figure 6A. Anomalous seismic interval velocity volume derived from the Riverton Dome 3-D seismic survey. Figure shows location of 1620 CDPs used in this study; for each of the CDPs, a velocity-depth (i.e., time) pro le was constructed. 
Anomalous Velocity Model, Emigrant 3D Survey

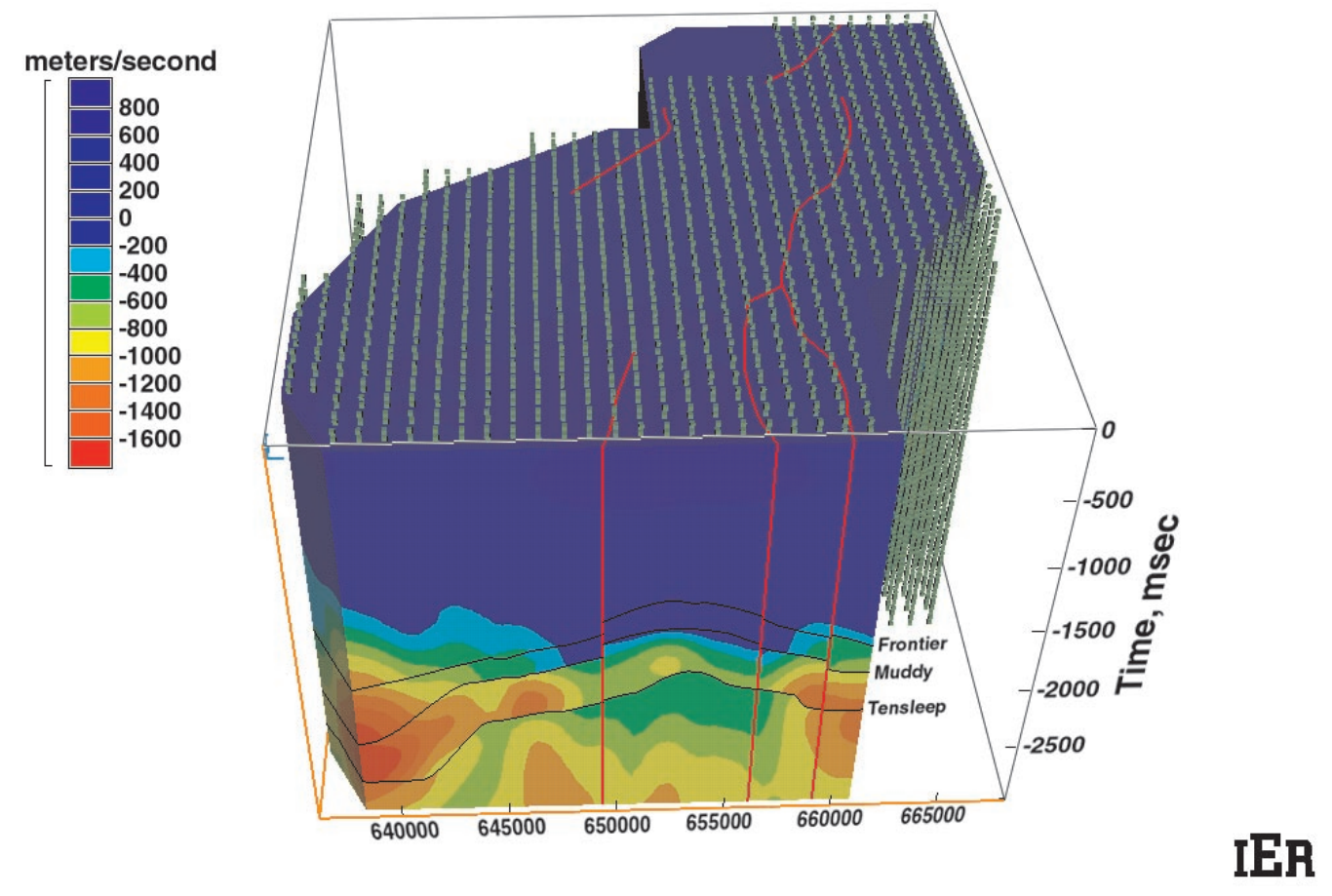

Figure 6B. Anomalous seismic interval velocity-volume derived from the Emigrant 3-D seismic survey.

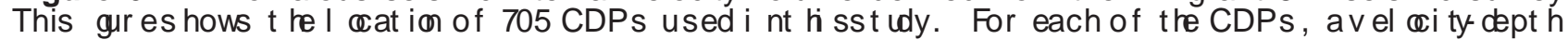
(i.e., time) pro le was constructed.

moving the typical regional normal velocity-depth profile from the observed velocity-depth gradients at each of the sample points. As is noted in Figures 7A through 7C, the match with depth (or time) between the anomalous seismic interval velocity and anomalous sonic velocity are not exact. The velocity-time gradients shown in Figures 7A - 7C are from wells that deviate from vertical, so it is impossible to match exactly the geographic position of a well with a CDP from the seismic survey. The comparisons shown in Figures 7A - 7C are from geographic overlapping CDPs (seismic velocity) and well locations (sonic velocity). Therefore, most of the differences noted in Figures 7A - 7C when comparing the seismic and sonic velocities can be attributed to uncertainties resulting from the deviation of the drilled wells. Any velocity domain falling below the typical regional velocity-depth profile is con- sidered to be anomalously slow and is assigned a negative sign to signify that it is anomalously slow.

The methodology used in this study to isolate anomalous velocities is explained in more detail by referring to a real situation. Figure 9 shows the semblance picks for the stacking velocities (i.e., white dots), the stacking velocities as determined by converting velocities from the sonic log to stacking velocity (i.e., smooth black curve to the left on diagram), and the resultant interval velocities calculated from the seismic stacking velocities (i.e., irregular black line on right side of semblance picks) at CDP 114971 from the Riverton Dome 3-D seismic survey. Note that in Figure 9, there is a very signi cant vel $\propto$ ity inversion (i.e, reversal) at $1650 \mathrm{~ms}$ two way traveltime (TWTT) and that the velocities appear to be anomalously slow down to a TWTT of $2400 \mathrm{~ms}$ (which is below or slower than 

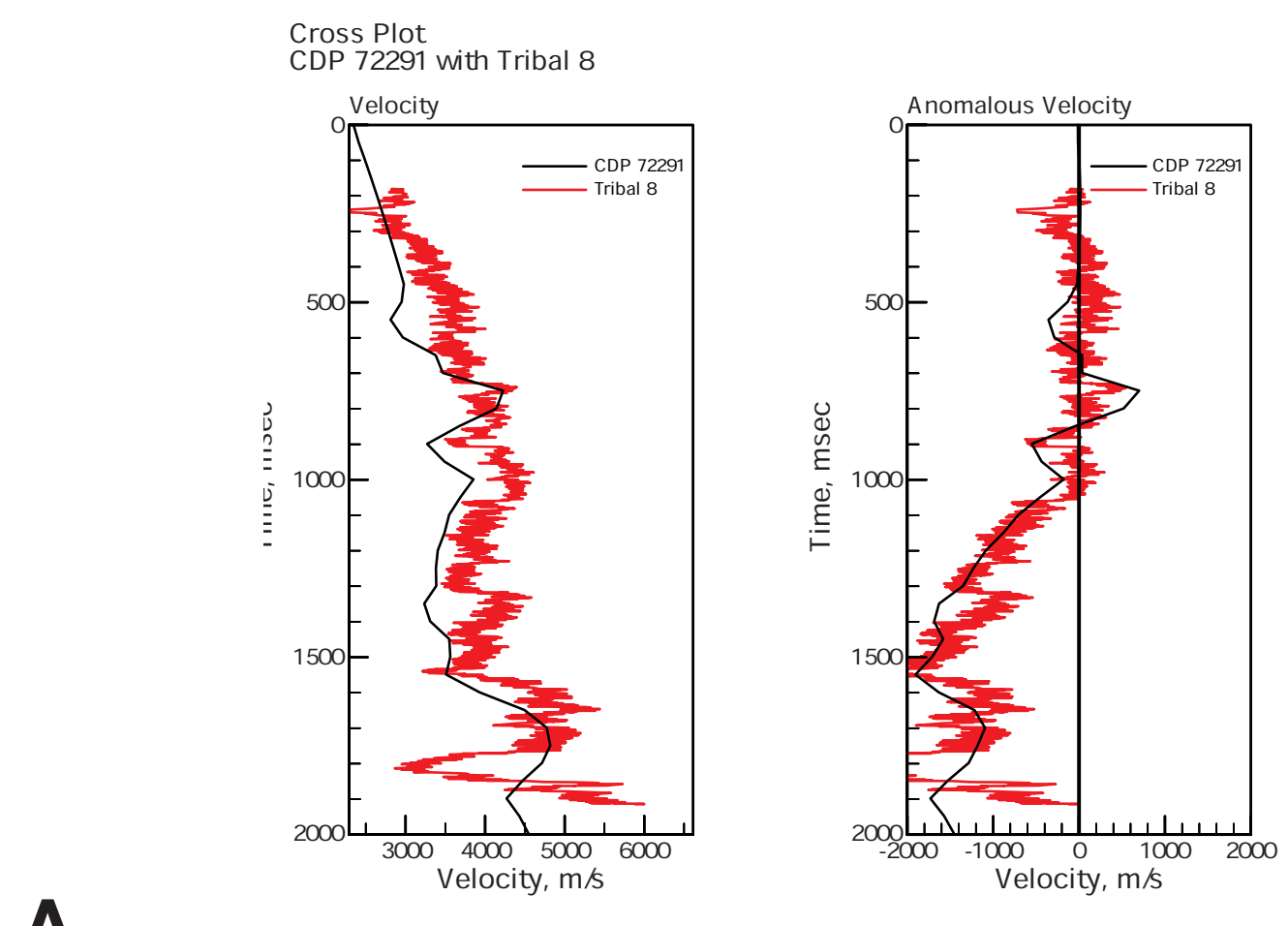

A.
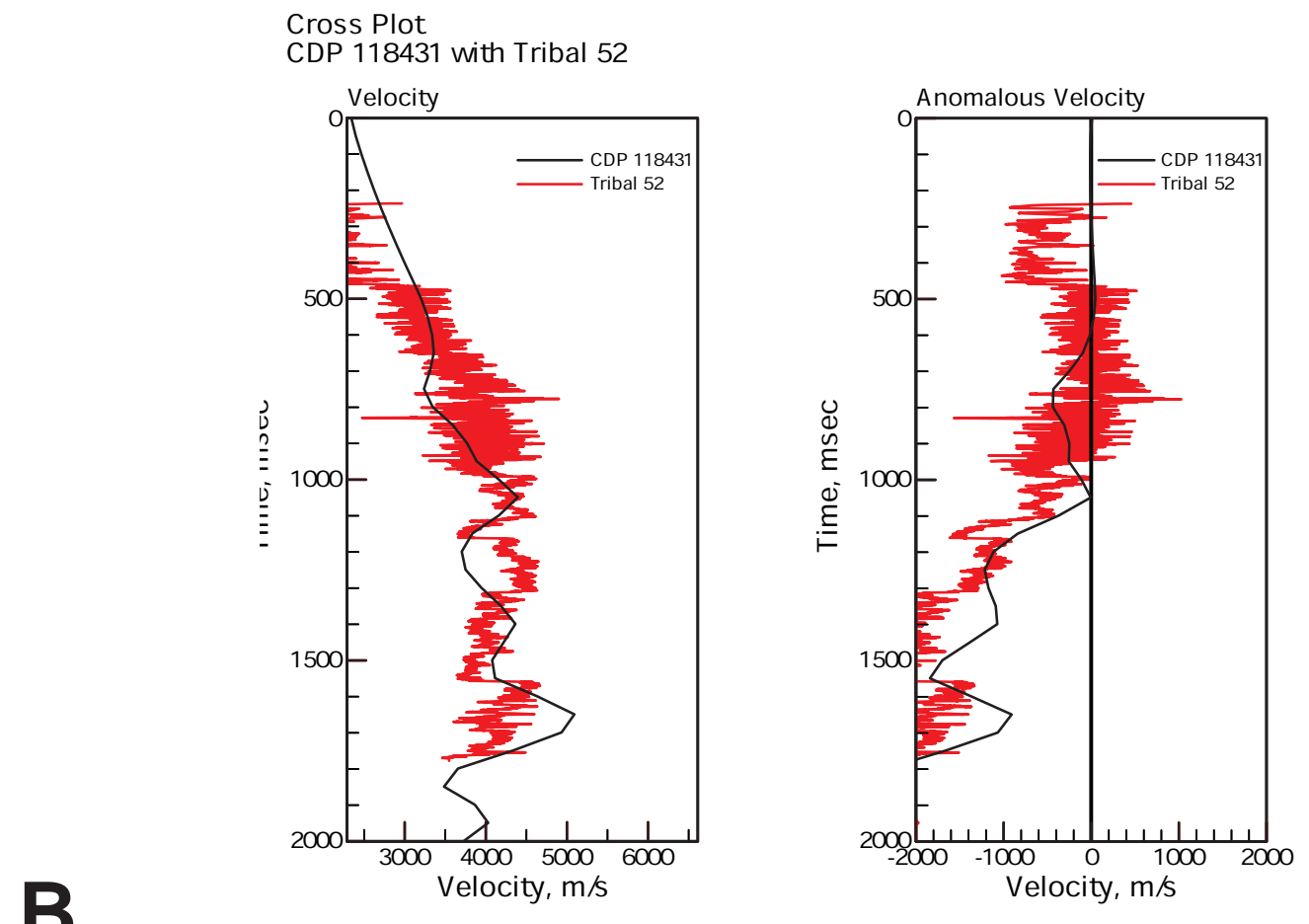

IER

IER

Figures 7A-C. Sonic and seismic interval velocity-depth pro les $f$ romc oi rei cent wel II gs and sei sm $c$ line CDPs on the right side of the diagram (i.e., anomalous velocity profile) the typical velocity-depth gradient has been removed from both the sonic and seismic velocity pro les al low $\operatorname{rg} f o$ the $i$ sol $a$ in of anomalously slow velocity domains. 

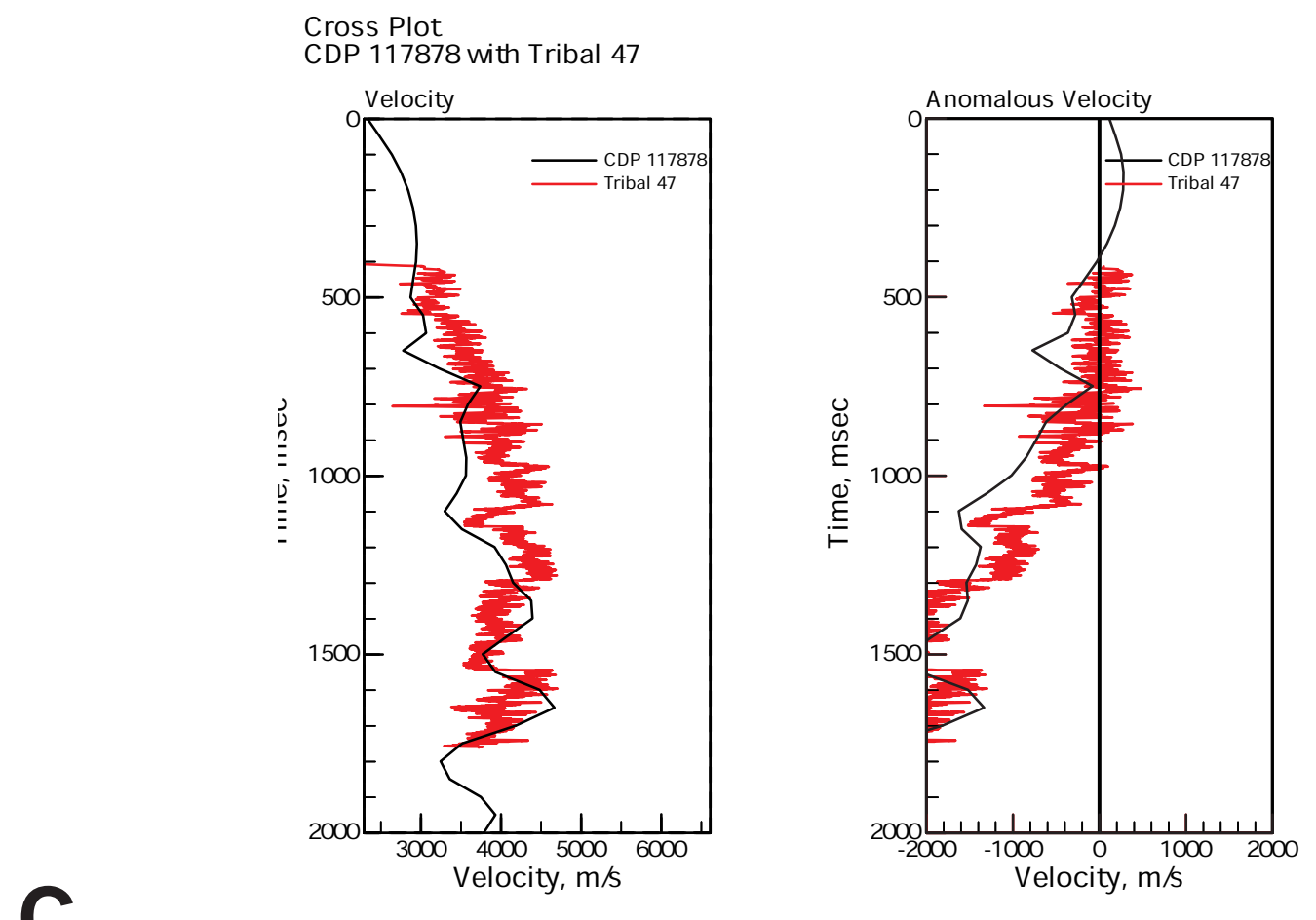

IER

Anomalous Velocity Model, Riverton Dome Project

View to Northeast

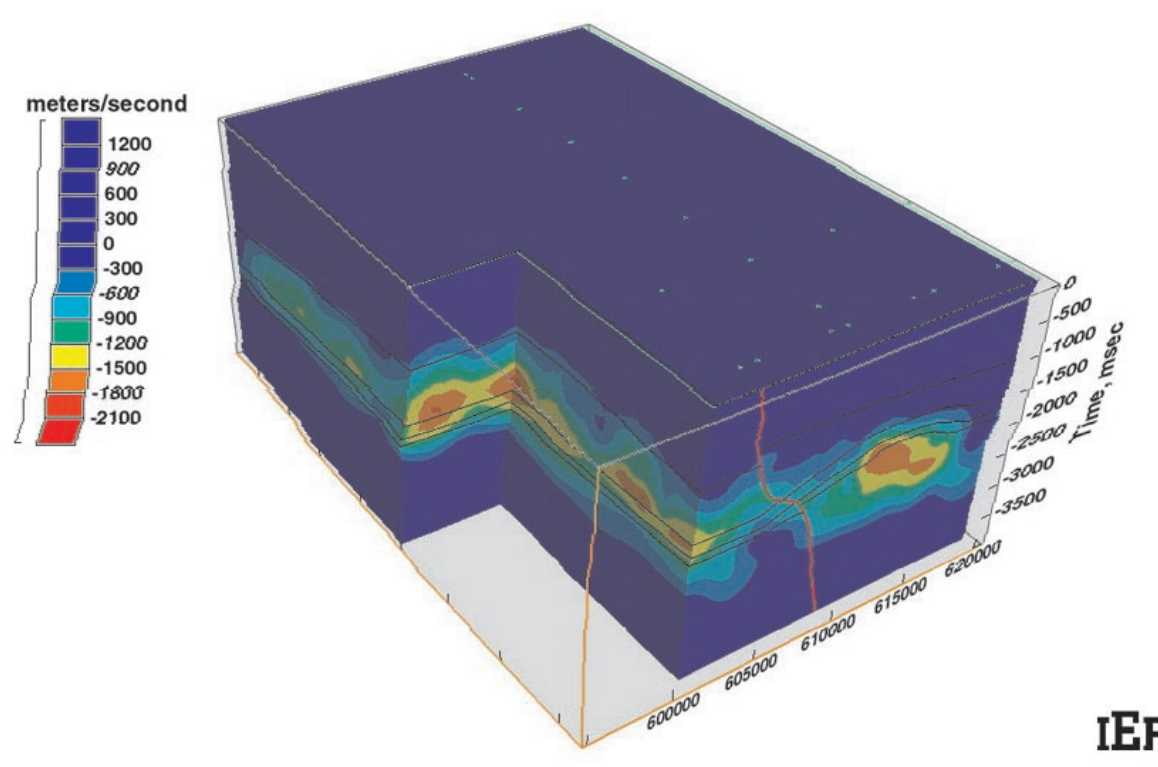

Figure 8A. Anomalous seismic velocity volume for the Riverton Dome, 3-D seismic survey. That portion of the volume shown in dark blue consists of rocks with a uid system following ahydrostatic gradient and a normal or typical velocity-depth gradient. In contrast, those rocks shown in light blue, green, yellow, orange, and red have uid systems t hat are anomalously pressured and $t$ hat are characterized by anomalously slow seismic velocities (i.e., fall below the typical regional velocity-depth gradient). 


\section{Anomalous Velocity Model, Emigrant 3D Survey}
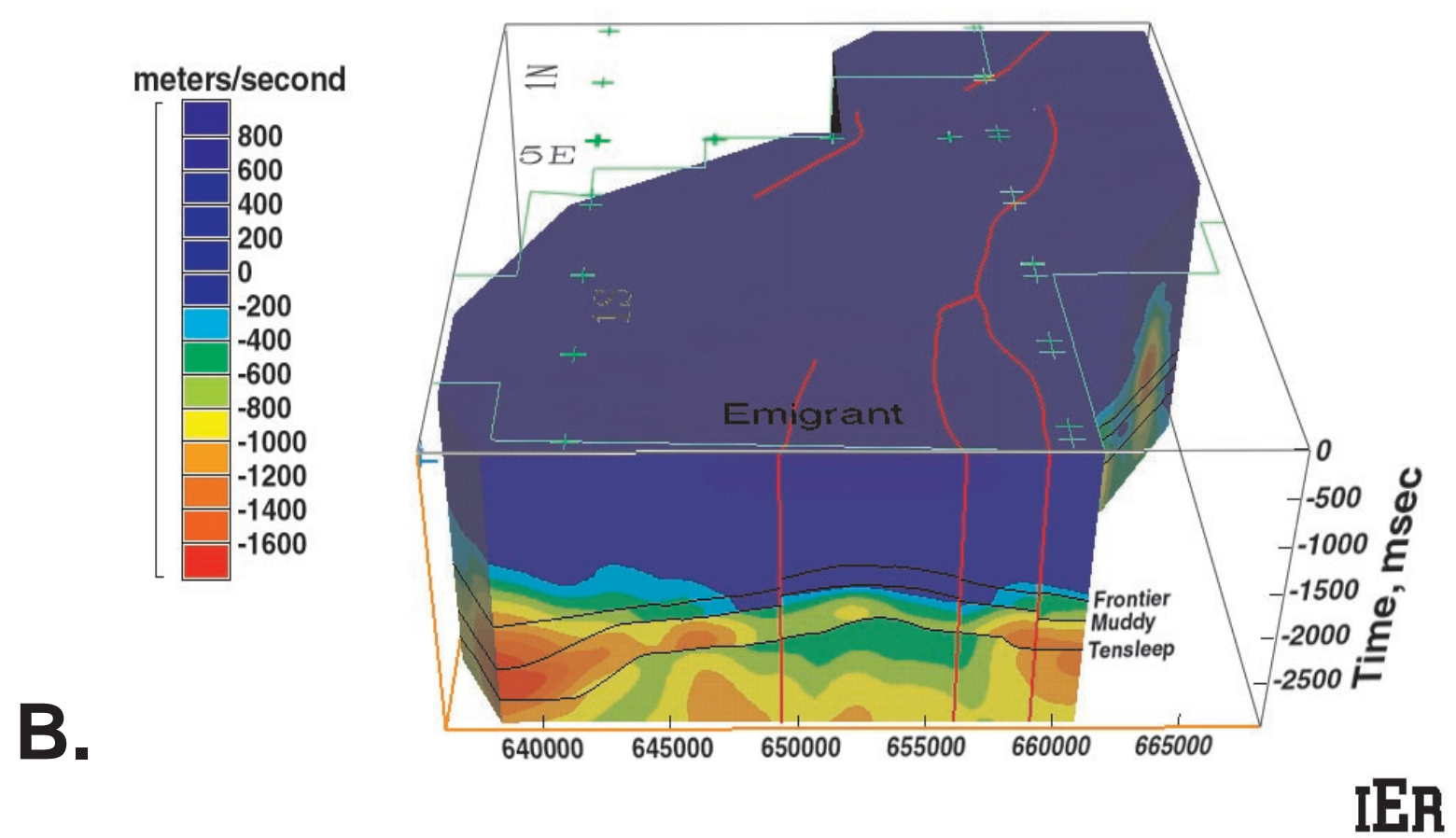

Figure 8B. Anomalous seismic velocity volume for the Emigrant 3-D seismic survey. The color scheme and pressure-velocity gradient relationships are the same as for Figure $8 \mathrm{~A}$.

the interval velocity-time gradient from 400 to 1600 ms TWTT). Below 2400 ms TWTT, the calculated interval velocities appear to signi cant ly increase, and as such they are no longer considered anomalously slow (Figure 9).

The anomalously slow velocities over the 1600 to $2400 \mathrm{~ms}$ TWTT interval are up to $6000 \mathrm{ft} / \mathrm{sec}$ below the velocity-time gradient. Is it possible that the velocity inversion and anomalously slow velocities are a product of uncertainties in the velocity selection routines? Using the velocity selection routines applied in this study, Buggenhagen (1999) has shown that the maximum uncertainties inherent in the resultant interval velocities are approximately $2000 \mathrm{ft} / \mathrm{sec}$ (i.e., $600 \mathrm{~ms}$ ). Thus, the velocity inversion ( $1600 \mathrm{~ms}$ TWTT) and anomalous interval velocities over the 1600 to $2400 \mathrm{~ms}$ TWTT interval shown in
Figure 9 are not the result of uncertainties in the velocity evaluation procedures.

\section{RIVERTON DOME RESULTS}

Using the procedures outlined above, it is possible in the Riverton Dome 3-D seismic survey area to detect and to delineate anomalously slow velocity domains in 3-D visualizations, as well as the regional pressure surface boundary/velocity inversion surface (see Figures 10A,B). Figures 10A and $10 \mathrm{~B}$ are east-west cross sections through the anomalous velocity volume (Figure $8 \mathrm{~A}$ ) in the study area viewed from the southwest to northeast. The red line shown in Figures $10 \mathrm{~A}$ and $10 \mathrm{~B}$ is a significant north-south fault in the Riverton Dome area; the position of the fault was determined from geological data provided to IER by Santa Fe Snyder Oil Company. Clearly 


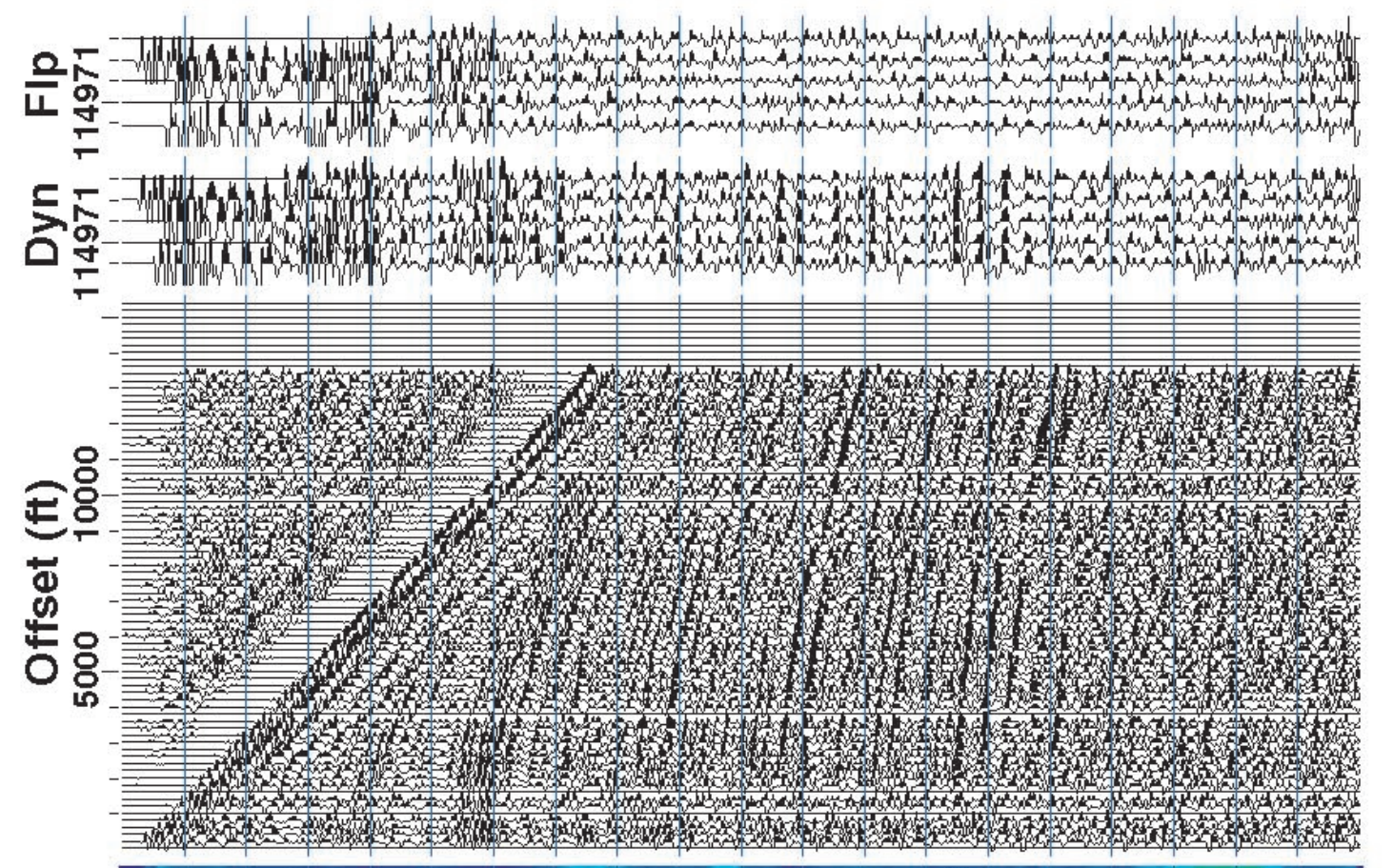

ㄸ⿶ㅂ

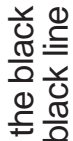

के 등

은응

잉

단

을음

ช0

के

迅产至

옹.을

음

त्र

응

过

ब㘼

흥 눙.

호응

क.

닝

क $\overline{\overline{0}}$.

응

过

穹온

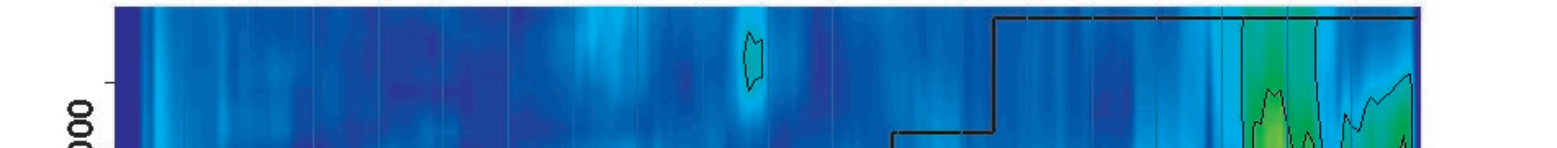

옽응ㅎㅇ

흥이

舫

क

을 잉유

कs क

क

政

लं 잉

(1) 전

ह

웡

드을

훙. 은.을

엉

등응

궁

흘

t。

응

궁ㅎํ

응

인

d 휴뭉

응 항

즌 $0 . \frac{\pi}{0}$

है일

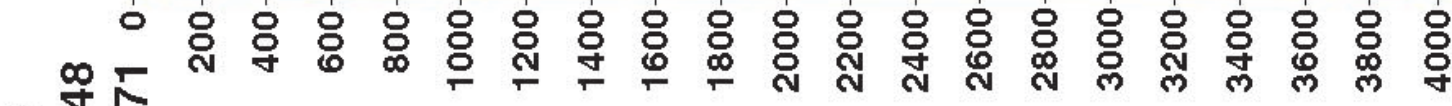
为

정응

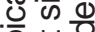

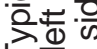

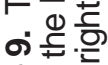

닌 일

운으 
Anomalous Velocíty ModeI, Riverton Dome Project

View to Northeast

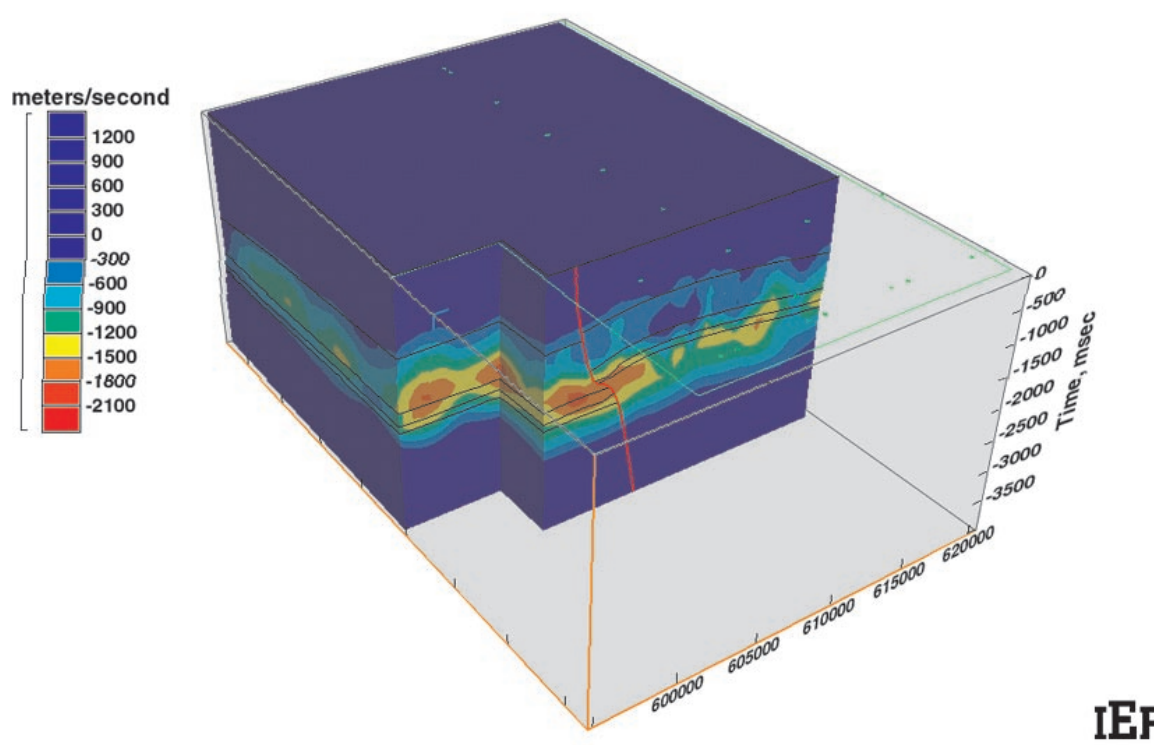

Anomalous Velocity Model, Riverton Dome Project

View to Northeast

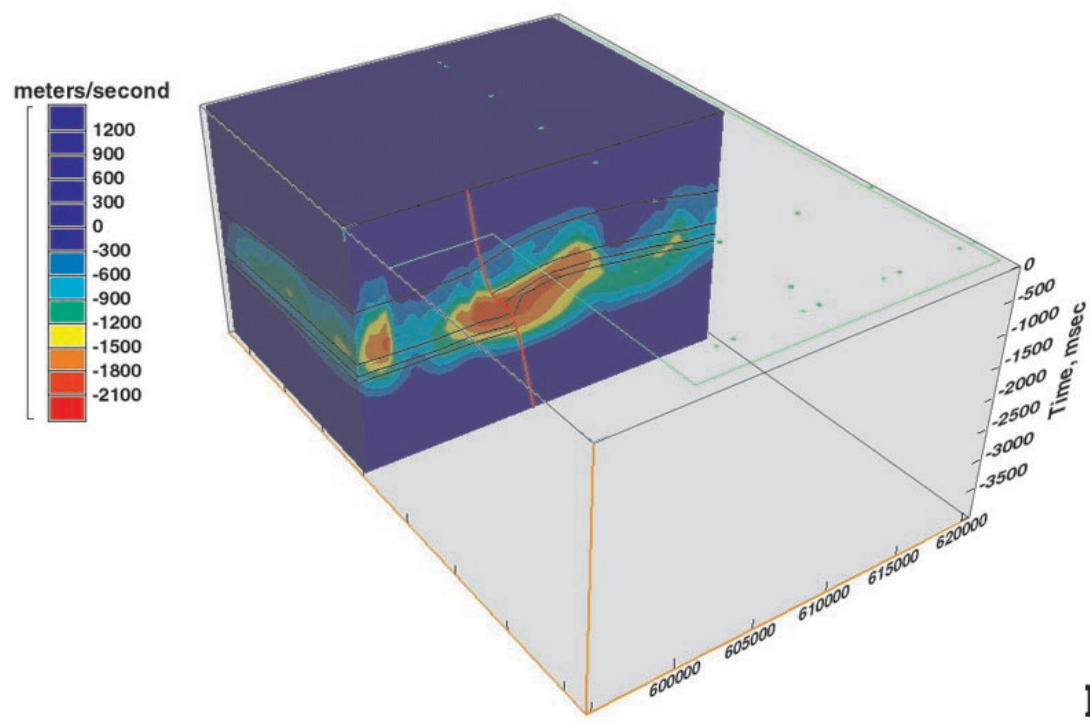

IER

B.

Figures 10A,B. A. East-west section through the anomalous velocity volume illustrated in Figure $8 \mathrm{~A}$; the cross section is viewed from the southwest to northeast. Diagram demonstrates the intense velocity anomaly adjacent to the North-South fault running through the 3-D seismic survey area. Also note the topographic relief on the regional velocity inversion surfaces (i.e., color change from dark to light blue). B. Same as Figure 10A, only the east-west cross section is farther to the north. 
illustrated in Figures $10 \mathrm{~A}, \mathrm{~B}$ is the top of anomalous pressure (uppermost velocity inversion surface shown in the gur es as a color change from dark to light blue) and domains of intense anomalously slow velocities (red areas).
Figures 11A-C are a series of north-south cross sections viewed from east to west through the anomalous velocity volume (Figure 8A). Again the regional velocity inversion surface (i.e., pressure surface boundary) is clearly delineated, as are the

\section{Anomalous Velocity Model, Riverton Dome Project \\ View to West}
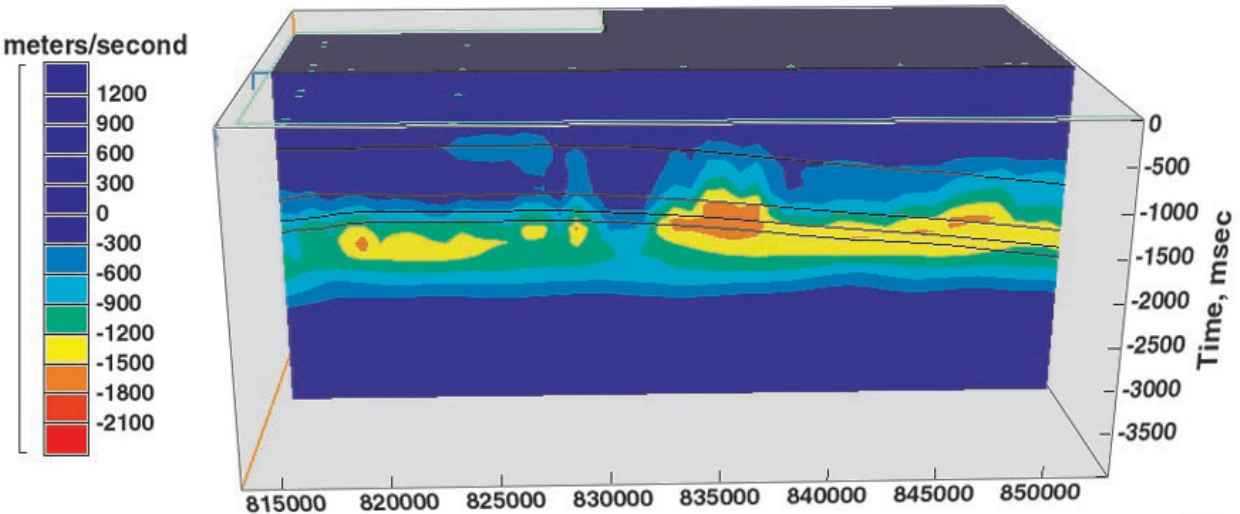

Anomalous Velocity Model, Riverton Dome Project

View to West
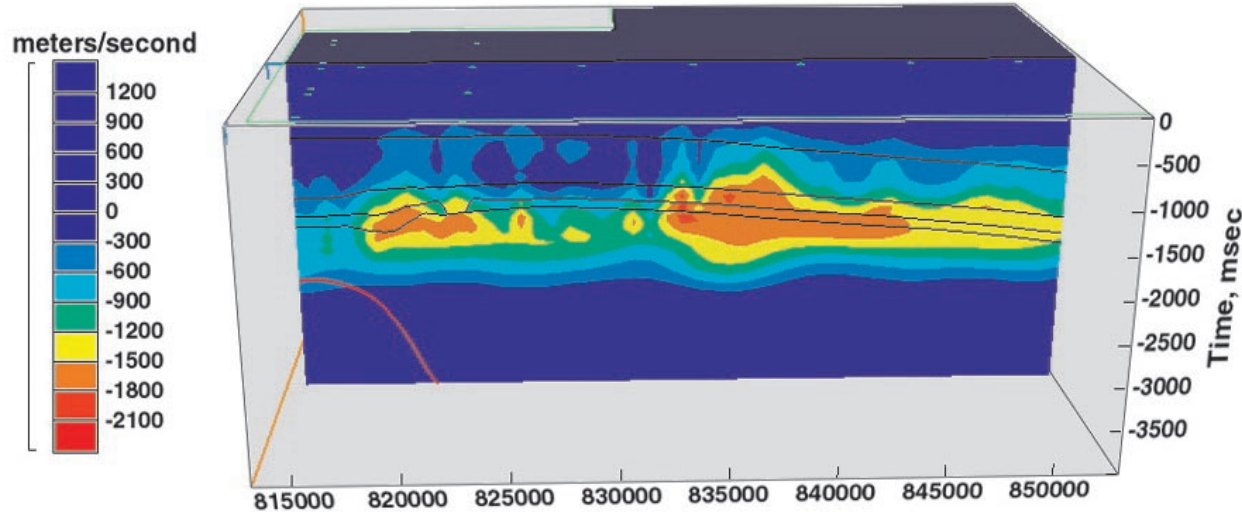

IER

Figures 11A,B. Two north-south cross sections, view from east to west, through the anomalous velocity volume shown in Figure 8A. Figure 11B is farther west than Figure 11A. 


\section{Anomalous Velocity Model, Riverton Dome Project}

View to West

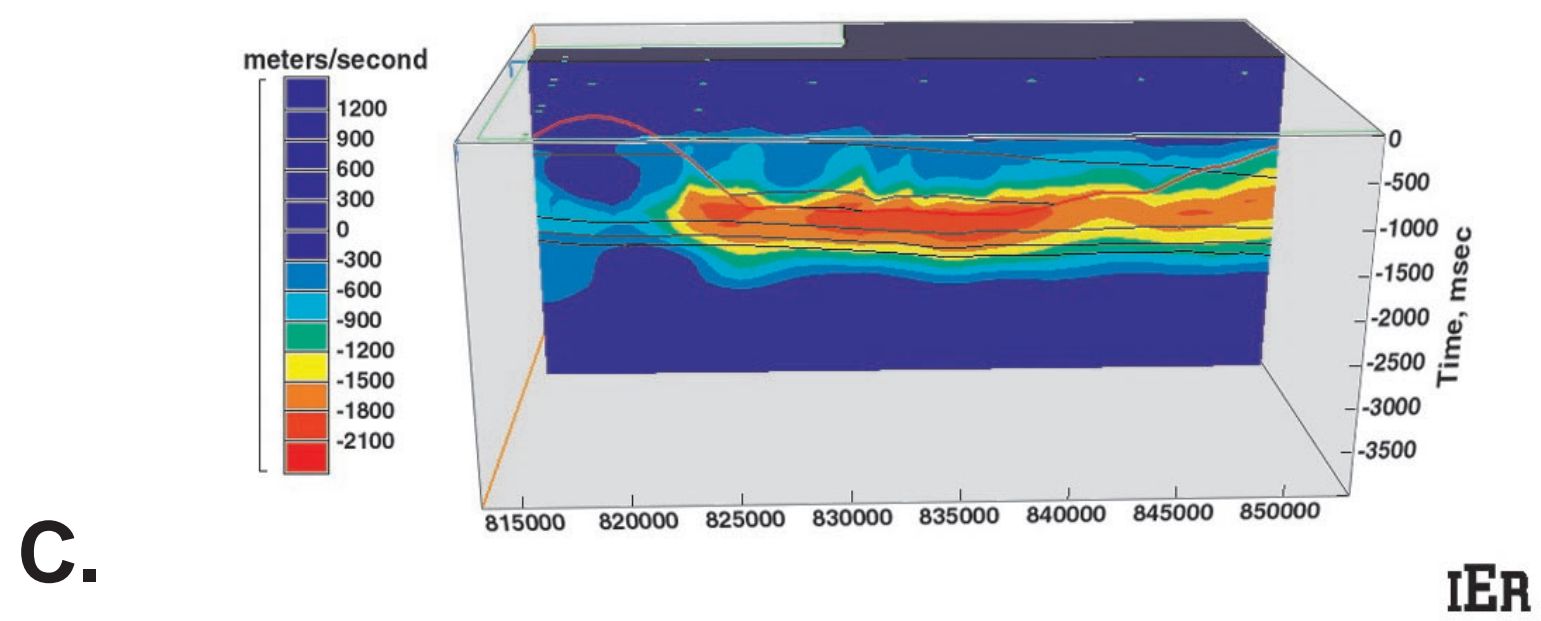

Figure 11C. North-south cross section through the anomalous velocity volume (Figure 8A) approximately parallel to the fault plane of the major north-south fault that is located downdip and west of the major structural closure in the area (i.e., doubly plunging north-south anticline).

intense velocity anomalies beneath the inversion surface. Note the significant topographic relief characterizing the regional velocity inversion surface (see especially Figures $11 \mathrm{~A}-\mathrm{C}$ ). The topographic highs on the velocity inversion surface (Figures $11 \mathrm{~A}-\mathrm{C}$ ) represent areas where gas is penetrating up into the overlying stratigraphic section.

Figure $11 \mathrm{C}$ is a cross section cut very close to the location of the north-south fault mentioned previously. Based on the relationship between the fault plane and the velocity anomalies, it is concluded that the north-south fault plane is a controlling factor with regard to the distribution of anomalous velocity domains within the Riverton Dome velocity volume.

Also, it is possible to study the configuration of the regional velocity inversion surface by stripping away all of the overlying section to view the surface in three dimension (Figure 12A). The volume shown in Figure 12A represents not only the uppermost surface of the anomalous velocity volume, but also the whole anomalous velocity volume (both top and bottom). In Figure 12B, all anomalous velocity layers down to $1500 \mathrm{~ms}$ (anomalously slow) have been stripped off of the anomalous velocity volume; therefore Figure 12B is a representation of the most intense anomalously slow velocities in the anomalous velocity volume. As a consequence, of the operations illustrated in Figures 10, 11, and 12, it is possible to more fully define in detail the distribution and configurations of all anomalous velocity domains in the Riverton Dome 3-D seismic survey.

\section{Velocity Anomalies}

In Figures 13A and 13B, the stratigraphic section above the Cody Formation has been removed from the anomalous velocity volume. Therefore, the viewer is looking at the velocity character of the anomalous velocity at the top of the Cody Formation in both inclined (Figure 13A) and map views (Figure 13B). From Figures 


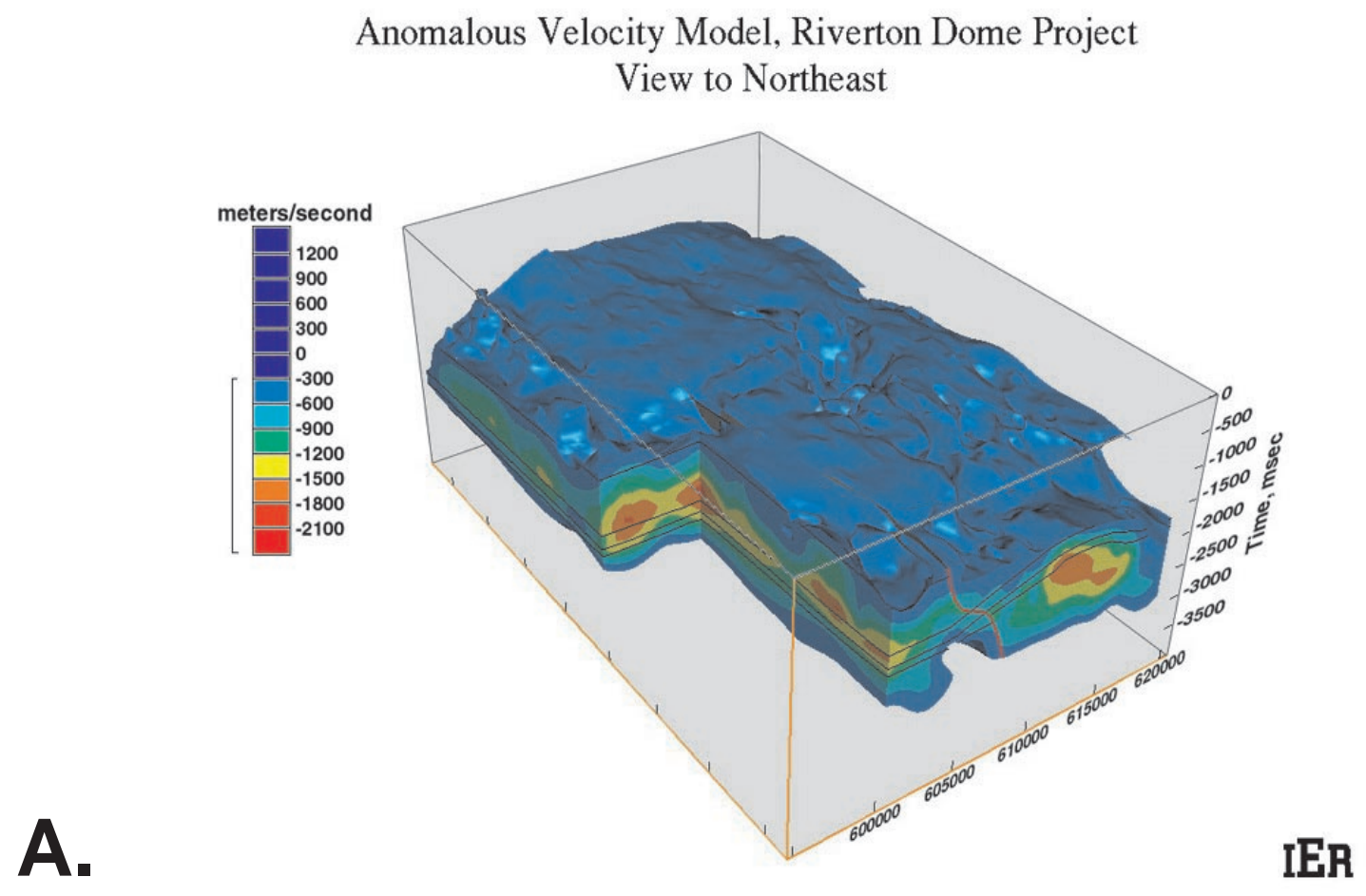

Figure 12A. Anomalous velocity volume where all the stratigraphic units above the top of the regional velocity surface (i.e., pressure surface boundary) have been removed. In addition the rocks with normal velocity characteristics below the anomalous velocity volume also have been removed.

Anomalous Velocity Model, Riverton Dome Project

View to Northeast
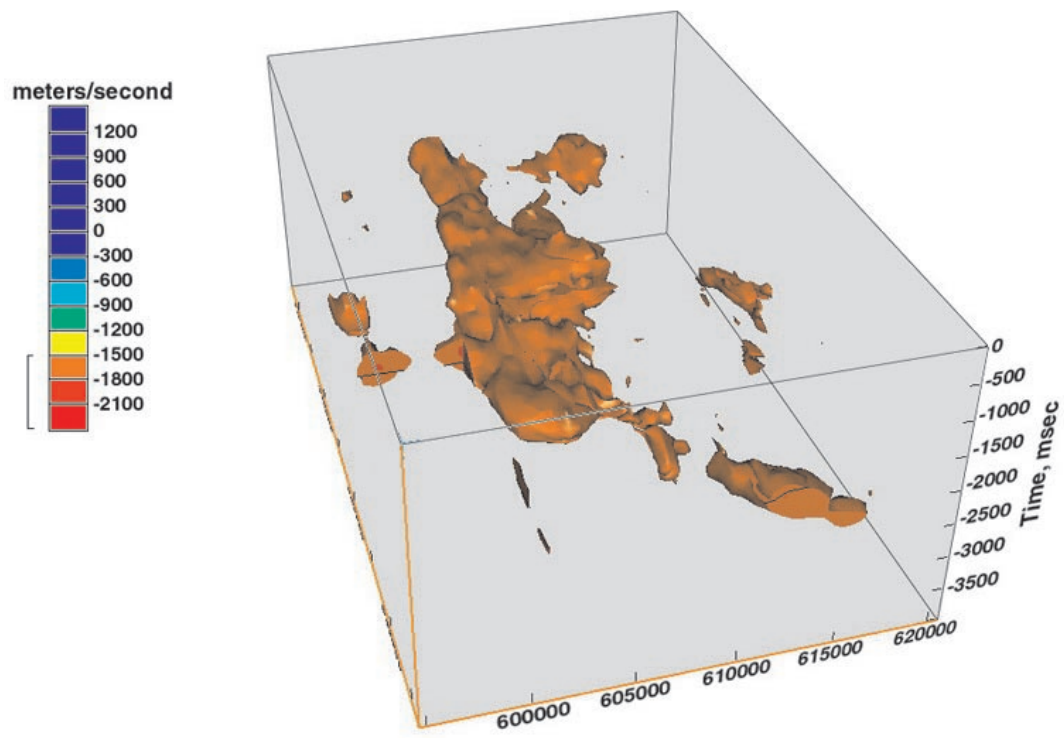

IER

Figure 12B. Isolated anomalous velocity volume showing only rocks characterized by velocities at least 1500 ms slower than the regional velocity-depth gradient (i.e., intense anomalously slow velocities). 
Anomalous Velocity Model, Riverton Dome Project

Top of Cody
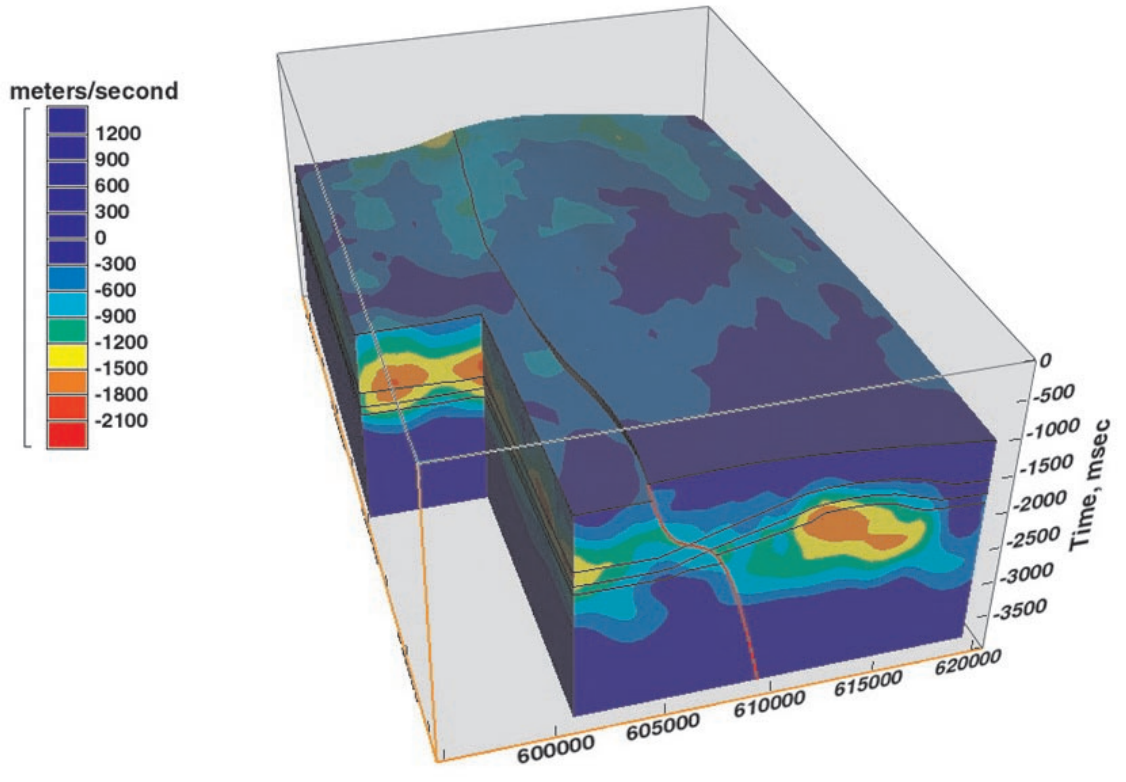

IER

Figure 13A. Anomalous velocity volume in which all the stratigraphic units above the top of the Cody Formation have been removed. The top of the volume in this gure is the top of the Cody Formation.

Anomalous Velocity Model, Riverton Dome Project

Top of Cody
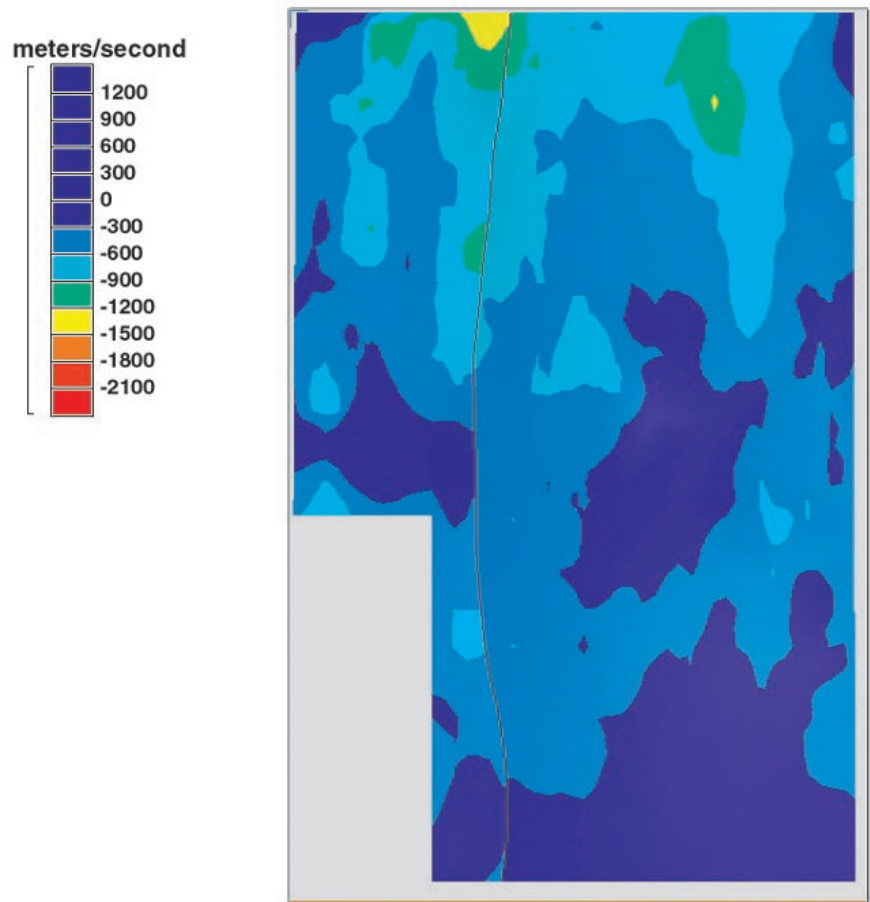

IFR Figure 13B. Map view of the top of the Cody Formation showing the anomalous velocity distribution at the top surface of the Cody Formation. 
$13 \mathrm{~A}, \mathrm{~B}$, it is apparent that in the southern half of the study area, the Cody is characterized by normal seismic interval velocity, and presumably normal pressures; whereas in the northern half of the area, the Cody is characterized by anomalously slow seismic interval velocities, and presumably anomalous pressures.

Figures $14 \mathrm{~A}, \mathrm{~B}$ are similar constructions for the top of the Frontier Formation. It is clear from Figures 14A,B that there is a significant domain adjacent to the northsouth fault that is anomalously slow. This particular velocity anomaly is observed in $10 \%$ or 160 of the $1620 \mathrm{CDP}^{\prime} \mathrm{s}$ shown in Figure 6. From Figure 10A it is concluded that this anomaly extends down into the main portion of the Frontier Formation.

East of the anomaly along the fault at the crest of the structure there is normally pressured hydrocarbon production in the Frontier Formation (see location of the
Tribal 8 well on Figure 15B). Figures 15A,B clearly illustrate that at the crest of the structure east of the fault, a portion of the Frontier Formation is characterized by normal velocity (i.e., velocity values falling on the typical regional velocity-depth gradient). In both Figures 15A,B, the rocks within that part of the Frontier Formation characterized by normal velocity have been removed. Clearly, the removal of the rocks creates a canyon or topographic low on the Frontier anomalous velocity volume at the crest of the structure and trending from south to north. Production histories demonstrate that the Frontier rocks that were removed (thereby creating the topographic low; Figure 15B) are normally pressured. From the geometry of the topographic low, it is speculated that the low represents a north-south channel-like sandstone within the Frontier Formation that is draped over the structure. This "chan-

Anomalous Velocity Model, Riverton Dome Project Top of Frontier
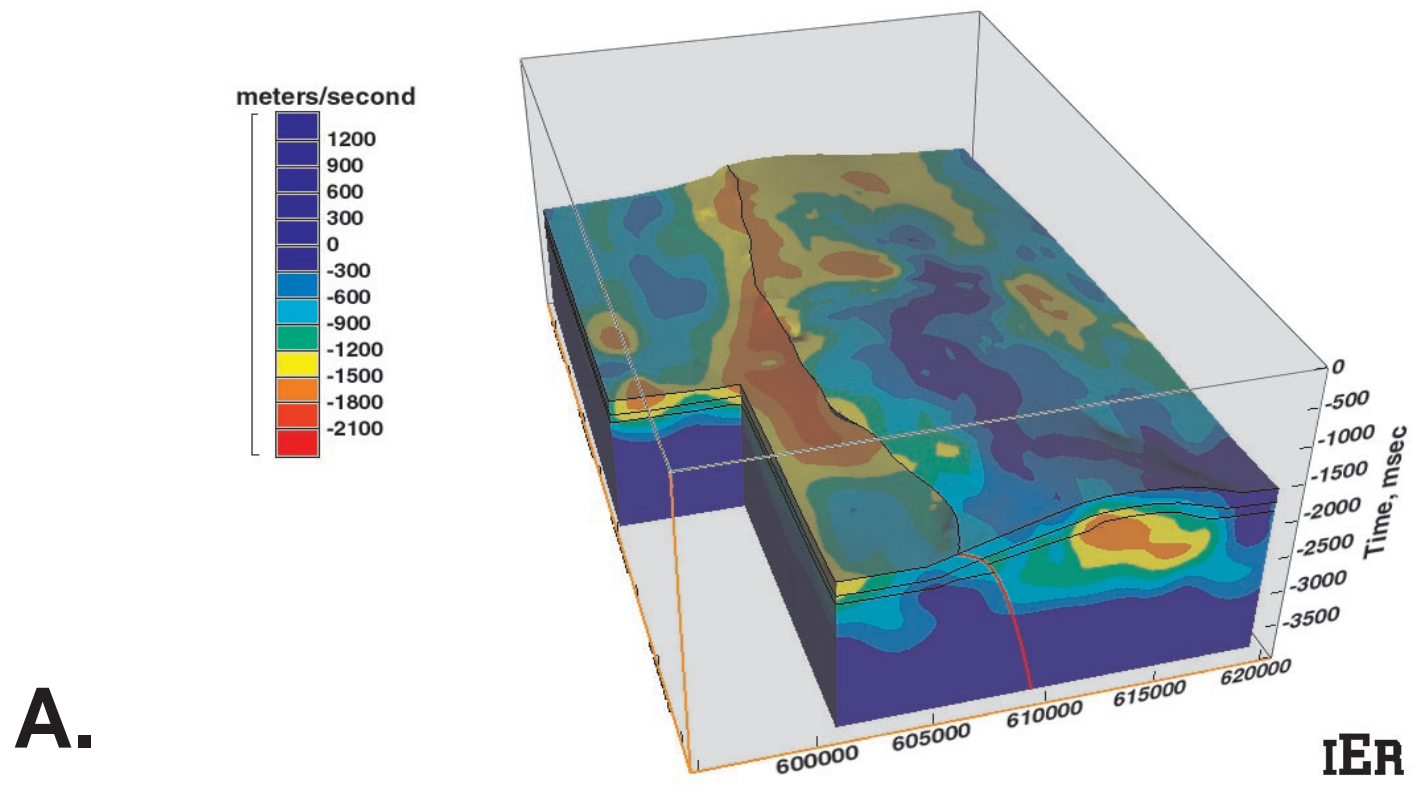

Figure 14A. Anomalous velocity volume in which all the stratigraphic units above the top of the Frontier Formation have been removed. The top of the volume in this gure is the top of the Frontier Formation. 
Anomalous Velocity Model, Riverton Dome Project

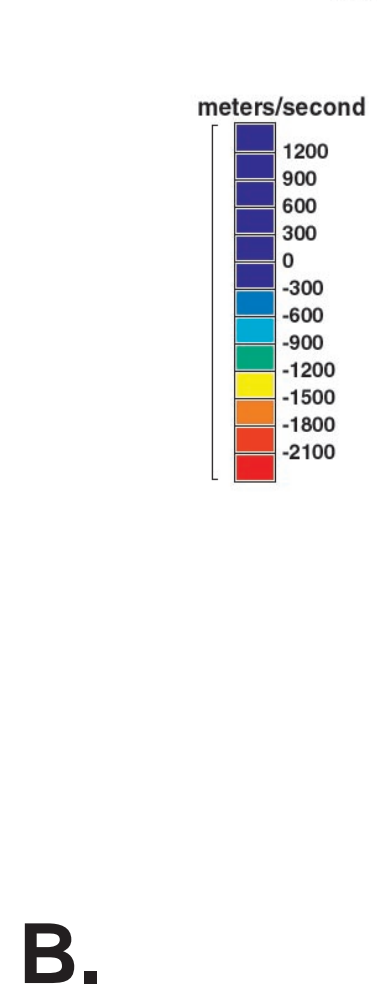

Top of Frontier

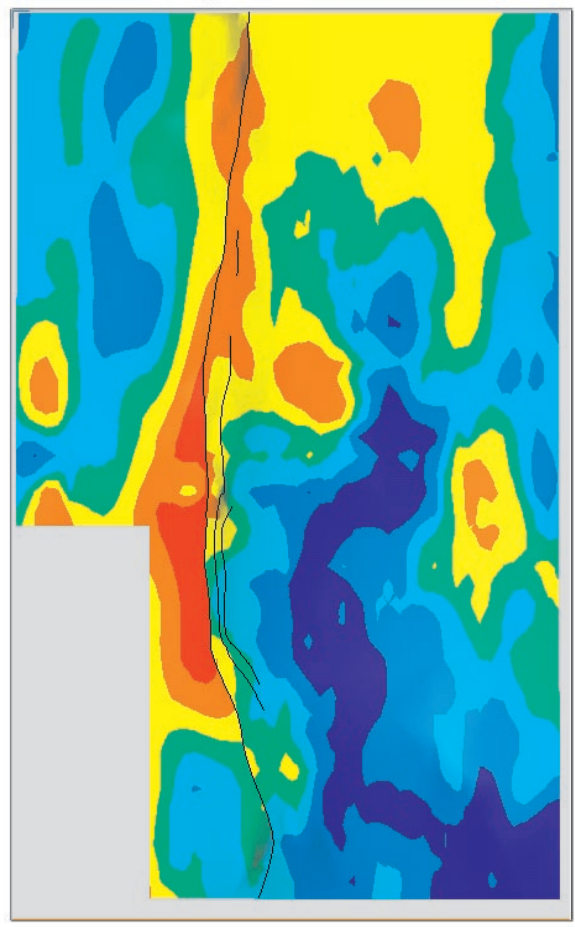

Figure 14B. Map view of the top of the Frontier Formation showing the anomalous velocity distribution at the top surface of the Frontier Formation. nel" sandstone is probably connected to the Frontier outcrop that occurs to the south of the Riverton Dome area. This scenario would explain how the Frontier Formation could be normally pressured (i.e., fluid system follows a hydrostatic gradient) at the crest of the structure, but with anomalously pressured rocks downdip to the west in the vicinity of the north-south fault. The sandstones within the channel probably are recharged by meteoric water from the south with hydrocarbons collecting at the crest of the structure due to a strong water drive. In strong contrast, the Frontier Formation downdip to the west is isolated from the outcrop and is being charged with hydrocarbons migrating up along the north-south fault.

Figures 16A,B represent inclined and map views of the Muddy Formation. The spatial pattern of the anomalous velocities is similar to the pattern observed for the Frontier Formation. At the crest of the struc- ture at the southern end of the survey area, there is a significant velocity anomaly in the Muddy Formation (Figures 16A,B). The most intense and volumetrically important velocity anomaly in the Muddy Formation, like in the Frontier Formation, occurs along both sides of the north-south fault (Figures $16 \mathrm{~A}, \mathrm{~B})$. In summary, this velocity anomaly occurs on both the up and down thrown sides of the fault (Figures 10A,B); with the fault clearly controlling the distribution of the velocity anomaly, and presumably the gas saturated, anomalously pressured rocks within the Muddy Formation.

Figures $17 \mathrm{~A}, \mathrm{~B}$ are similar velocity reconstructions for the Nugget Formation. Although the con gur ation of the Nget Formation velocity anomaly is similar to that of both the Frontier and Muddy formations, there is one important difference; the most intense Nugget velocity anomalies are con red to the eastern side of the north-south fault (Figures $17 \mathrm{~A}, \mathrm{~B})$. The intense velocity anomalies with- 


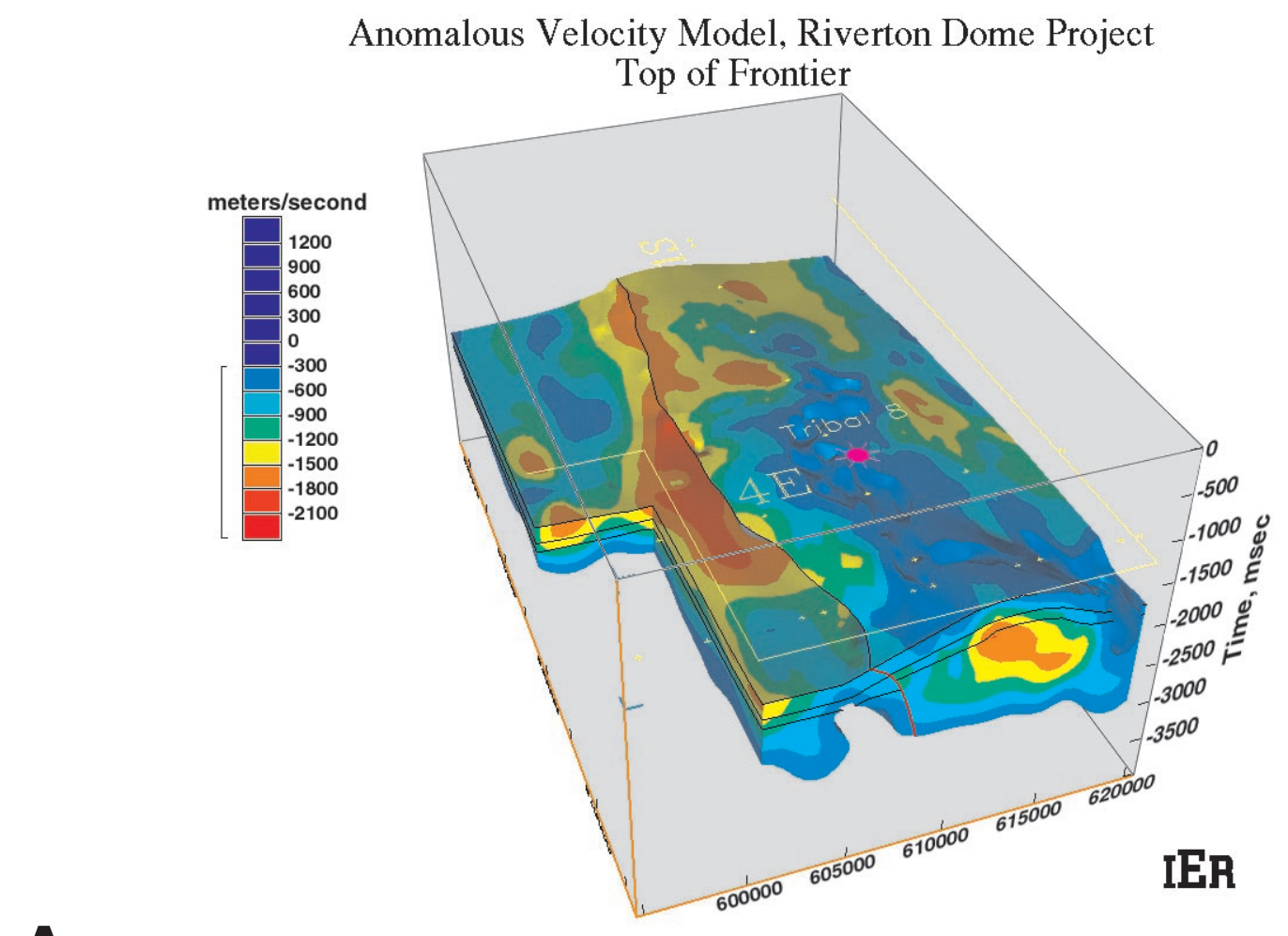

A.

Anomalous Velocity Model, Riverton Dome Project Top of Frontier

ieters/second
\begin{tabular}{|l|l}
\hline & 1200 \\
\hline & 900 \\
\hline & 600 \\
\hline & 300 \\
\hline & 0 \\
\hline \hline & -300 \\
\hline & -600 \\
\hline & -900 \\
\hline & -1200 \\
\hline & -1500 \\
\hline- & -1800 \\
\hline- & -2100 \\
\hline
\end{tabular}

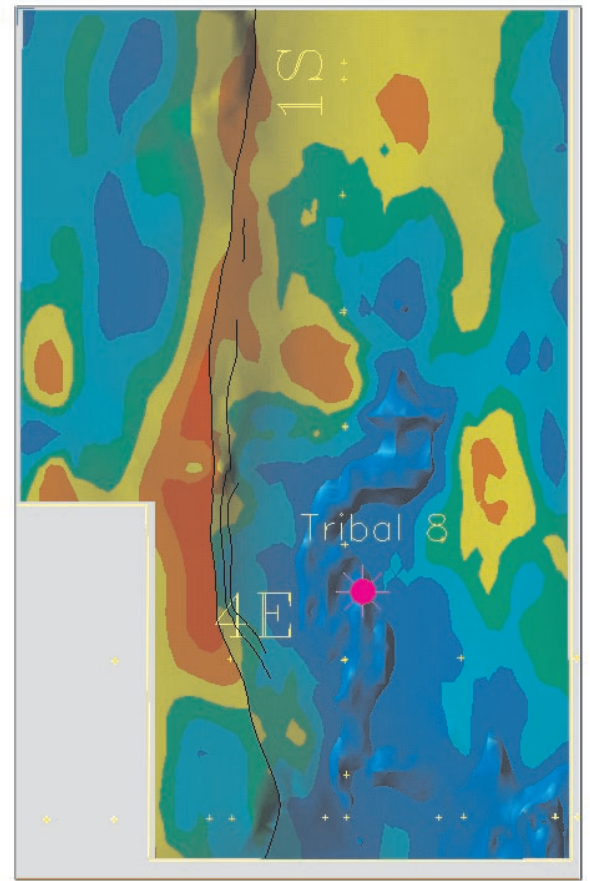

IER

Figures 15A,B. Same as Figures $14 \mathrm{~A}$ and 14B only all Frontier rocks characterized by normal velocities (i.e., probably normally pressured) have been removed. The position of the Tribal 8 well is shown (pink dot) because it is producing normally pressured hydrocarbons from the Frontier Formation at the top of the structural closure. 


\section{Anomalous Velocity Model, Riverton Dome Project Top of Muddy}
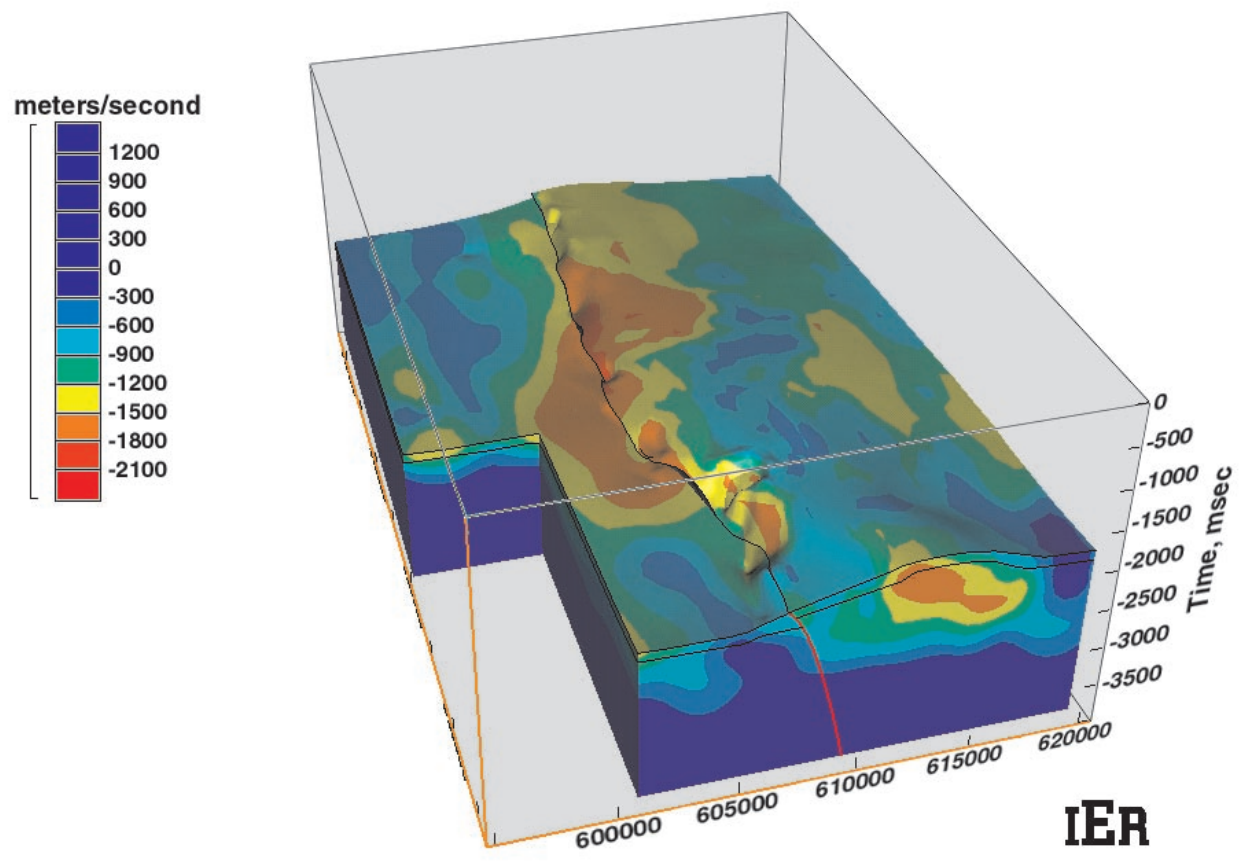

Figure 16A. Anomalous velocity volume in which all the stratigraphic units above the top of the Muddy Formation have been removed. The top of the volume in this gur e is the tø $\delta$ the M ddy For rat iø.

Anomalous Velocity Model, Riverton Dome Project

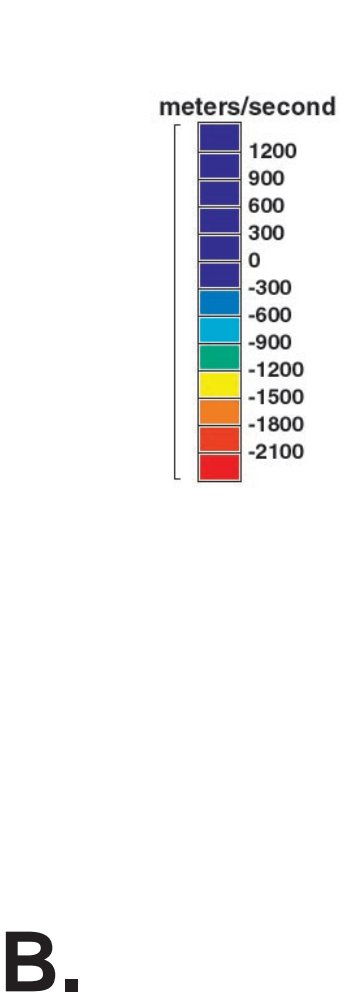

Top of Muddy

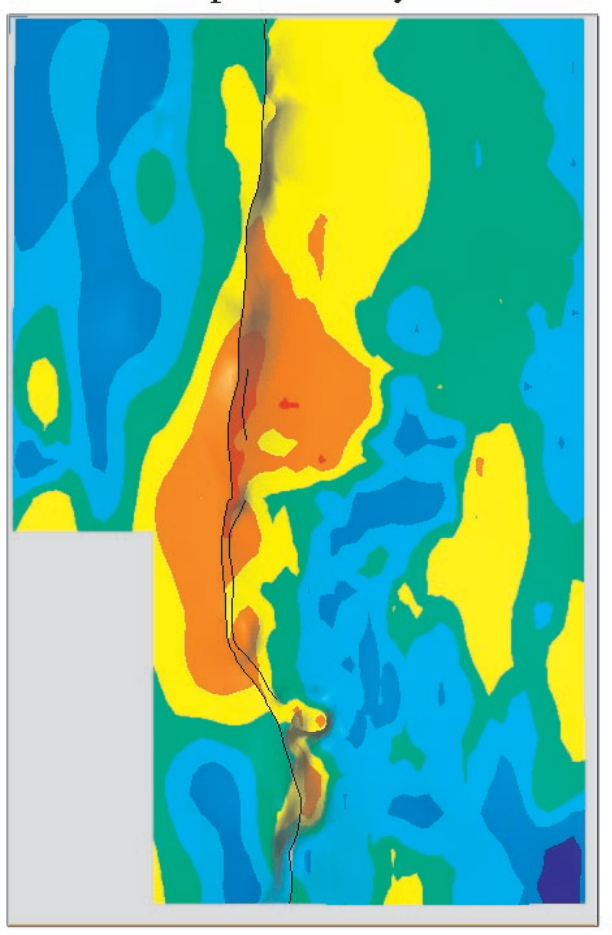

IER

Figure 16B. Map view of the top of the Muddy Formation showing the anomalous velocity distribution at the top surface of the Muddy Formation. 
in the Nugget Formation are very important, for the Nugget is typically a porous sandstone, whereas the sandstones in the Frontier and Muddy formations commonly are relatively tight. So the velocity anomalies within the Nugget may represent signi cant gas accut mulations in a porous sandstone reservoir. Elsewhere in the general area, the Nugget commonly is water- lled. ai $\mathrm{n}$ it shoul d be noted that the most intense velocity anomaly occurs along the north-south fault and downdip from the crest of the structural closure.

\section{INTERPRETATION}

The velocity anomalies demonstrated in Figures 14 through 17 can be isolated and visualized in three dimensions using the IER technology (Figures 12A,B). The importance of this operation is that the volume shown in Figure 12B is gas saturated and anomalously pressured. Core observations in the area show that the Cody, Frontier, Muddy, and Nugget formations are not undercompacted. Therefore, the best explanation for the intensely slow velocities shown in Figure 12B is that the $\dot{u}$ ds ystemwi thi nt he vol ume contain signi cant $f$ ree gas i $n$ the id plase (Surdam et al., 1997). As a result the anomalous velocity volume shown in Figure 12B is an important lead as to where to explore for anomalously pressured gas accumulations in the Riverton Dome area. This exploration lead will evolve into a serious gas prospect if it can be shown that potential reservoir units with commercial porosity/permeability intersect the anomalous velocity volume shown in Figure 12B.

\section{VALIDATION OF THE IER EXPLORATION TECHNOLOGY}

During the time that the velocity field evaluation was progressing at IER, six Muddy

\section{Anomalous Velocity Model, Riverton Dome Project}

Top of Nugget
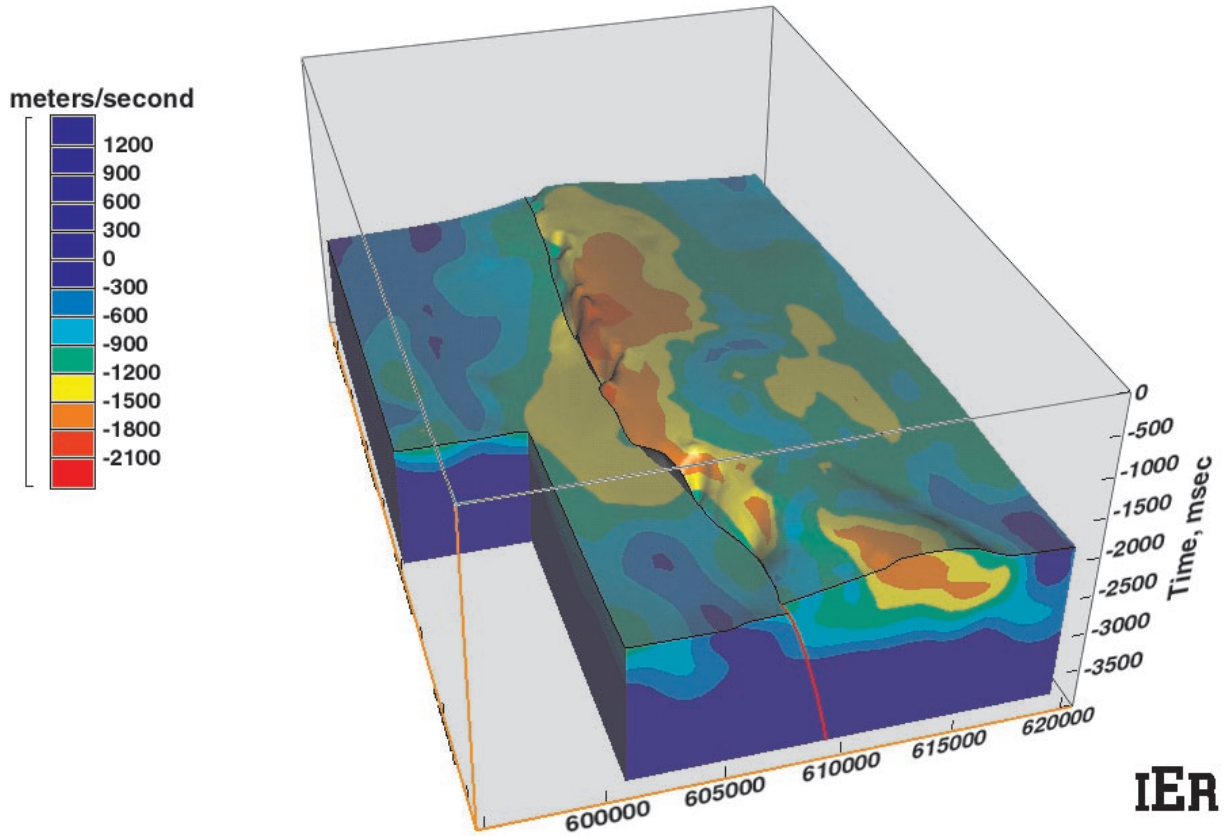

Figure 17A. Anomalous velocity volume in which all the stratigraphic units above the top of the Nugget Formation have been removed. The top of the volume in this gur e is the top of the Nigget For rat iø. 


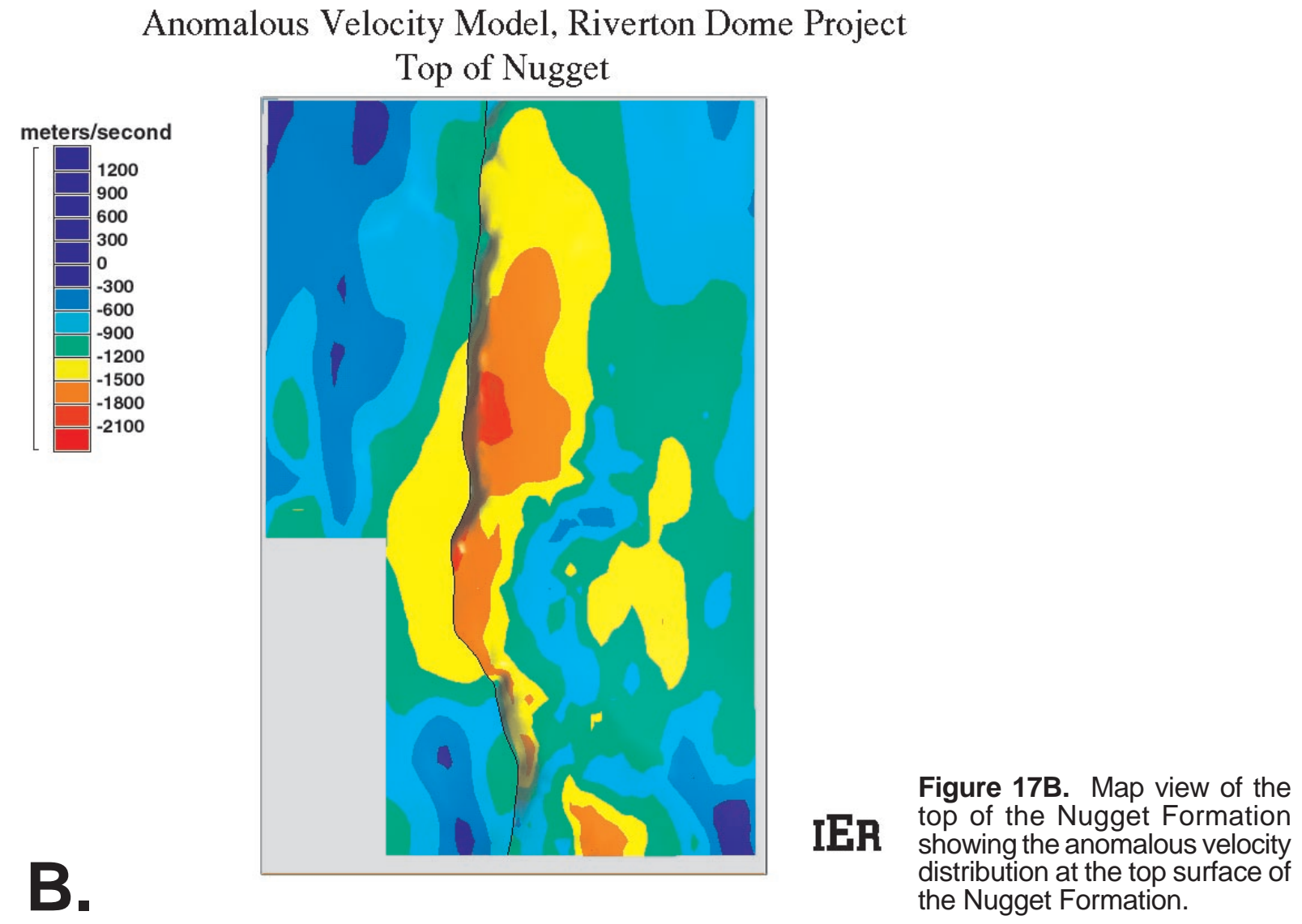

Formation tests were completed by Santa Fe Snyder Corporation. From the perspective of the IER researchers, these were blind tests of the exploration strategy. The test well results were made known to IER only after the ral results of the Riverton Dome velocity evaluation were presented to Santa Fe Snyder Corporation by IER in Laramie, Wyoming on January 27,1999. The range of initial gas production of the six wells was < one to four mmcf/day. Figure 18A is a map view of the anomalous velocity values at the top of the Muddy Formation. In Figure 18A, all anomalous velocity layers $<1200 \mathrm{~ms}$ slower than the regional velocity-depth (or time) gradient have been removed from the anomalous velocity volume. Thus, the anomalous velocity remnant shown in Figure 18A includes all rocks within the Muddy Formation that have anomalous velocities more than $1200 \mathrm{~ms}$ slower than the regional velocity-depth gradient. Also plotted on the anomalous velocity diagram (Figure
18A) are the positions of the six test wells and their characteristic initial production (IP) values in mmcf/day. Figure $18 \mathrm{~B}$ is an enlarged display of the area of interest within the Riverton Dome survey area showing in detail the relationship between the anomalous velocity domain within the Muddy Formation and the IP values for the six recent test wells. Wells completed in the Muddy Formation and in those rocks characterized by anomalous velocity values $1500 \mathrm{~ms}$ slower than the regional velocity-depth gradient (i.e., three wells) have IP values ranging from three to four mmcf/day. The one well at the edge of the velocity anomaly (i.e., anomalous velocity value of $<1200 \mathrm{~ms}$ below, or slower than the regional velocity-depth gradient) had an IP value of one mmcf/day. The two wells drilled into Muddy Formation rocks with a maximum anomalous velocity value of $<900 \mathrm{~ms}$ had IPs of $<$ one mmcf/day and at last notice were shut in. In fact, judging from Figure 16B, 
Anomalous Velocity Model, Riverton Dome Project Top of Muddy

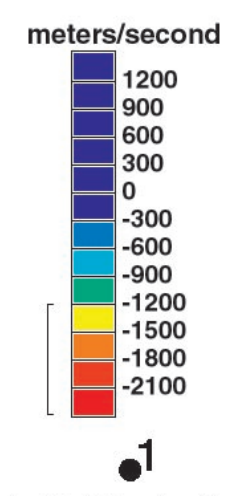

Initial Production $1 \mathrm{mmcf}$

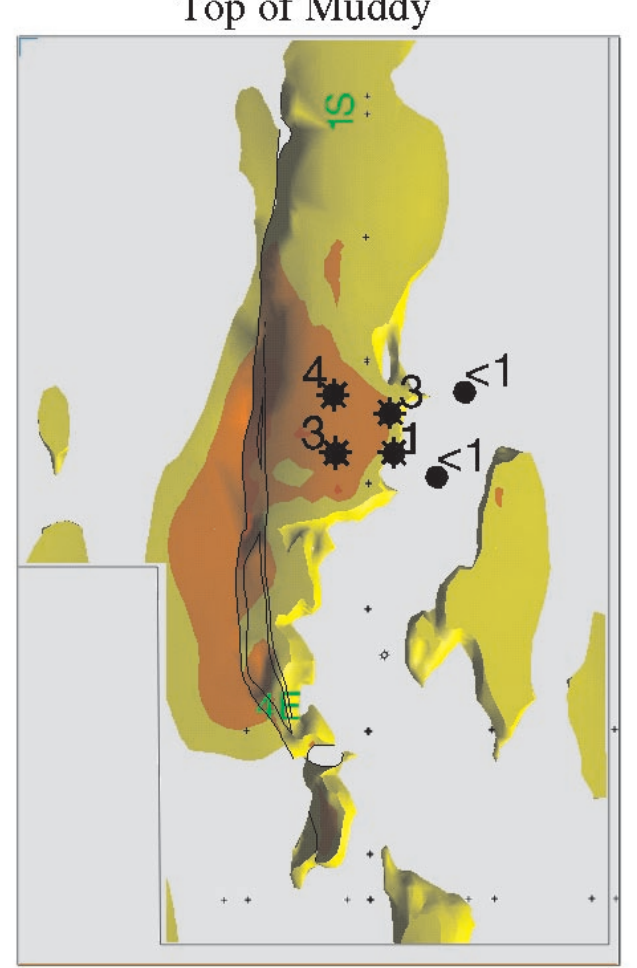

IER
Figure 18A. Map view at the top of a targeted reservoir interval (i.e., Muddy Formation); map is derived from a 3-D anomalous velocity volume constructed from a 3-D seismic survey in the Wind River Basin. In a blind test six recent Muddy Formation wells were plotted on the anomalous velocity surface at the top of the Muddy Formation. The wells within the velocity anomaly (i.e., > $1200 \mathrm{~m} / \mathrm{sec}$ below the regional velocitydepth gradient) had initial production values of three to four $\mathrm{mmcf} / \mathrm{day}$; the well at the edge of the velocity anomaly (i.e., $<1200 \mathrm{~m} / \mathrm{sec}$ below regional gradient) had initial production of one mmcf/day; whereas the two wells drilled outside the velocity anomaly had initial productions of $<$ one mmcf/day and presently are shut in.

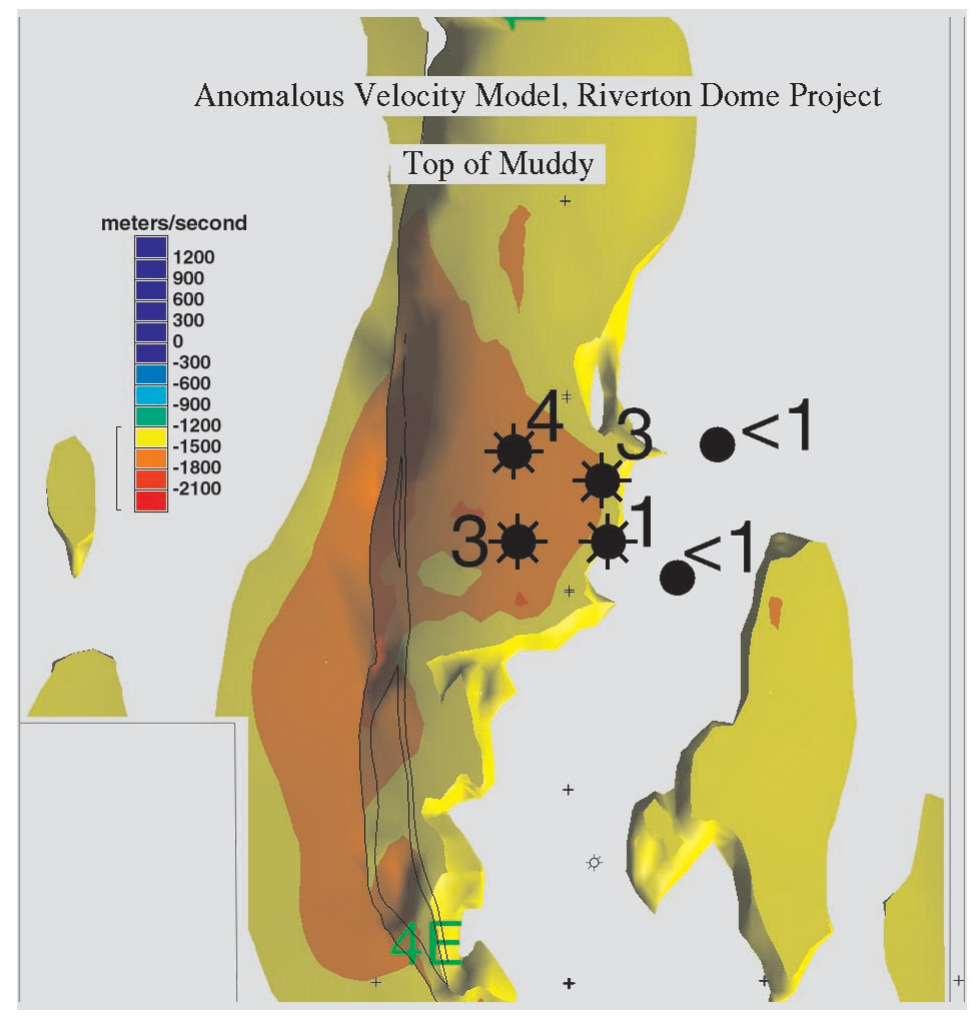

IER

Figure 18B. Enlarged diagram showing the details of the area of interest in Figure 18A. 
the Muddy Formation in the vicinity of the < one mmcf/day well may have an anomalous velocity value of only 300 to $600 \mathrm{~ms}$ (i.e., slow). Recall in earlier discussion that the uncertainty associated with the velocity selections and resultant anomalous velocity values derived in this study are on the order of no more than $600 \mathrm{~ms}$, and perhaps as low as $300 \mathrm{~ms}$. It is concluded, with respect to the six recent Muddy test wells, that the IER exploration strategy for detecting and delineating commercial anomalously pressured gas accumulations is valid within the Riverton Dome 3-D seismic survey area, and can be utilized to signi cant lyr educe exploration risk and increase pro tability of so-called deep basin accumulations.

\section{CONCLUSIONS}

\section{An Ideal Test of the IER Exploration Technology}

Armed with the new conceptual model and resultant exploration paradigm, plus the detection and delineation techniques discussed in this report, it should be possible to greatly reduce exploration risk in the Riverton Dome area and in other Rocky Mountain Laramide Basins. The ultimate value of the new technology will be determined by the degree to which it is able to predict in a forward fashion the distribution of basincenter gas accumulations. As such, the following ral test is suggested. A caref $\mathrm{u}$ review of all the results from this study suggest that a prime location exists in the Riverton Dome survey area where the new concept, IER exploration paradigm, technology, and detection techniques can be tested in three formations by a single well. The location is shown by a black dot on Figures 19A (i.e., Frontier anomalous velocity map), 19B (i.e., Muddy anomalous velocity map), and 19C (i.e., Nugget anomalous velocity map). In each case, the drill site (the black dot) is located over an intense velocity anomaly in each of the respective formations. The drill site is located at CDP 124896
Anomalous Velocity Model, Riverton Dome Project Top of Frontier

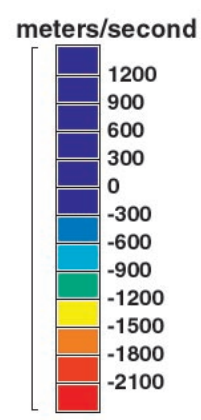

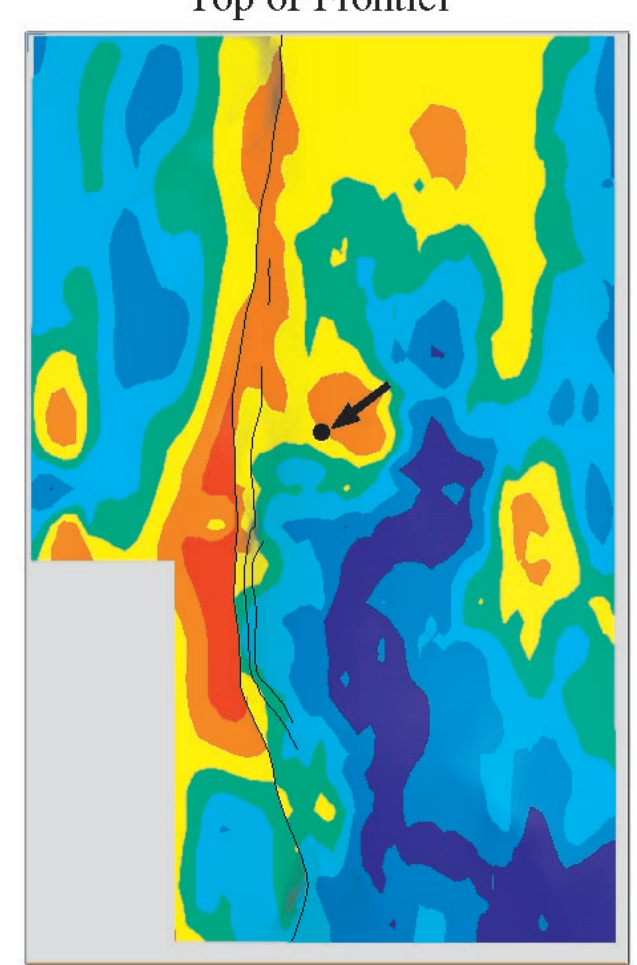

IER
Figure 19A. Anomalous velocity map of top of Frontier Formation (Figure 14B) with the location of the proposed test well shown with a black dot (CDP 124896 in the Riverton Dome 3-D seismic survey area). 


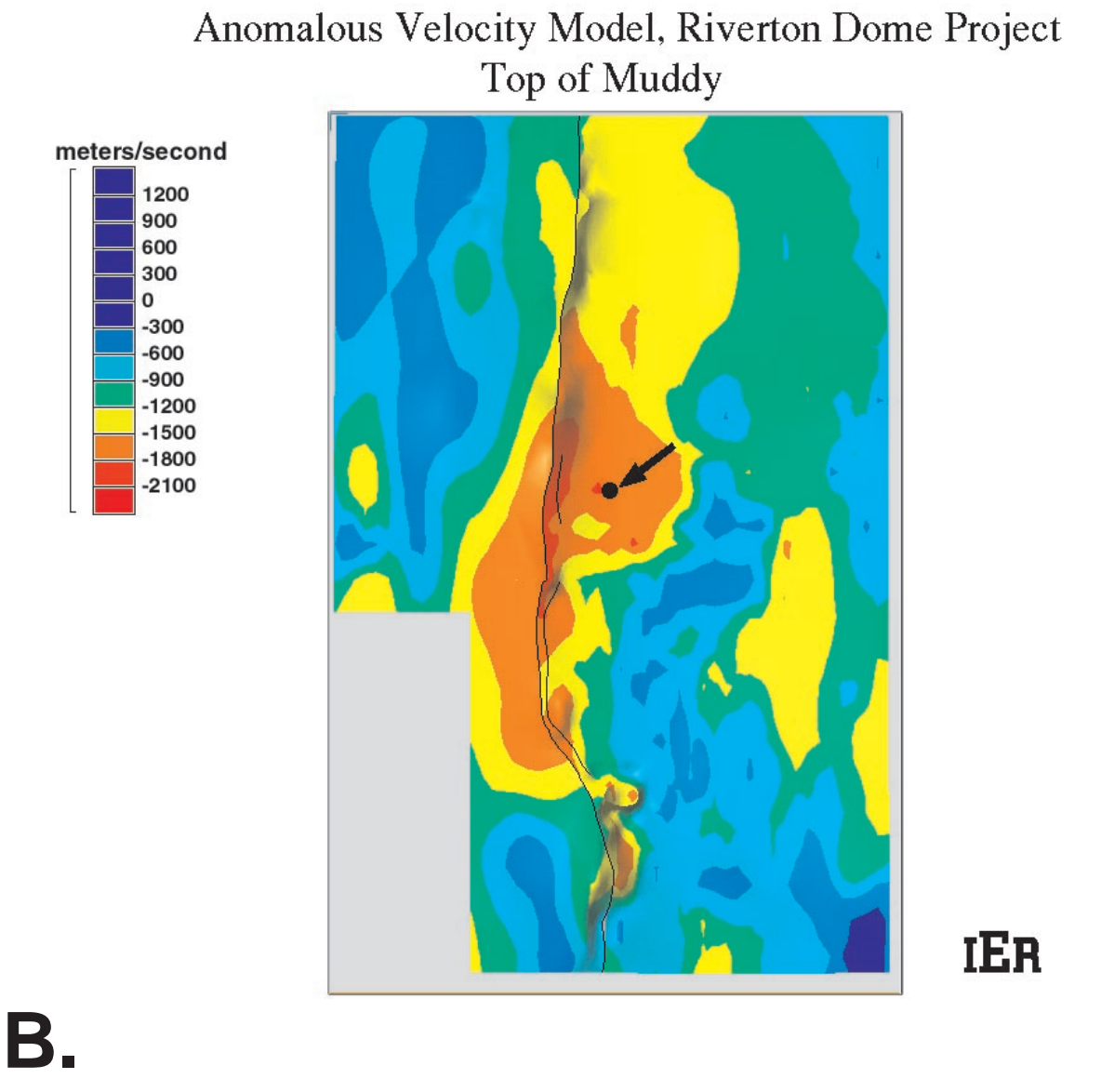

Anomalous Velocity Model, Riverton Dome Project Top of Nugget

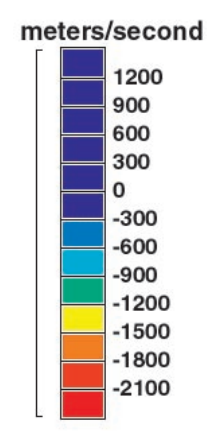

Figure 19B. Same as Figure $19 \mathrm{~A}$ only map is of the anomalous velocity distribution on the top of the Muddy Formation.
Figure 19C. Same as Figures $19 \mathrm{~A}$ and $19 \mathrm{~B}$ only map is of the anomalous velocity distribution on the top of the Nugget Formation. 
of the Riverton Dome 3-D seismic survey. Figure 20 is an interval velocity and anomalous velocity pro le for the dill site (at DP 124896). The anomalous velocity increases from $-1100 \mathrm{~ms}$ to $-1800 \mathrm{~ms}$ in the Frontier Formation, the anomalous velocity increases from $-1800 \mathrm{~ms}$ to $-1900 \mathrm{~ms}$ in the Muddy, and reaches $-1900 \mathrm{~ms}$ in the upper portion of the Nugget Sandstone. These are truly signi cant anom lausly slow vel œities in each of the target reservoir intervals, and demonstrate that all three formations can be tested in a single well.

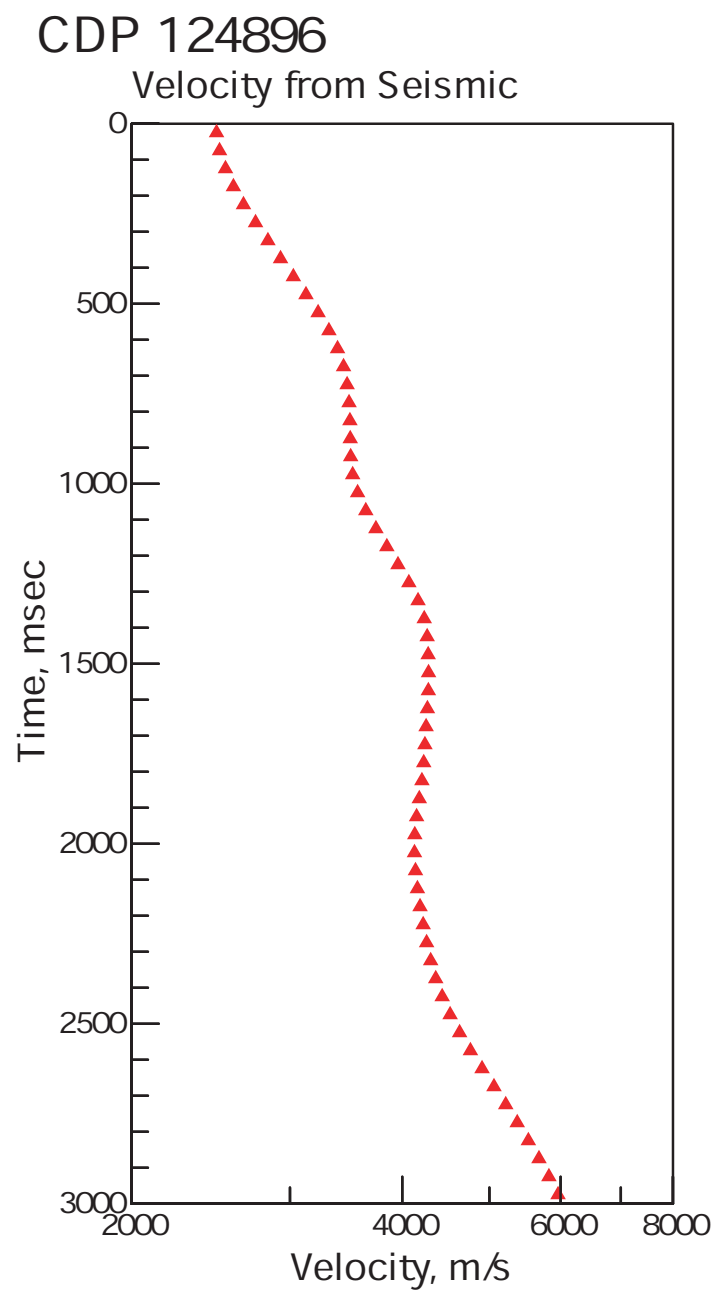

To further illustrate the velocity characteristics of the suggested drill site (i.e., CDP 124896), north-south and east-west anomalous velocity profiles that intersect at the drill site have been constructed [Figure 21A (north-south profile) and Figure 21B (east-west profile)]. Both Figures 21A and 21B illustrate that the Frontier, Muddy, and Nugget potential reservoir intervals are characterized by intensely slow velocities beneath the drill site location. It is also important to note that the regional velocity inversion surface is characterized

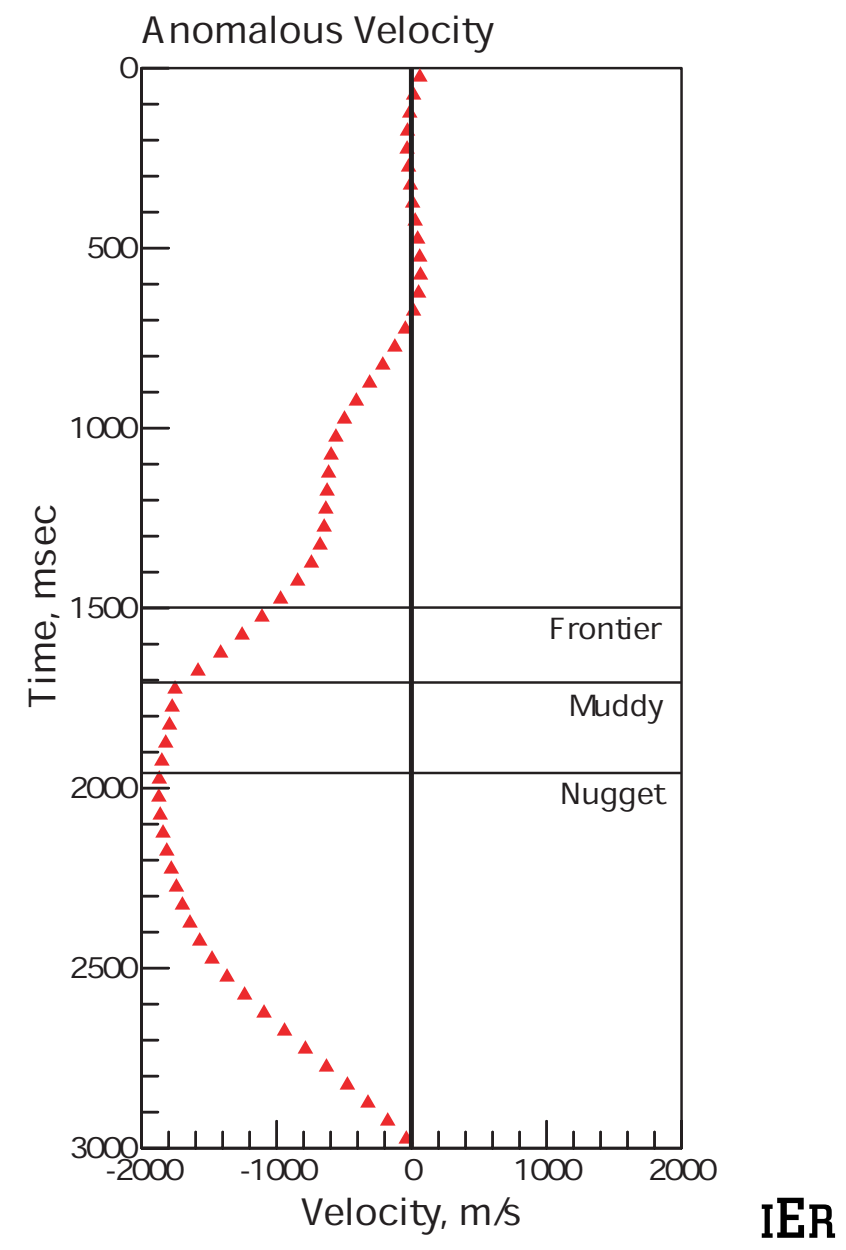

Figure 20. On the right the seismic interval velocity pro le a CDP 124896 , and on the left the anomalous velocity pro le at CDP 124896. 


\section{Anomalous Velocity Model, Riverton Dome Project}

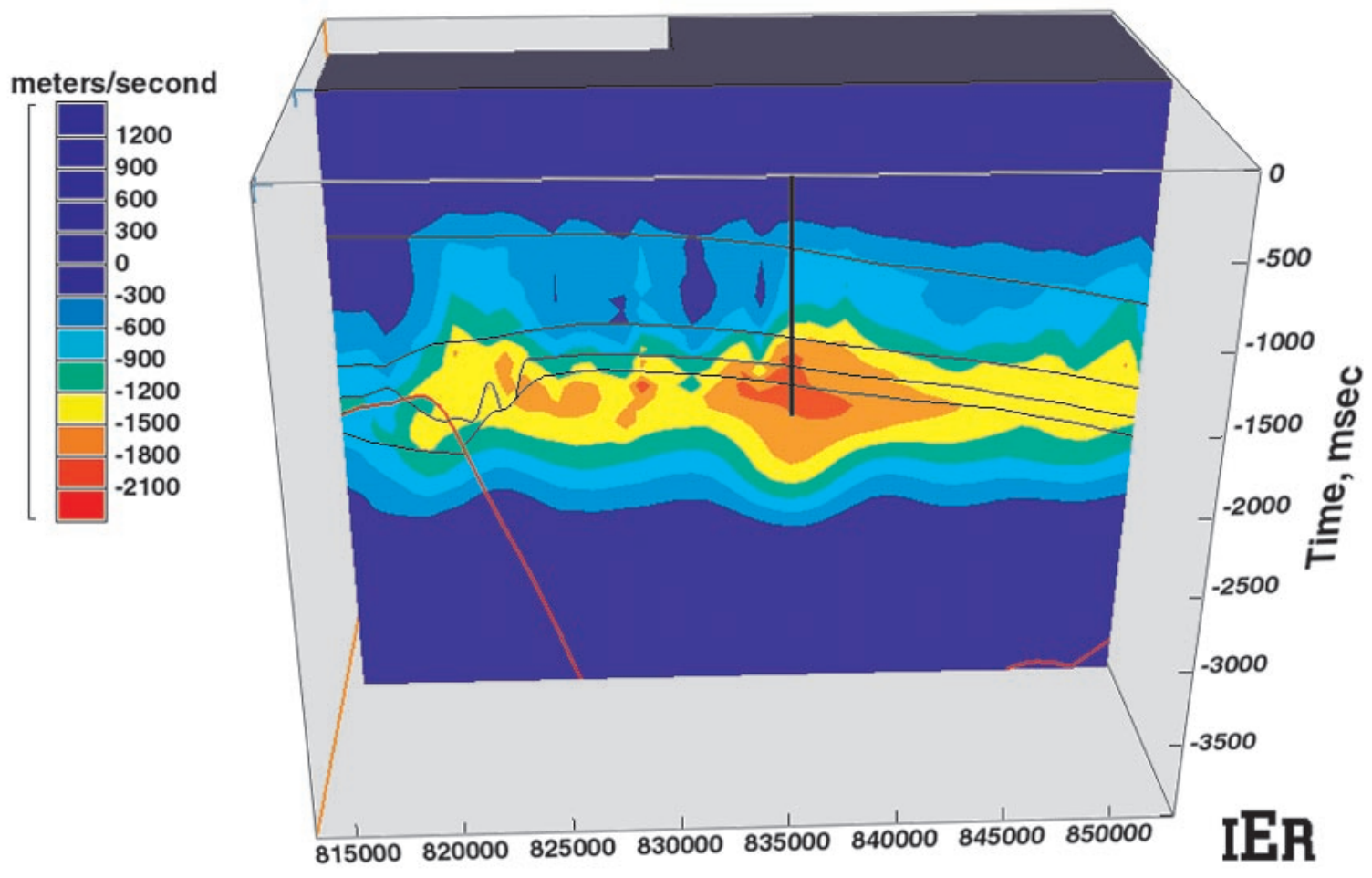

Figure 21A. North-south anomalous velocity cross section through the proposed drill site (i.e., CDP 124896). The black vertical line indicates location of proposed well on the cross section. Note that the Frontier, Muddy, and Nugget Formations all are characterized by anomalous velocities at least 1500 ms slower than the regional velocity depth gradient.

by a very significant topographic high, suggesting that at this location gas is migrating further up into the section than in most other parts of the survey area.

The velocity anomaly described above strongly suggests that the rocks within the anomaly are gas saturated. However, the velocity anomaly by itself does not guarantee that the potential reservoir intervals contain commercial porosity and permeability. Using the IER strategy, the exploration risk can be substantially reduced if other porosity and permeability indicators can be shown to overlap the velocity anomaly (see Figure 22).

In the Riverton Dome area, limited core studies in the Muddy Formation interval suggest that the best porosity and permeability characteristics are found in uwi al channels within valley-fill depositional settings (Figure 23). For example, Figures $24 \mathrm{~A}$ and $24 \mathrm{~B}$ compare the porosity characteristics of a typical fluvial channel sandstone within a sandstone from the estaurine facies in the Muddy Formation in the Riverton Dome area. A primary exploration objective is to find locations with the survey area where the fluvial channel depositional setting within the Muddy Formation intersects a velocity anomaly.

Figure 25 is an Event Similarity Prediction (ESP) map at the top of the Muddy Formation in the Riverton Dome 3-D seismic survey area. There is an ESP disconti- 


\section{Anomalous Velocity Model, Riverton Dome Project}

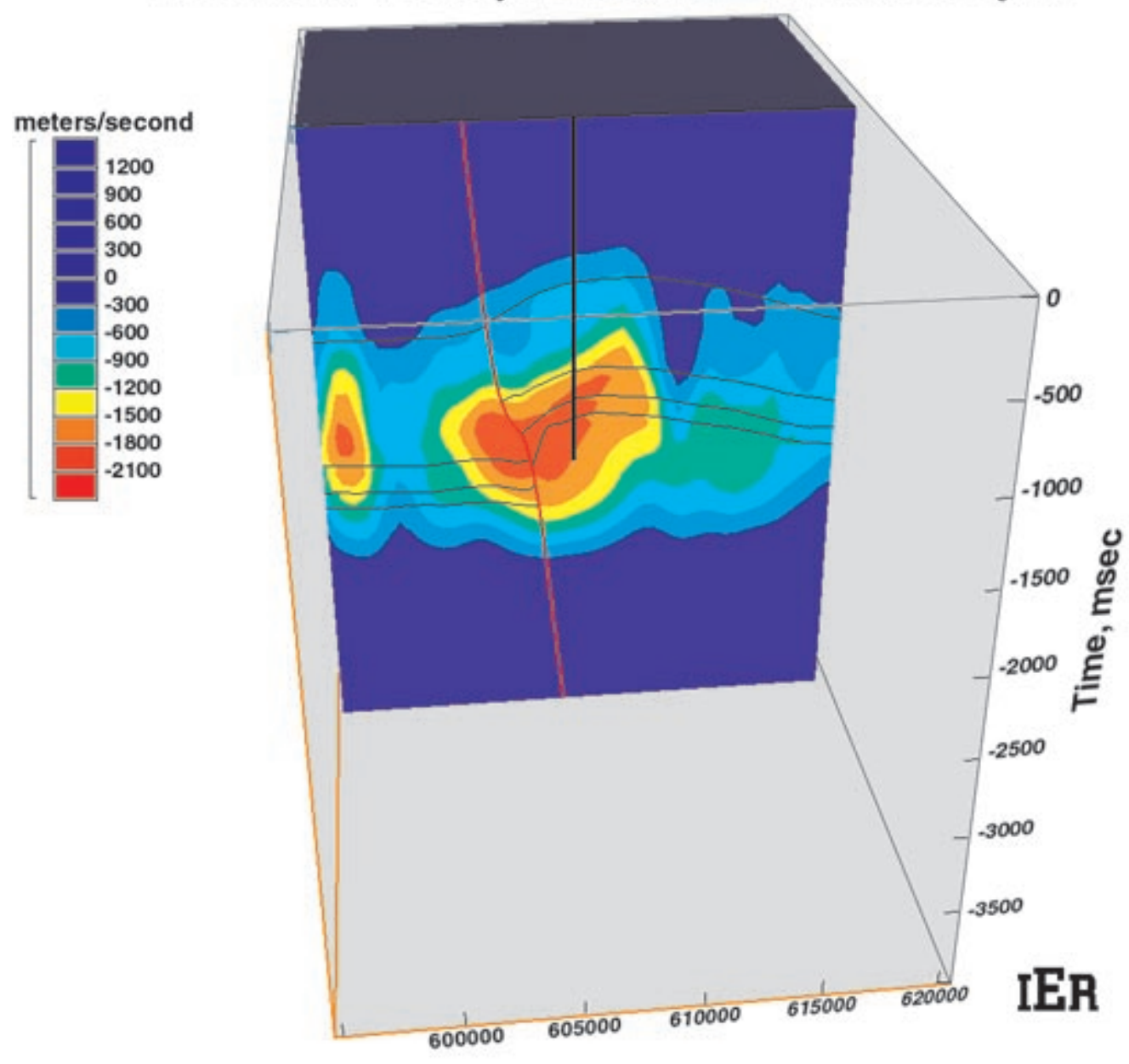

Figure 21B. East-west anomalous velocity cross section through the proposed drill site (i.e., 124896). The black vertical line indicates location of the proposed well on the cross section (same location as in Figure 21A). Again note that the Frontier, Muddy and Nugget Formations are all characterized by intense velocity anomalies. For a more exact measure of the intensities of the anomalous velocities see Figure 20.

nuity at the top of the Muddy Formation that is oriented in a north-south direction (Figure 25). This ESP discontinuity in the Muddy Formation is between the major N-S fault and the crest of the dominant N-S regional structure (Figure 25). This ESP discontinuity is interpreted as a valley11 de positional system $\dot{w}$ thi $n$ the M ddy Formation.

Figure 26 illustrates the overlap between the velocity anomaly and the ESP discontinuity. Thus, whether the ESP discontinuity represents a valley- 11 de posit, or perhaps fractures, there should be enhanced porosity / permeability and gas saturation where the discontinuity overlaps the anomalously slow velocities within the Muddy Formation. The velocity anomaly at CDP 124896, the site nominated as the ideal drilling location in the Riverton Dome 3-D seismic survey area, is located at the center of the ESP discontinuity. Certainly based on the IER exploration strategy (Figure 22), the nominated location (i.e., CDP 124896) represents the ultimate drilling site for the Muddy Formation in the Riverton Dome 3-D seismic survey area. 


\section{IER Integrated Exploration Technology}

\section{Prospect Delineation}

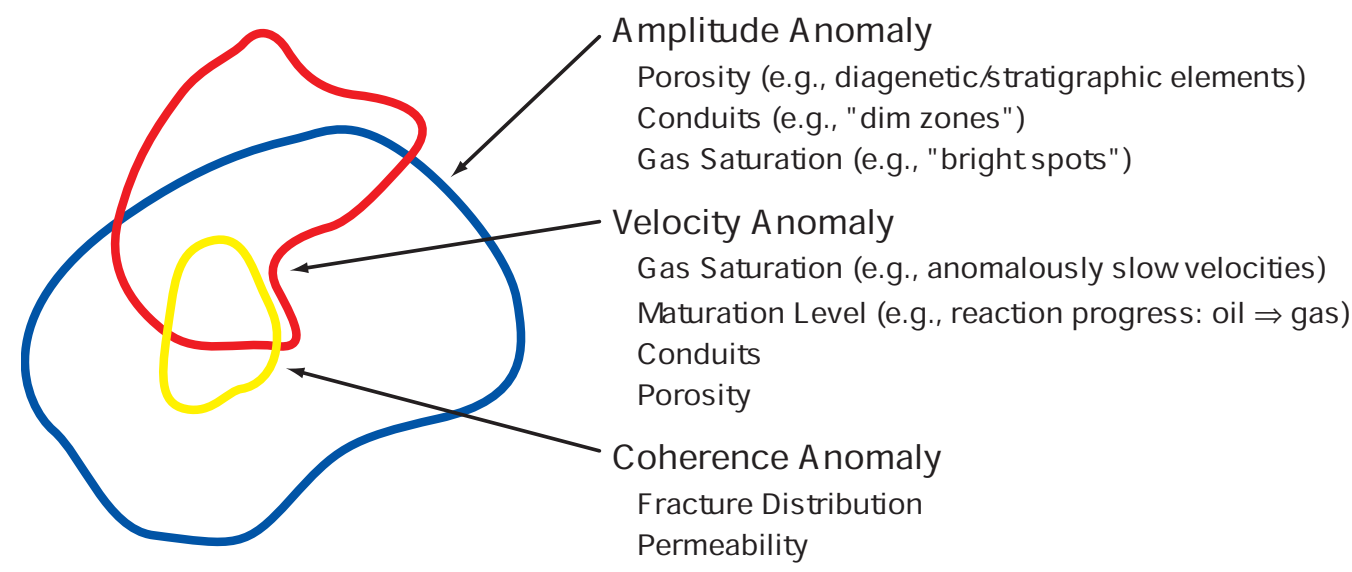

\section{Other Useful Information}

\author{
Thermal Anomalies \\ Regional Large Scale \\ Velocity A nisotropy \\ Fracture Orientation \\ Fracture Condition
}

\author{
Pressure Anomaly \\ Permeability \\ Compartment Boundaries
}

Chemical Anomalies

Compartmentalization

\author{
Regional Structural Setting \\ Compartment Boundaries \\ Fracture Potential \\ Diagenetic Modeling \\ Zones of Cementation \\ Enhanced Porosity \\ Maximum Porosity
}

Figure 22. Schematic diagram of the IER exploration technology. Diagram illustrates that for maximum effectiveness the velocity studies need to be integrated with a variety of other geological and geophysical information.

Thus, it is concluded that a well drilled at CDP 124896 in the Riverton Dome 3-D seismic survey is not only an ideal test of the IER exploration technology, but also the highest priority drill site for so-called basin center gas accumulations within the survey area.

\section{EMIGRANT RESULTS}

The same analytical techniques used to study the Riverton Dome 3-D seismic survey were utilized to study the Emigrant 3 -D seismic survey. Figure 27 is the anomalous velocity volume for the Emigrant 3-D seismic survey (the view is to the north). In the east-west cross section along the southern edge of the area, the regional pressure surface boundary, or velocity inversion surface, is clearly illustrated (i.e., the color boundary between light and dark blue in Figure 27).

Figure 28 was constructed by removing all rocks in the study volume that fall on a typical, or normal, velocity depth gradient (i.e., equivalent to normally pressured rock). As a consequence, the surface shown in Figure 28 represents the top of anomalously 


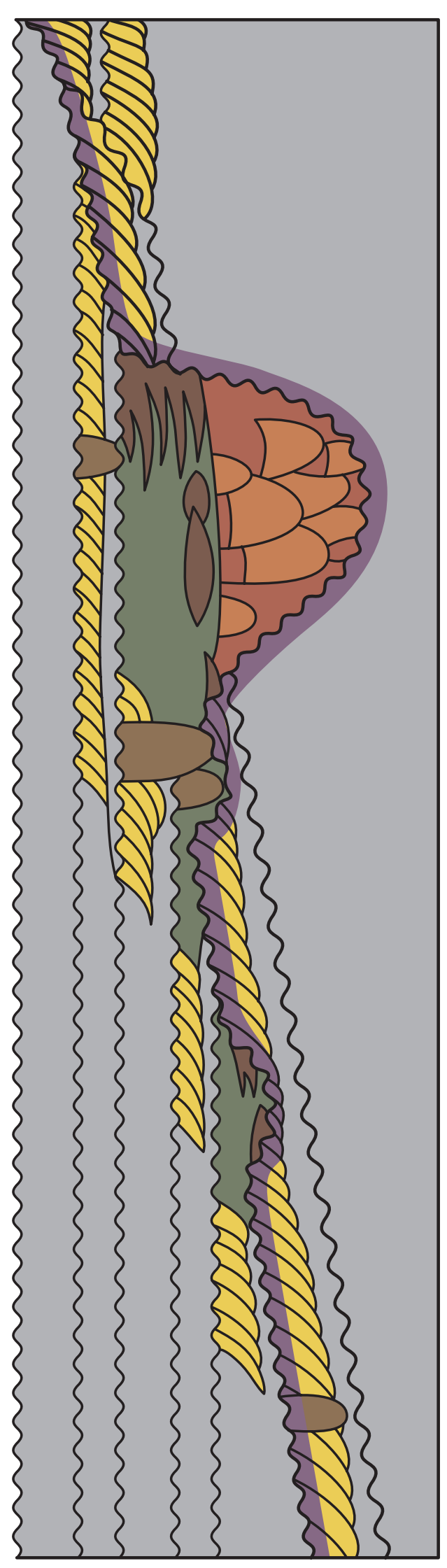

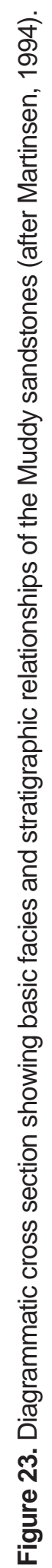




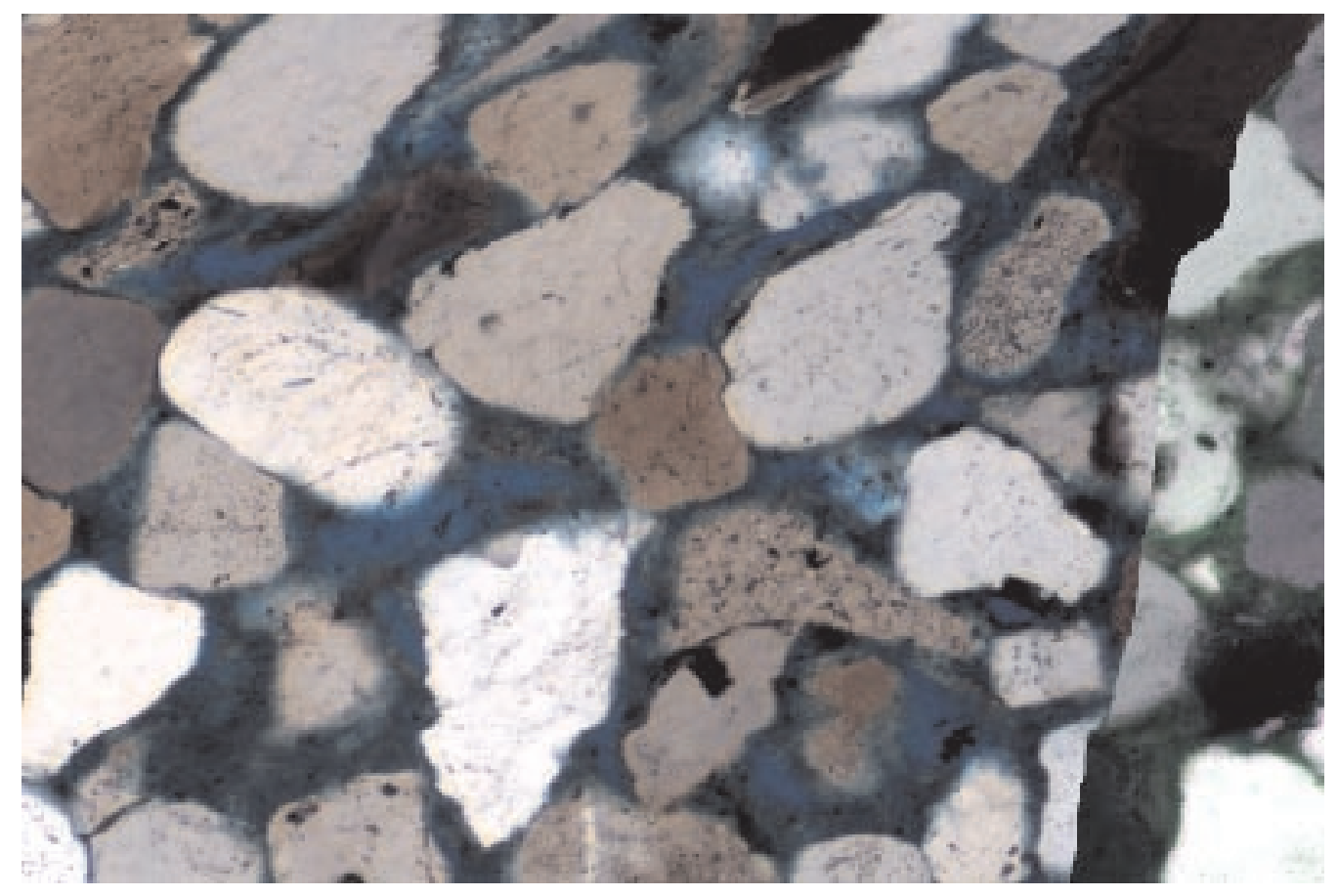

Figure 24A. Photomicrograph of the wi d channel sandst one $f \mathrm{xi} \in \mathrm{i}$ in the Mu ddy For nation $f$ ramt te Riverton Dome area.

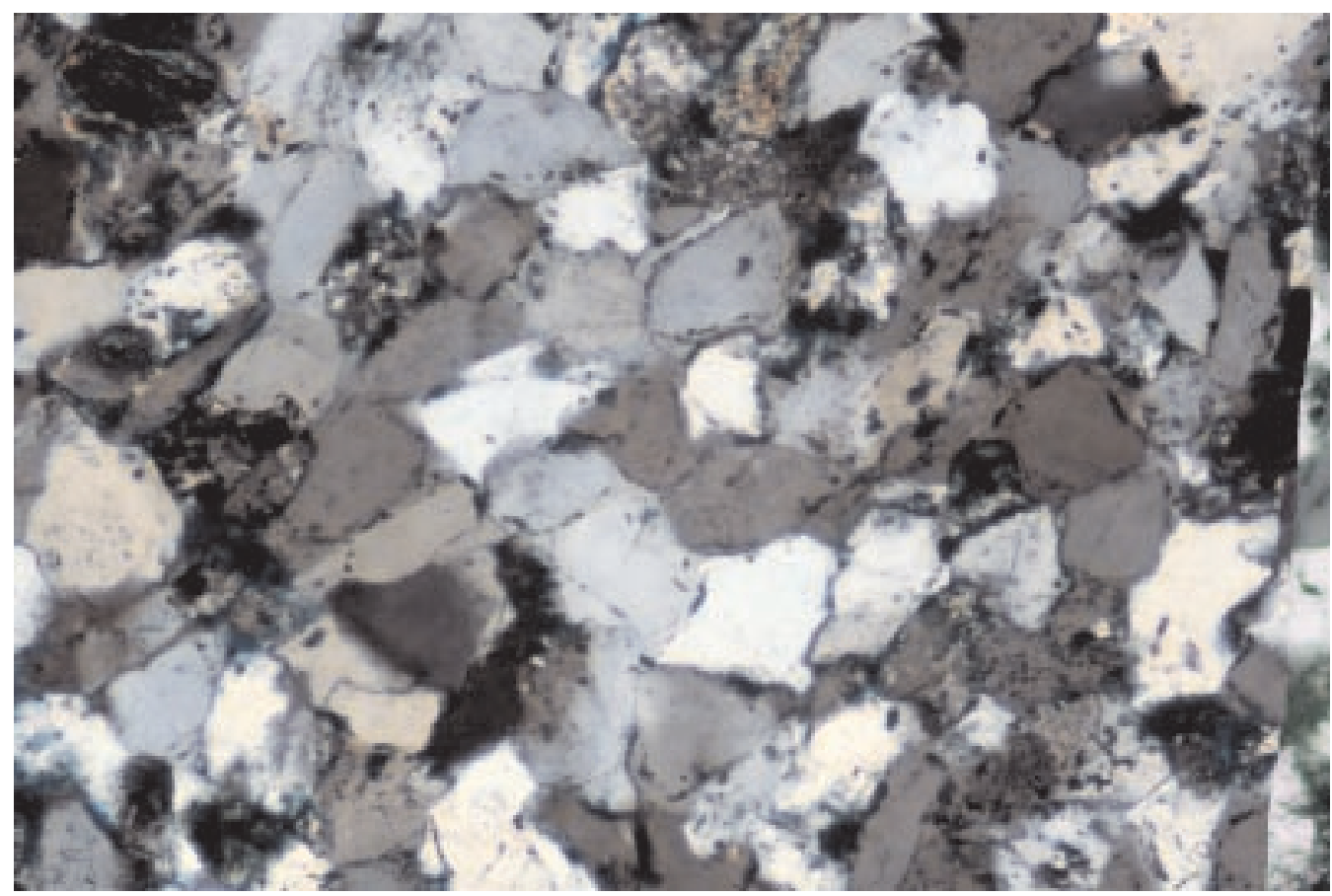

Figure 24B. Photomicrograph of a sandstone from the estaurine facies in the Muddy Formation from the Riverton Dome area. 


\section{Muddy Formation ESP}

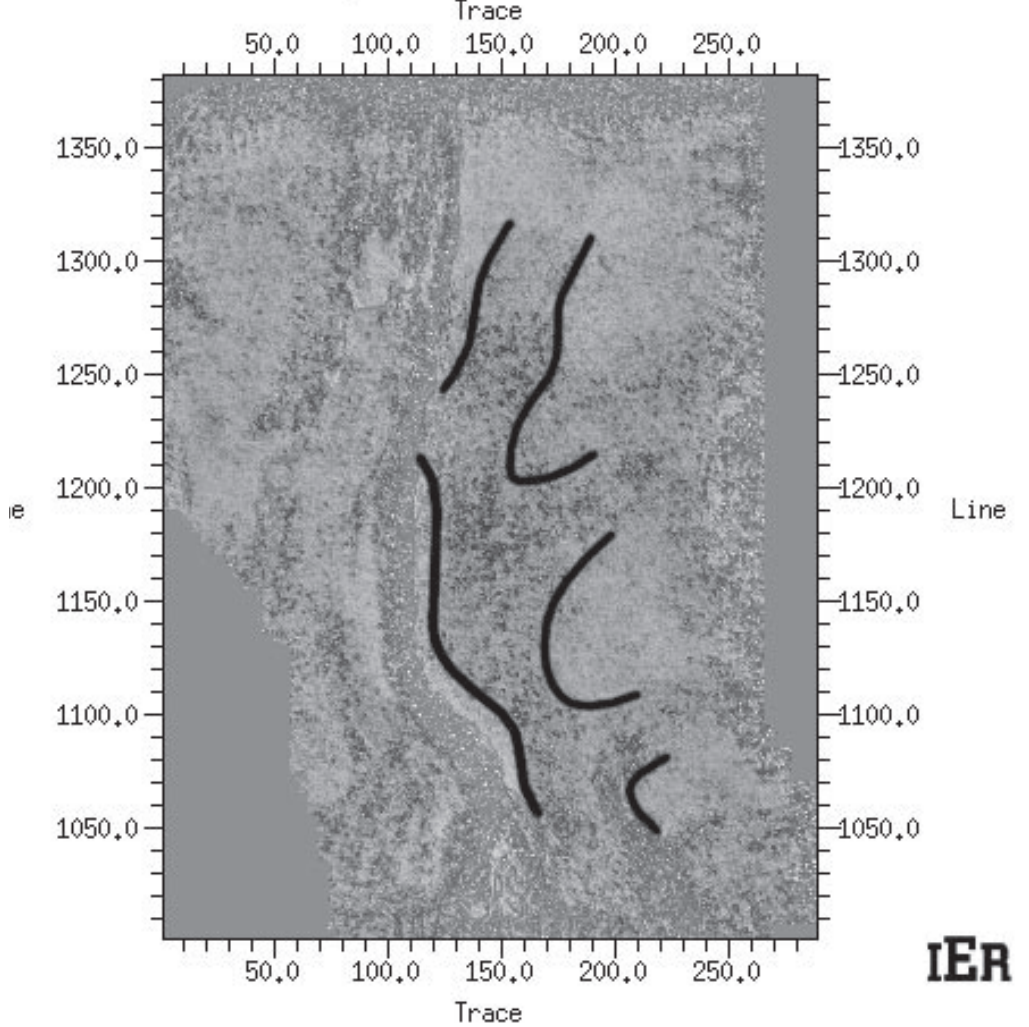

Figure 25. Event Similarity Prediction (ESP) map flattened on the top of the Muddy Formation. Black lines show the distribution of an ESP discontinuity is interpreted as a valley- II ceposit i $n$ the Maddy Formation.

\section{Anomalous Velocity/ESP, Muddy Formation}
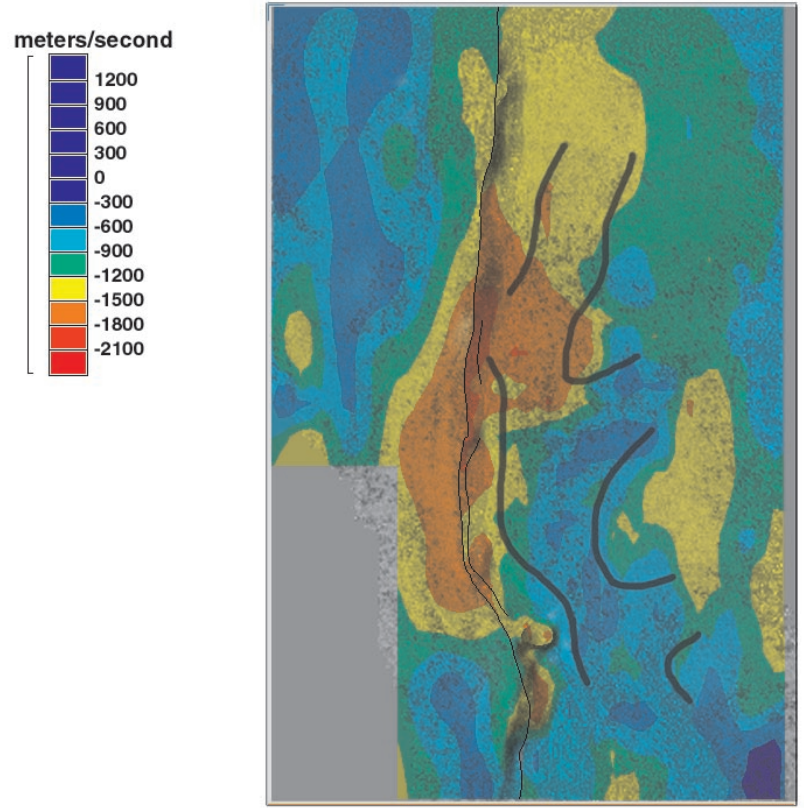

IER

Figure 26. Superposition of the anomalous velocity map and ESP discontinuity map for the top of the Muddy Formation. Note the overlap of the ESP discontinuity and intense anomalous velocity area in the central portion of the diagram. 


\section{Anomalous Velocity Model, Emigrant 3D Survey}

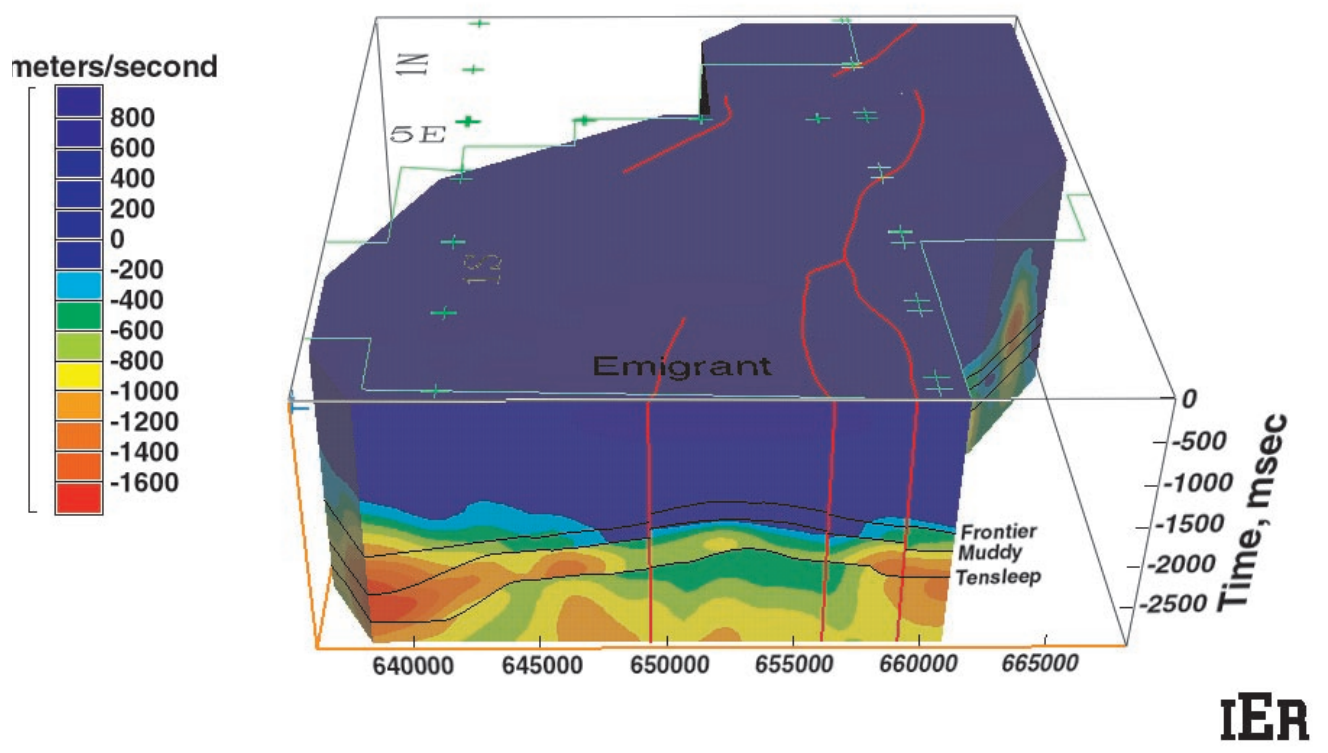

Figure 27. Anomalous seismic interval velocity volume for the Emigrant 3-D seismic survey. That portion of the volume shown in dark blue consists of rocks with a uid system f ollowing ahydrostatic gradient and a normal, or typical velocity-depth gradient. In contrast, those rocks shown in light blue, green, yellow, orange, and red have uid systems that are anomalously pressured and t hat ae characterized by anomalously slow seismic velocities (i.e., fall below the typical regional velocity-depth gradient).

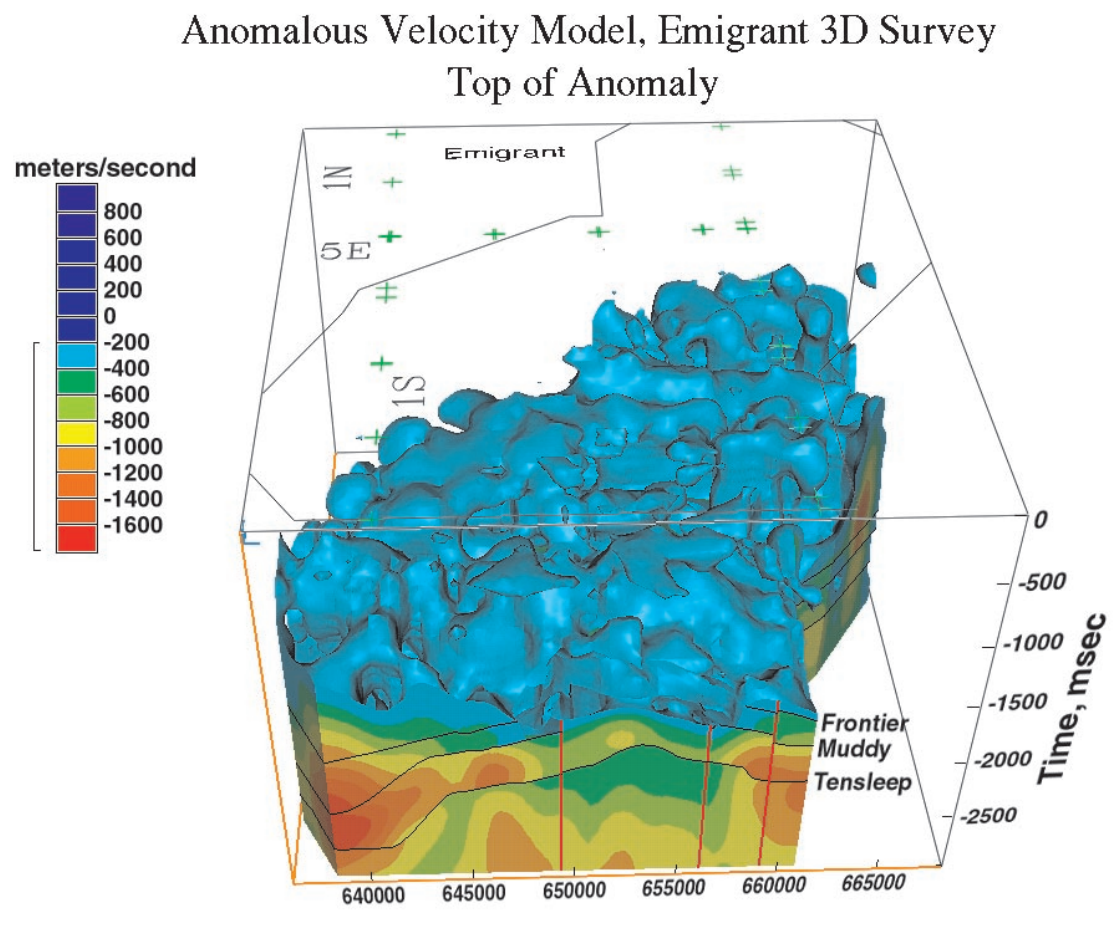

\section{IER}

Figure 28. Anomalous velocity volume where all the stratigraphic units above the top of the regional velocity surface (i.e., pressure surface boundary) have been removed. In addition, the rocks with normal velocity characteristics below the anomalous velocity volume also have been removed. 
pressured rock in the Emigrant area. The rough nature (choppy topography) of this surface is noteworthy, for it indicates that the top of the regional anomalously pressured rock (where a significant free gas phase is present) is not necessarily following stratigraphic boundaries. The signi cant topography on the upper velocity inversion surface also suggests that structural elements are playing an important role in determining the geometry of the regional pressure surface boundary. The more intense velocity anomalies (e.g., slow) in the Emigrant survey area are shown in Figure 29. Also shown in Figure 29 are those rocks characterized by velocities $1400 \mathrm{~m} / \mathrm{sec}$ or more below (slower) than the typical regional velocity depth gradient. This diagram from Emigrant can be compared to Figure 12B, which is a similar diagram for the Riverton Dome. Note that in the Emigrant area, the intense velocity anomalies (Figure 29) are discontinuous and generally smaller than the velocity anomalies characterizing the Riverton Dome area (Figure 12B).

The structure characterizing the Emigrant area is an anticline plunging to the north (Figures 30A and 30B). There is a major north-south fault cutting the eastern side of the structure (Figure 30A); this fault bifurcates into two branches in the south. The fault is seen clearly as a discontinuity in Figure 30A, which is an east-west ESP section through the structure. Figure $30 \mathrm{~B}$ is a north-south ESP section through the structure showing the plunging nature of the anticline.

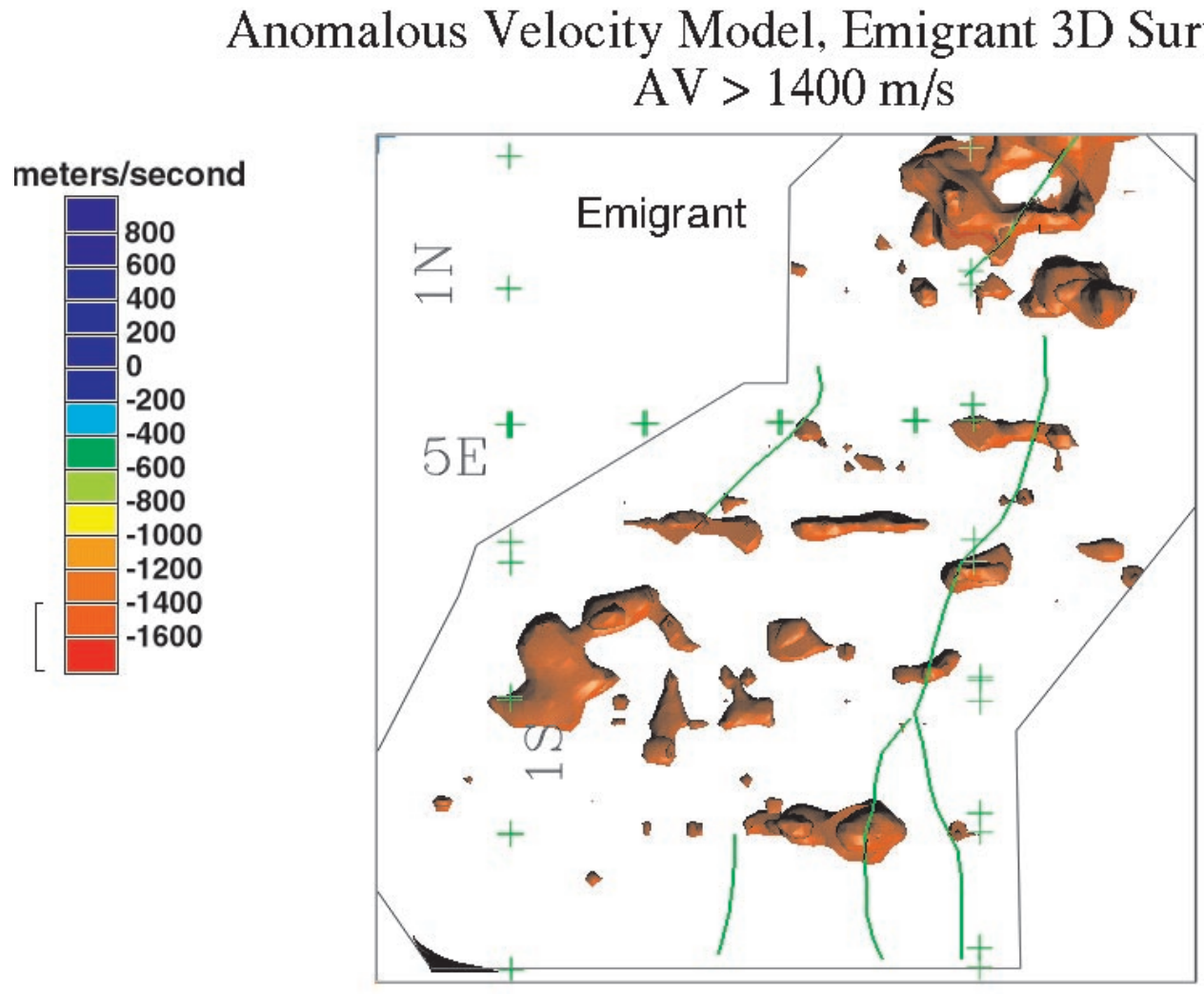

Figure 29. Isolated anomalous velocity volume showing only rocks characterized by velocities at least $1400 \mathrm{~ms}$ slower than the regional velocity-depth gradient (i.e., intense, anomalously slow velocities). 


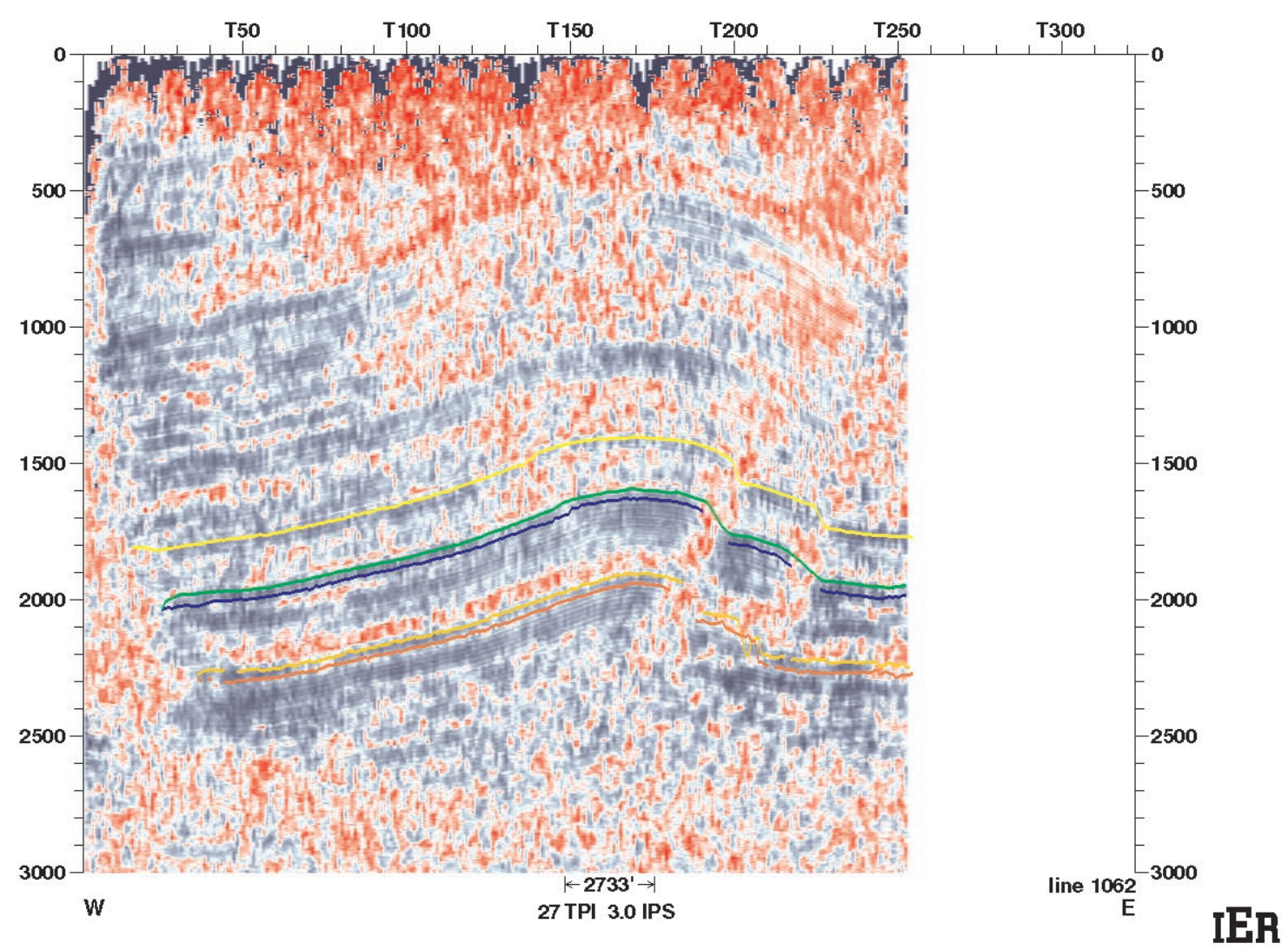

Figure 30A. East-west Event Similarity Prediction (ESP) cross sections through the Emigrant 3-D seismic survey volume. The yellow line is the top of the Frontier Formation, the green line is the top of the Muddy Formation, the blue line is the top of the Nugget Formation, the orange line is the top of the Phosphoria Formation, and the red line is the top of the Tensleep Formation. This diagram nicely illustrates the regional structure (anticline) with two signi cant faults on the eastern side of the anticline.

\section{Velocity Anomalies}

Figure 31 is an index map showing the location of six east-west sections (from south to north, inlines $1062,114,1152,1191,1230$, and 1268) and one north-south section (cross line 167). These anomalous velocity pro les are shown in Figures 32A-G. Note that the amplitude stack, ESP profile, and seismic interval velocity $\mathrm{eld}$ for ech of the se sections can be found in Appendix I of this report. The most obvious aspect of the spatial distribution of the velocity anomalies are as follows:

1. The anomalies are laterally discontinuous;

2 . The anomalies are not necessarily associated with the crest of the northward plunging anticline; and
3. The anomalies tend to be associated with anomalous velocity chimneys (see especially Figure 32G; north-south section through the velocity $\mathrm{eld}$ vi ene $\mathrm{d}$ from west to east).

These three aspects of the velocity $\mathrm{dd}$ are interpreted as resulting from the gas migration pattern in the Emigrant area. The migration pattern suggests that in the Emigrant study area, the primary gas migration routes are vertical. Therefore, it is suggested that the gas is moving upward along conduits resulting from enhanced permeability. Moreover, it is further suggested that the enhanced permeability is the result of fracturing. It is dif all $t$ toi m gi re any 


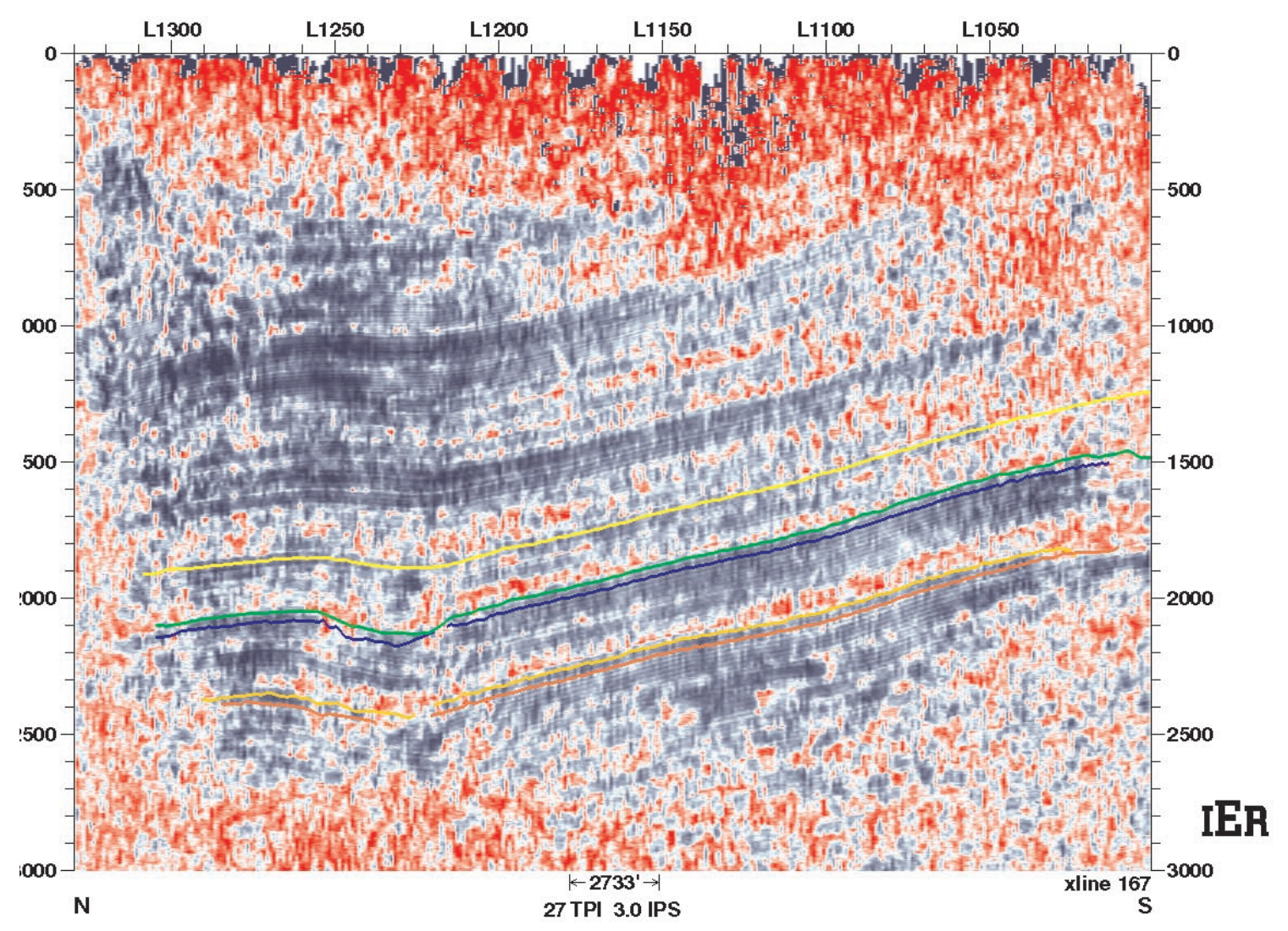

Figure 30B. North-south Events Similarity Prediction (ESP) cross section through the Emigrant 3-D Seismic survey volume. Diagram illustrates the northward plunging nature of the regional structure.

other mechanism that would provide vertical enhanced permeability chimneys connecting rocks from below the Tensleep Formation to above the Frontier Formation (see Figures 32A-G).

The laterally discontinuous, but vertically continuous nature of the velocity anomalies becomes more obvious when horizontal slices through the anomalous velocity volumes are viewed (Figures 33, 34, and 35). Figures 33,34 , and 35 are nearly horizontal slices that have been at tened on the Frontier, Muddy, and Tensleep formations, respectively. For each of these three gur es, there is an inclined vi ew ( $A$ and a map view (B). For the largest and most intense anomalies, there is signi cant overlap, especially apparent on the map views (compare Figures 33B, 34B, and 35B). It is also apparent from Figures 33, 34, and
35 that the velocity anomalies are most numerous and intense at the level of the Muddy Formation, and become fewer and less intense both up and down section from the Muddy Formation.

\section{Exploration Targets}

In developing potential exploration targets, the Muddy Formation will be the primary objective because it contains the most numerous and intense velocity anomalies. However, the Frontier Formation also will be given signi cant consideration.

Figure 34B illustrates the velocity anomalies at the top of the Muddy Formation. The anomalies within the Muddy Formation that will be considered in more detail from north to south are at the following CDPs: 98437 and 95227; 85596 and 85606; 69406; 66277; 


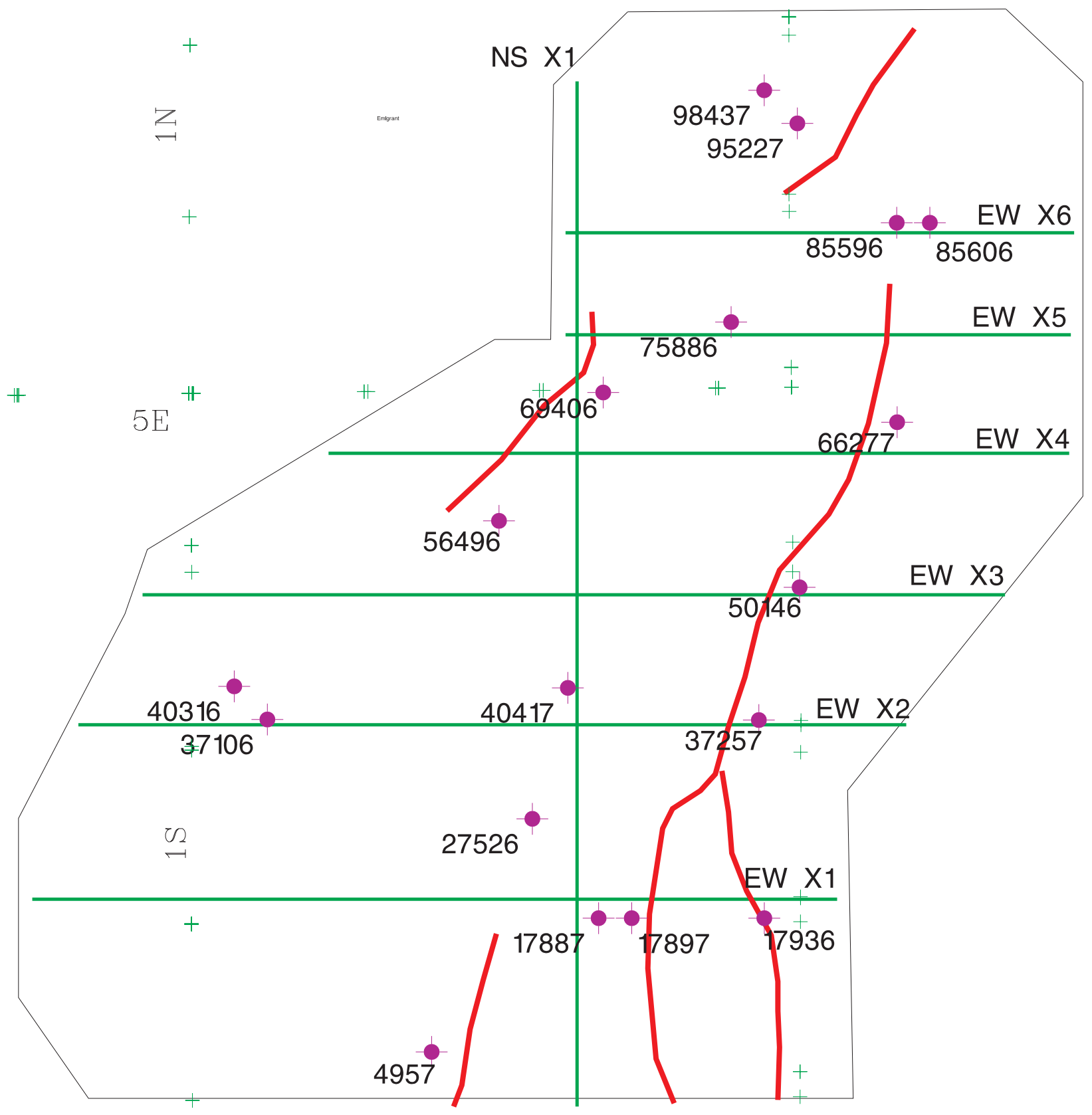

Figure 31. Index map showing the locations of subsequent anomalous velocity cross sections (e.g., Figures $32 \mathrm{~A}-32 \mathrm{G})$. The map also shows the location of CDPs where individual anomalous velocity-depth pro les have been constructed (see Appendix II). 
Anomalous Velocity Model, Emigrant 3D Survey

EW Cross Section 1 (1062)

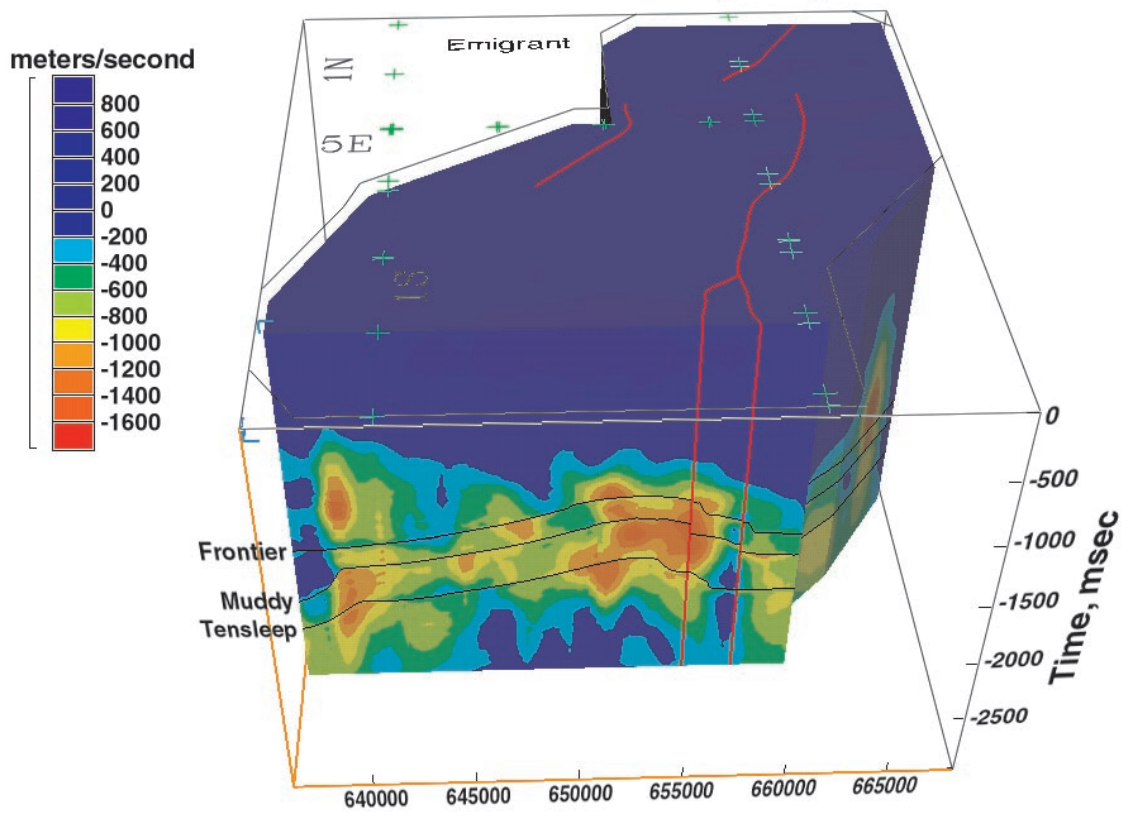

IER

Figure 32A. East-west cross sections through the anomalous velocity volume illustrated in Figure 27; the cross sections are viewed from the south to north. The diagram demonstrates the laterally discontinuous nature of the anomalously slow velocities. Also note the topographic relief characterizing the regional velocity inversion surface.

Anomalous Velocity Mlodel, Emigrant $3 \mathrm{U}$ Survey

EW Cross Section 2 (1114)

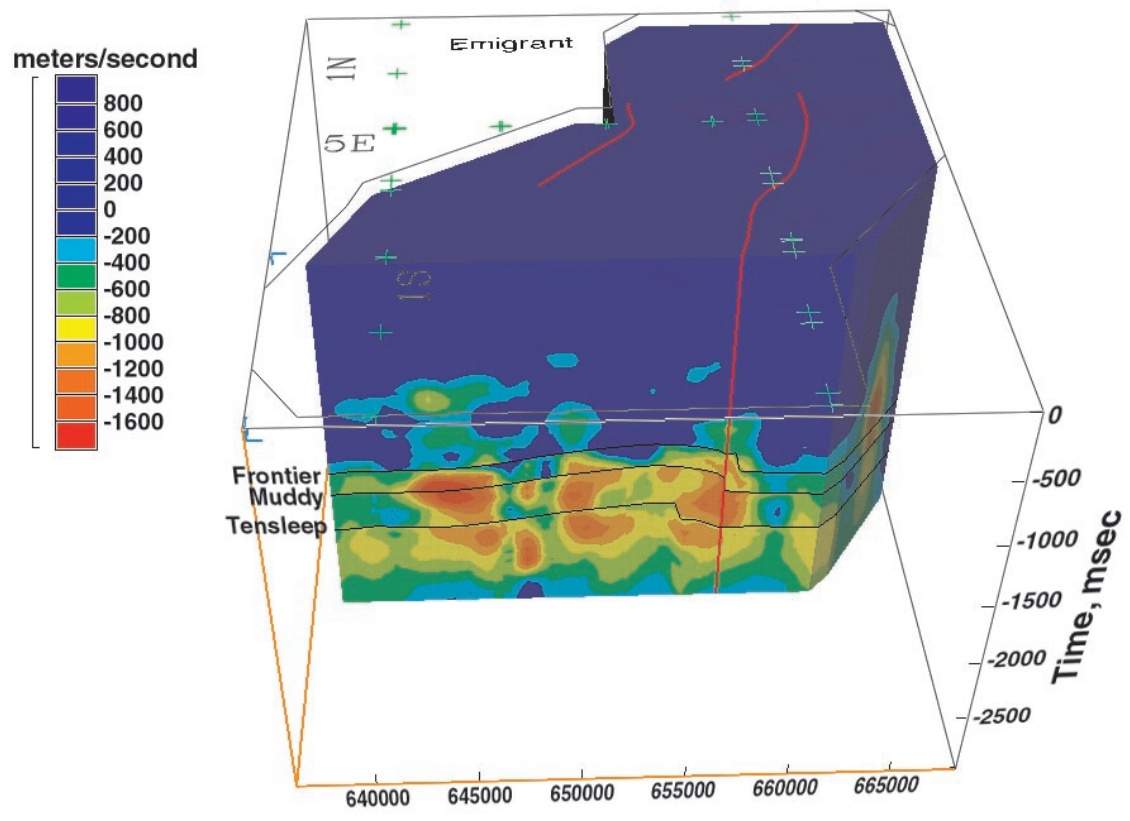

Figure 32B-F. Same as Figure 32A, only each successive is cut farther to the north. 
Anomalous Velocity Model, Emigrant 3D Survey

EW Cross Section 3 (1152)

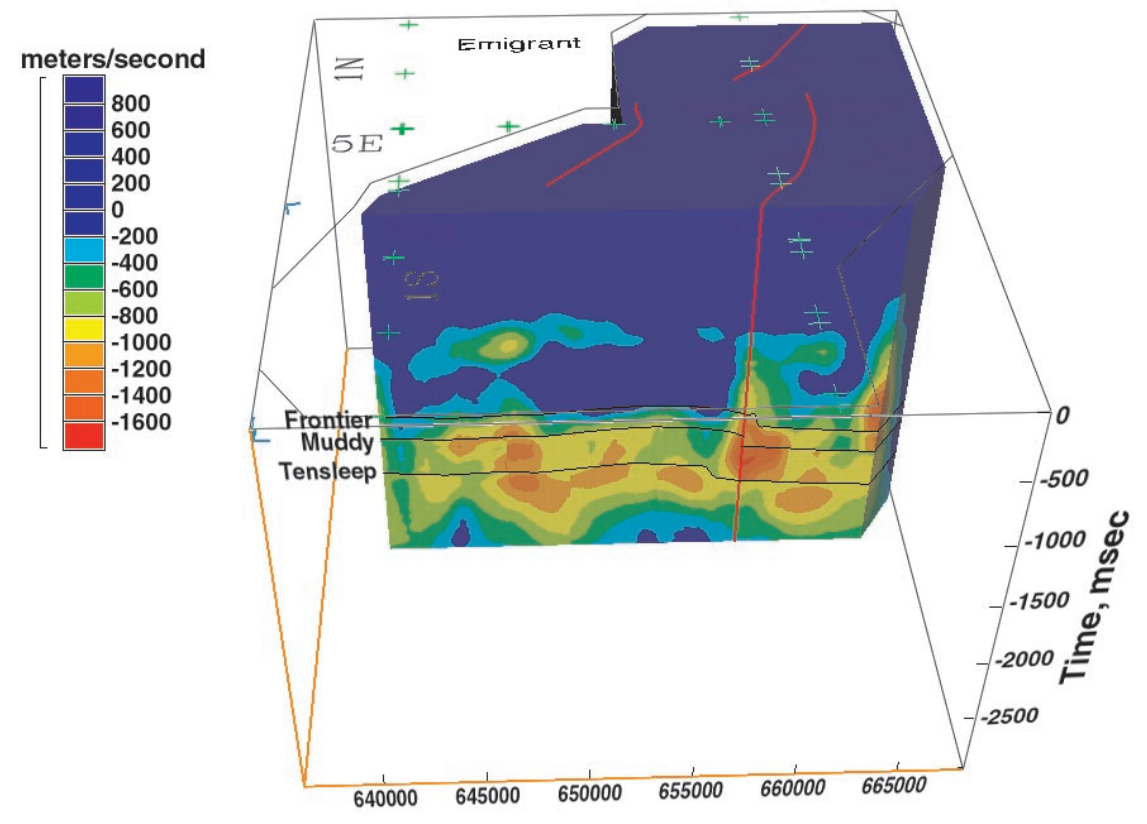

IER

Figure 32C.

Anomalous Velocity Model, Emigrant $3 \mathrm{U}$ Survey

EW Cross Section 4 (1191)

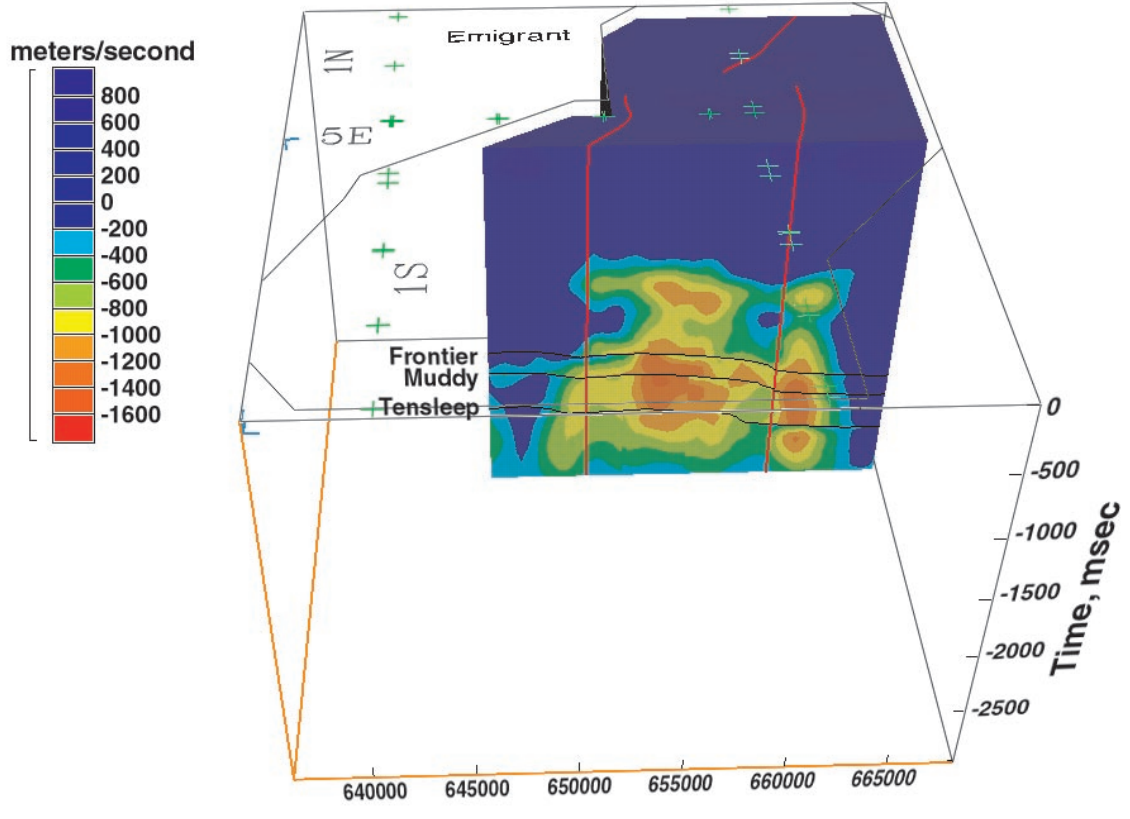

IER

Figure 32D. 
Anomalous Velocity Model, Emigrant 3D Survey

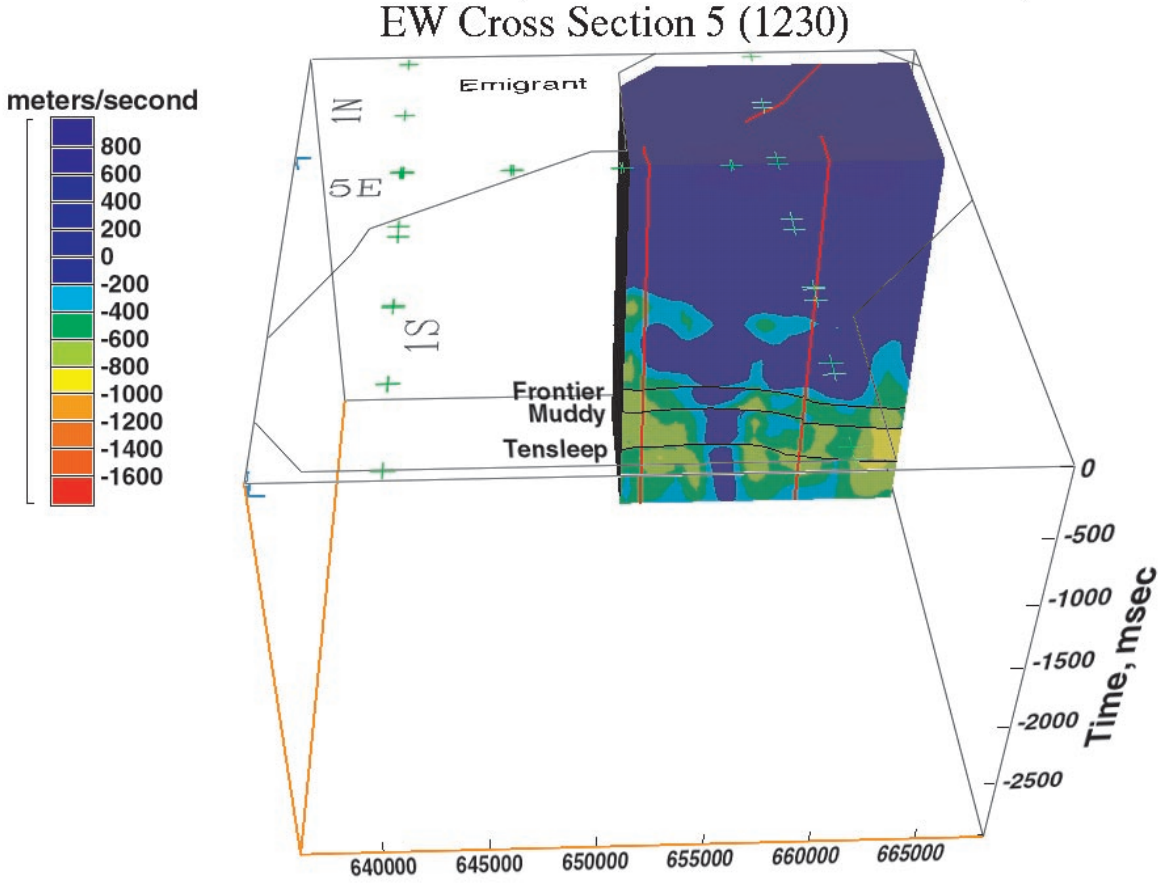

IER

Figure 32E.

Anomalous Velocity Model, Emigrant 3D Survey

EW Cross Section 6 (1268)

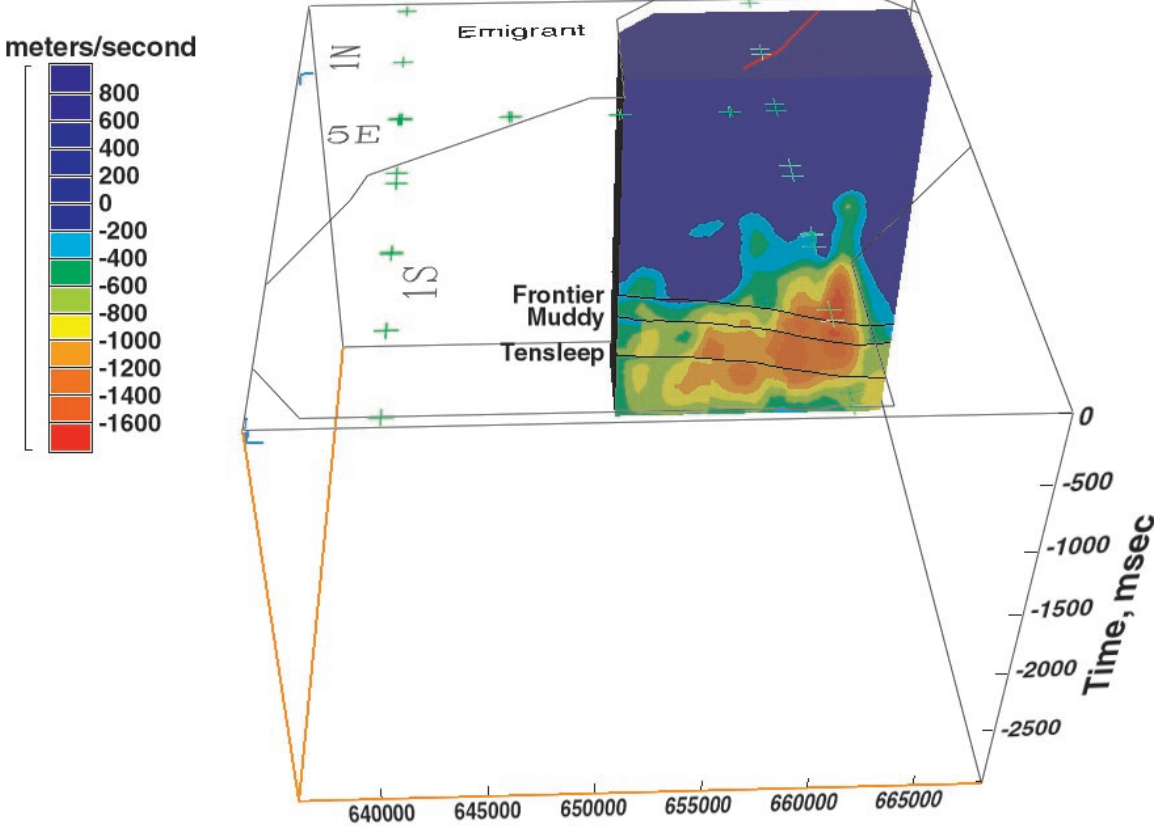

Figure 32F. 


\section{Anomalous Velocity Model, Emigrant 3D Survey \\ NS Cross Section (X165), View to East}

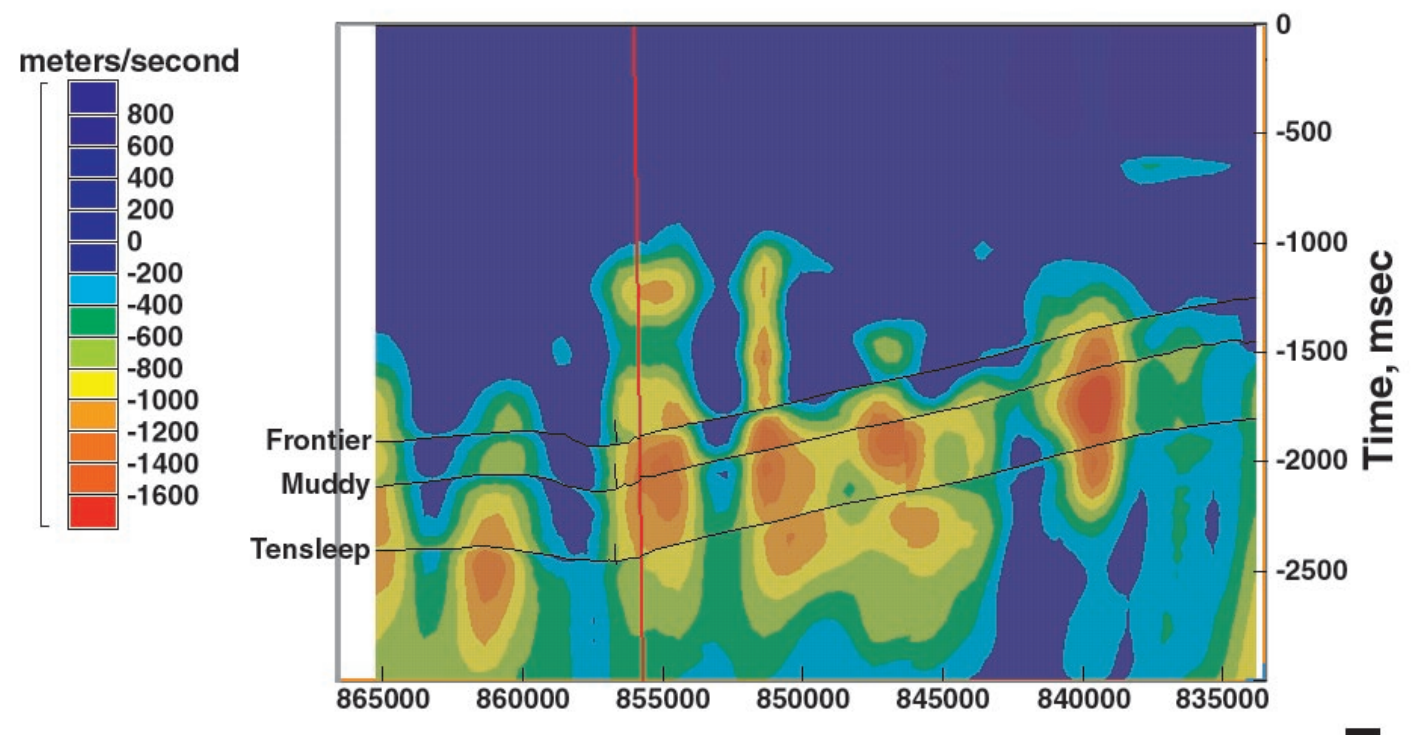

IER

Figure 32G. North-south anomalous velocity section through the anomalous velocity volume shown in Figure 27.

\section{Anomalous Velocity Model, Emigrant 3D Survey} Top of Frontier
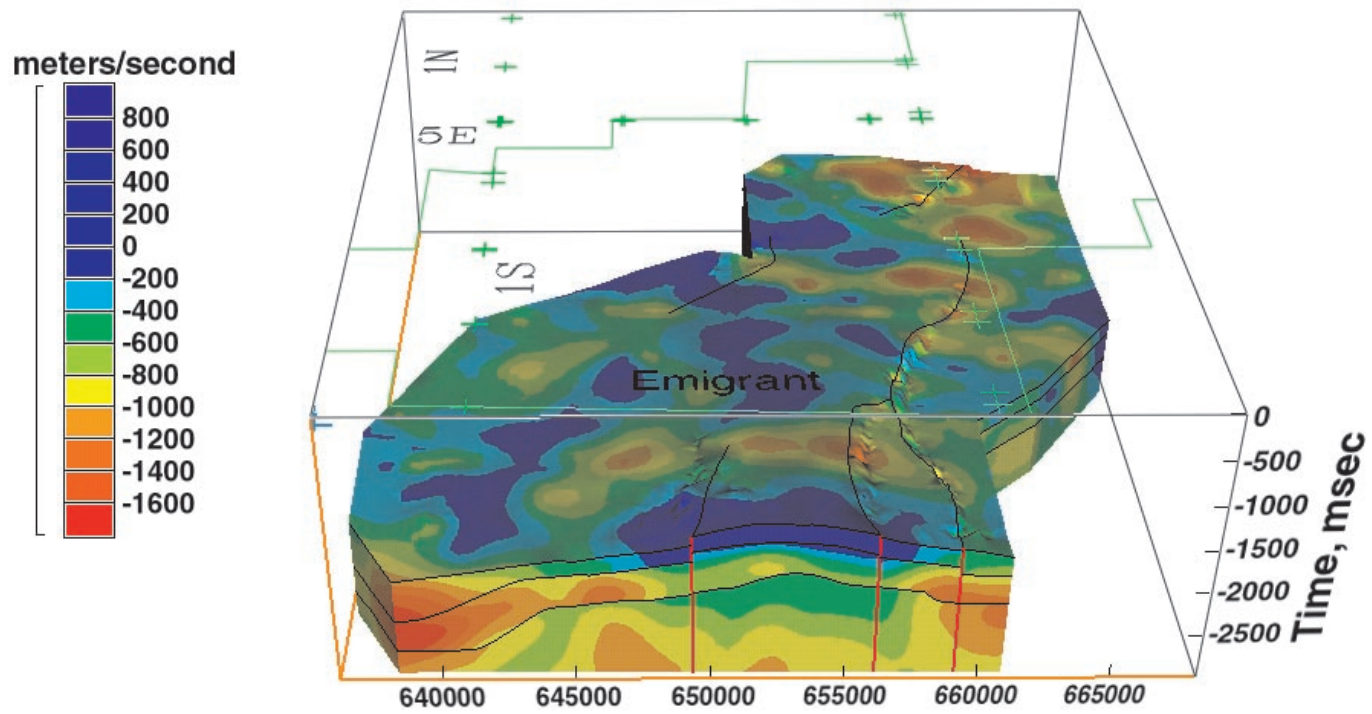

IER

Figure 33A. Inclined view of the anomalous velocity surface a tened on the tq of the ff ont ie For ratim. 


\section{Anomalous Velocity Model, Emigrant 3D Survey Top of Frontier}
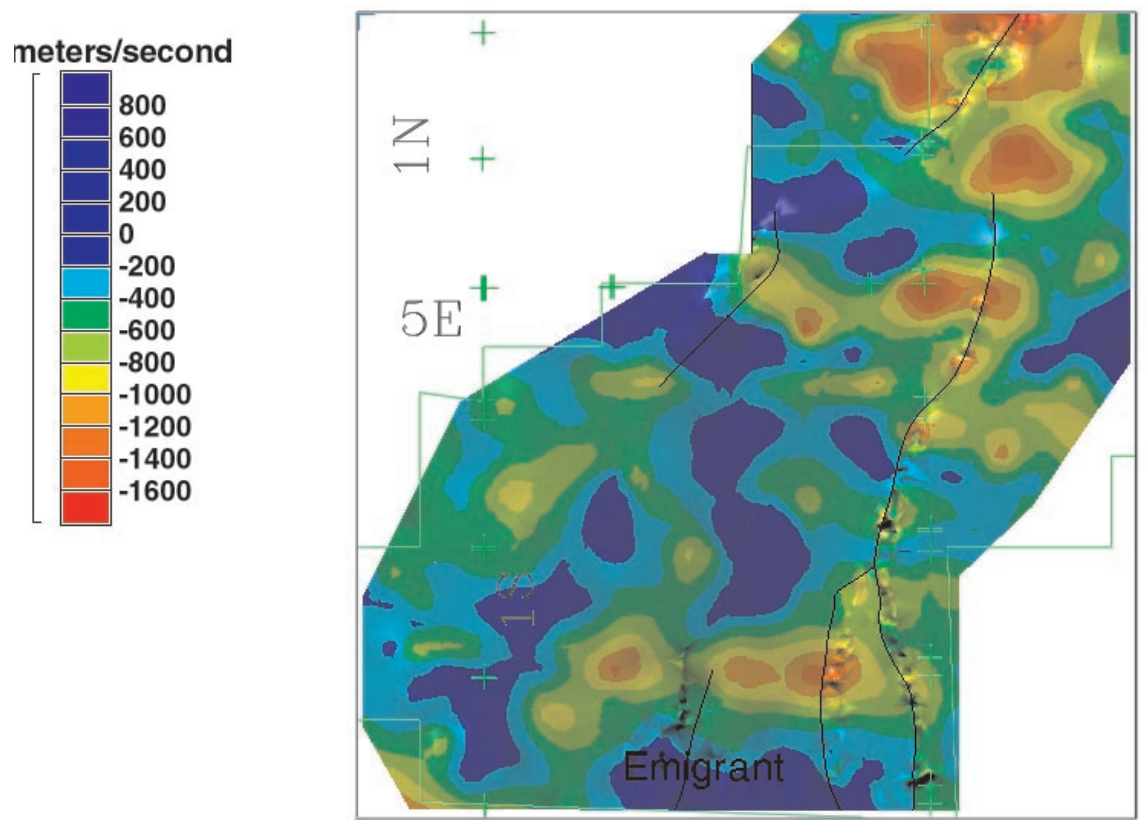

IER

Figure 33B. Map view of the anomalous velocity surface shown in Figure 33A.

\section{Anomalous Velocity Model, Emigrant 3D Survey Top of Muddy}
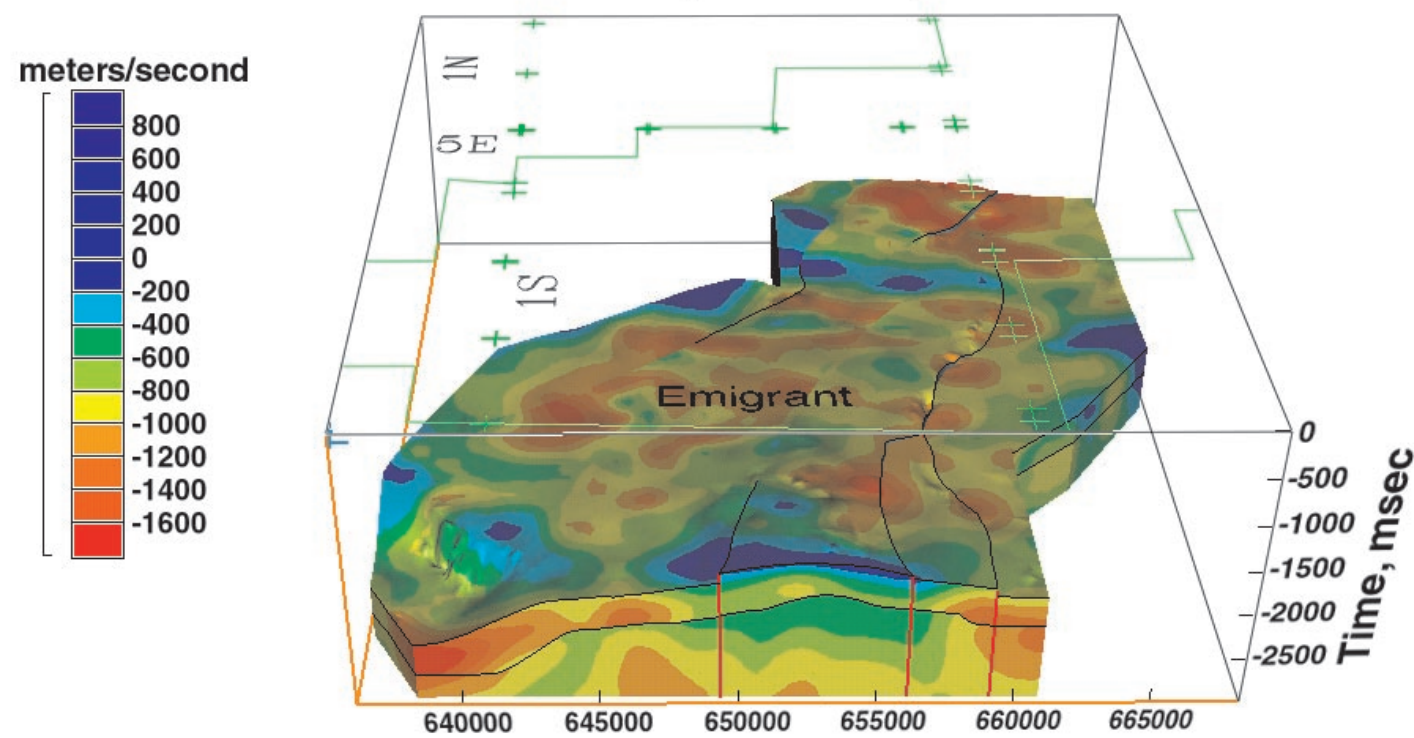

IER

Figure 34A. Inclined view of the anomalous velocity surface a tened on the to of the M ddy For ra tiø. 


\section{Anomalous Velocity Model, Emigrant 3D Survey Top of Muddy}

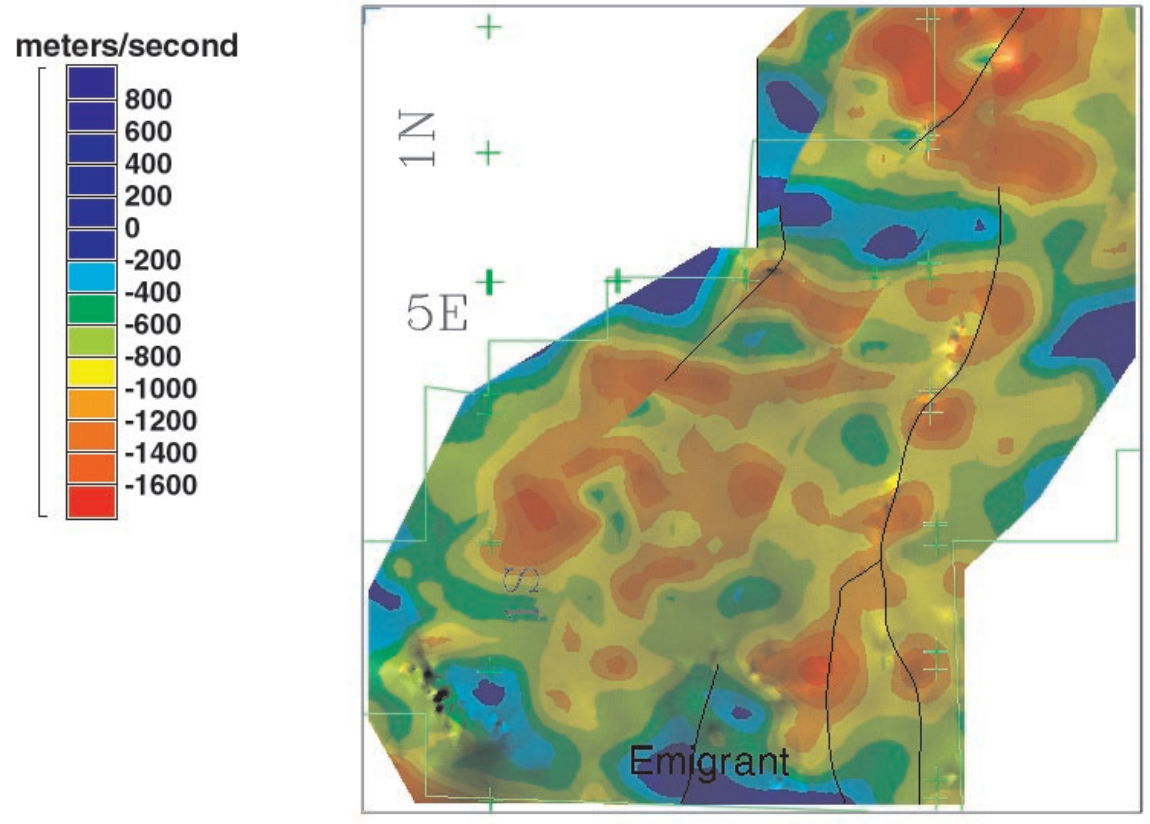

Figure 34B. Map view of the anomalous velocity surface shown in Figure 34A.

\section{Anomalous Velocity Model, Emigrant 3D Survey} Top of Tensleep

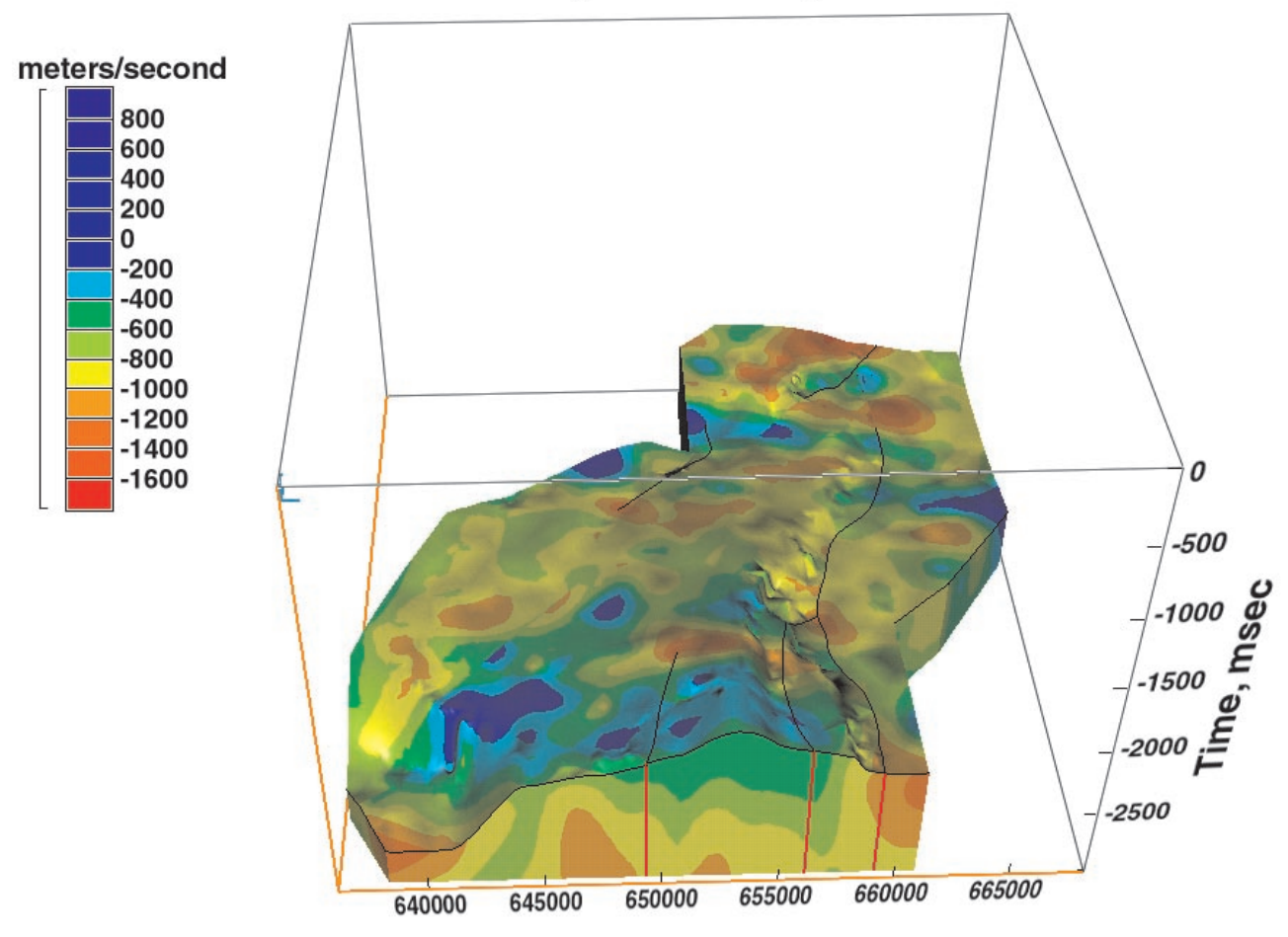

Figure 35A. Inclined view of the anomalous velocity surface a tened on the top of the Tensl œp For ra tiø. 
Anomalous Velocity Model, Emigrant 3D Survey

Top of Tensleep
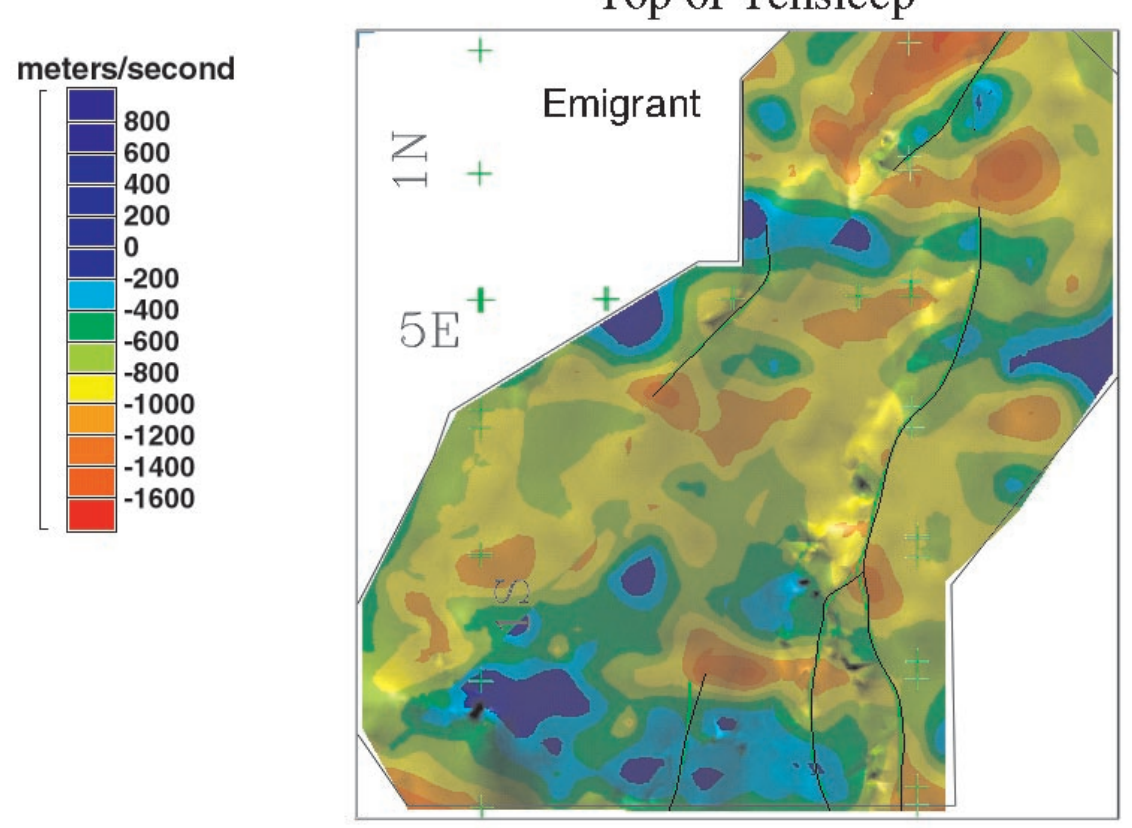

IER

Figure 35B. Map view of the anomalous velocity surface shown in Figure 34A.

50146; 56496; 40417; 40316 and 37106; 37257; 17936; and 17887 and 17897 (see Figures 31 and 36 for locations). For each of the above velocity anomalies a velocity pro le has been constructed at speci c DP s (see Appendix II). Also included in Appendix II are two contour maps (in time-msec) for the top of the Muddy and Frontier formations. Using the anomalous velocity profiles and time value (i.e., depth) for each CDP, it is possible to evaluate the velocity characteristics at each of the anomalies shown in Figure 36. Based on anomalous velocity values at stratigraphic levels approximating the Muddy Formation, it is possible to sort the anomalies into two groups. The first group has anomalous velocity values $1800 \mathrm{msec}$ or greater at the approximate level of the Muddy Formation (i.e., range of 1800 to $2200 \mathrm{msec}$ ), whereas the second group has anomalous velocity values of $1600 \mathrm{msec}$ or less (i.e., range of 1200 to $1600 \mathrm{msec}$ ). Based on this anomalous velocity grouping, the anomalies at CDPs 098437, 095227,
085586, 085606, 050146, 037106, 17887, and 17897 are considered to be more attractive exploration targets than the CDPs in the second group.

For each of the ve anom 1 ies onsidered to be superior exploration targets, northsouth and east-west anomalous velocity sections or pro les have been constructed that intersect the anomalies. The east-west pro le ( $\$ X 1$; Fi gure 37$)$ and the north south anomalous velocity pro le ( $\mathrm{EN}$ X6; Figure 38) cut through the velocity anomaly at CDPs 85596 and 85606 (see Figure 36 for locations). Figures 37 and 38 demonstrate that the anomaly at CDPs 85596 and 85606 is signi cant and that it is dharacterized by a de ri te di $m$ ey shape.

The north-south anomalous velocity section (NS X2; Figure 39) cuts through two of the best anomalies, the northern anomaly at CDPs 98437 and 95227, and the more southerly anomaly at 50146 . The east-west anomalous velocity section (EW X7; Figure 40) cuts through the northern anomaly, where- 


\section{Anomalous Velocity Model, Emigrant 3D Survey \\ Top of Muddy}
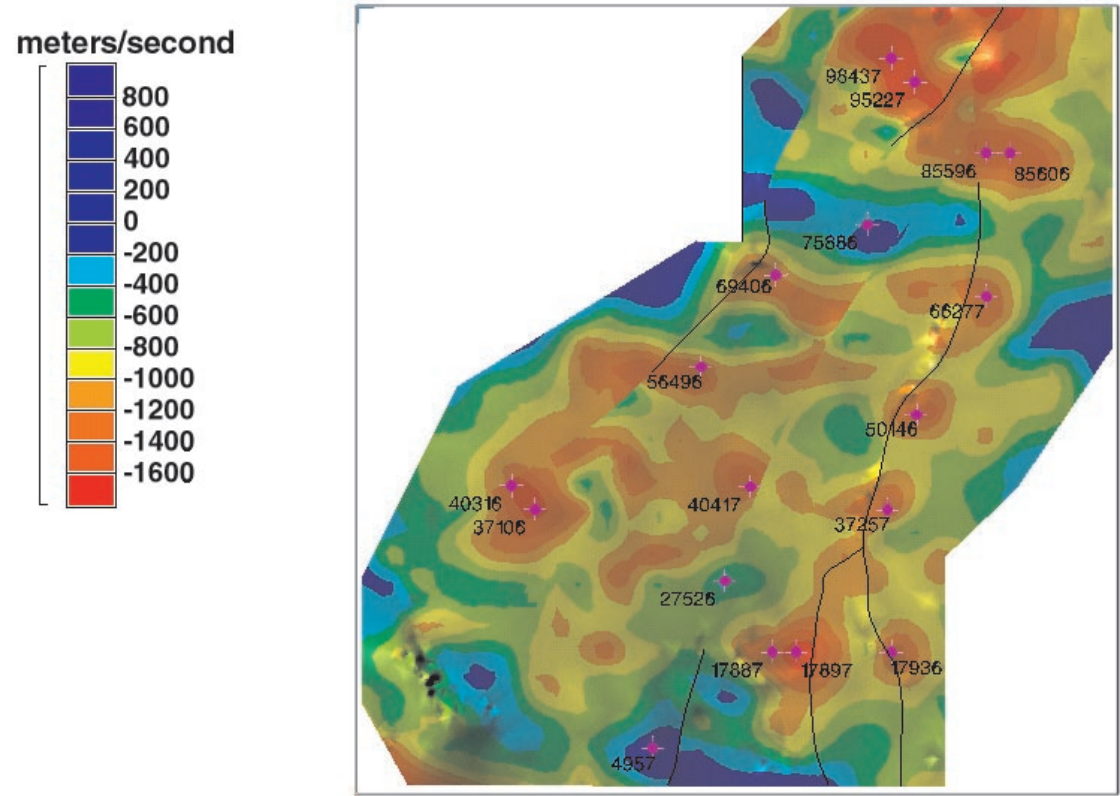

IER

Figure 36. Map view of the anomalous velocity surface at the top of the Muddy Formation (same map as shown in Figure 34B). Also shown are the locations of the N-S and E-W sections cut through the anomalous velocity volume (Figure 27) to illustrate the spatial distribution of velocity anomalies shown in Figures 34B and 36 . The position of the CDPs are shown also (see Appendix II). These CDPs were chosen to reveal the velocity-depth characteristics at each of the signi cant anoma I ies shown in ff gur e 34B.

\section{Anomalous Velocity Model, Emigrant 3D Survey \\ NS Cross Section 1, View to West}
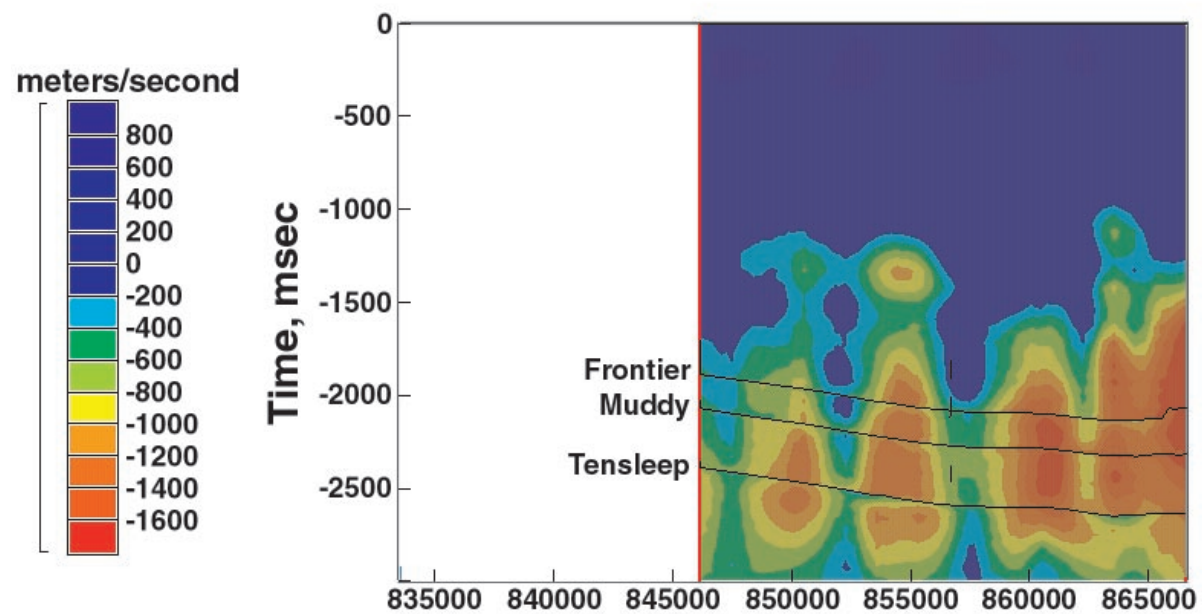

\section{IER}

Figure 37. North-south anomalous velocity section through the anomalies at CDPs 85596 and 85606, and 66277 (see Figure 36 and Appendix II). 


\section{Anomalous Velocity Model, Emigrant 3D Survey}

EW Cross Section 6 (1268)

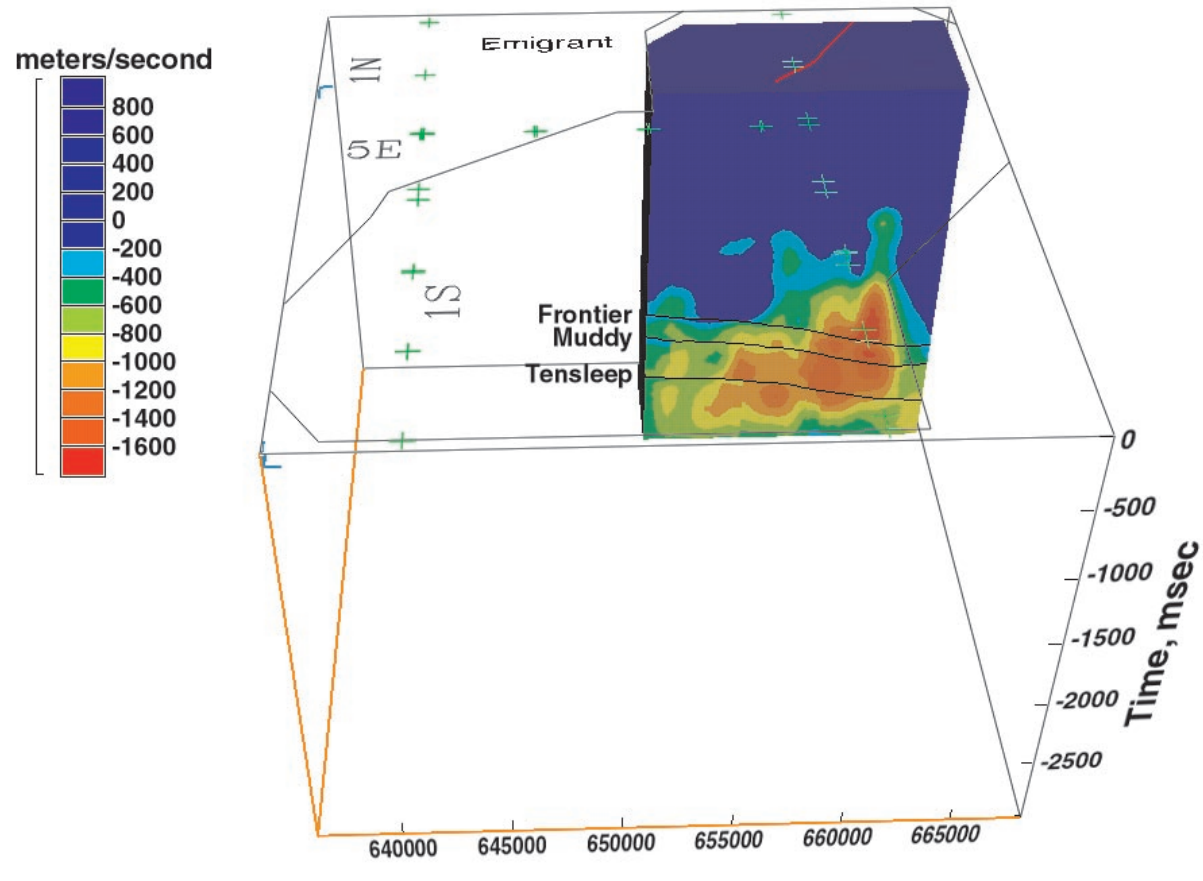

\section{IER}

Figure 38. East-west anomalous velocity section through the anomaly at CDPs 85596 and 8566 (see Figure 35 and Appendix II).

\section{Anomalous Velocity Model, Emigrant 3D Survey} NS Cross Section 2, View to West
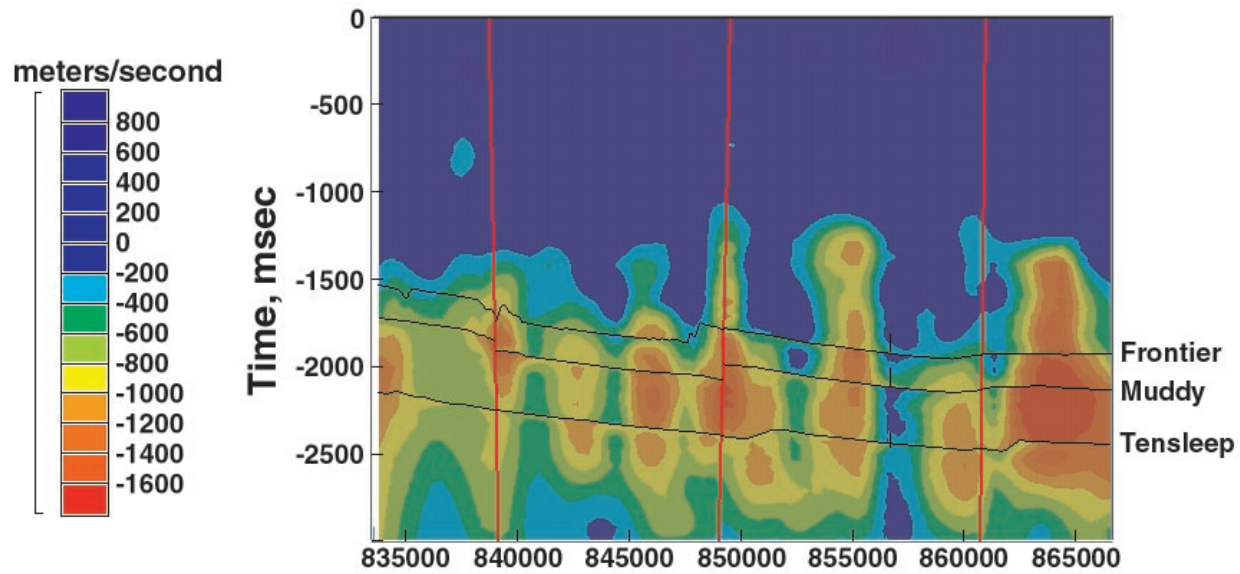

IER

Figure 39. North-south anomalous velocity section through the anomalies at CDPs 98437 and 95277, 50146, 37257, and 17936 (see Figure 35 for location of anomalies and CDPs; see also Appendix II for velocity-depth pro I@) . 


\section{Anomalous Velocity Model, Emigrant 3D Survey EW Cross Section 7, View to North}
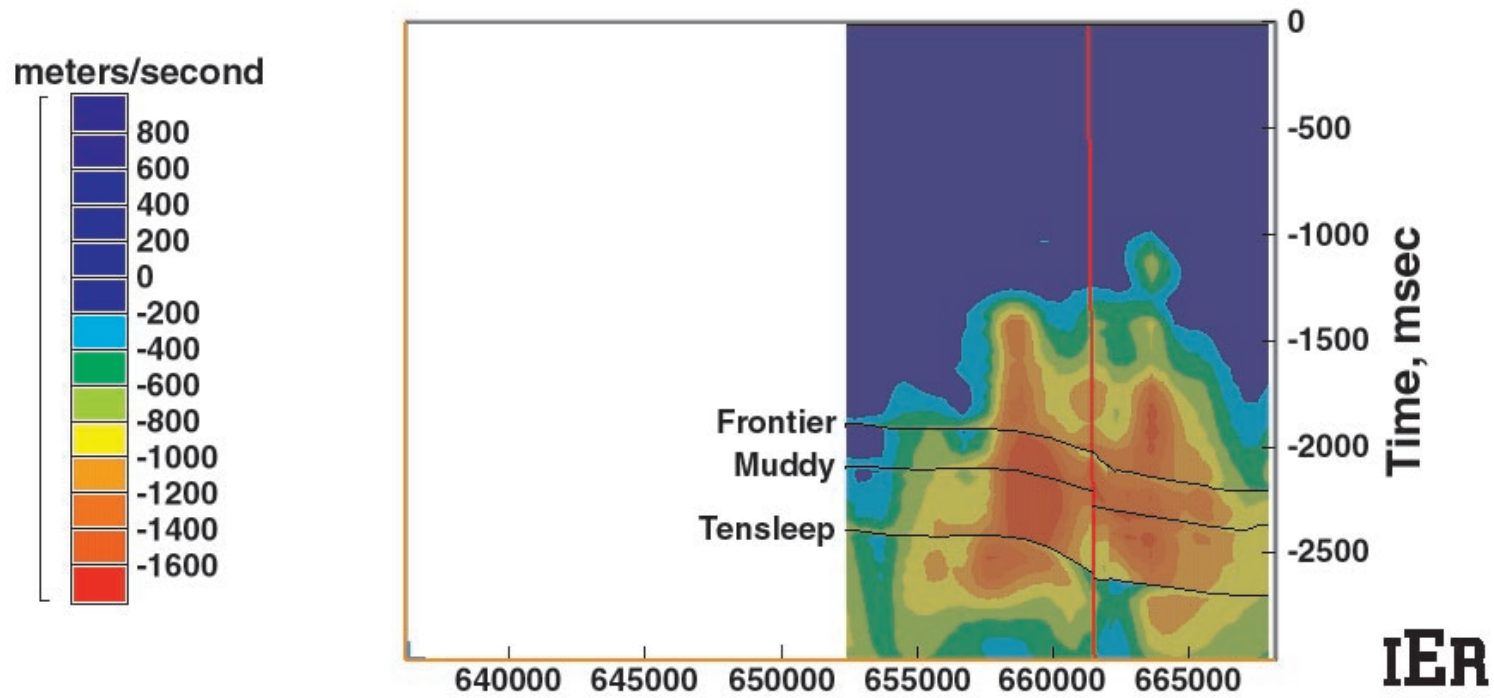

Figure 40. East-west anomalous velocity section through the anomaly at CDPs 98437 and 95227 (see Figure 36 and Appendix II).

\section{Anomalous Velocity Model, Emigrant 3D Survey}

EW Cross Section 3 (1152)

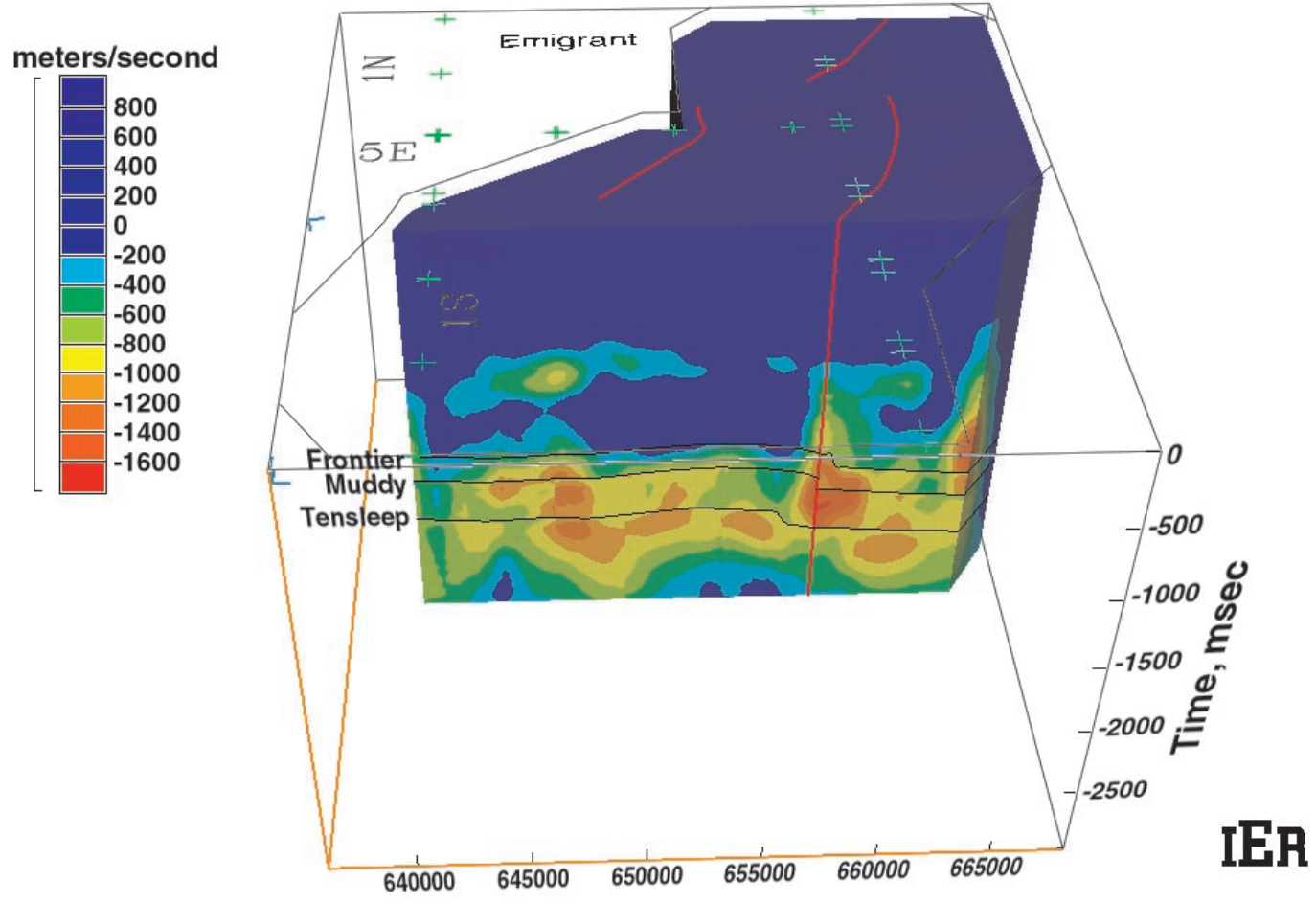

Figure 41. East-west anomalous velocity section through the anomaly at CDP 50146 (see Figure 36 for location and Appendix II for velocity-depth pro les). 
as the east-west section (EW X3; Figure 41) cuts through the southern anomaly along $\mathrm{N}-\mathrm{S}$ section 2. The anomaly at CDPs 98437 and 95227, illustrated in Figures 39 and 40, is a large velocity anomaly with a distinct chimney shape. This particular anomaly extends from below the Tensleep to well above the Frontier Formation (Figures 39 and 40). The anomaly to the south at CDP 50416 is smaller, but is also chimney shaped (Figures 39 and 41). This particular anomaly occurs on the eastern side of the major north-south fault at a location where the fault changes orientation (where it bends to the northeast).

The north-south anomalous velocity section (NS X3; Figure 42) intersects two more of the important velocity anomalies (at CDPs 17887 and 17897, and farther north at CDP 69406). The anomaly in the south (CDPs 17887 and 17897) is volumetrically important and extends vertically from the Tensleep Formation to above the Frontier Formation. The anomaly to the north at CDP 69406 is a relatively narrow chimney or zone extend- ing vertically from the Tensleep Formation to well above the Frontier Formation, probably into the Lower Fort Union Formation. The topographic relief on this narrow anomaly is at least $0.5 \mathrm{sec}$ TWTT. The east-west anomalous velocity section (EW X1; Figure 43, see Figure 36 for locations of the east-west and north-south anomalous velocity sections) intersects the large velocity anomaly at CDPs 17887 and 17897. This anomaly occurs at the crest of the structure and is situated on both sides of the major north-south fault (Figure 43).

The north-south anomalous velocity section (NS X4; Figure 44) and the east-west anomalous velocity section (EW X2; Figure 45) both intersect the velocity anomaly at CDPs 40316 and 37106 (see Figure 36 for location). The velocity anomaly is volumetrically signi cant and has a chimney shape that is not as pronounced as the chimneys observed at some of the other velocity anomalies (compare Figure 44 with Figures 37, 39, and 42). Based on volumetrics, the anomalies at CDPs 98437 and 95227, 85596 and 85606,40316 and 37106 , and 17887 and 17897 are elevated to preferred ex-

\section{Anomalous Velocity Model, Emigrant 3D Survey NS Cross Section 3, View to West}
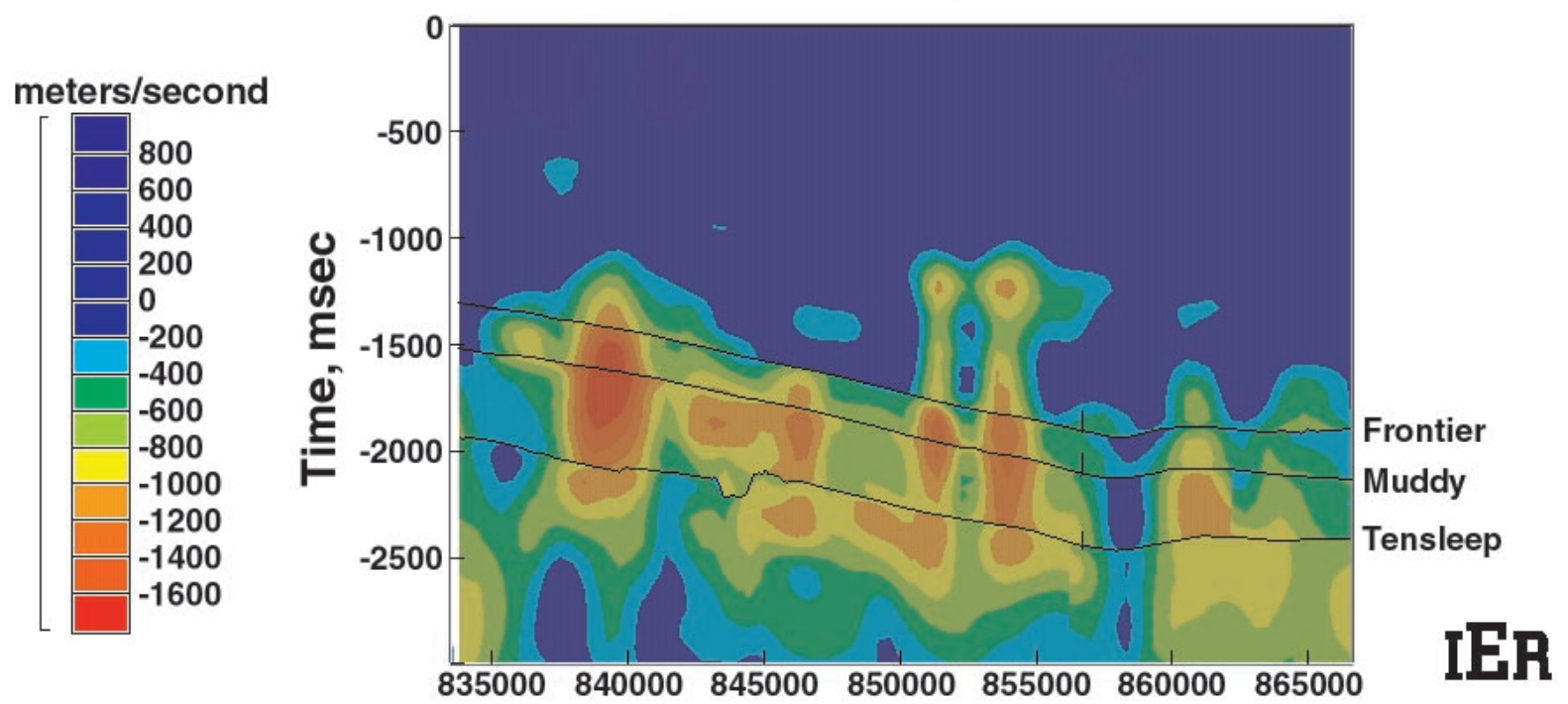

Figure 42. North-south anomalous velocity section through the anomalies at CDPs 69406 and 17887 and 17897 (see Figure 36 and Appendix II). 


\section{Anomalous Velocity Model, Emigrant 3D Survey}

EW Cross Section 1 (1062)

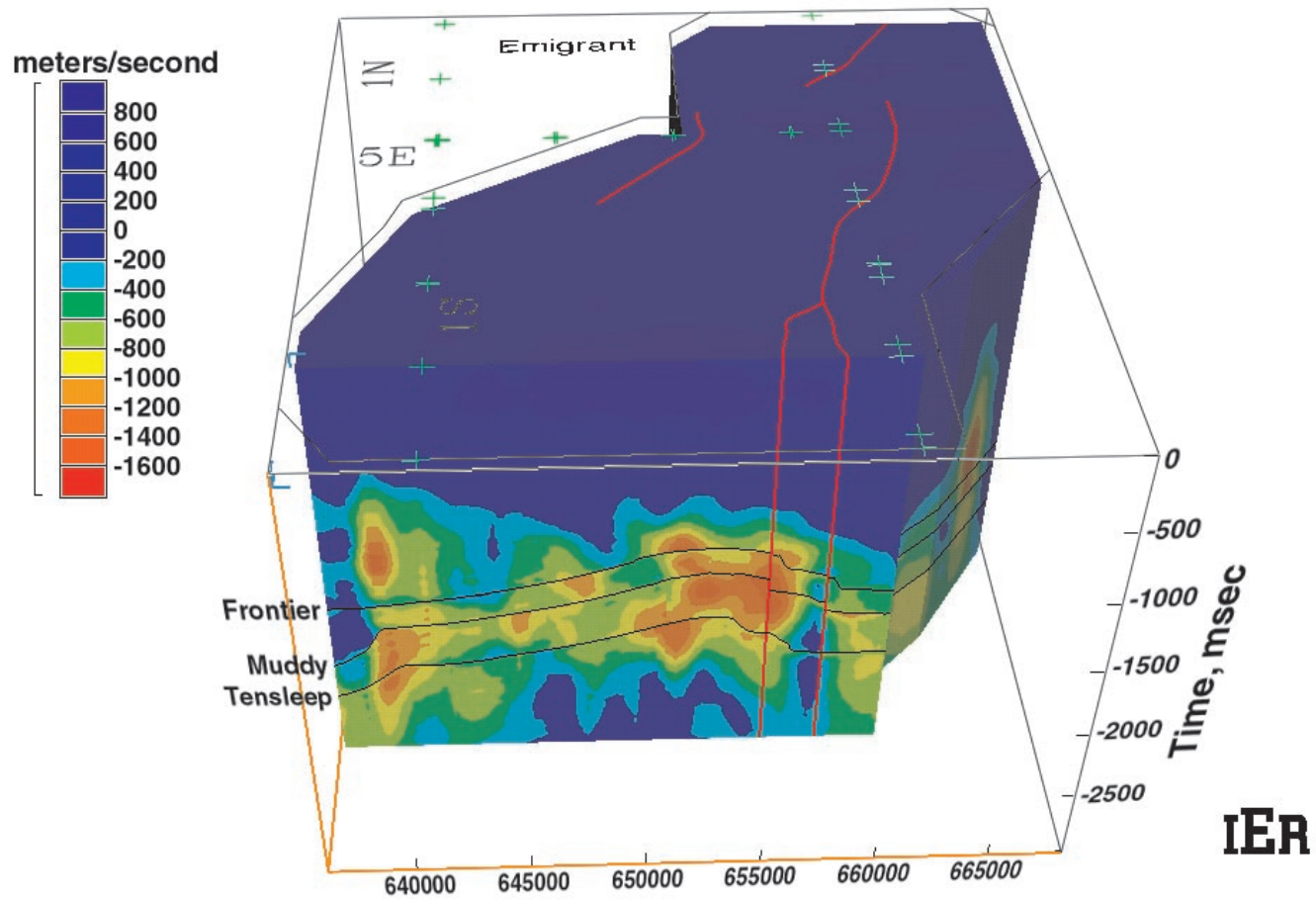

Figure 43. East-west anomalous velocity section through anomalies at CDPs 17887 and 17897 and 17936 (see Figure 36 and Appendix II).

Anomalous Velocity Model, Emigrant 3D Survey

NS Cross Section 4, View to West
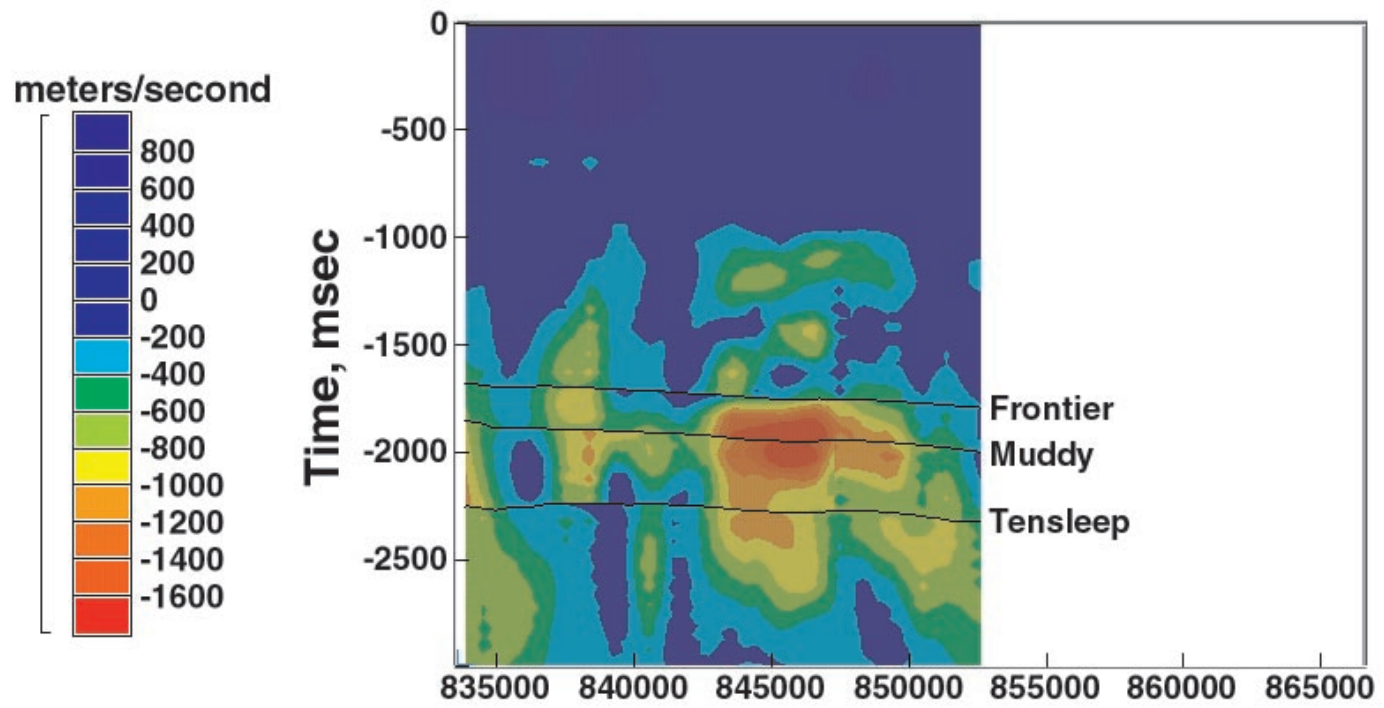

IER

Figure 44. North-south anomalous velocity section through anomaly at CDPs 40316 and 37108 (see Figure 36 for locations and Appendix II for individual velocity-depth pro les). 
EW Cross Section 2 (1114)

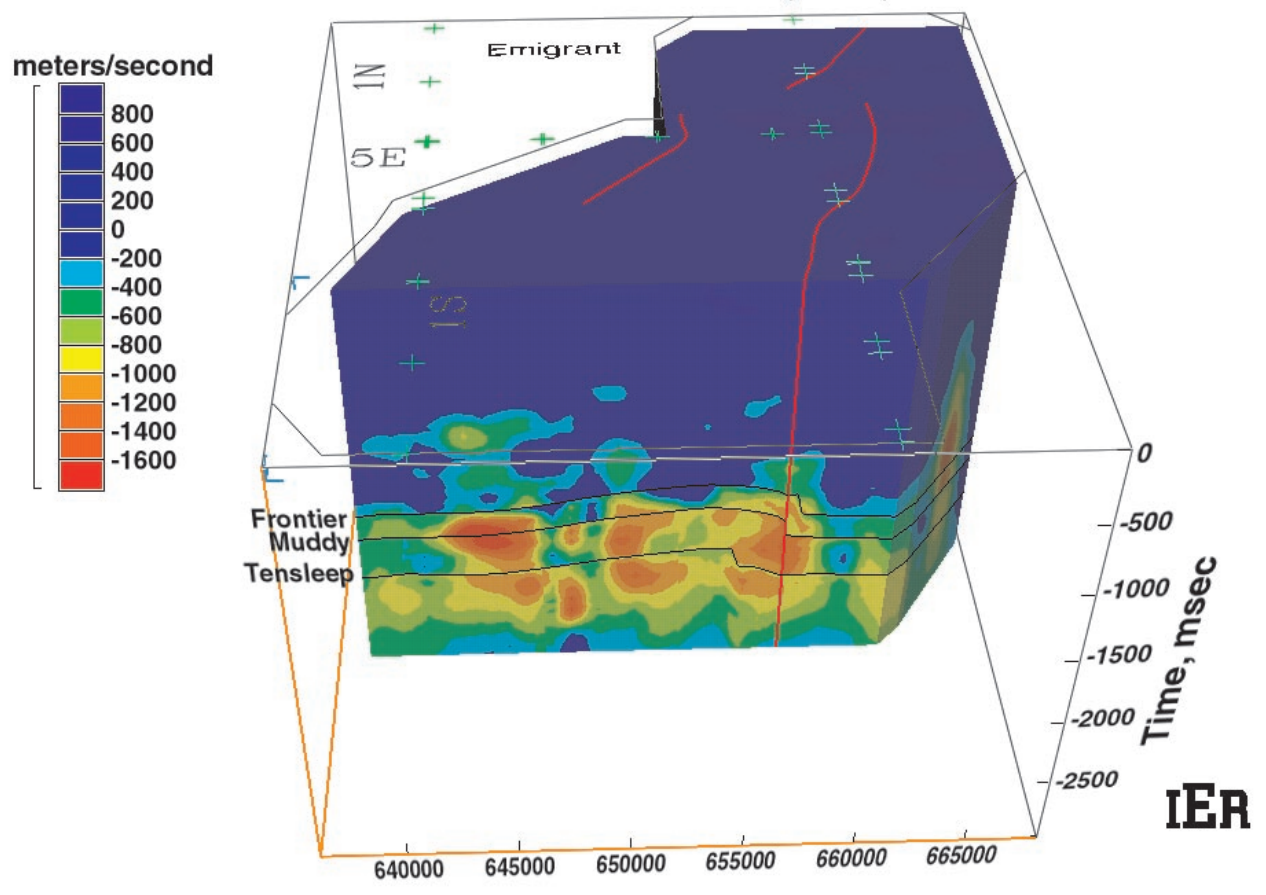

Figure 45. East-west anomalous velocity section through anomalies at CDPs 40316 and 37106, 40417, and 37257 (see Figure 35 and Appendix II).

ploration targets. It is important to note that, based on Figures 37-45, the velocity anomalies and their typical chimney shape clearly represent the vertical migration of gas.

\section{Event Similarity Prediction (ESP) Discontinuity}

In order to determine the potential for enhanced porosity/permeability, two ESP horizontal slices were cut through the Emigrant ESP cube. The rst section $\mathrm{S}$ att ered on the top of the Frontier Formation (Figure 46) and the second was at tened on the top of the Muddy Formation (Figure 47). On the top of the Frontier, there are signi cant BP d scont ini ties in the northeastern, central, and southeastern portions of the Emigrant study area (Figure 46). In addition, the major north-south fault is nicely illustrated on the Frontier map.

From the ESP map at the top of the Muddy Formation, a major valley- 11 (VF) deposit has been interpreted, as well as a significant north-south fault system (F; see Figure 47). As described early in the discussion of the Riverton Dome survey, in this portion of the Wind River Basin wi al channels in valley- 11 de posits commo nl y are characterized by enhanced porosity/ permeability.

\section{Exploration Targets}

The last step in prioritizing exploration targets and developing potential drilling sites in the Emigrant study area is to compare the anomalous velocity maps and ESP maps for both the Frontier and Muddy Formations. For the Frontier Formation, there are two signi cant overlaps bet en Front ier velocity anomalies (Figure 33B) and ESP discontinuities (Figure 46). The two overlaps are in the vicinity of CDPs 85596 and 85606, and 66277 (see Figure 36 for CDP locations). Of the two possible spots character- 


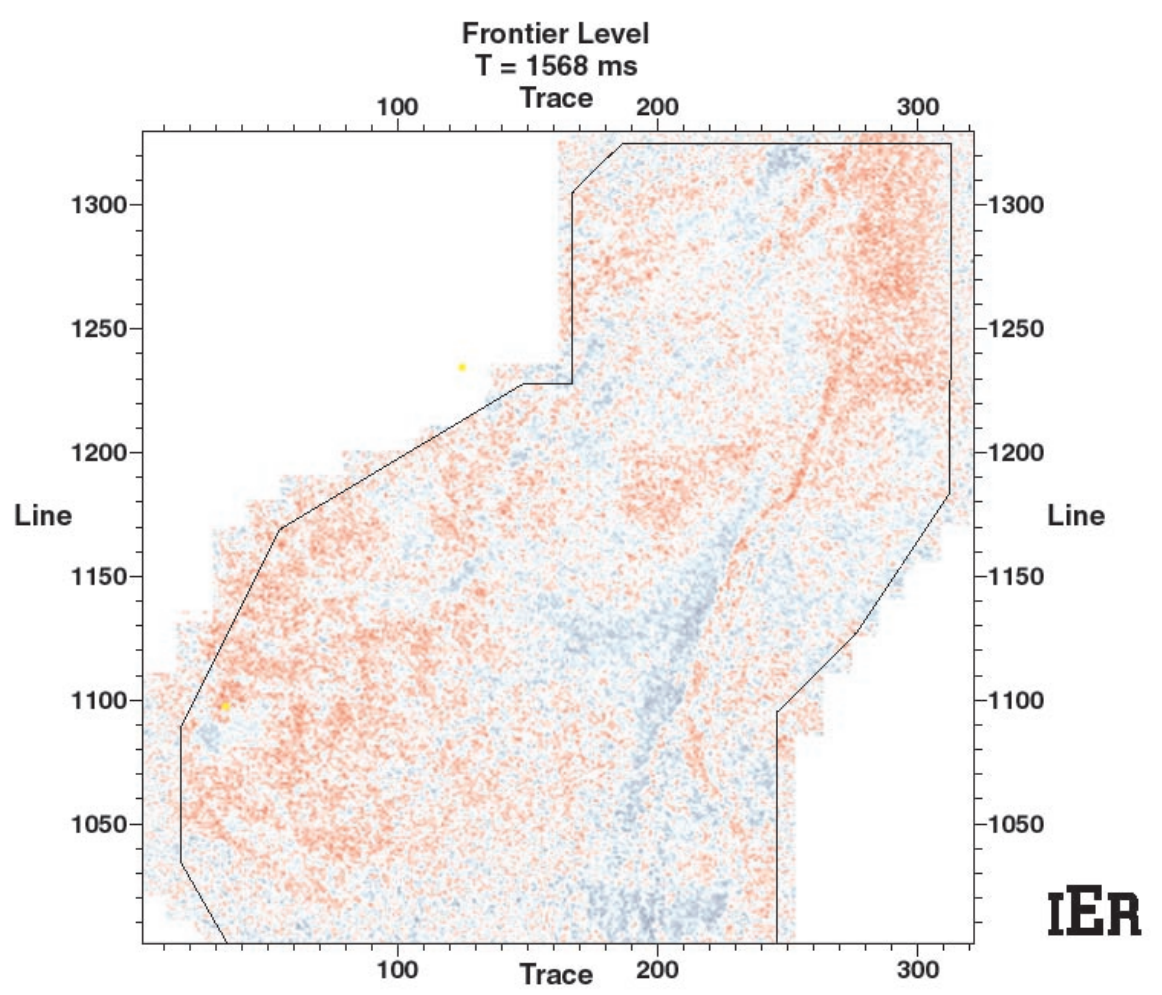

Figure 46. Event Similarity Prediction (ESP) map drawn at the top of the Frontier Formation. The red shows areas characterized by discontinuities.

ized by anomalous velocity/ESP overlaps, the northern one is the most impressive.

For the Muddy Formation, important overlaps between velocity anomalies (Figure 34B) and ESP discontinuities (Figure 47) occur at CDPs 96437 and 95227, 40316 and 37105 , and 17887 and 17897 . With respect to targets in the Muddy Formation, these three velocity anomaly/ESP discontinuities are the most important.

\section{Drilling Recommendations}

The exploration uncertainties and therefore risk are significantly higher in the Emigrant area than in the Riverton Dome area. However, the IER strategy employed in this report suggests that there are gas exploration targets worthy of drilling, particularly in the Muddy Formation in the Emigrant 3D seismic survey area. Also, as noted earlier, when signi cant vel $\propto$ ity anom $l$ ies $\propto-$ cur in the Muddy Formation, typically there is a concomitant anomaly in the Frontier Formation.

Based on information contained within this report, the prioritized, nominated Muddy drilling sites are as follows:

1. CDP 098437. This is an outstanding Muddy target at $2200 \mathrm{msec}$; the section at 1400 to 1700 msec TWTT also has signi cant gas potential (see Appendix II and Figures 39 and 40).

2. CDP 037106. This site is primarily a Muddy target, for the stratigraphic section above is not as attractive as in target 1 above. However, the section below, down to the Nugget Formation, shows promise (see Appendix II and Figures 44 and 45).

3. CDP 017887 . This site is primarily a Muddy target, although the section below the Muddy down to $1700 \mathrm{msec}$ has promise. This is the most shallow Muddy tar- 


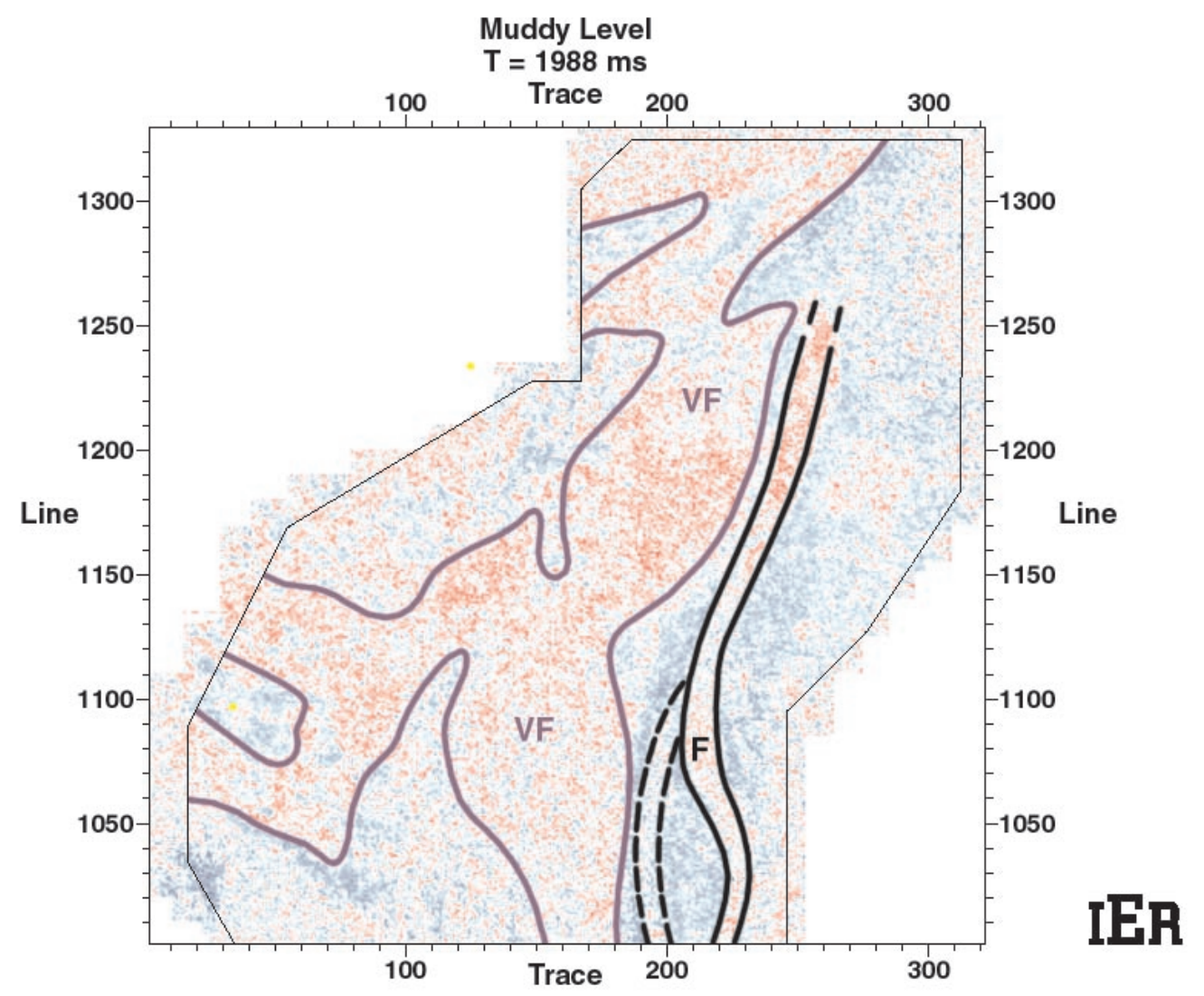

Figure 47. Event Similarity Prediction (ESP) map drawn at the top of the Muddy Formation. Interpreted valley- II (VF) deposits i $n$ the Mddy $F$ ormation are outlined i $n$ bue. Fault and $f$ racture zones ( $F)$ are outlined in black. Red areas are those characterized by discontinuities

get and it occurs close to the crest of the structure (see Appendix II and Figures 42 and 45).

The results of this study suggest that the above three prioritized drilling targets have the highest potential for success in the search for anomalously pressured gas accumulations in the Emigrant area. All three of these nominated targets are characterized by the following features: (1) significant, anomalously slow velocities; (2) an associated ESP discontinuity, and (3) a chimney-shaped con gur at ion.

Unfortunately, because of the following recent series of corporate mergers - Snyder into Snata Fe Snyder and Santa Fe Snyder into Devon - the test well was not drilled by Snyder Oil Company. Thus, work relating to the test well was not completed by the termi- nation date of the contract. The blind test described in this report remains the best available public validation of the new technology. In addition, because the test well was not drilled, it was impossible to complete the stimulation portion of the work.

\section{ACKNOWLEDGEMENTS}

Zun Sheng Jiao, Nicholas G.K. Boyd III, Sharon Kubichek, Henry Heasler, John Buggenhagen, Peigui Yin, and Scott Stookey, all scientists at the Institute for Energy Research, University of Wyoming, have contributed significantly to the ideas and concepts discussed in this report. Special acknowledgment goes to the Department of Energy (Contract No. DEFC26-97FT34181) for providing financial 
support of the work; to Gas Research Institute (Contract Nos. 5096-260-3833 and No. 5097-210-4085) for supporting the development of concepts explaining anomalously pressured gas accumulations in the Rocky Mountain Laramide Basins; and to Santa Fe Snyder Corporation, Belco, and Tom Brown Company for supplying Wind River Basin data. Dynamic Graphics EarthVision ${ }^{\mathrm{TM}}$ software was used in the geospatial modeling and visualization presented in this report. ProMAX seismic processing software and Landmark interpretation software provided to the Institute for Energy Research by Landmark Graphics Company also were used in these studies and greatly expedited the work presented in this report.

\section{REFERENCES}

Buggenhagen, John, 1999, Part 2: Understanding Unconventional Reservoirs: Reservoir Characterization of the Frontier Formation Reservoirs in the Badger Basin field, Bighorn Basin, Wyoming: Ph.D. Dissertation, University of Wyoming, Laramie, WY.

Martinsen, R.S., 1994, Stratigraphic Compartmentation of Reservoir Sandstones: Examples from the Muddy Sandstone, Powder River Basin, Wyoming, in P. Ortoleva, ed., Basin Compartments and Seals: American Association of Petroleum Geologists, AAPG Memoir 61, pp. 273-296.

Surdam, R.C., 1997, A New Paradigm for Gas Exploration in Anomalously Pressured "Tight Gas Sands" in the Rocky Mountain Laramide Basin, in R.C. Surdam, ed., Seals, Traps, and the Petroleum System: American Association of Petroleum Geologists, Tulsa, OK, Memoir 67, Chapter 17, pp. 283-298.

Surdam, R.C., Z.S. Jiao, and H.P. Heasler, 1997, Anomalously Pressured Gas Compartments in Cretaceous Rocks of the Laramide Basins of Wyoming: A New Class of Hydrocarbon Accumulation, in R.C. Surdam, ed., Seals, Traps, and the Petroleum System: American Association of Petroleum Geologists, Tulsa, OK, Memoir 67, Chapter 12, pp. 199-222. 


\section{Appendix I}

Amplitude stack, ESP pro le, and sei smi c irt erval vel œity ddf $\alpha$ ind res 1662 (EX1 ), 114

(EWX2), 1152 (EWX3), 1191 (EWX4), 1230 (EWX5), 1268 (EWX6), and cross line 167 (NSX1) 


\section{舀}

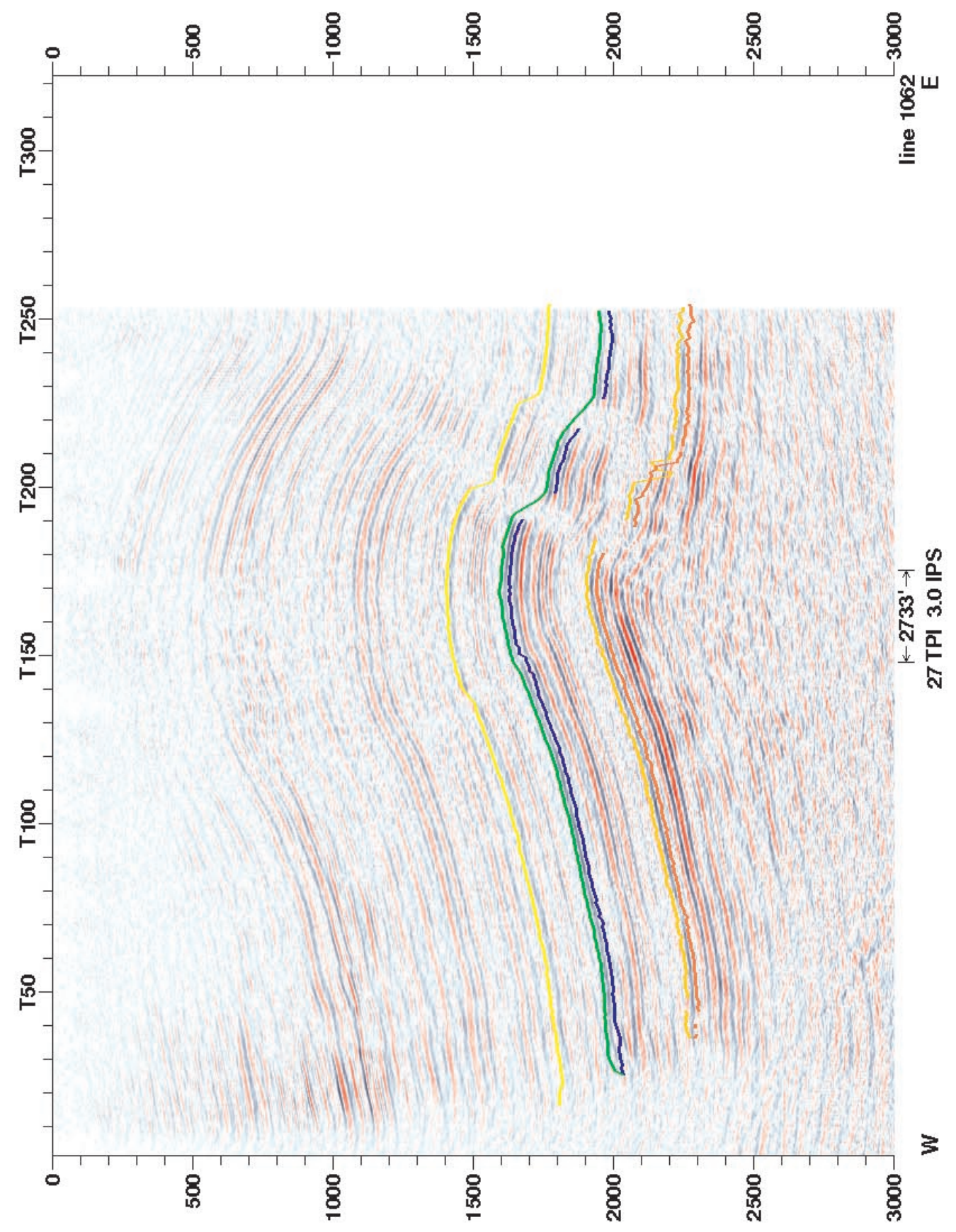


畄
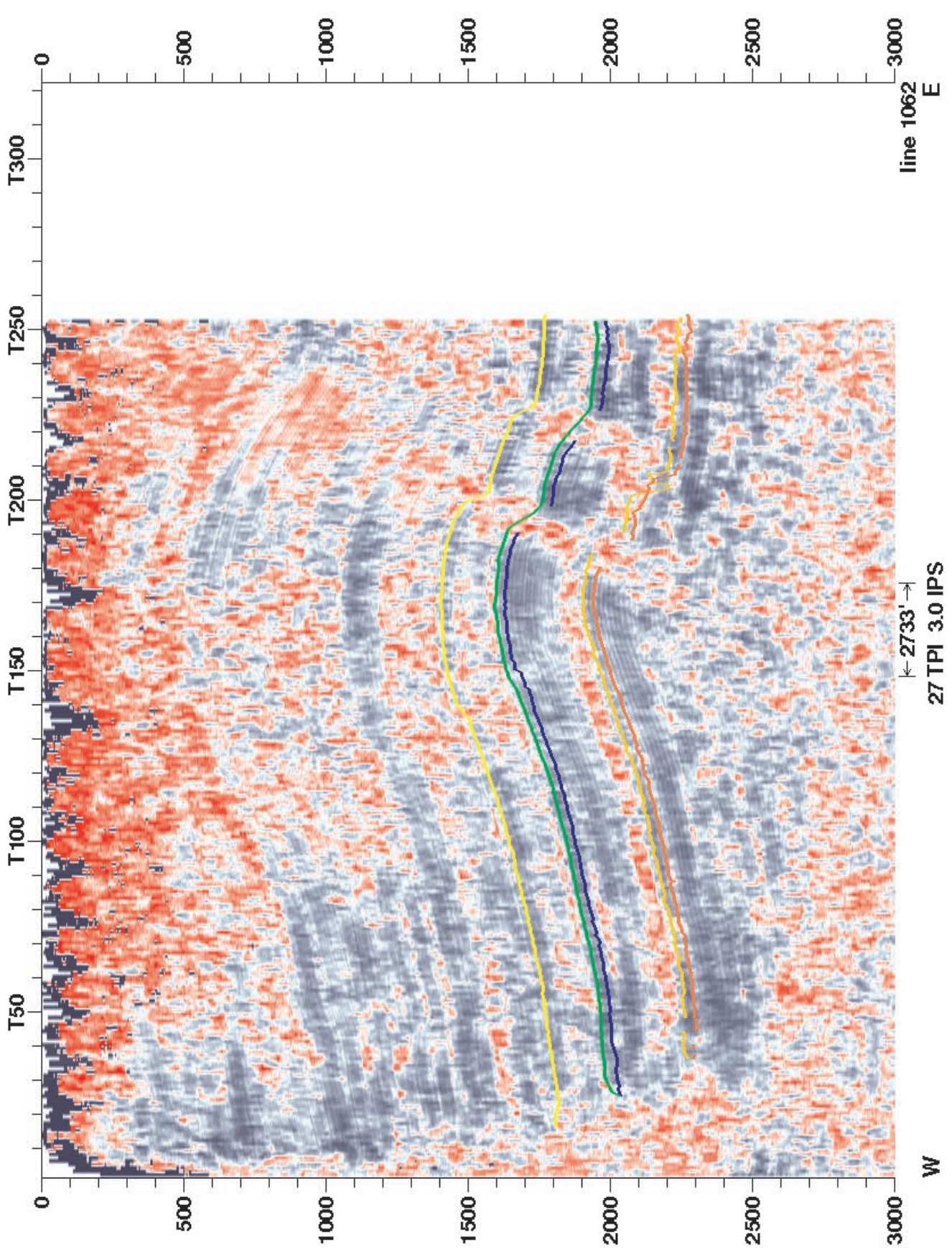


\section{岳}

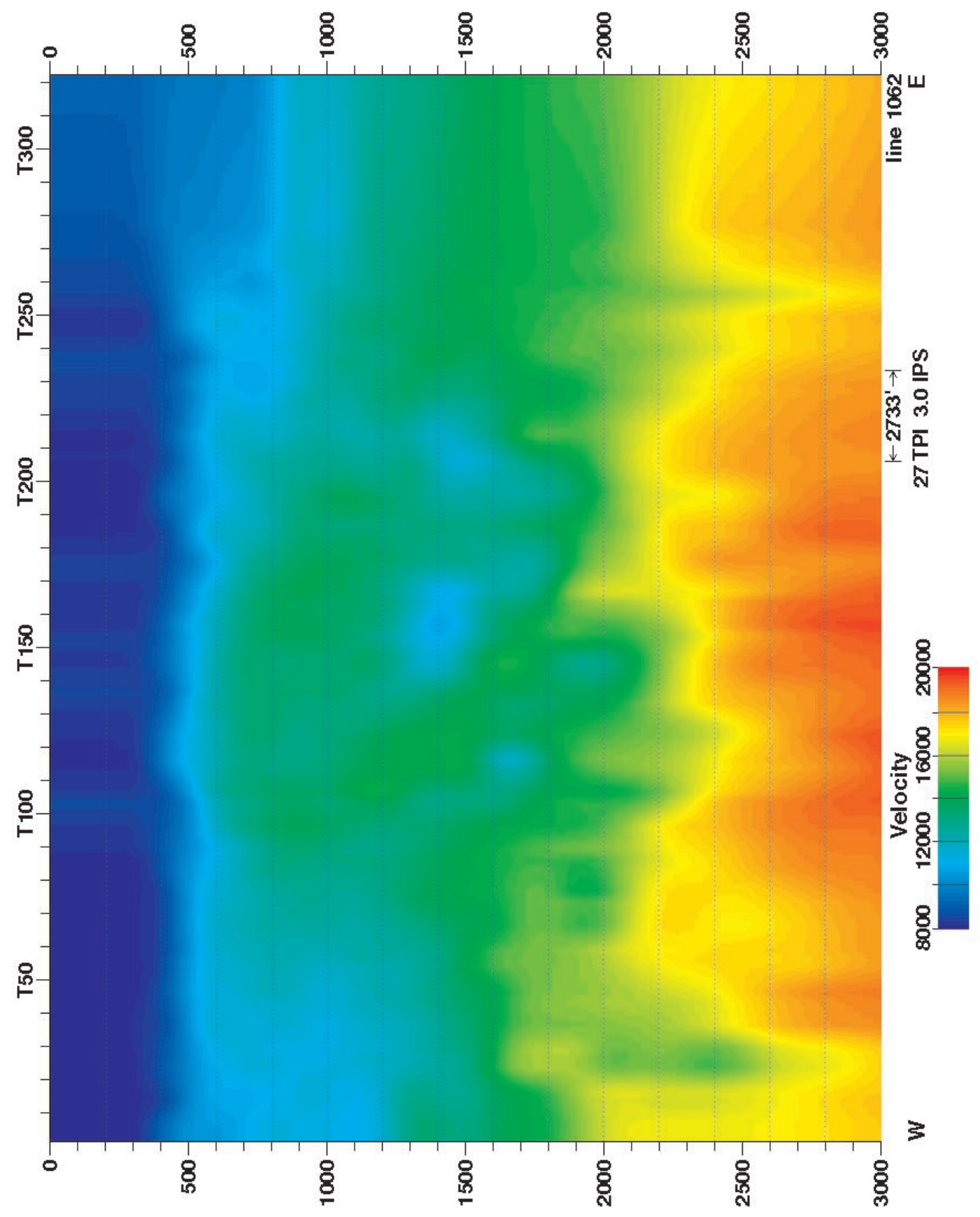



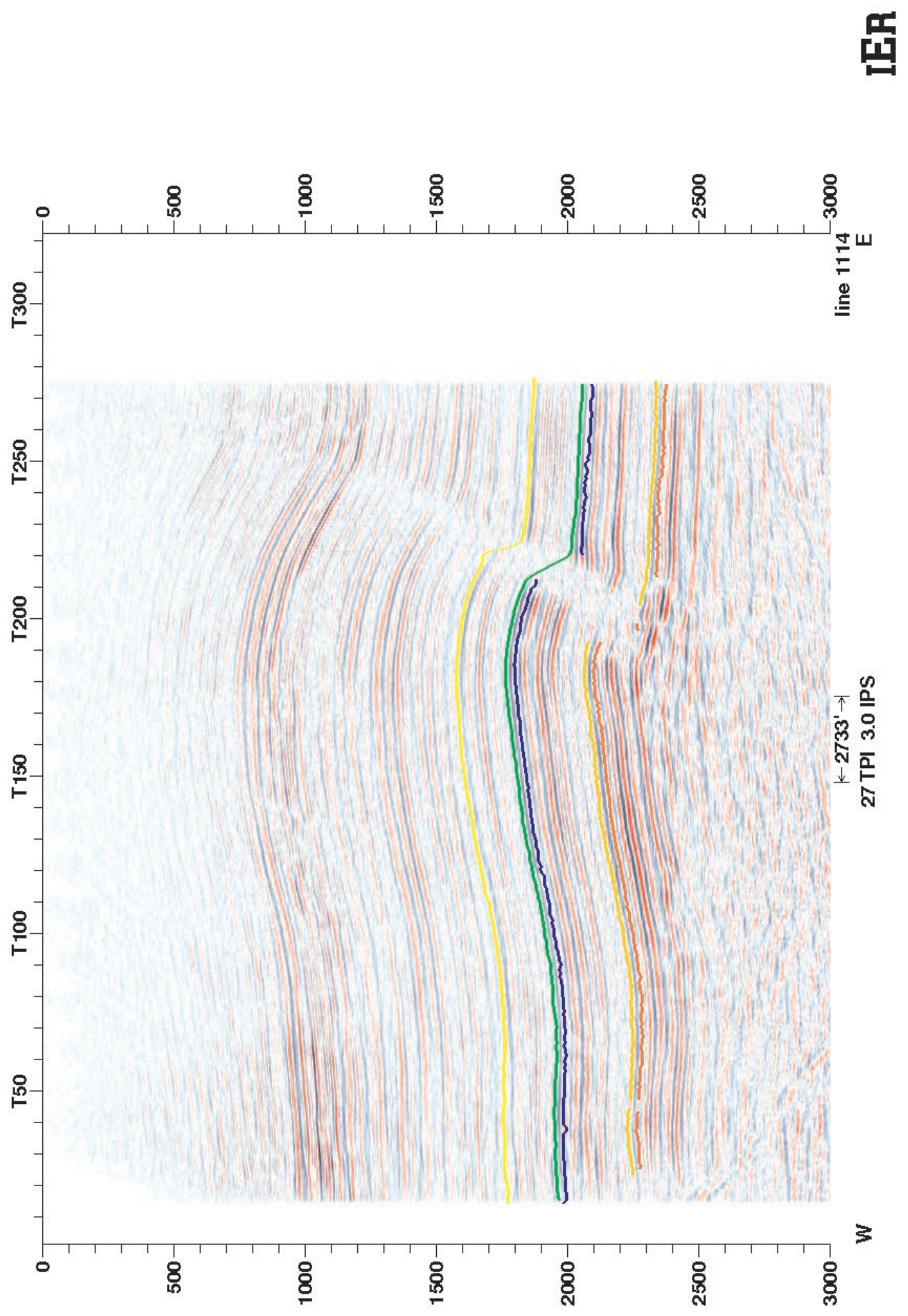


\section{岳}

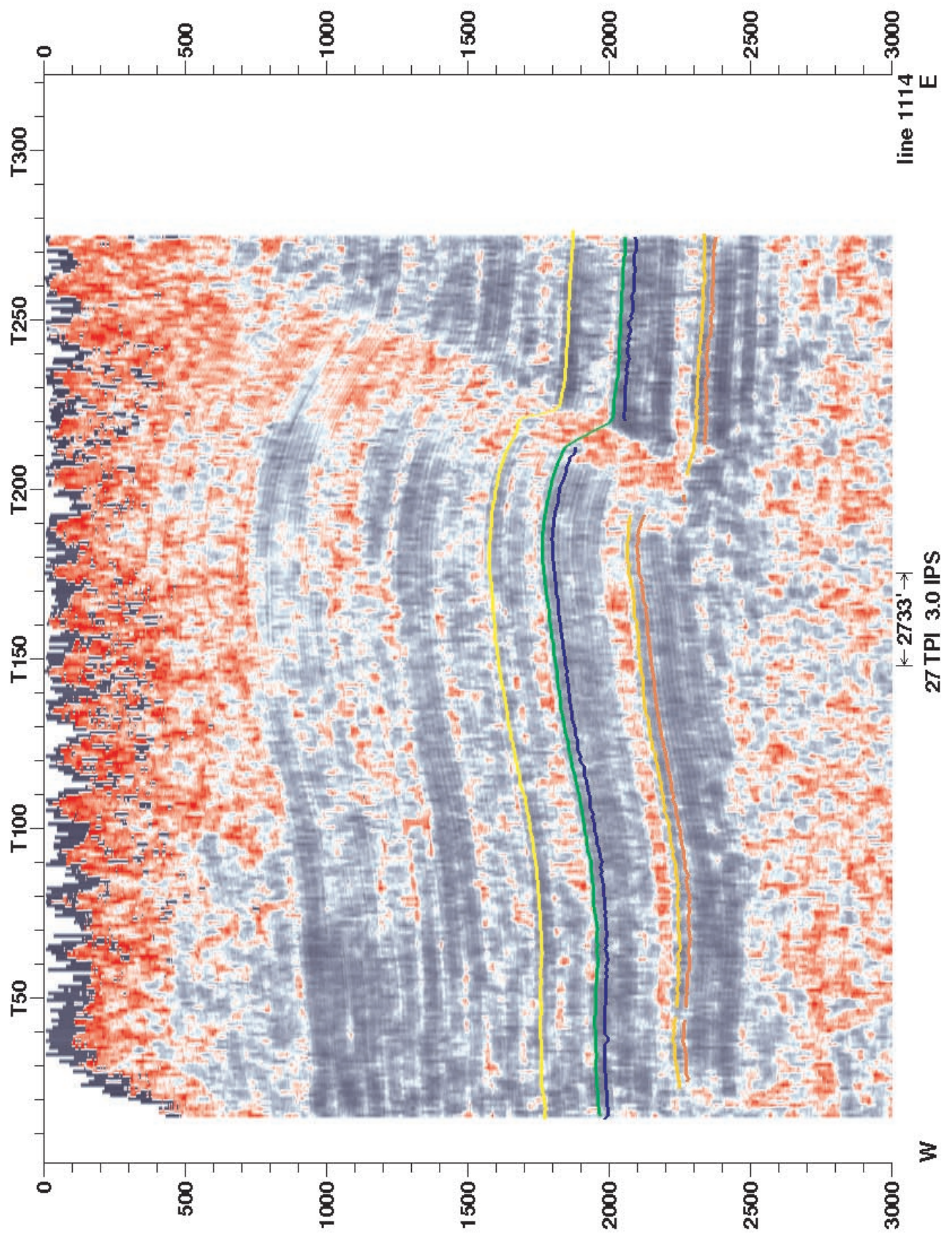


畐

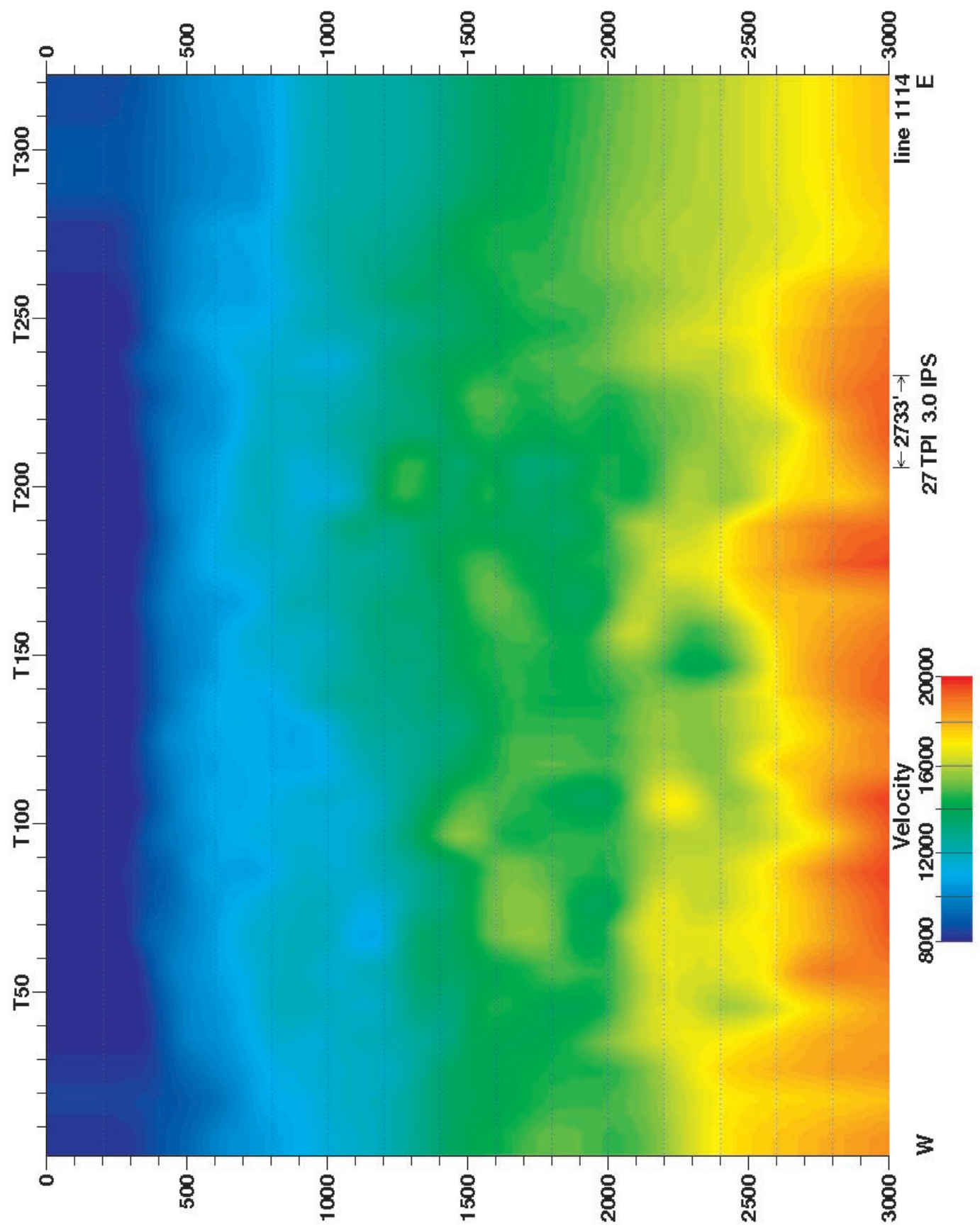




\section{舀}

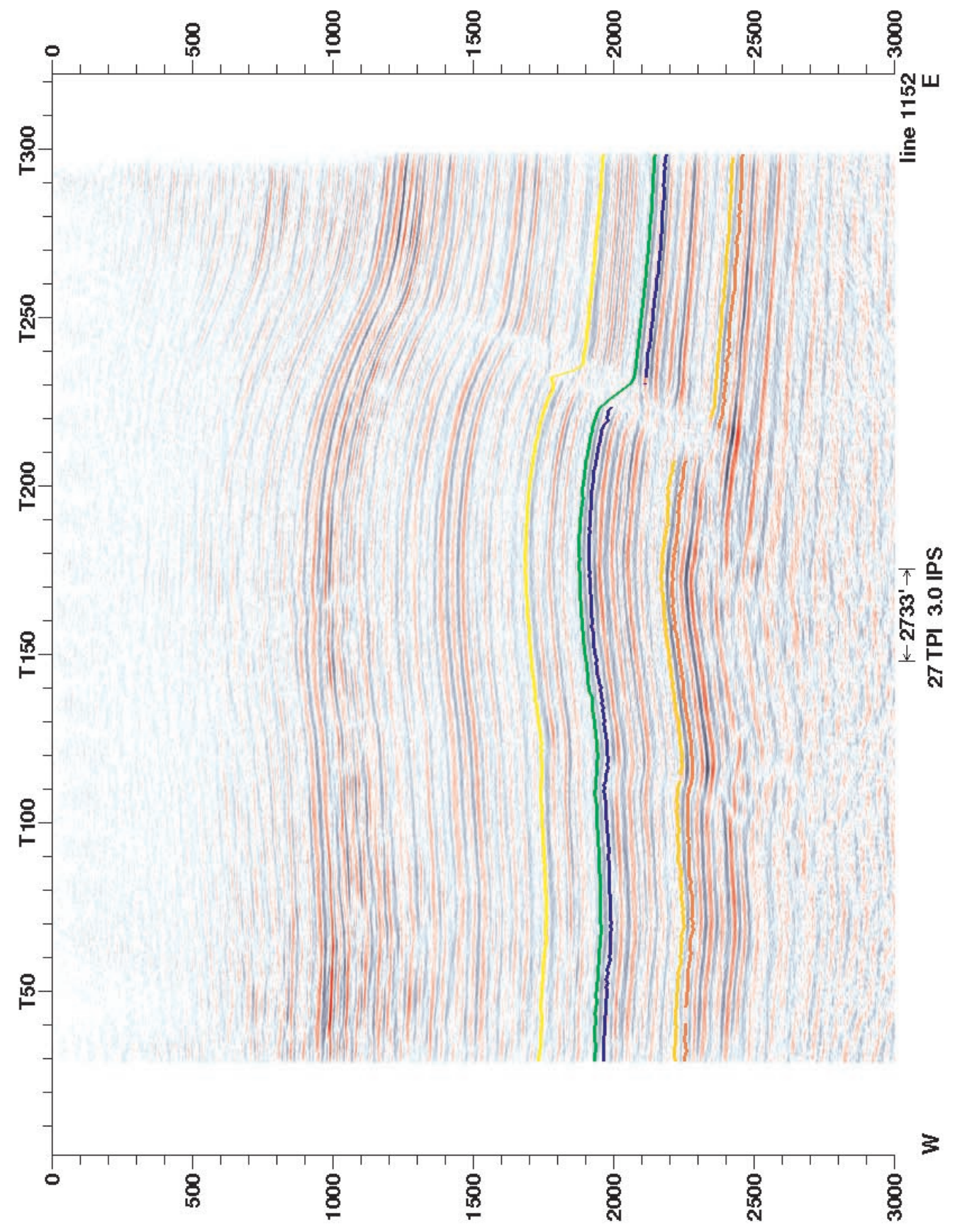


畐

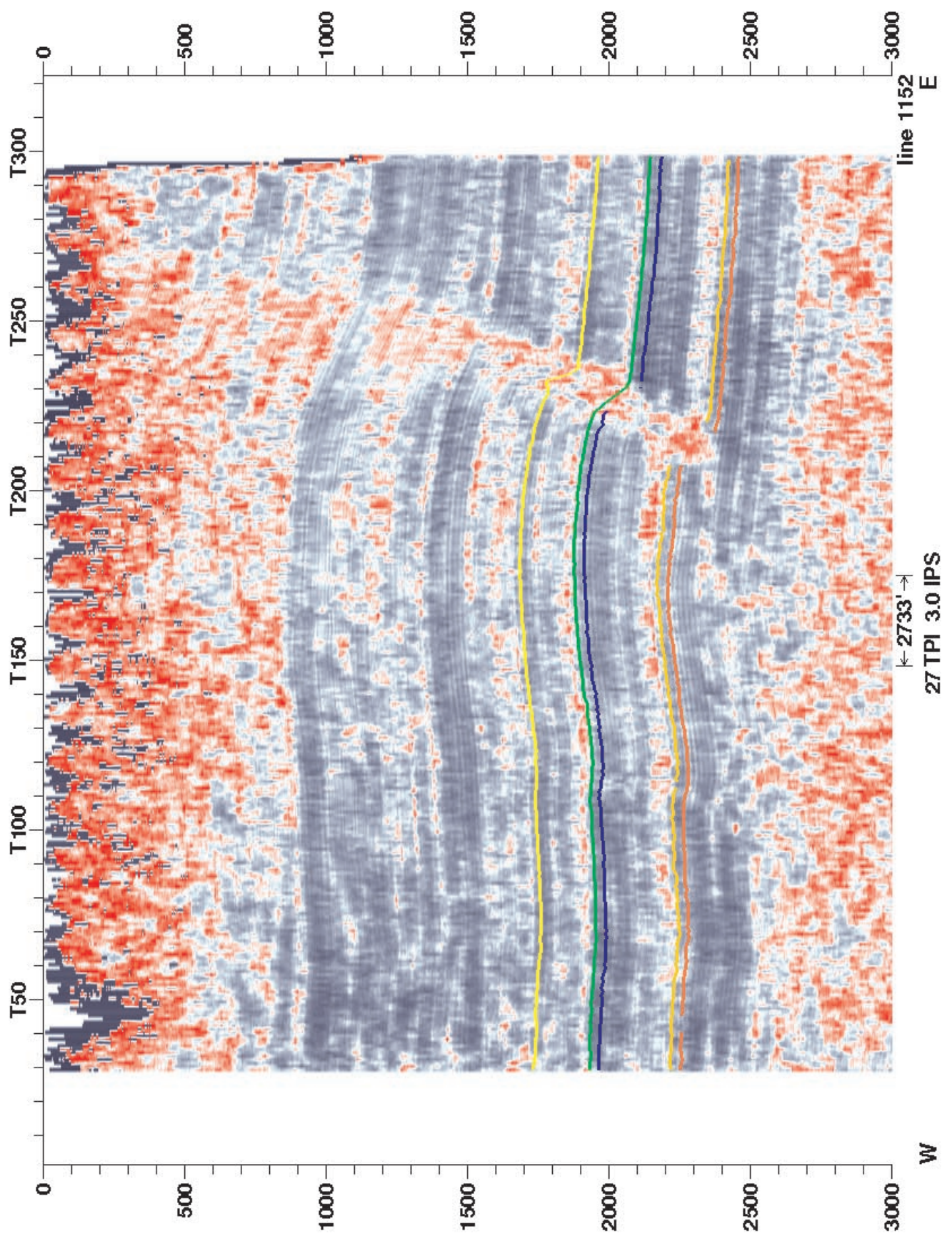




\section{岳}

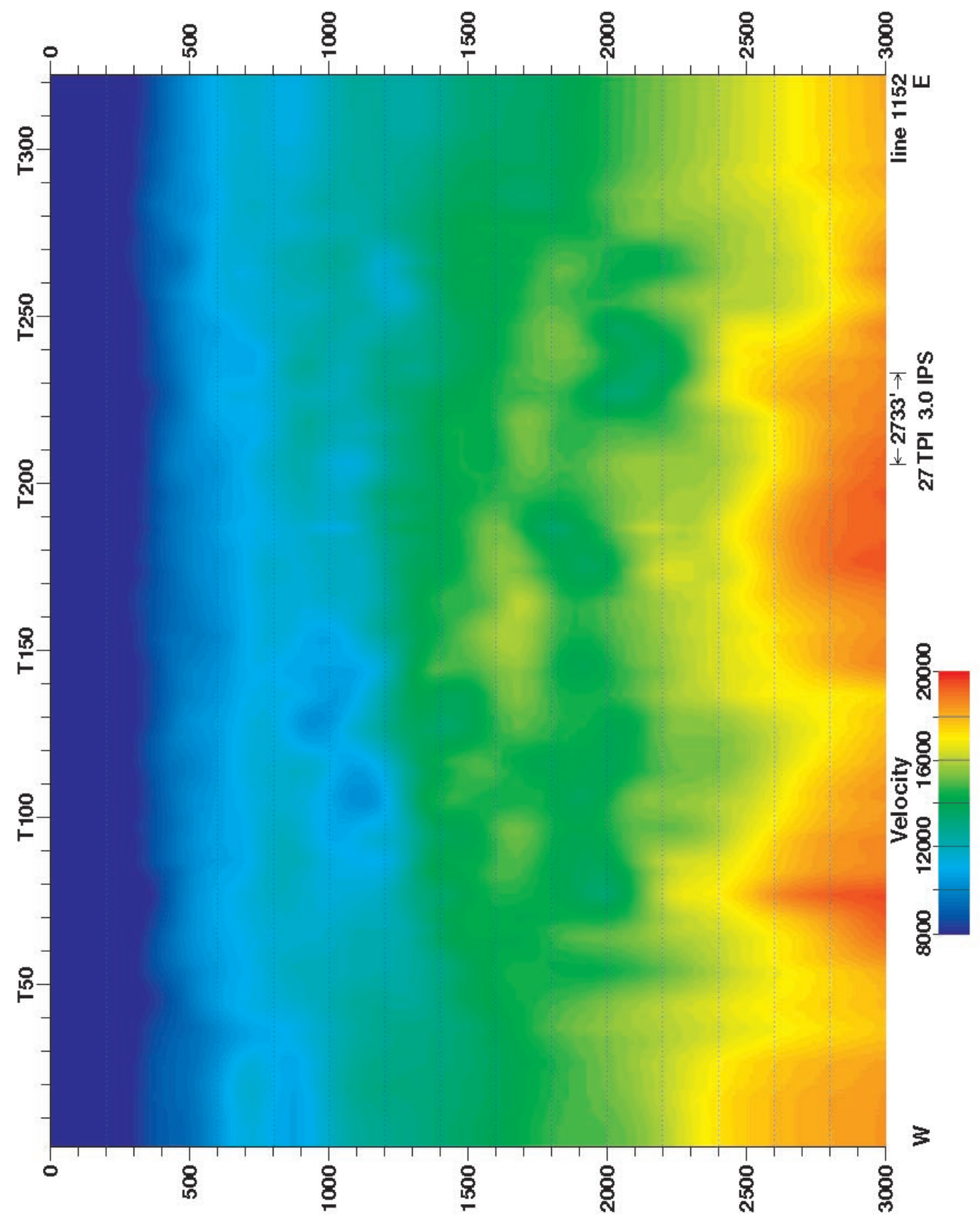


載

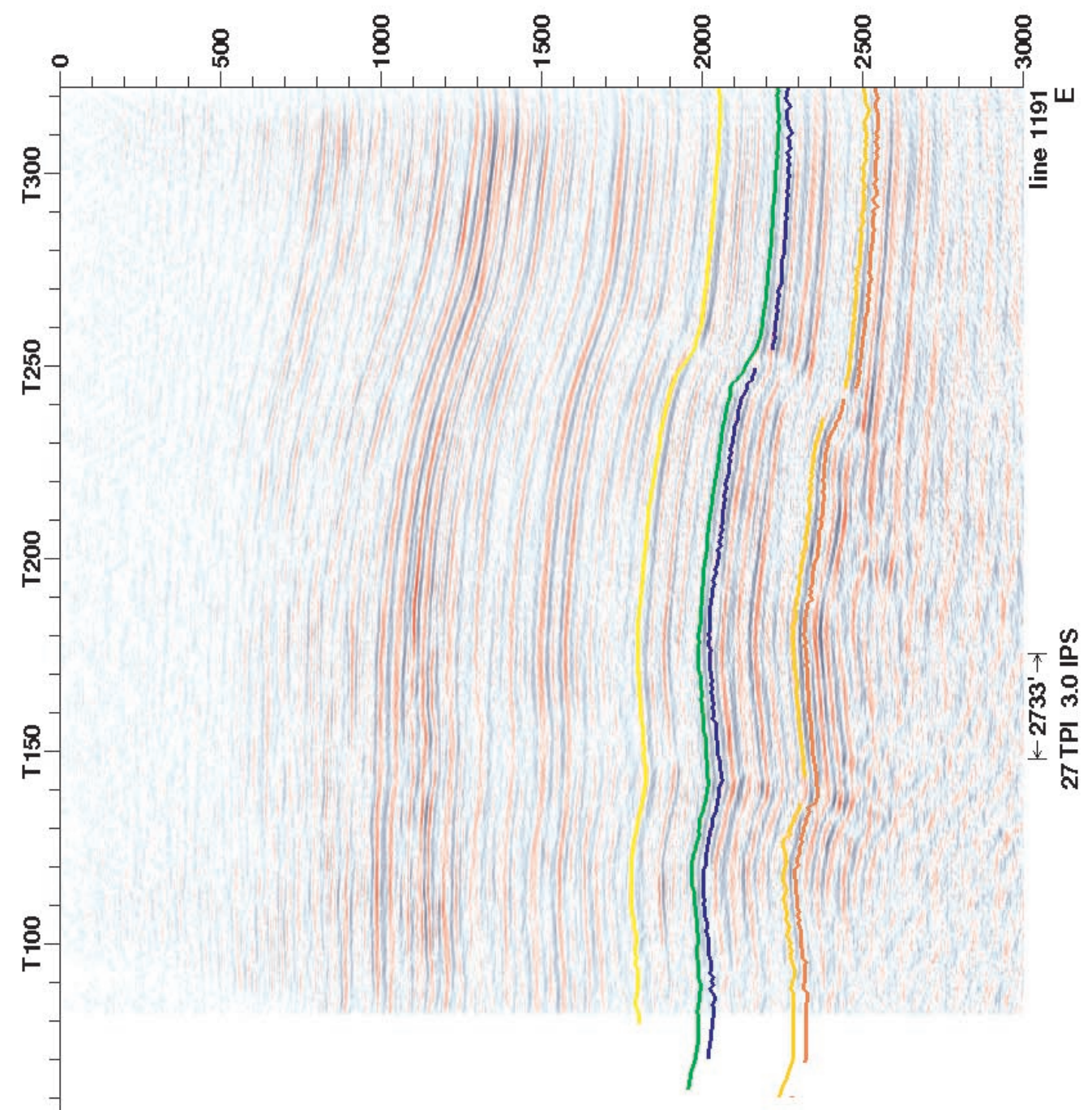

ํㅗㄴ

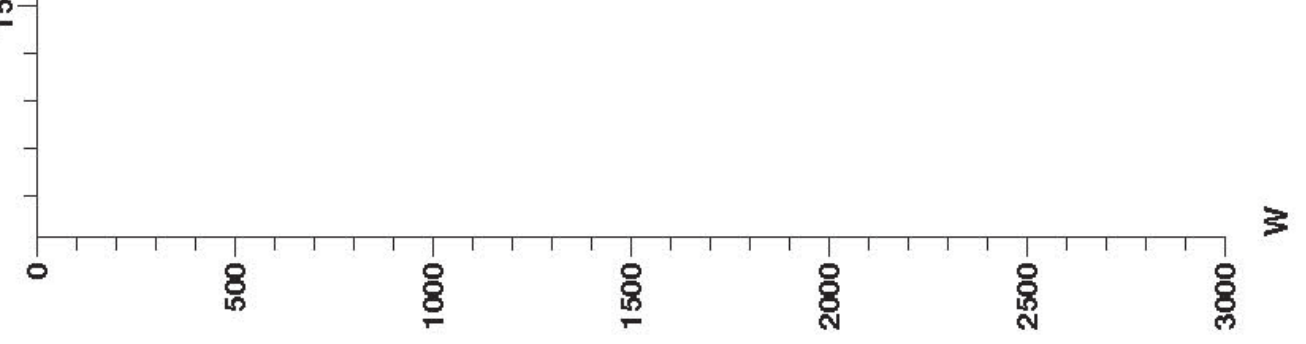




\section{岳}

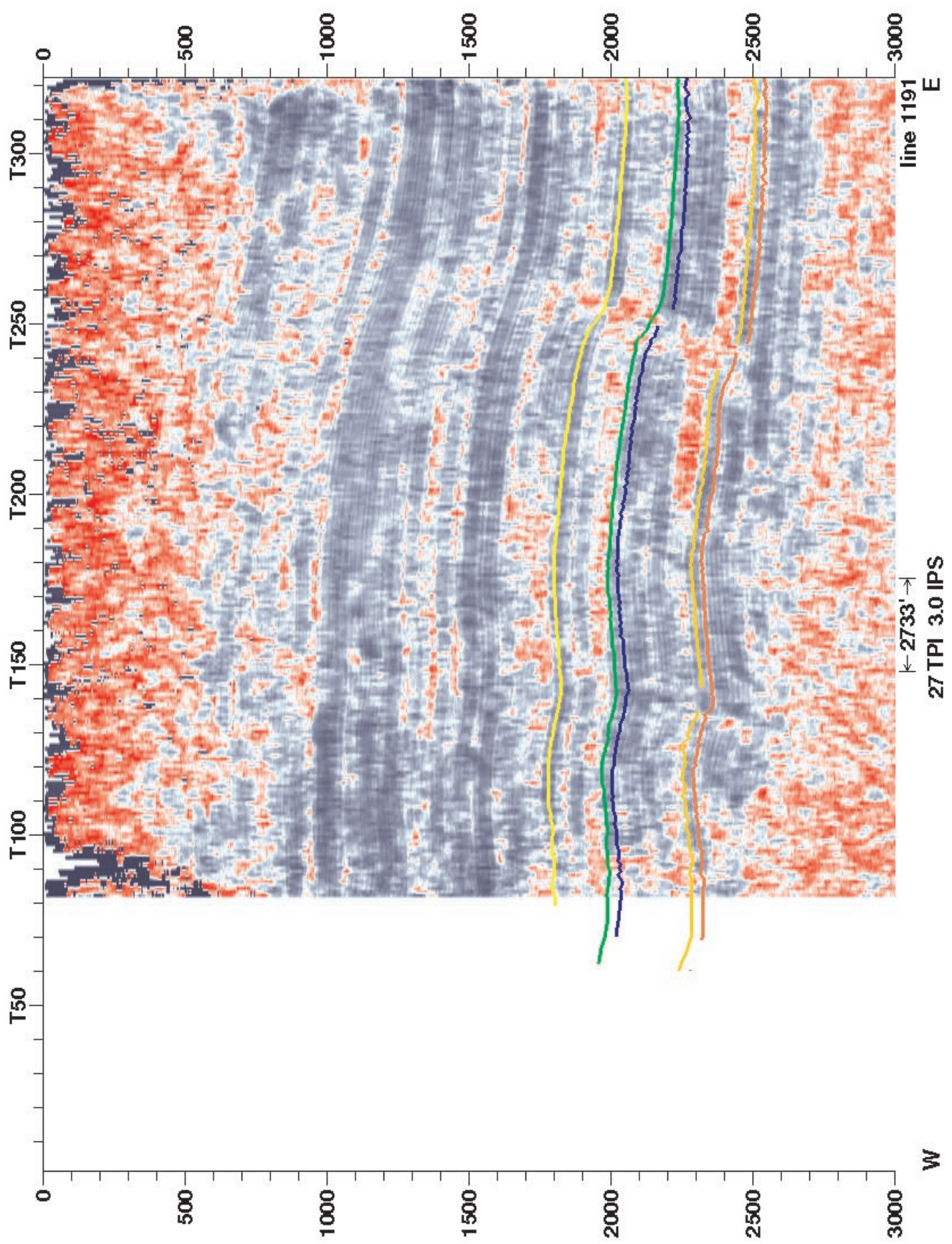




\section{䍃}

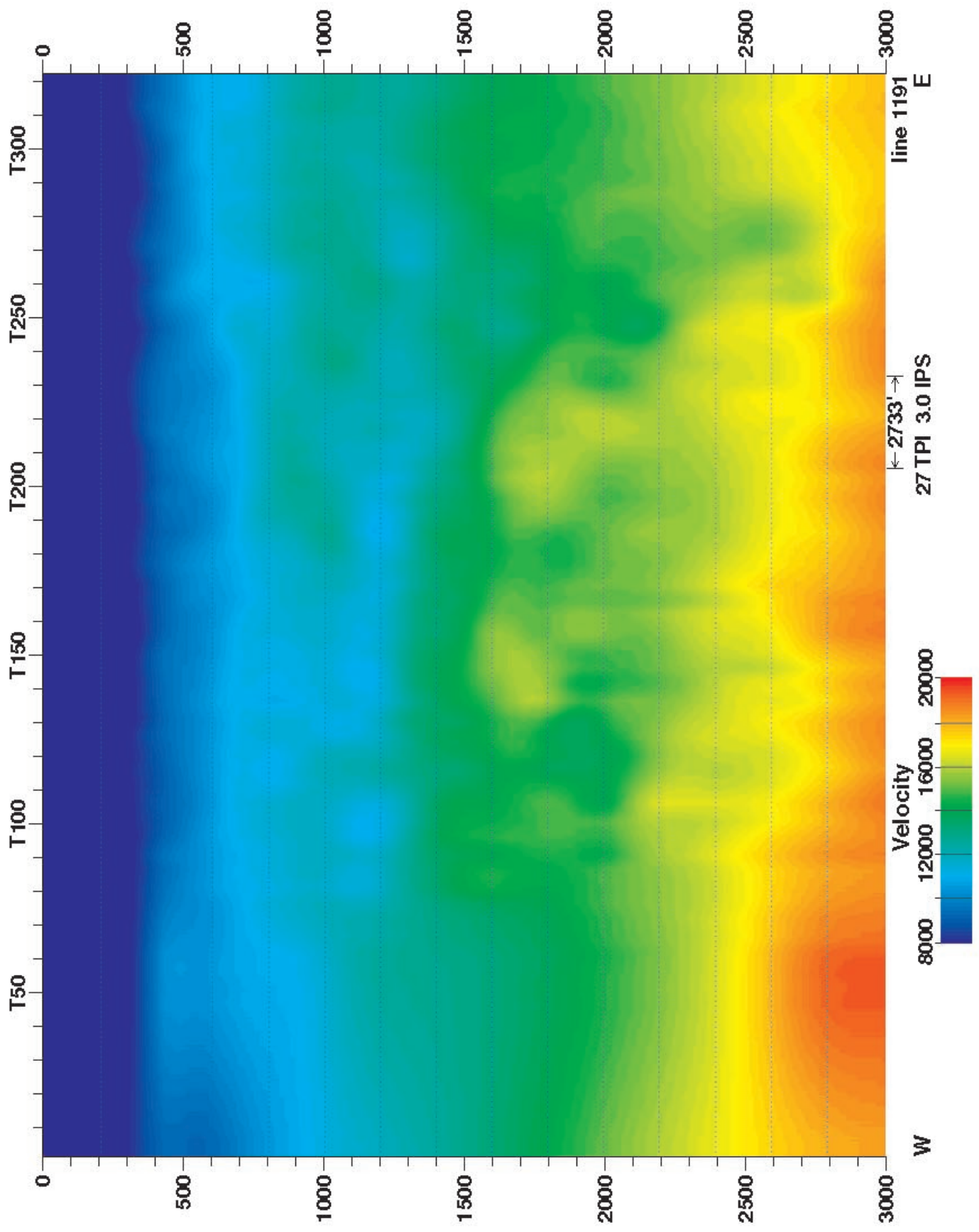




\section{舀}
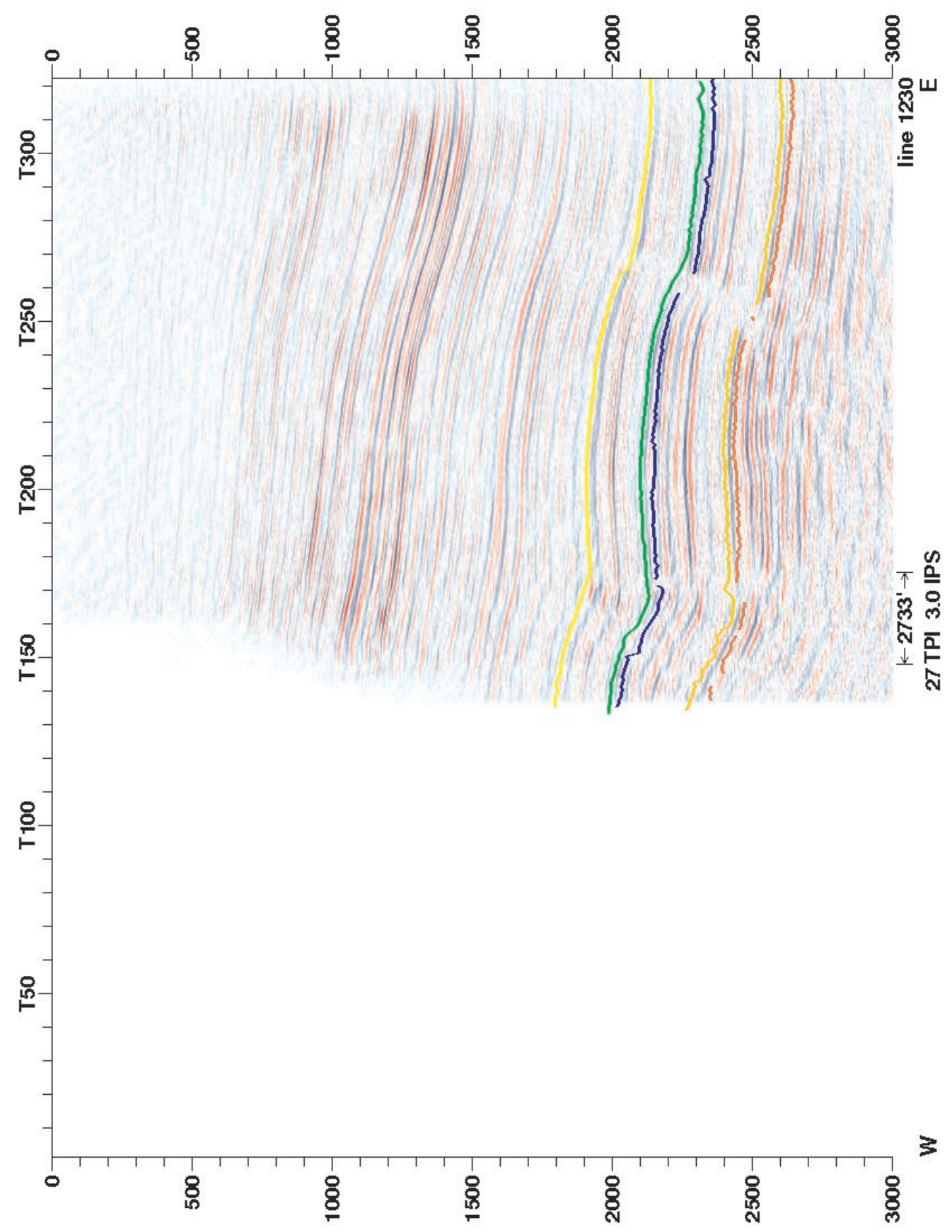
畐

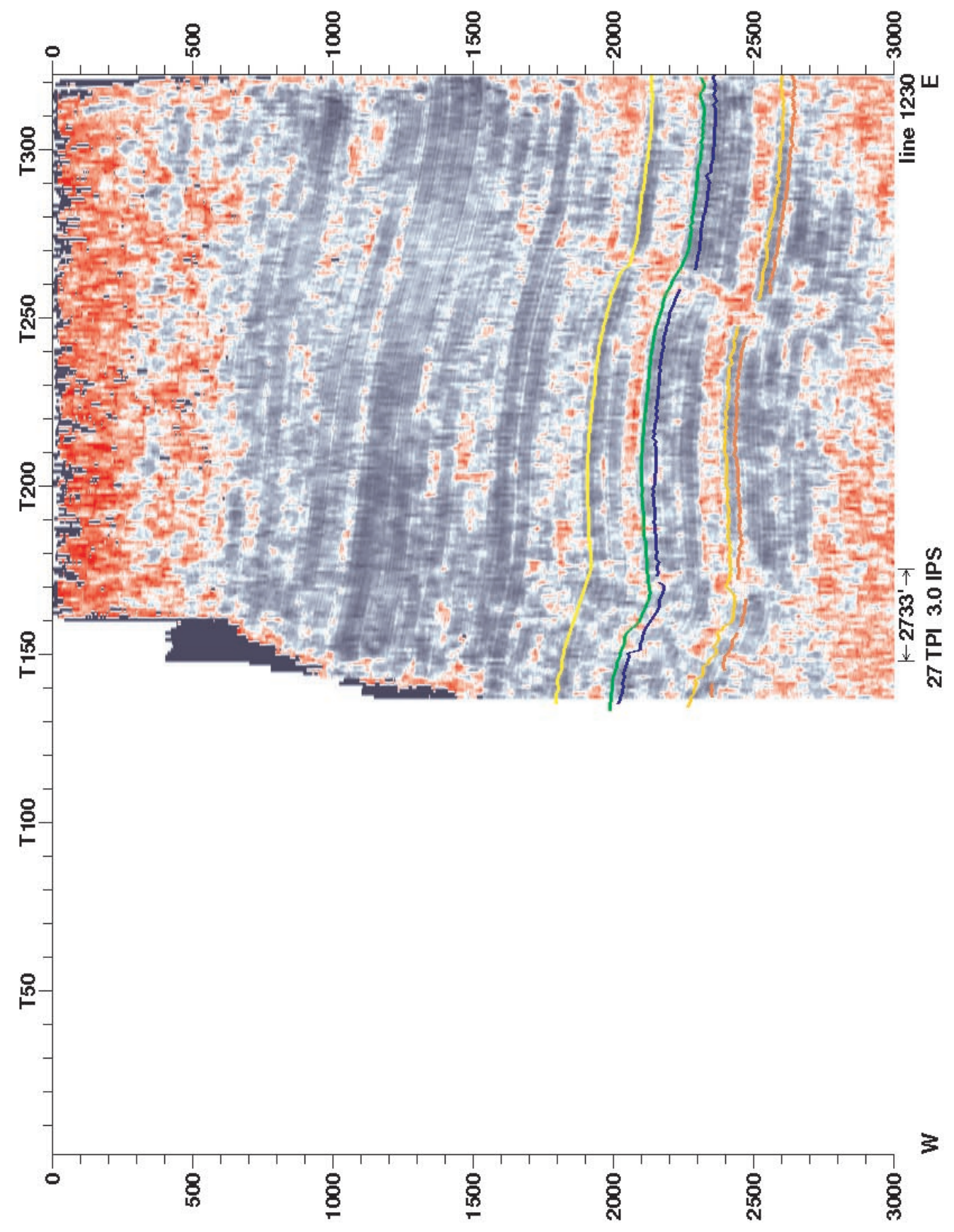




\section{岳}

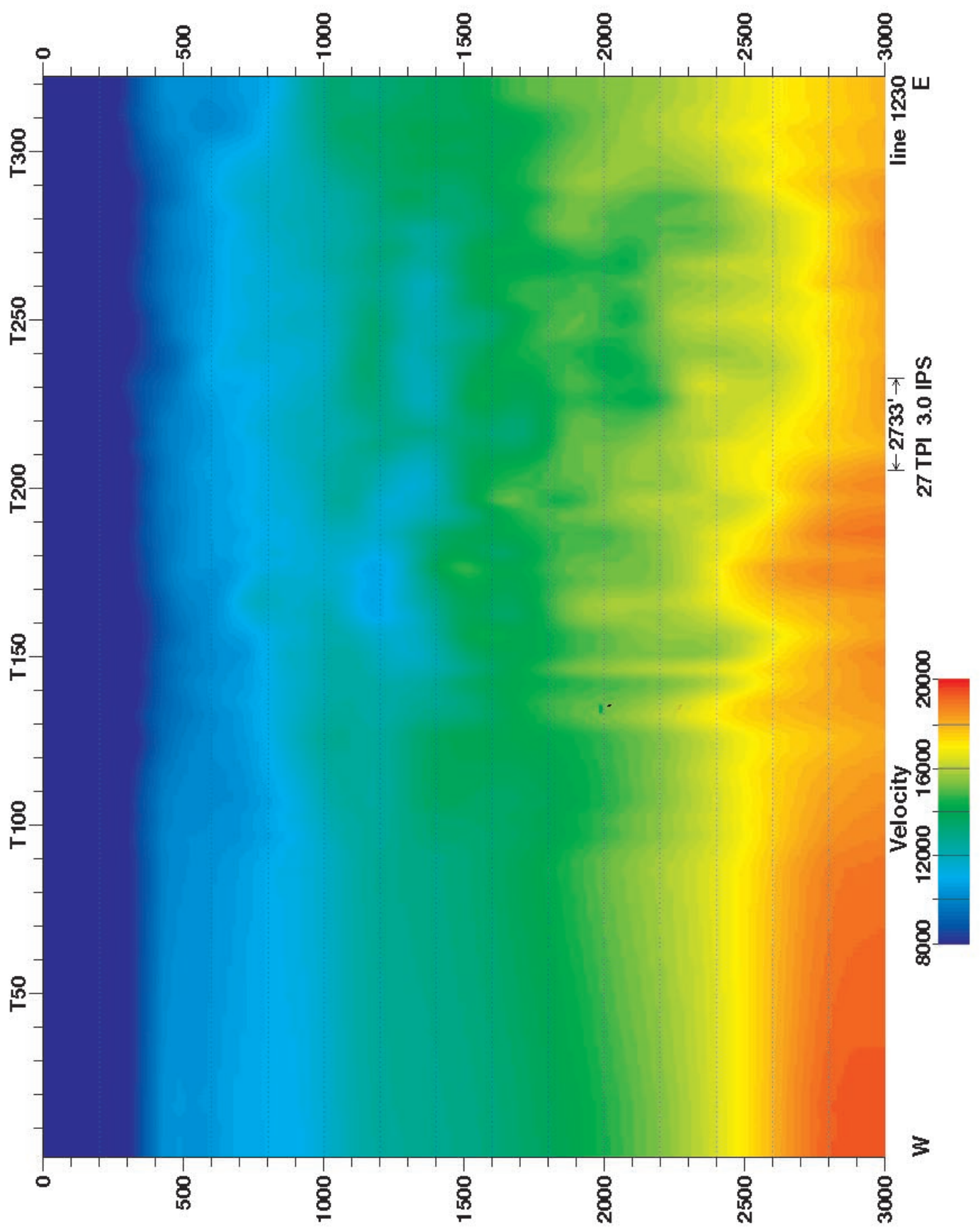


(1)
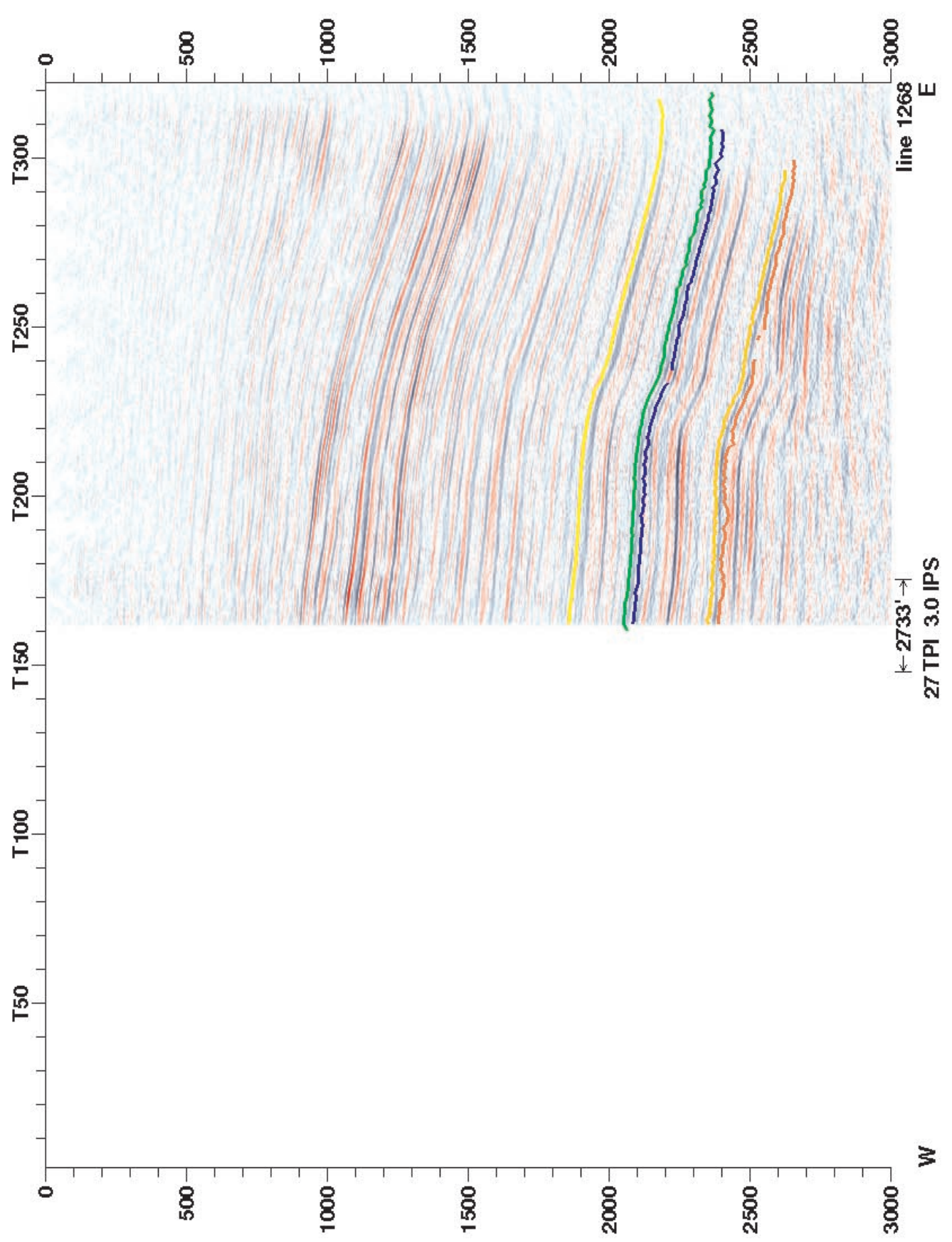


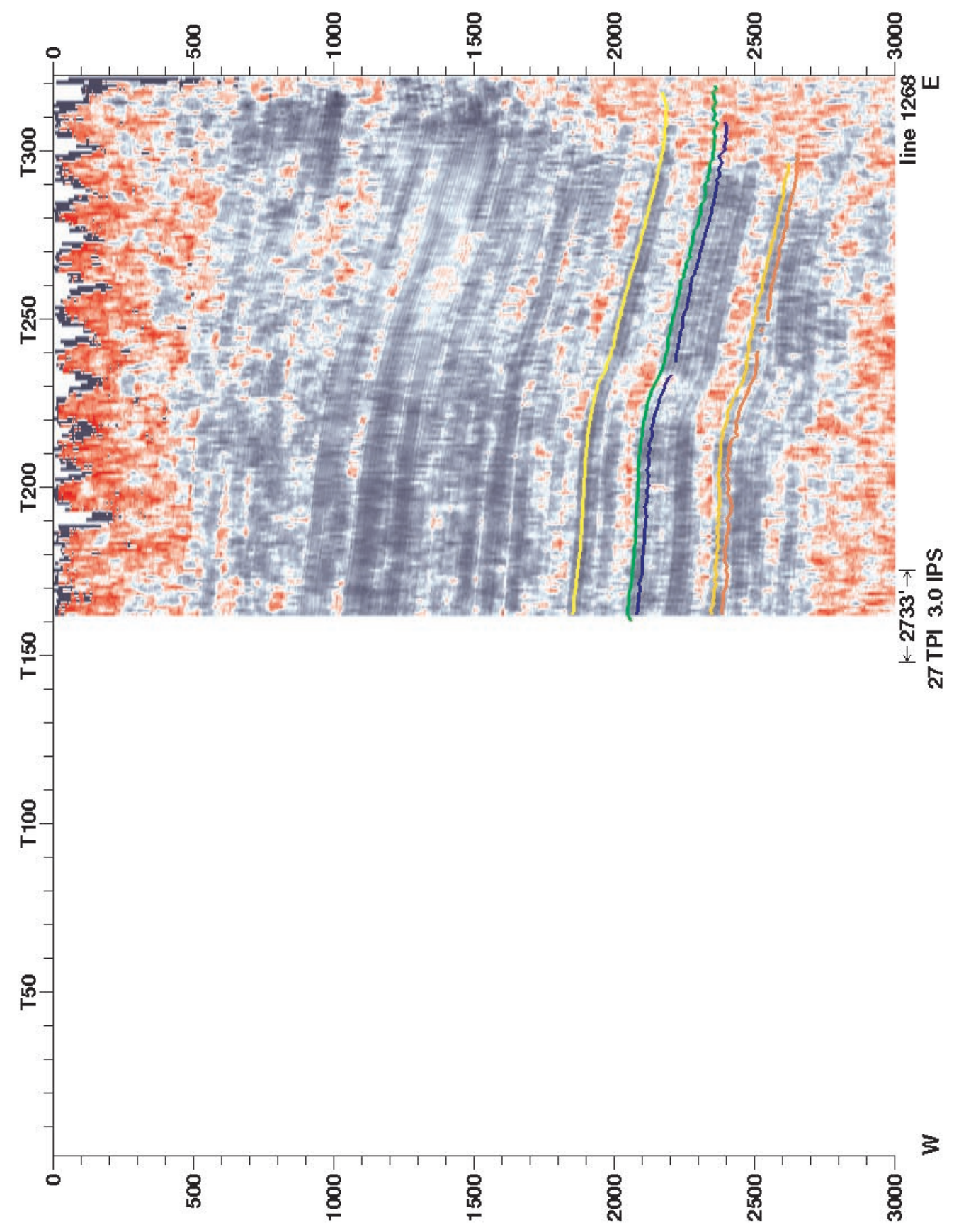




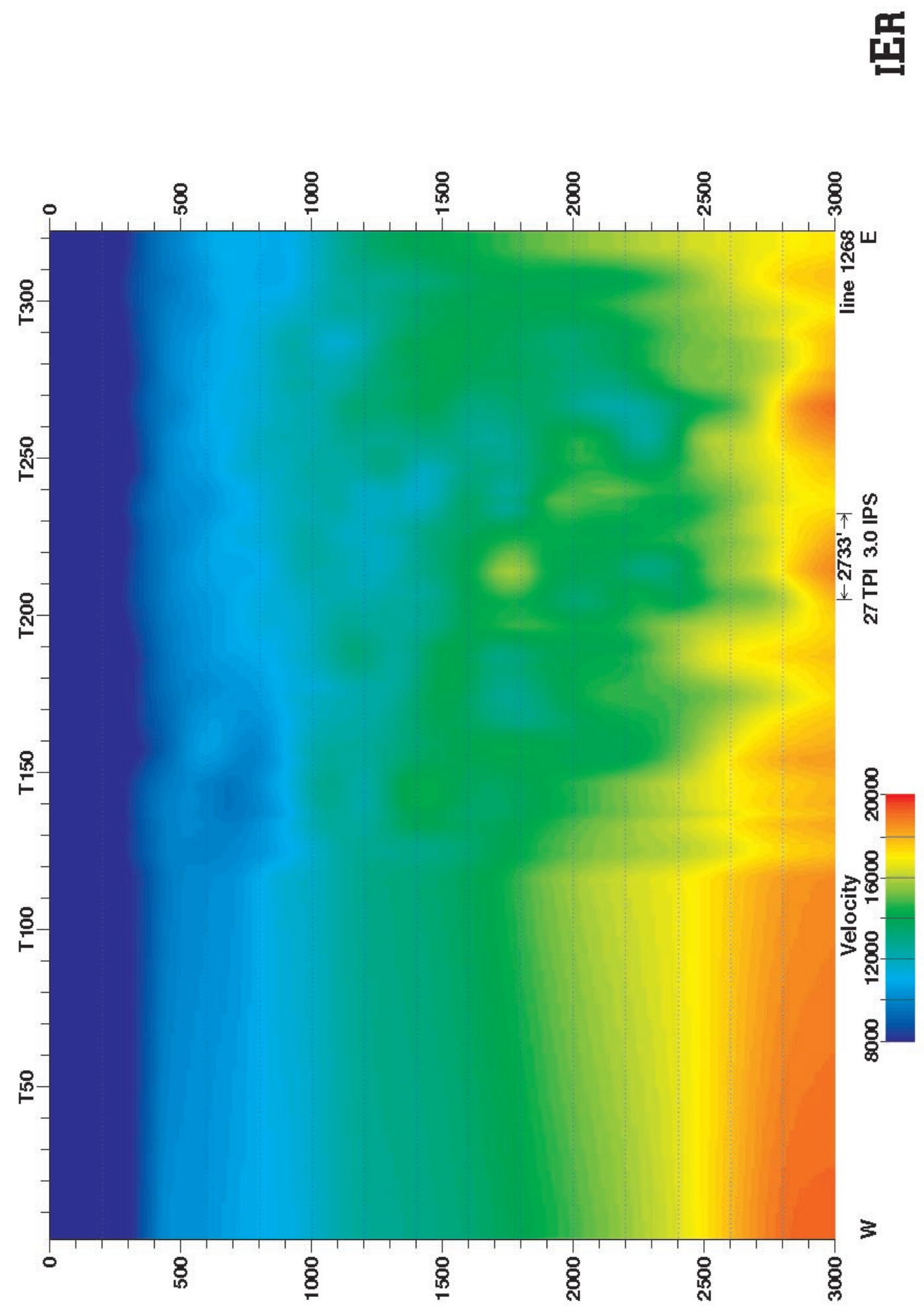


舀

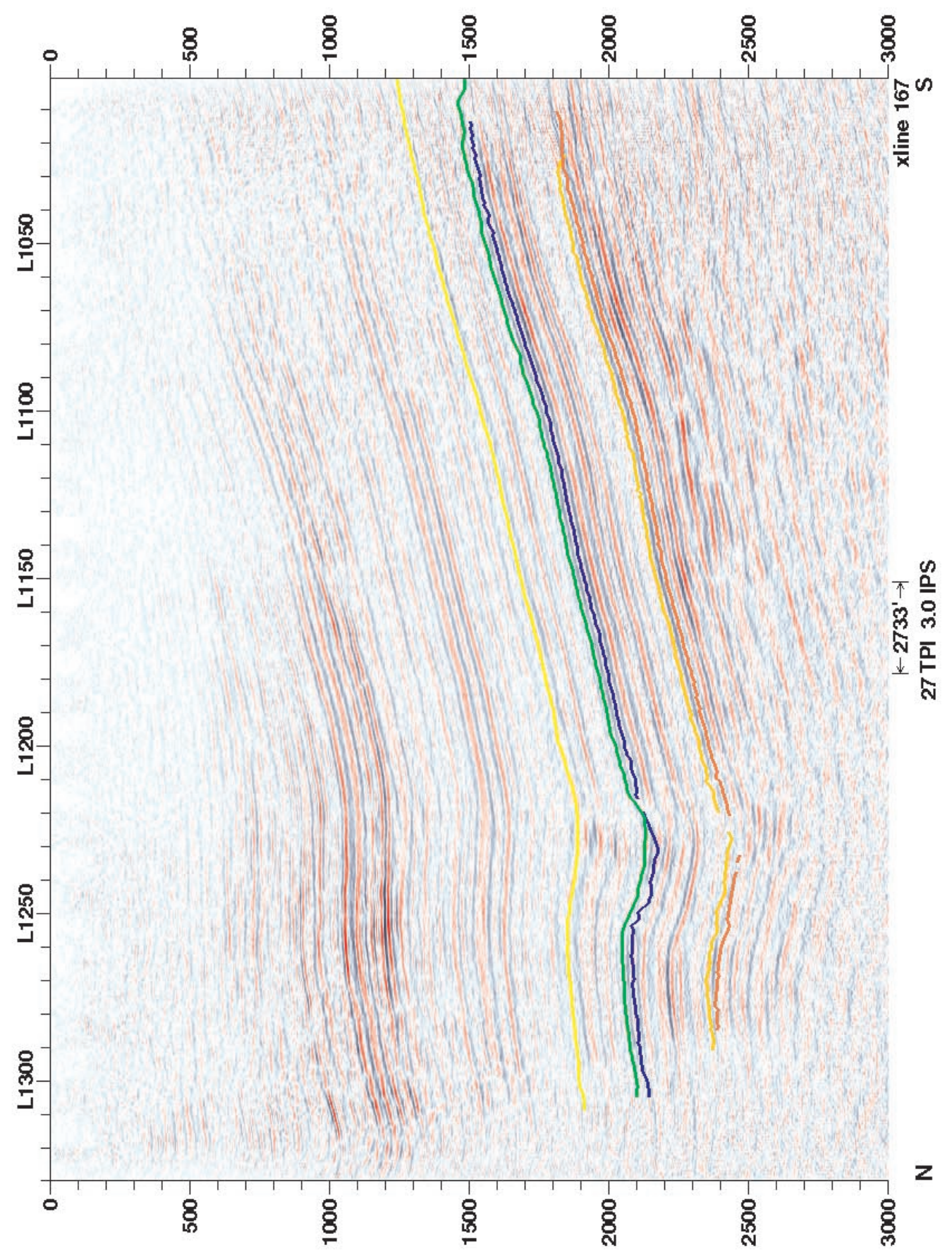




\section{䍃}

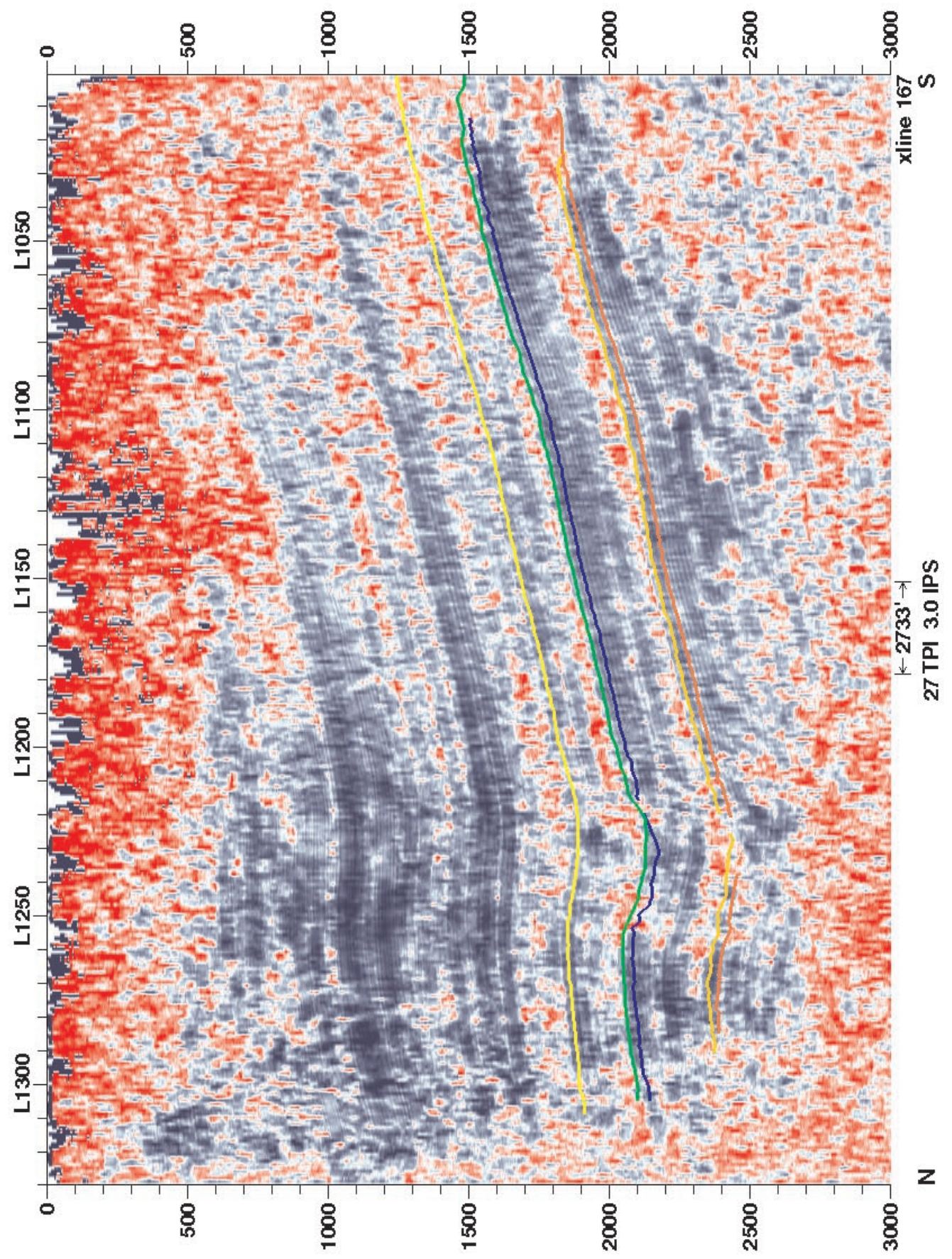




\section{岳}

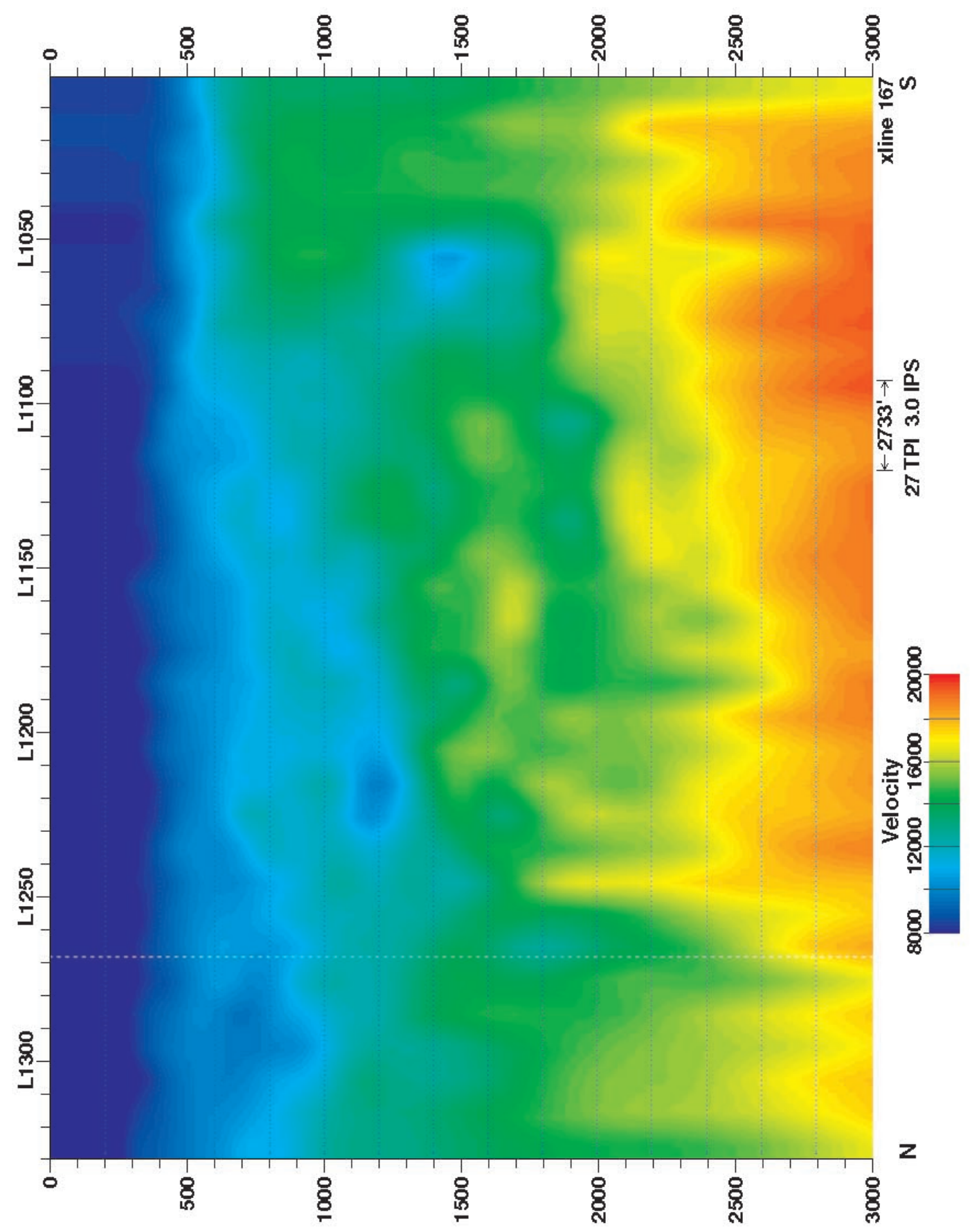




\section{Appendix II}

Contour maps of the top of the Frontier and Muddy formations in time (msec) and anomalous velocity pro les cons tructed a DPs (98437, \$5277, (85596, (85606, 669406, 66277, (56496, 050146, 040417, 040316, 037106, 037257, 017936, 017887, and 017897. Anomalous velocity pro les at CDPs 075886, 004957, and 27526 are included in Appendix II for purposes of comparison (e.g., these three CDPs are not associated with any velocity anomalies; see Figure 36 for locations). 

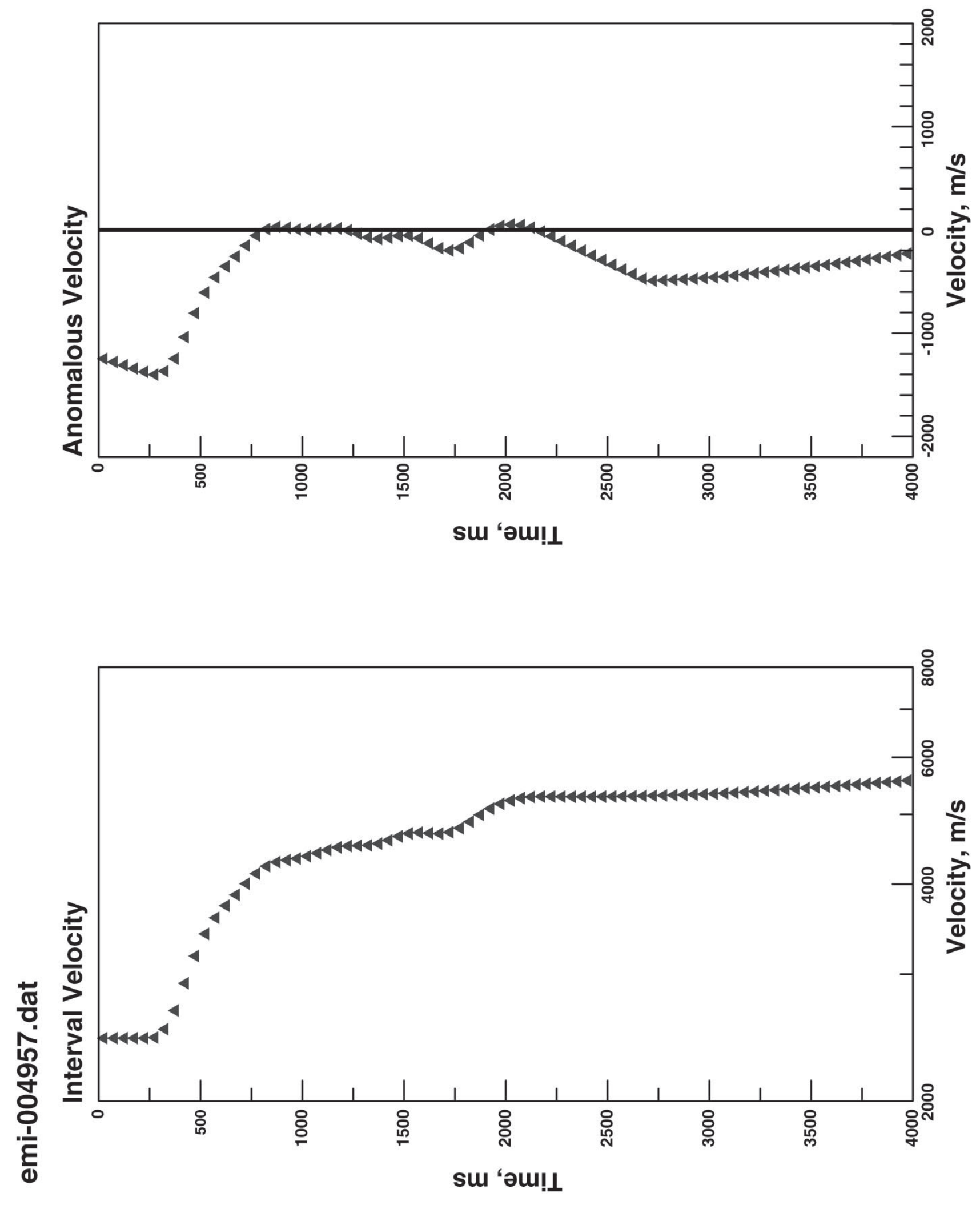

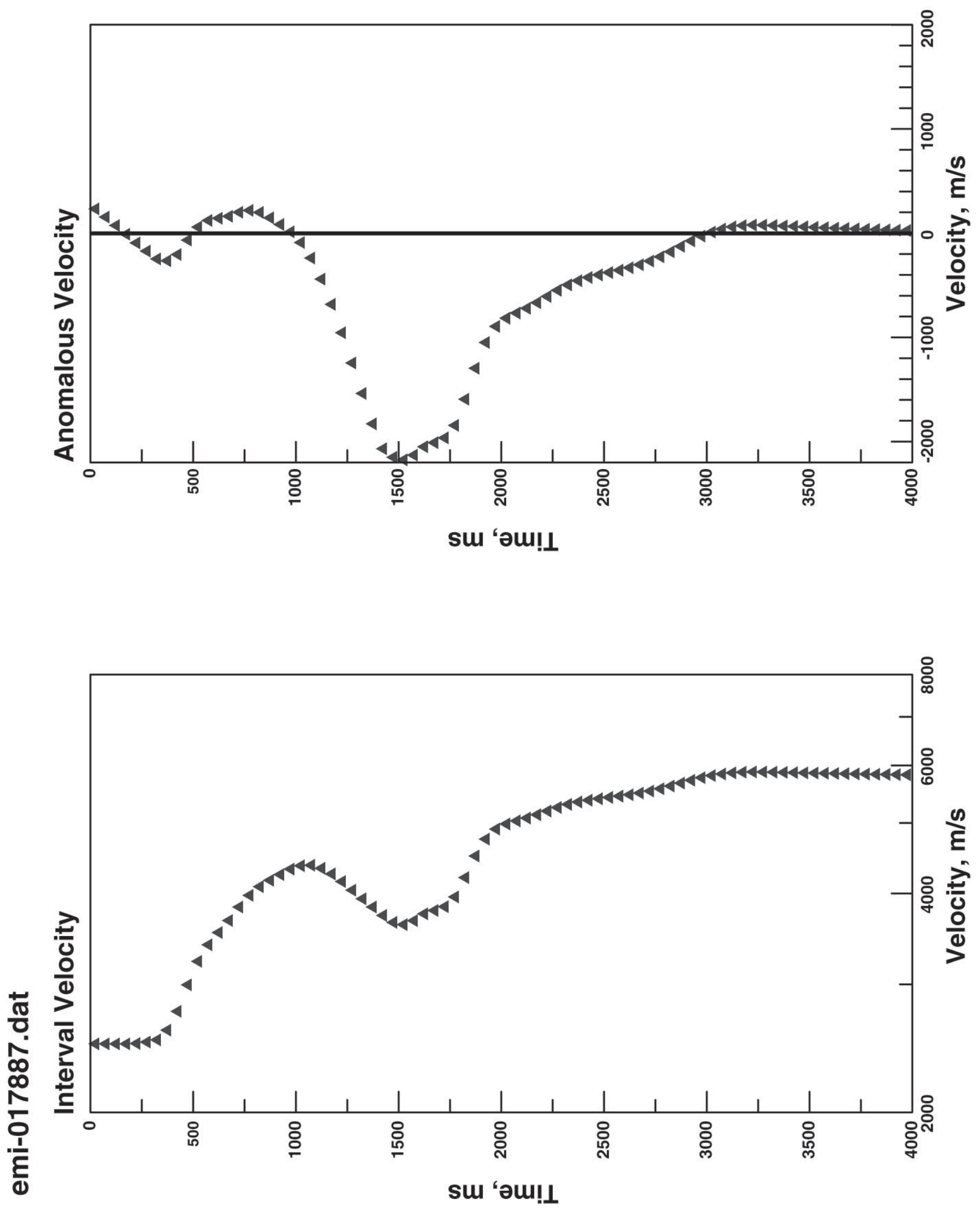

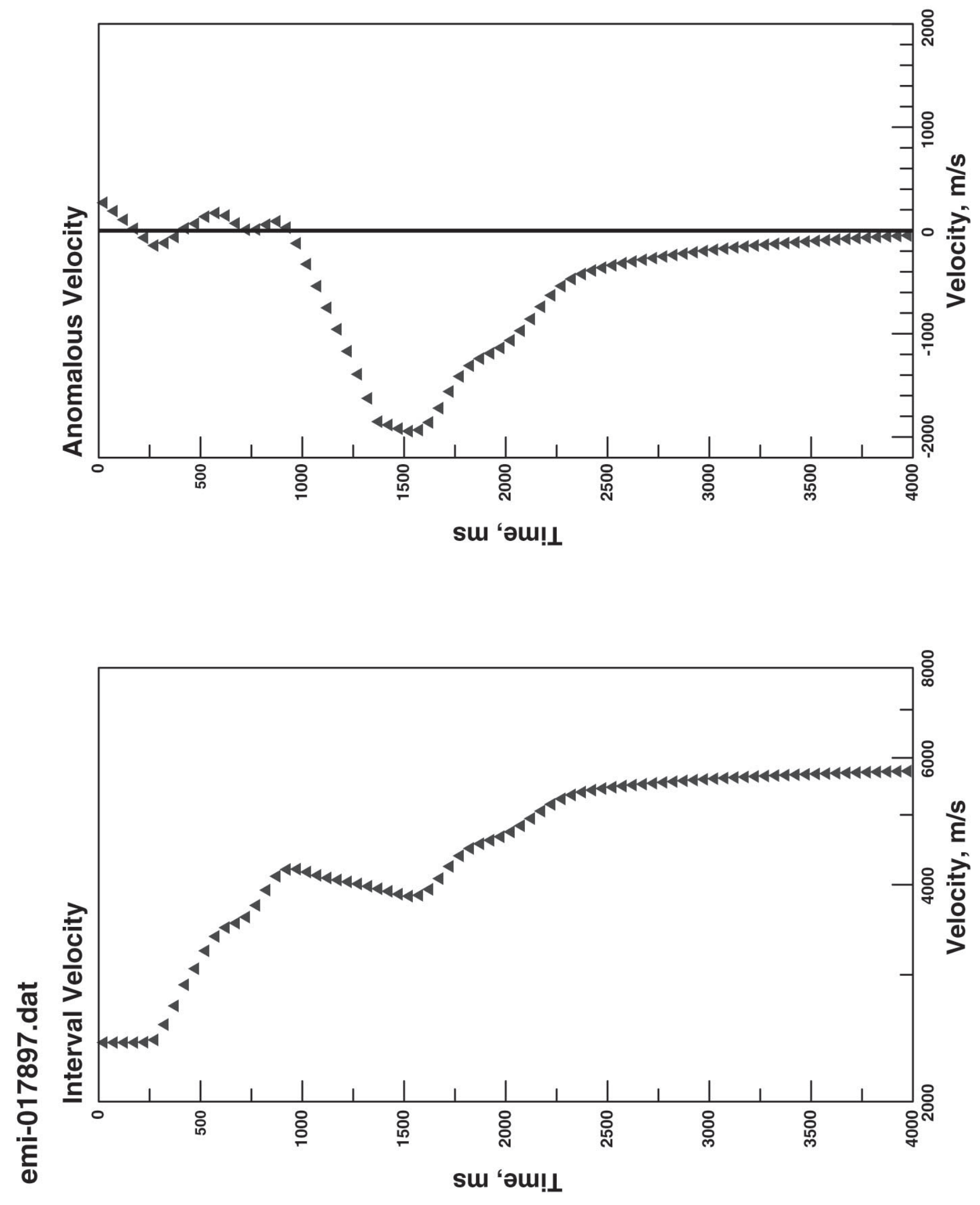

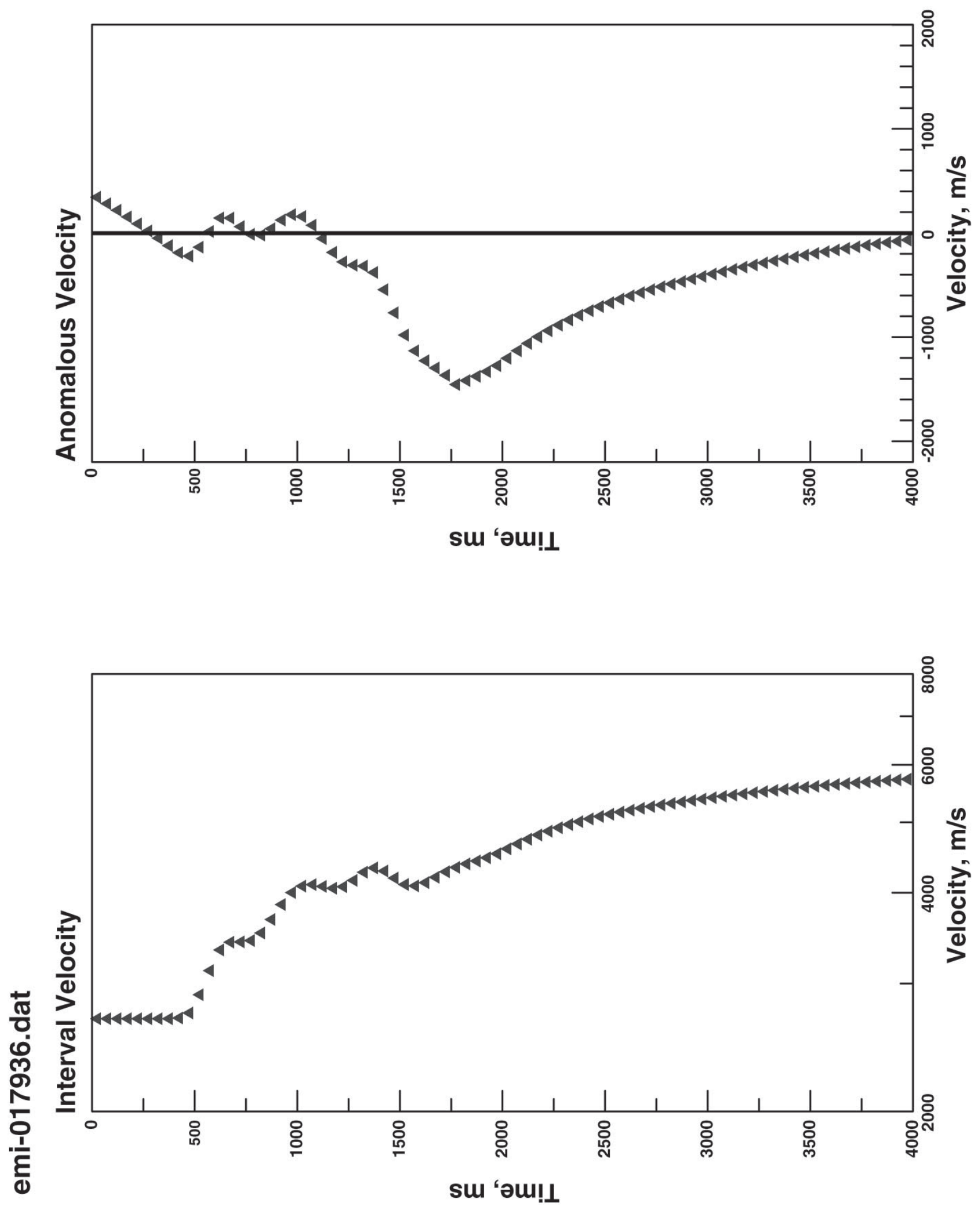

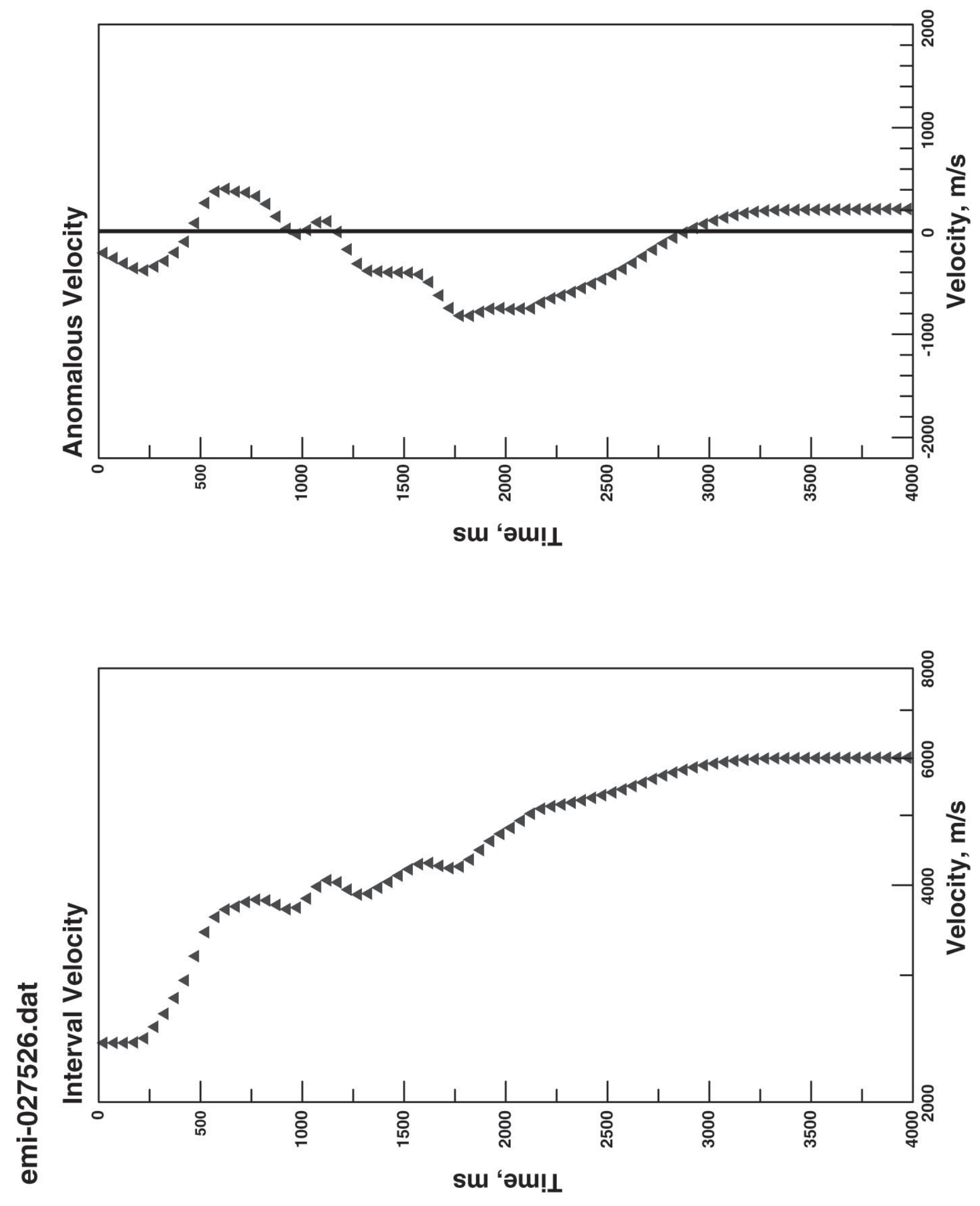

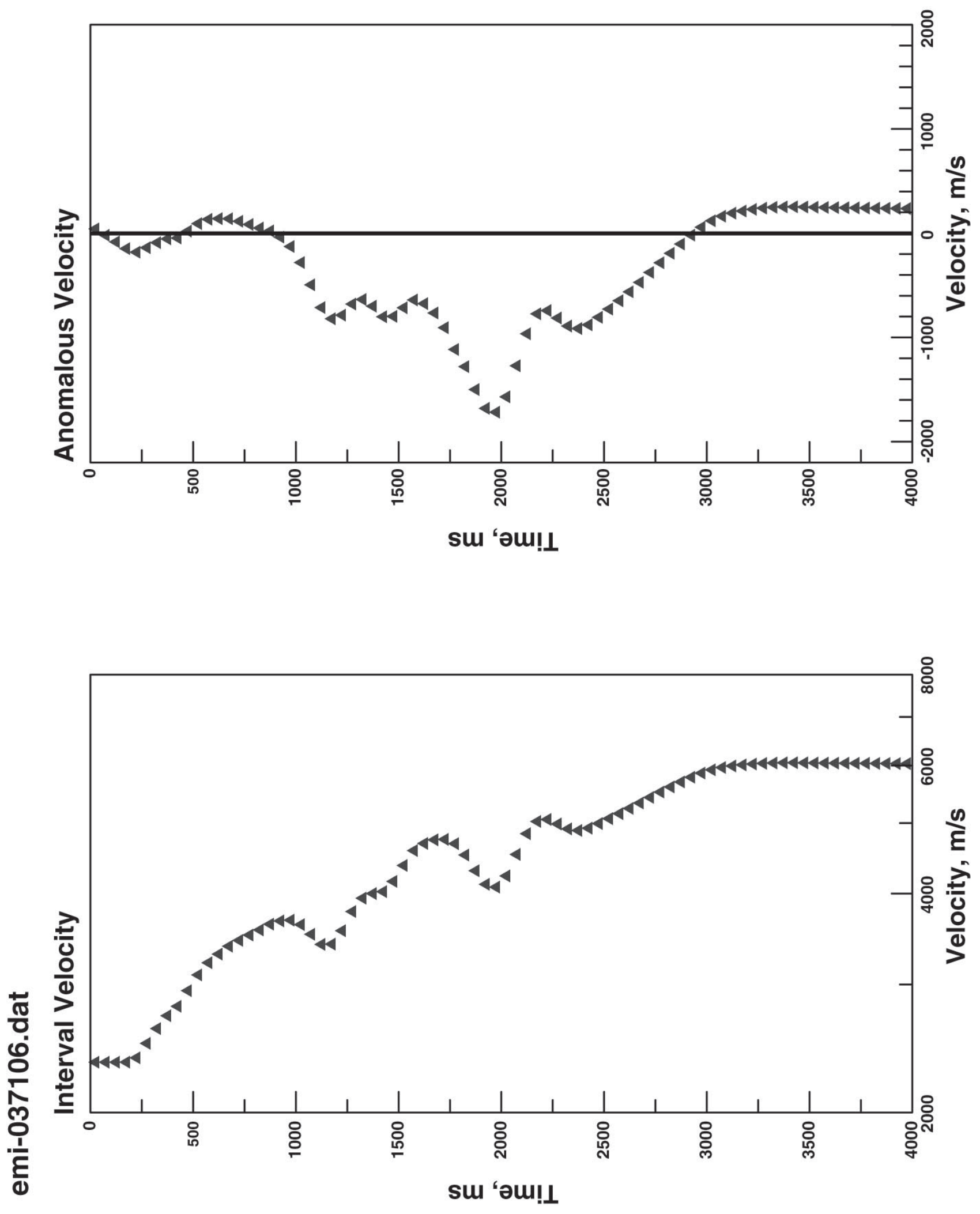

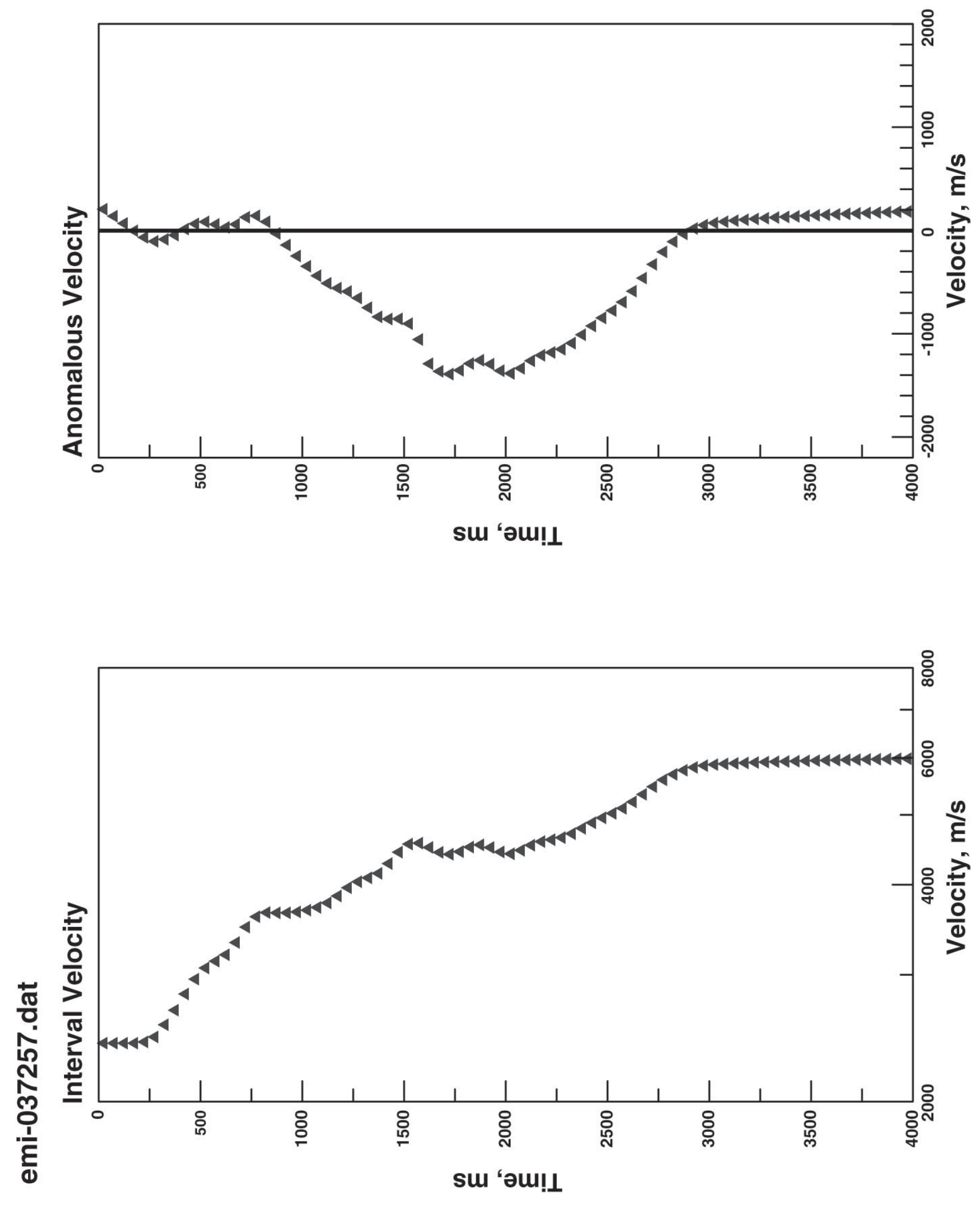

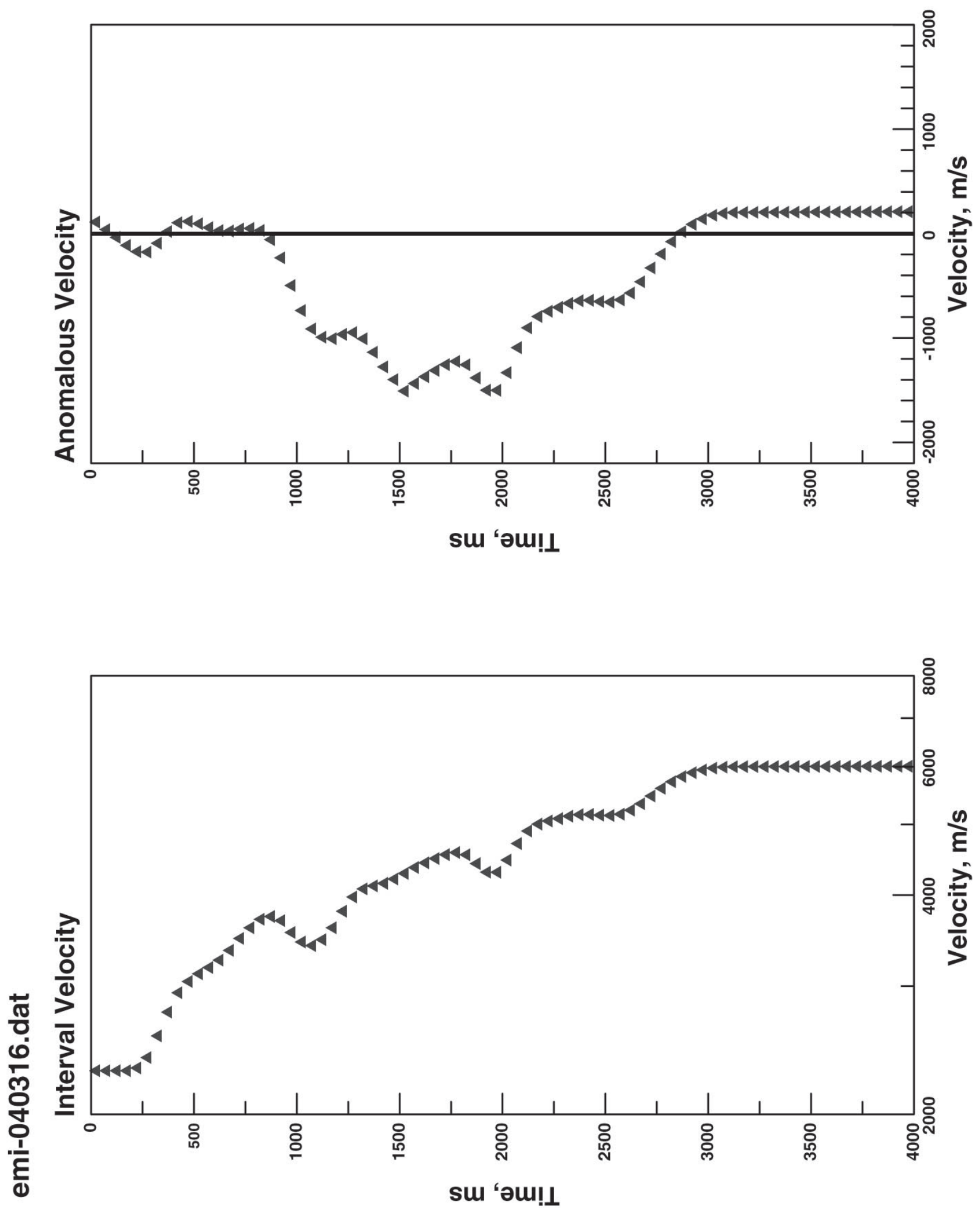

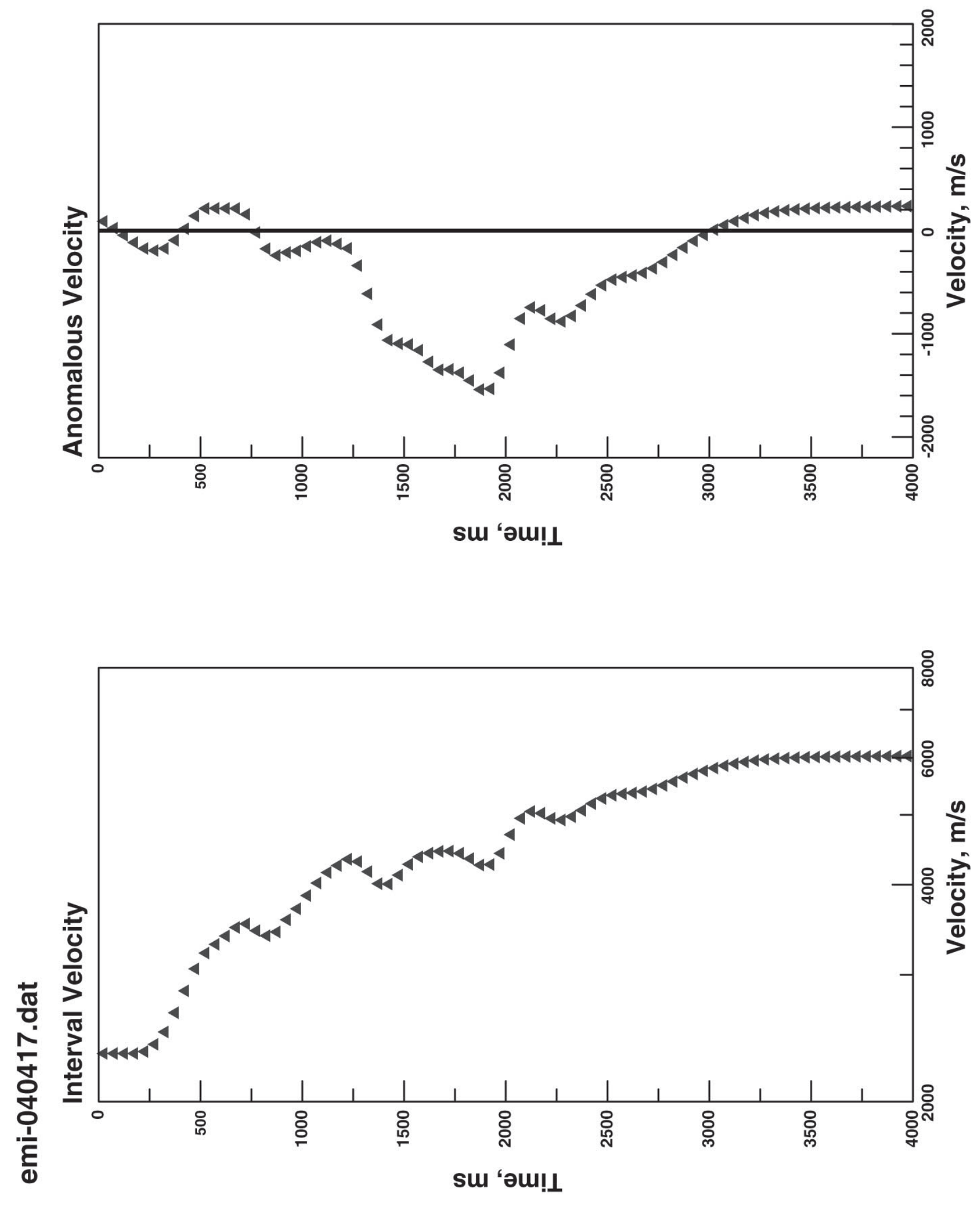

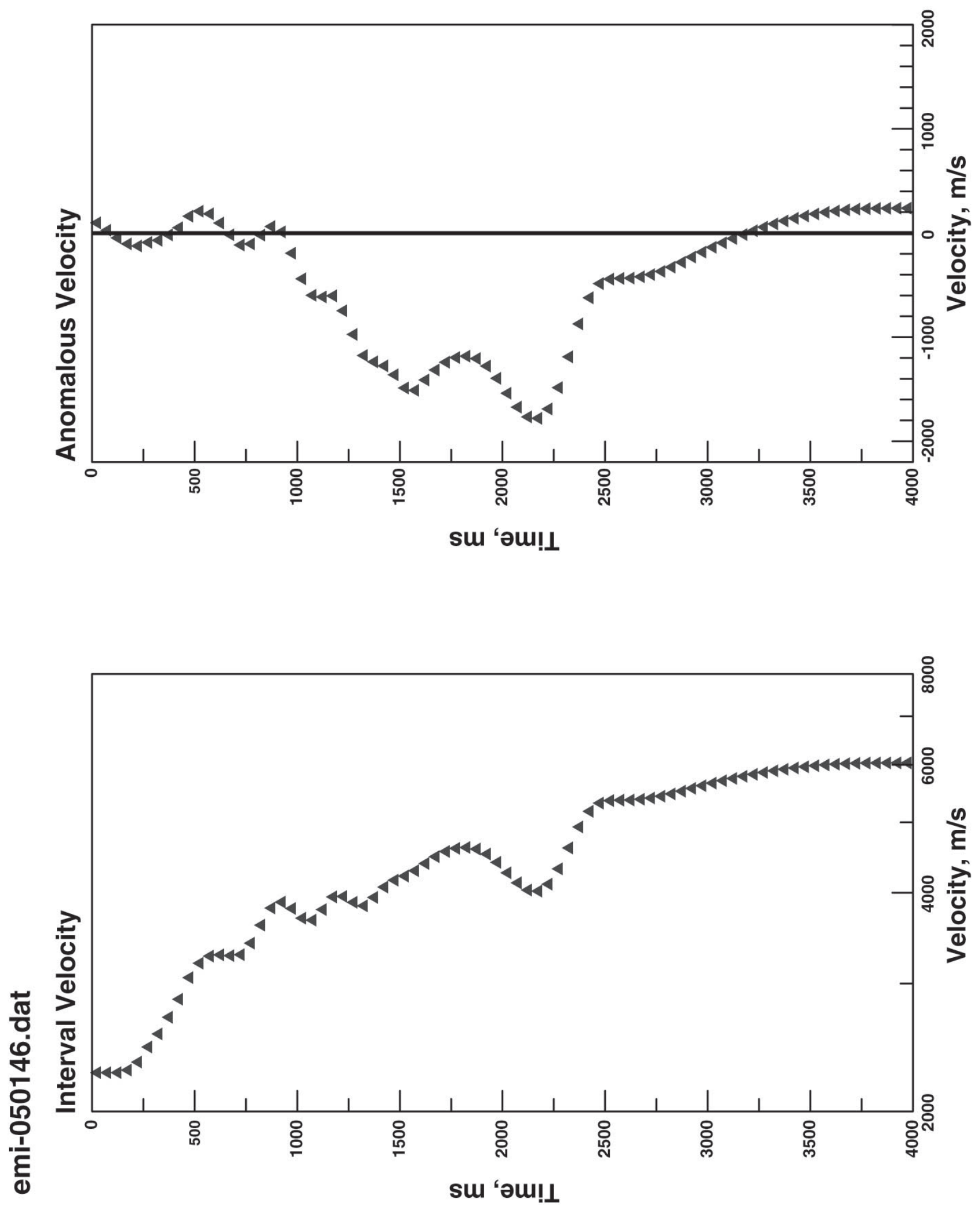

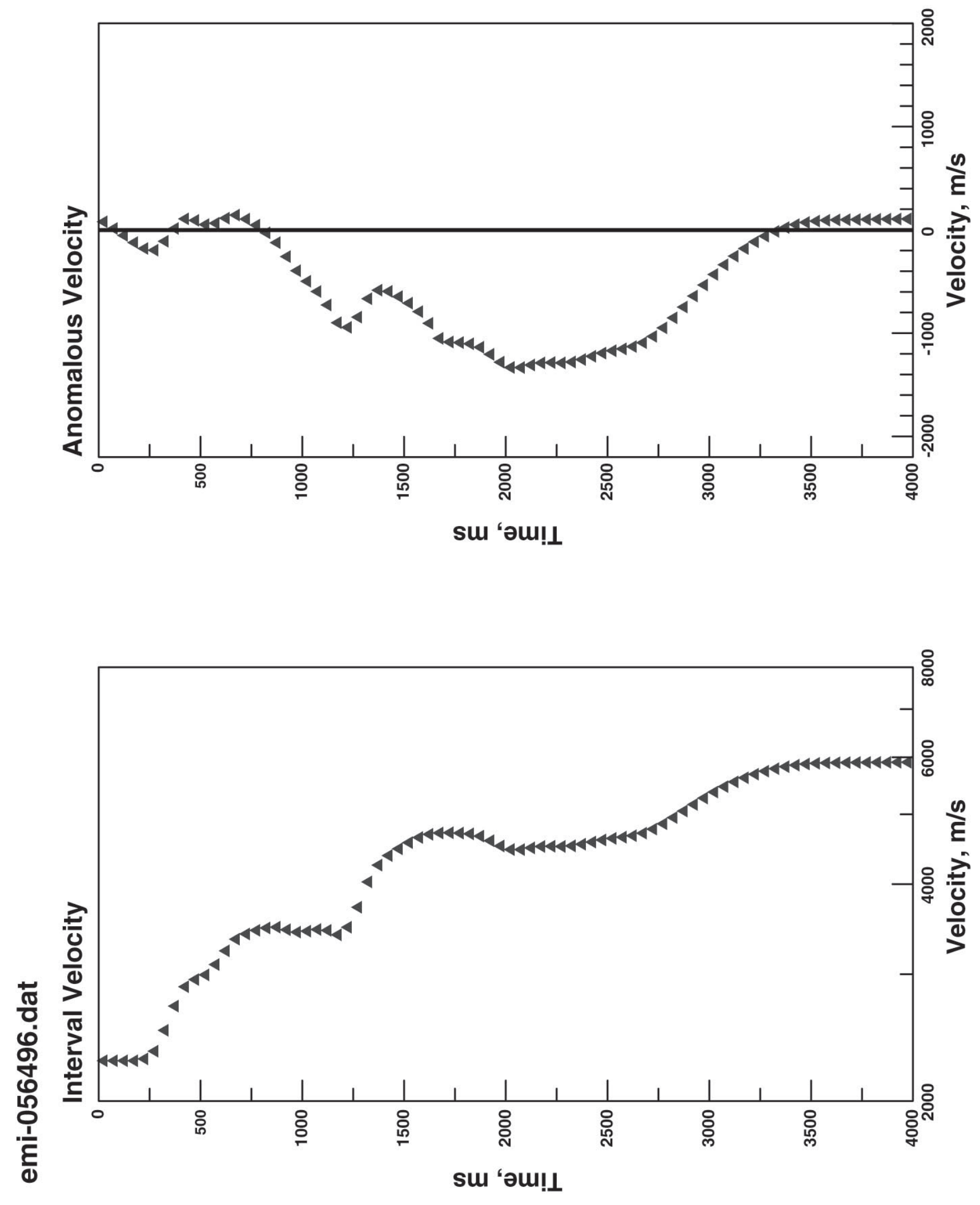

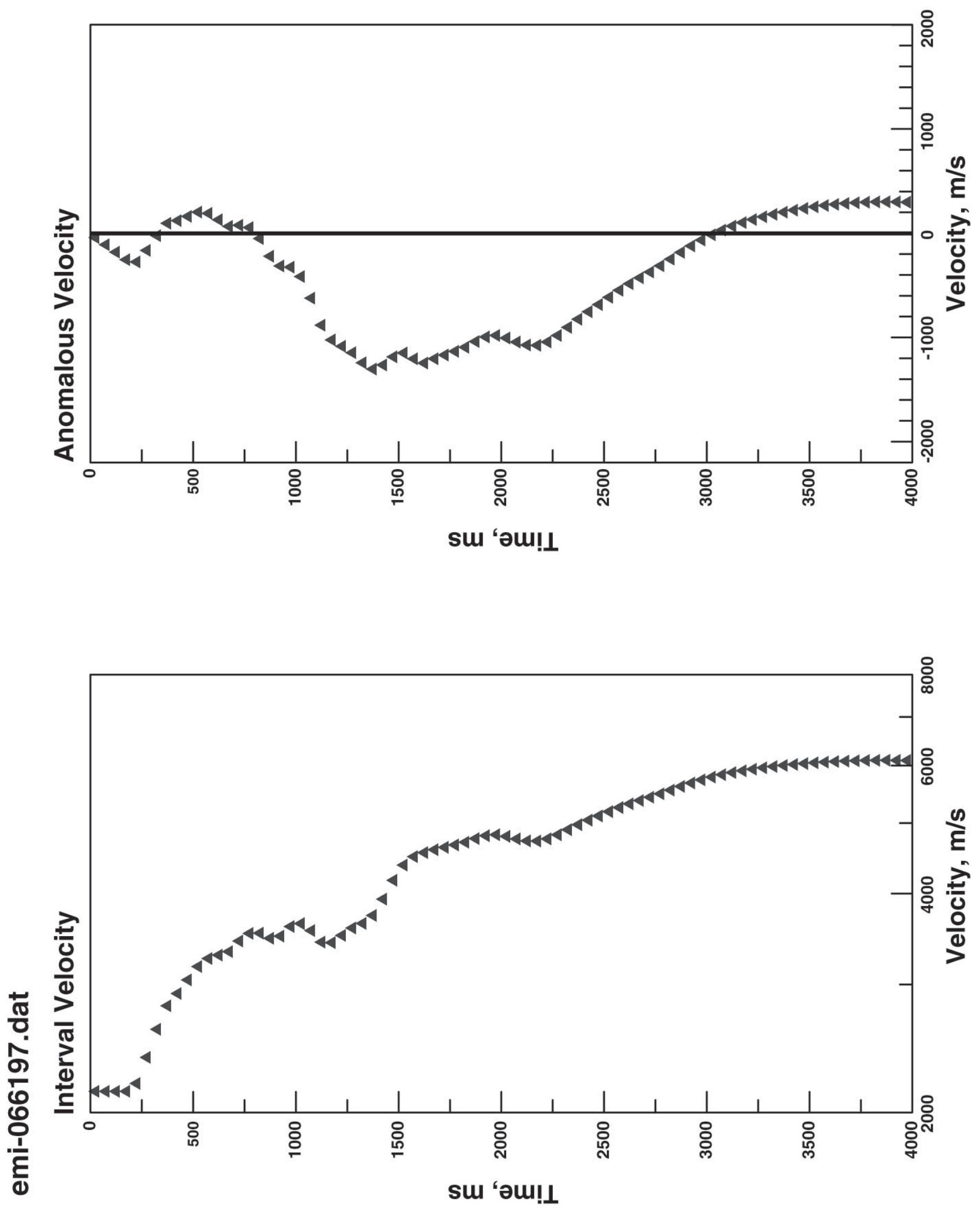

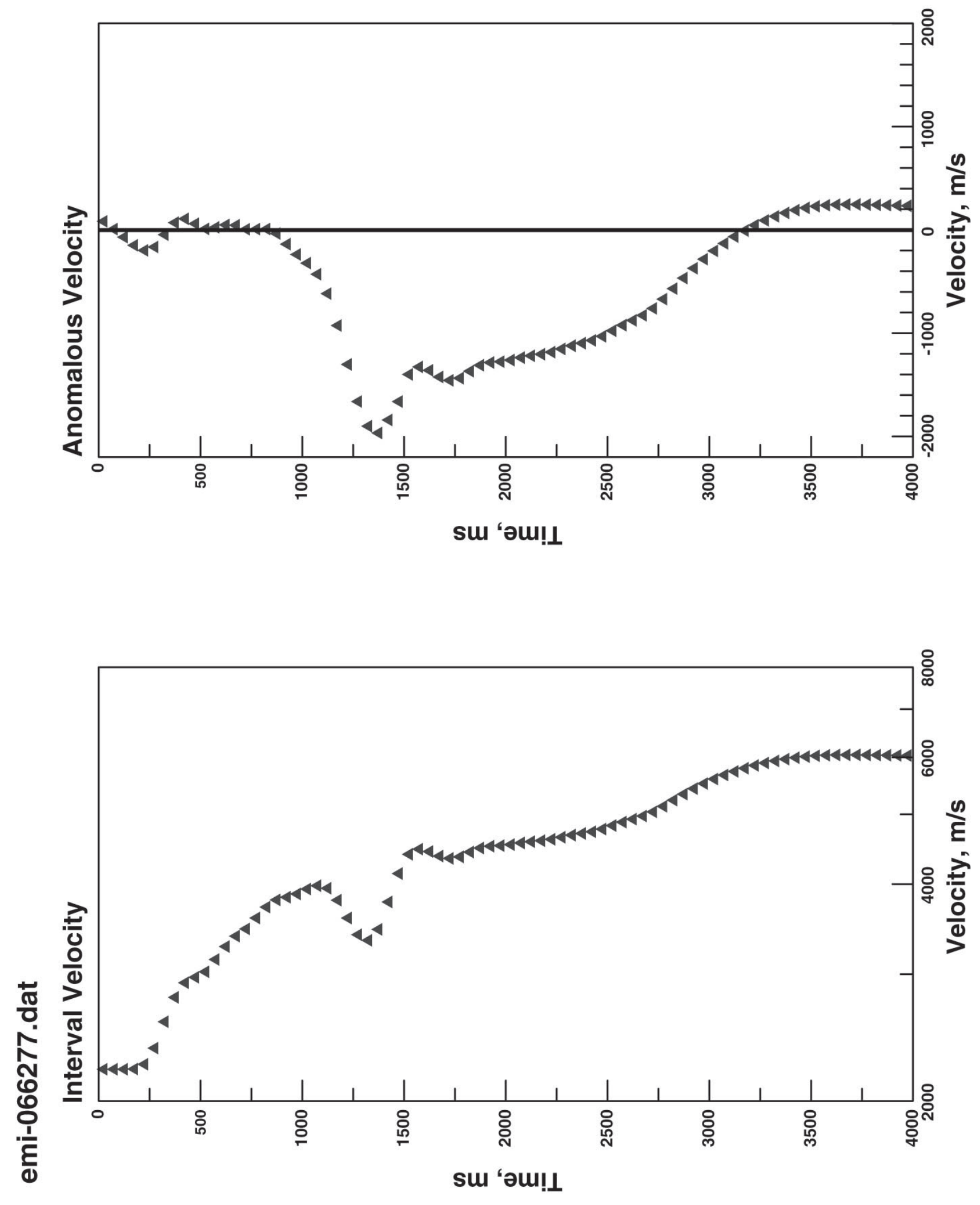

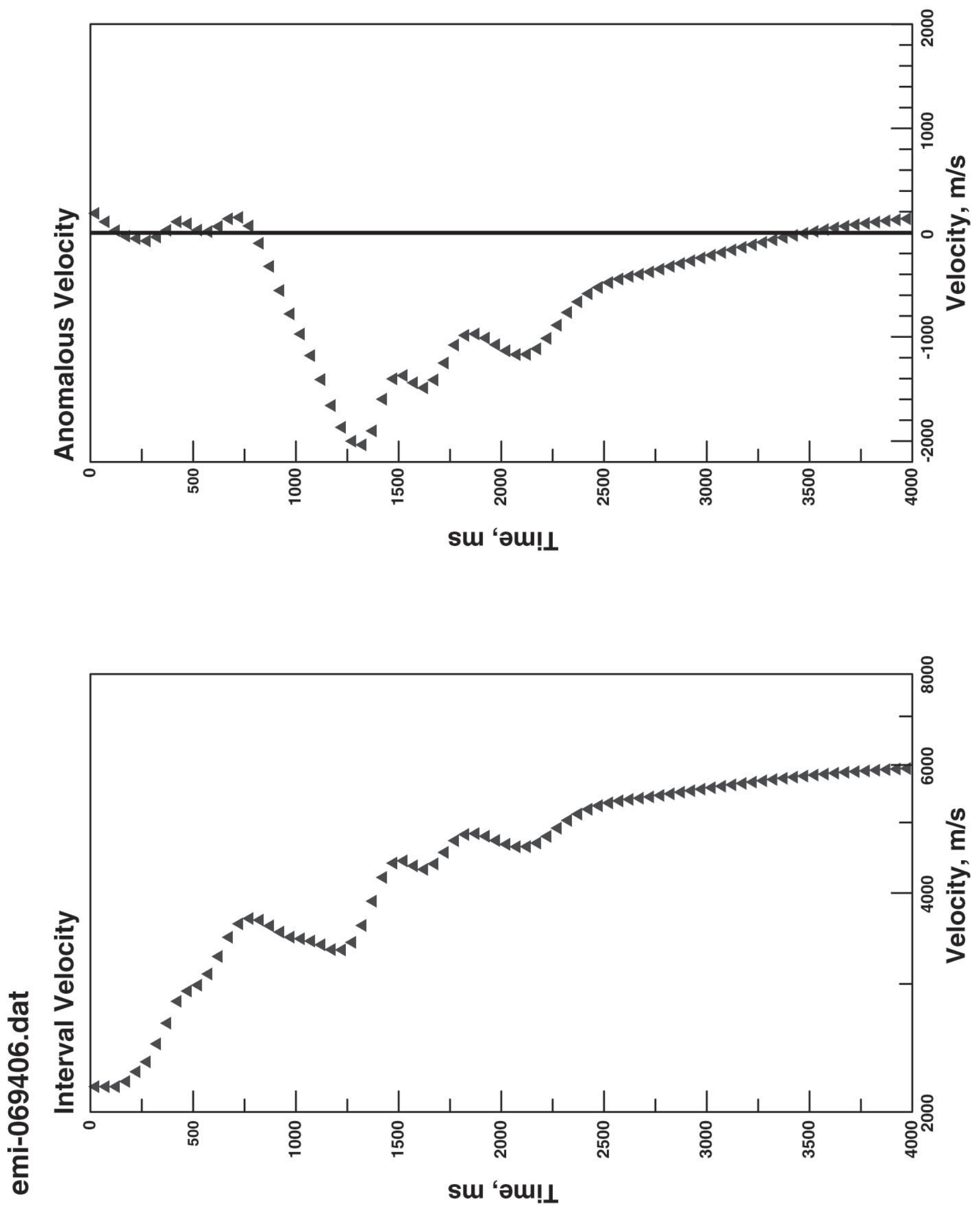

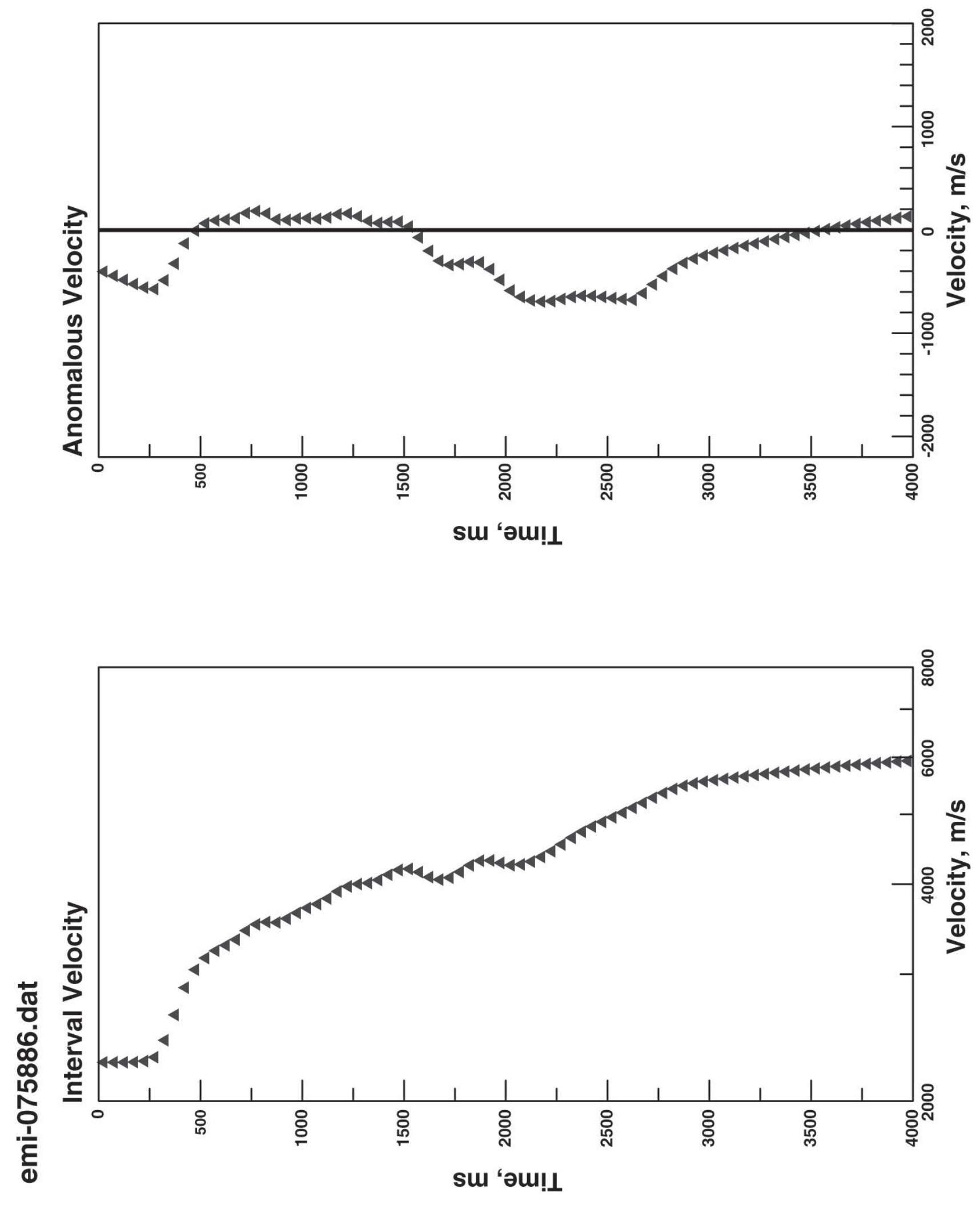

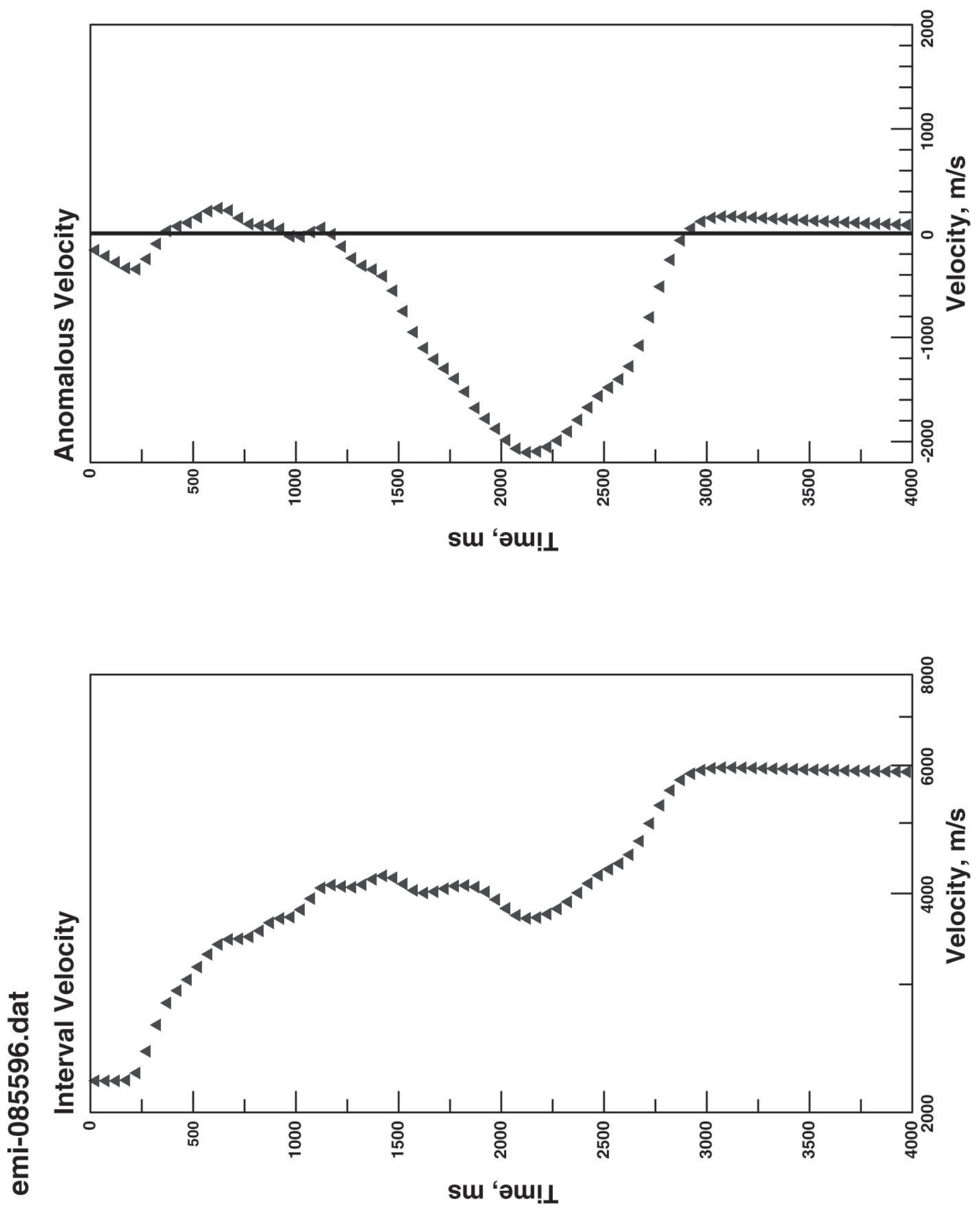

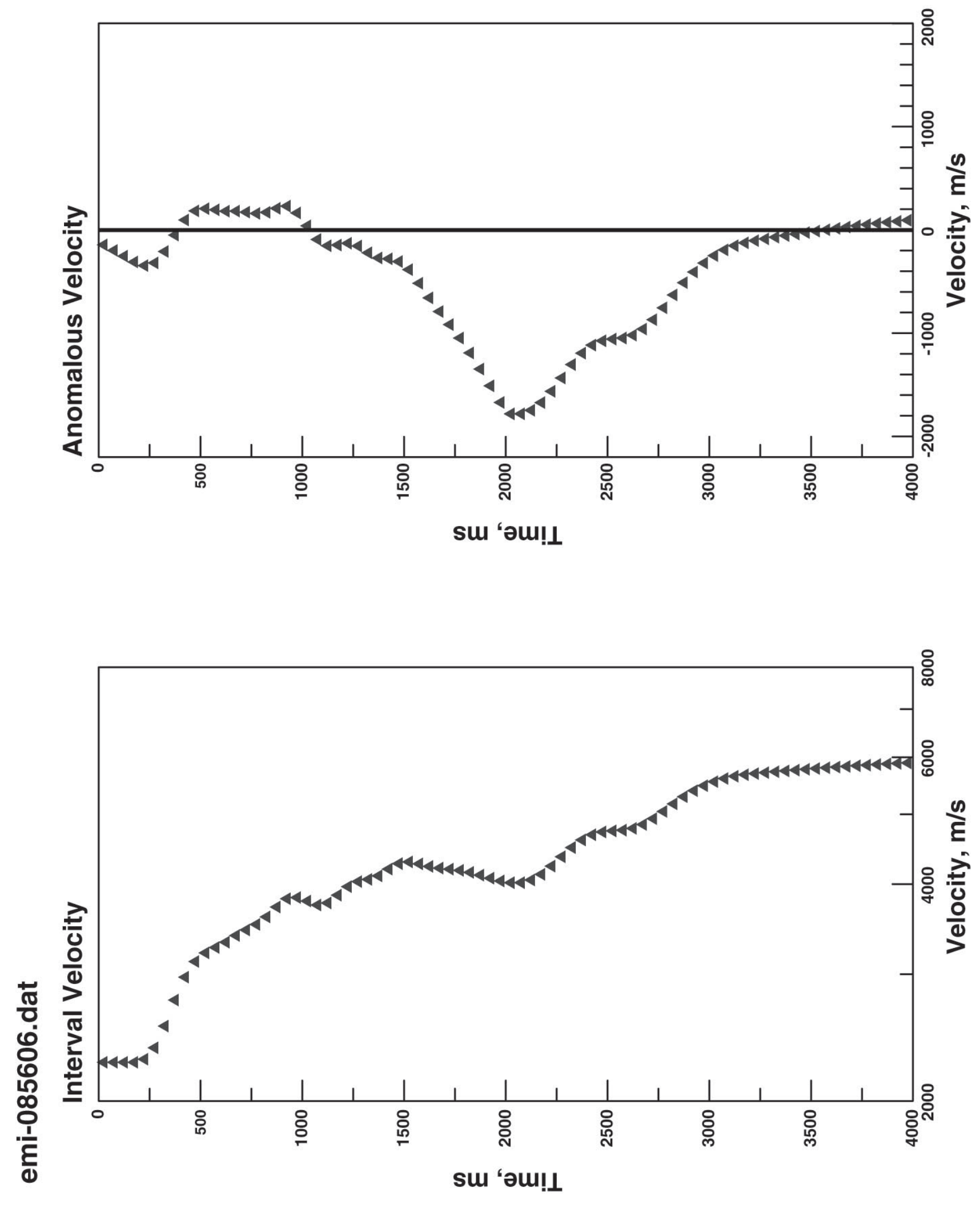

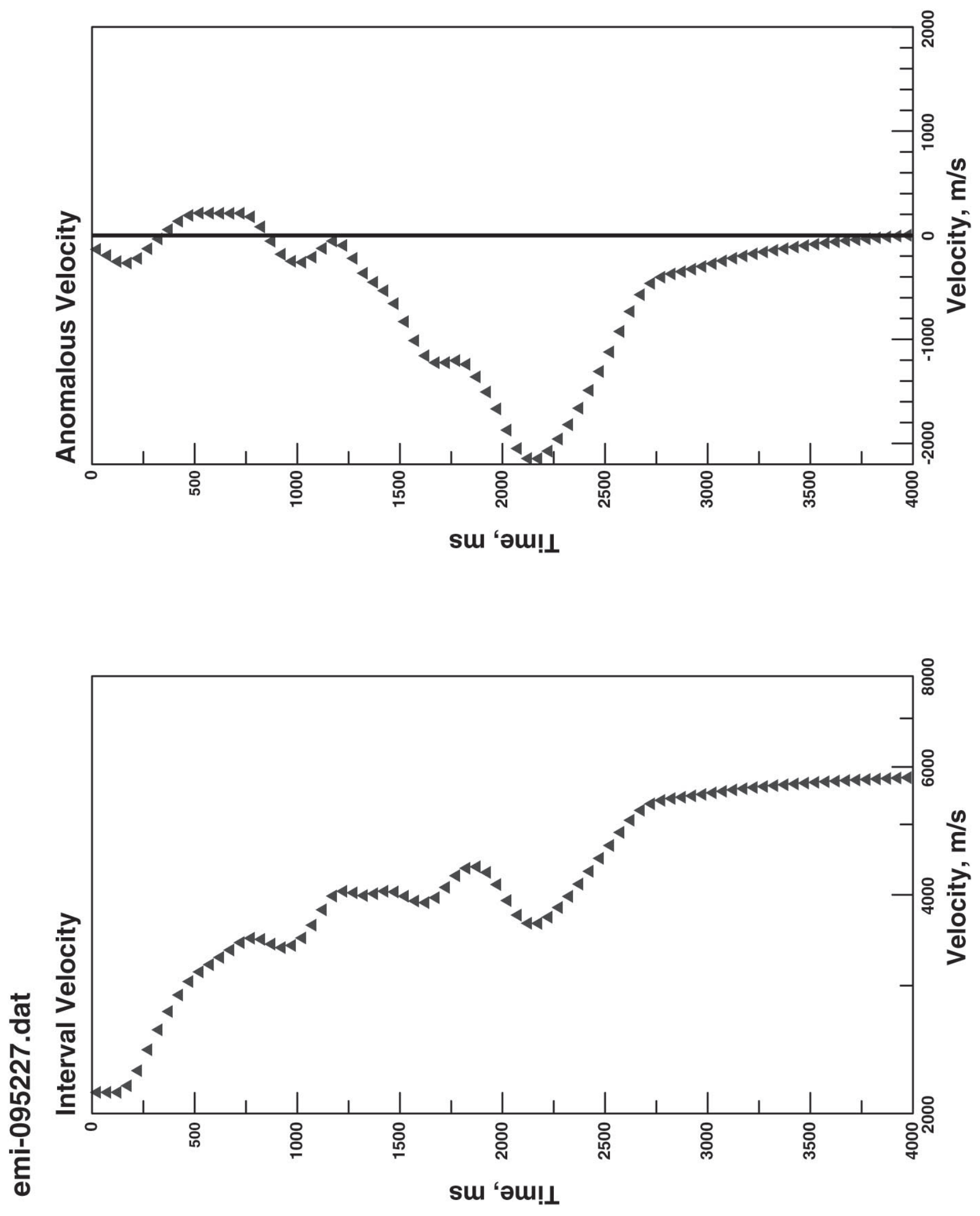

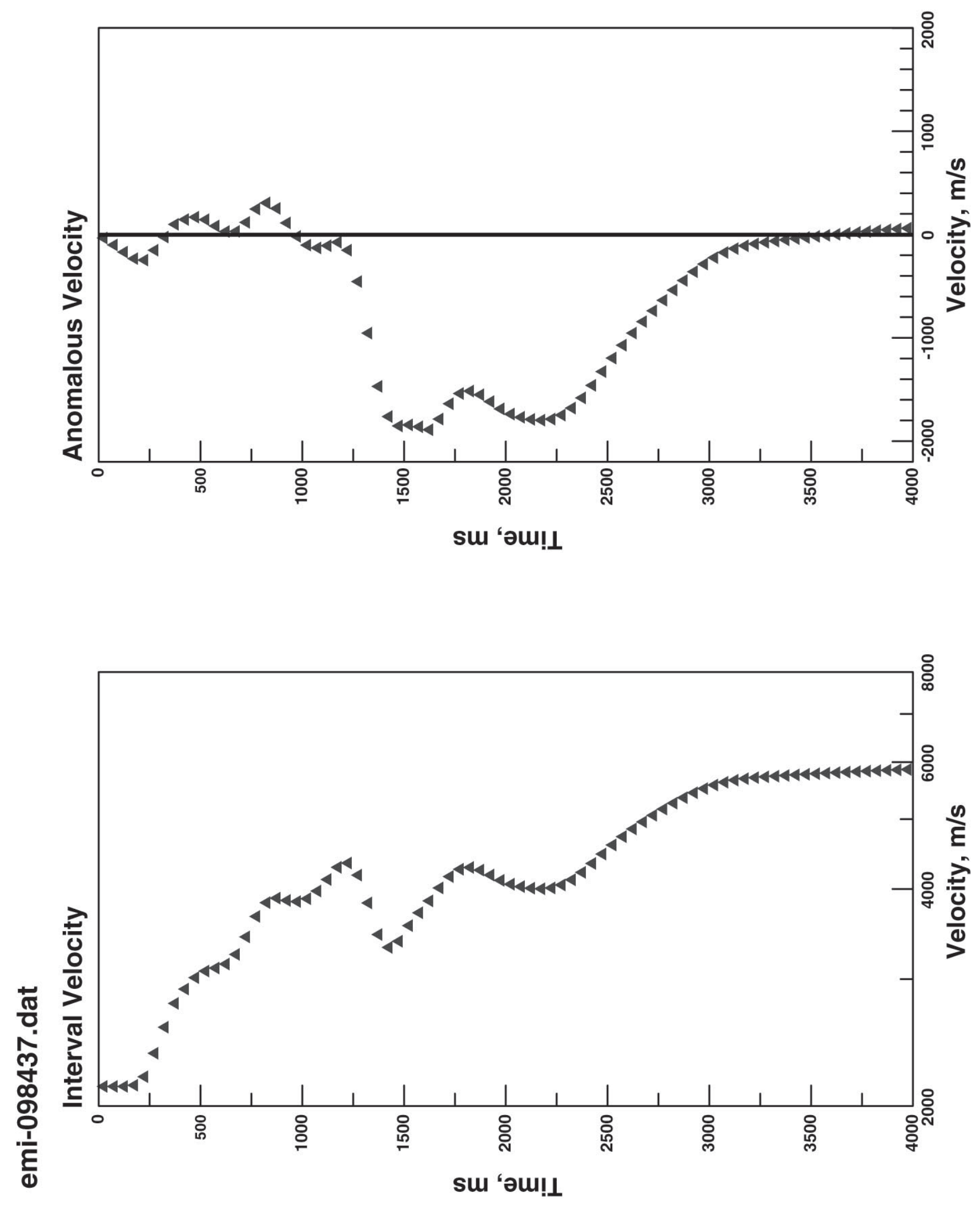


\section{Contour map of the top of the Frontier, Emigrant 3D survey}

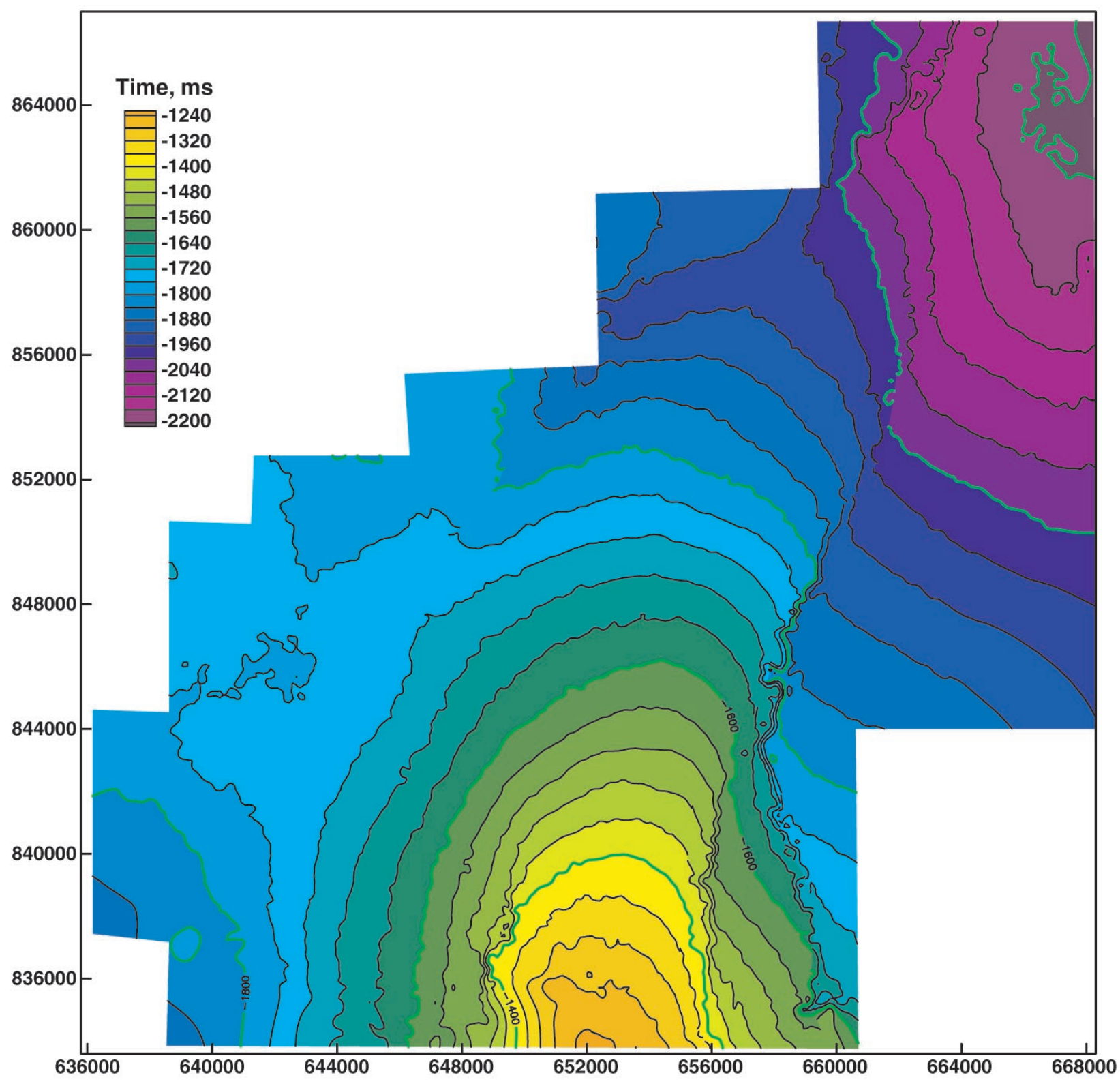




\section{Contour map of the top of the Muddy, Emigrant 3D survey}

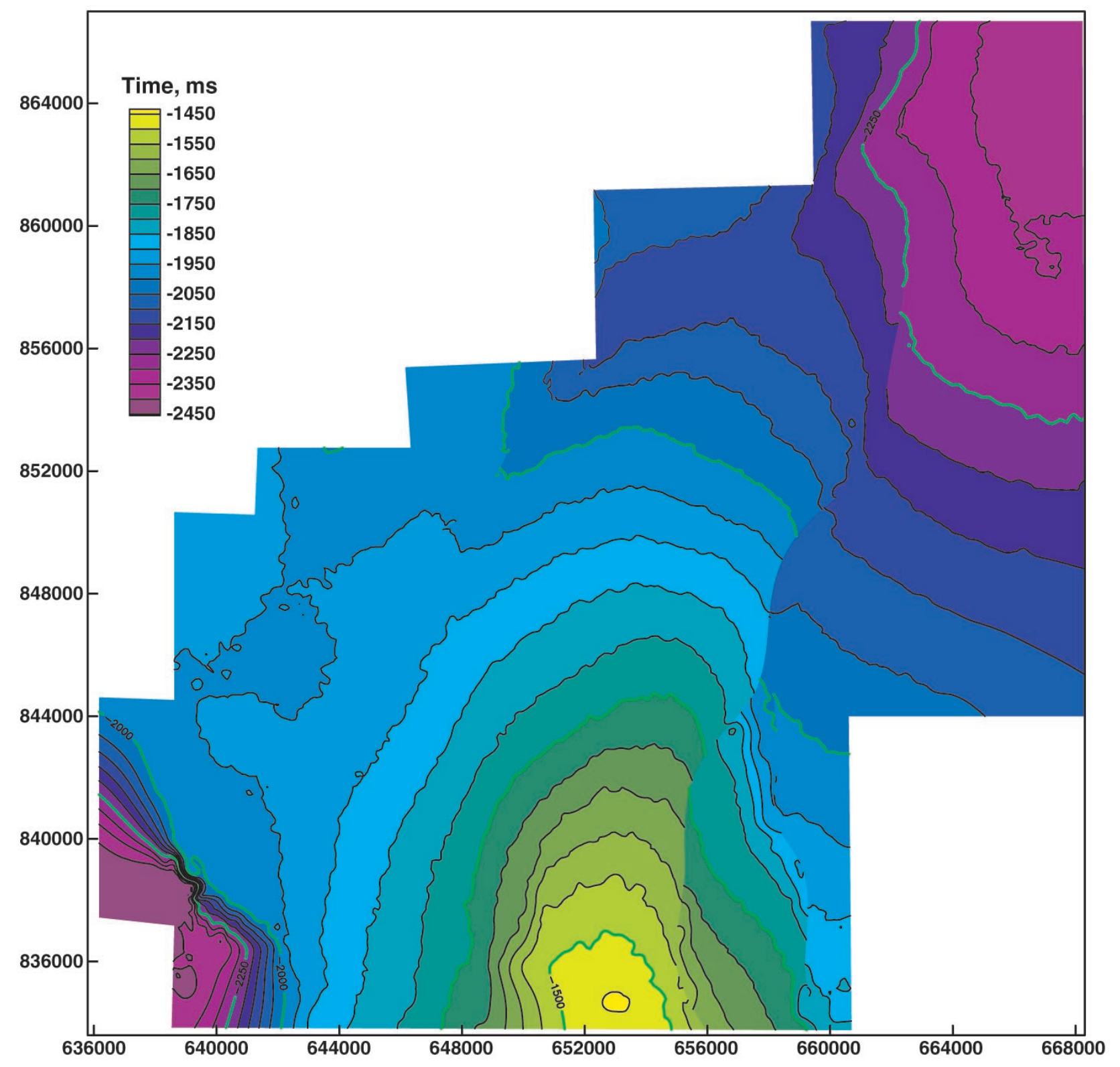

